LUCAS MOTTA DE NOVAES

ESTRATÉGIAS PARA O GERENCIAMENTO DA MISTURA AR COMBUSTÍVEL APLICADAS EM MOTORES FLEX

São Paulo 


\title{
ESTRATÉGIAS PARA O GERENCIAMENTO DA MISTURA AR COMBUSTÍVEL APLICADAS EM MOTORES FLEX
}

\author{
Dissertação apresentada à Escola \\ Politécnica da Universidade de São Paulo \\ para a obtenção do Título de Mestre em \\ Ciências
}

Orientador:

Prof. Dr. João Francisco Justo Filho 


\title{
ESTRATÉGIAS PARA O GERENCIAMENTO DA MISTURA AR COMBUSTÍVEL APLICADAS EM MOTORES FLEX
}

\author{
Dissertação apresentada à Escola \\ Politécnica da Universidade de São Paulo \\ para a obtenção do título de Mestre em \\ Ciências
}

Área de Concentração:

Engenharia Elétrica

Sistemas Eletrônicos

Orientador:

Prof. Dr. João Francisco Justo Filho 
Autorizo a reprodução e divulgação total ou parcial deste trabalho, por qualquer meio convencional ou eletrônico, para fins de estudo e pesquisa, desde que citada a fonte.

Este exemplarfoi revisado e corrigido em relação à versão original, sob responsabilidade única do autor e com a anuência de seu orientador.

São Paulo, de de

Assinatura do autor:

Assinatura do orientador:

Novaes, Lucas Motta de

ESTRATÉGIAS PARA O GERENCIAMENTO DA MISTURA AR

COMBUSTÍVEL APLICADAS EM MOTORES FLEX / L. M. Novaes -- versão corr. -- São Paulo, 2019. $198 \mathrm{p}$.

Dissertação (Mestrado) - Escola Politécnica da Universidade de São Paulo. Departamento de Engenharia de Sistemas Eletrônicos.

1.Gerenciamento eletrônico de um motor bicombustível 2.Concentração de etanol do combustível 3.Controle Ar/Combustível em malha fechada 4.ASCET (Advanced Simulation and Control Engineering Tool) 5.Sistemas embarcados de tempo real I.Universidade de São Paulo. Escola Politécnica. Departamento de Engenharia de Sistemas Eletrônicos II.t. 
Dedico este trabalho aos meus pais José O. Novaes e Marinilza M. Novaes, aos colegas do meio automotivo, a todos os meus familiares, amigos e professores. 


\section{AGRADECIMENTOS}

Agradeço primeiramente a Deus pelo dom da vida, a minha família, a minha companheira Karoline Martins dos Santos e aos colegas Bruno Silva Pereira, Demerson Moscardini e Paulo Alexandre Pizará Hayashida, que sempre se fizeram presentes me ajudando nessa caminhada. Ao amigo Pedro de Castro Rossetti pelas sugestões e esclarecimentos prestados. A todos os colegas do Grupo de Eletrônica Automotiva da Escola Politécnica da Universidade de São Paulo. Aos colegas do Laboratório de motores, engenharia térmica e combustíveis líquidos do Instituto de Pesquisa Tecnológicas do Estado de São Paulo. Aos colegas da Engineering Tools and Applications - ETAS Br Alexandre Kawamoto e André Pelisser. A todos que compõem a Escola Politécnica da Universidade de São Paulo - USP e que tornam esta instituição uma referência no ensino de qualidade. À CAPES (Coordenação de Aperfeiçoamento de Pessoal de Nível Superior) pela concessão da bolsa estudantil.

Por fim, e não menos importante agradeço incondicionalmente ao amigo Professor Doutor Armando Antônio Maria Laganá e ao meu Orientador Dr. João Francisco Justo Filho por toda dedicação, compreensão e confiança na minha capacidade em chegar até aqui, assim como, agradeço aos dois membros convidados da banca Prof. Dr. Edson Caoru Kitani e Prof. Dr. Sérgio Inácio Ferreira. Os meus sinceros agradecimentos a todos que direta e indiretamente ajudaram na execução desse trabalho, sem vocês nada seria possível. 
É preciso grande sabedoria para conhecer a extensão da própria ignorância.

(Thomas Sowell) 


\section{RESUMO}

No presente trabalho, emprega-se a medida da concentração de etanol do combustível para efetuar correções estequiométricas de maneira direta e instantânea, a fim de eliminar o período necessário para adaptação a partir da medida do sensor de oxigênio (sonda lambda) em eventos de reabastecimento no veículo. Com o objetivo de assegurar a operação flex-fuel, foram empregados métodos para a regulação ar/combustível em malha fechada, realimentados por sensores de oxigênio (banda larga amplificada e banda estreita). O projeto foi

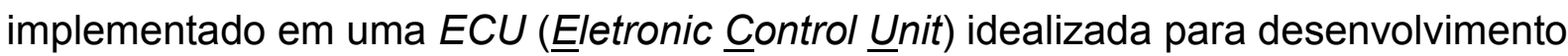
de rotinas de programa voltadas ao gerenciamento eletrônico para motores de combustão interna ciclo Otto, denominada Flex-ECU. A ETAS/Bosch Flex-ECU possui programação aplicada à ferramenta ASCET (ㅅdvanced Simulation and

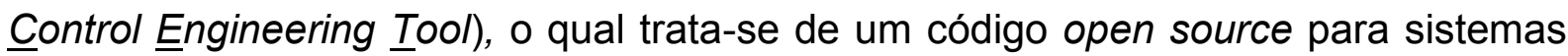
embarcados de tempo real. Por fim, são exibidos resultados de controle, desempenho e eficiência do motor para diferentes composições de combustível comercializados para a frota de veículos leves em território nacional. Os experimentos revelam a dinâmica de funcionamento do controle $\mathrm{A} / \mathrm{C}$ bicombustível e discute as suas principais características, com o objetivo de exemplificar métodos de otimização de sua eficiência.

Palavras chaves: Gerenciamento eletrônico de um motor bicombustível, Concentração de etanol do combustível, Controle Ar/Combustível em malha fechada, ASCET (ㅁdvanced Simulation and $\underline{\text { Control E}}$ Engineering $\underline{T}$ Tool), Sistemas embarcados de tempo real. 


\begin{abstract}
In the present work, the ethanol fuel concentration is used to establish stoichiometric corrections in a direct and instantaneous manner, to eliminate the period necessary for adaptation, from the measurement of the oxygen sensor (lambda probe) in events of refueling. To ensure Flex-fuel operation, closed-loop air/fuel regulation methods were used, fed by oxygen sensors (amplified wide band and narrow band). The

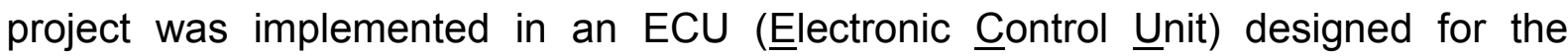
development of code routines for electronic management of an Otto cycle internal combustion engine, labeled Flex-ECU. The ETAS / Bosch Flex-ECU has

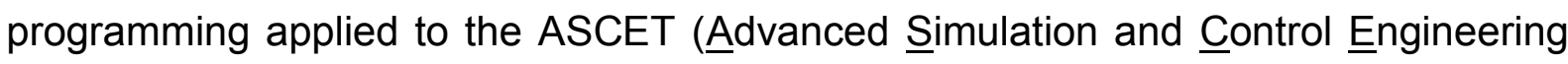
Tool) tool, which is an open source code for real time embedded systems. Finally, results of engine control, performance, and efficiency are presented for different fuel compositions available in Brazil for the fleet of light vehicles. The experiments show the dynamics of the operation of the bi-fuel $A / C$ control and discusses its main characteristics, aiming to exemplify optimization methods of its efficiency.
\end{abstract}

Key Words: Electronic Engine Management, Bi-Fuel applications, Fuel Ethanol Concentration, Air/Fuel control in closed-loop with ASCET (ㄹdvanced Simulation and Control Engineering Iool), Real time Embedded Systems. 


\section{LISTA DE ILUSTRAÇÕES}

Figura 2.1 - Períodos de trabalho de um motor de combustão interna de quatro tempos SI (ciclo Otto).

Figura 2.2 - Definições das dimensões geométricas do virabrequim, da biela e do cilindro de um motor.

Figura 2.3 - Representação ilustrativa dos volumes internos do cilindro referentes à relação de compressão do mesmo.

Figura 2.4 - Arquitetura de gerenciamento do motor baseada no torque.

Figura 2.5 - Modelo de controle para realização do torque desejado em um motor SI naturalmente aspirado e seus subsistemas de controle.

Figura 2.6 - Esquemático simples do funcionamento de uma válvula para estrangulamento do fluxo de ar com controle eletrônico (ETC).

Figura 2.7 - (a) Representação funcional de uma válvula injetora, (b) sinal do pulso de acionamento da válvula. 36

Figura 2.8 - Parâmetros básicos da vazão de combustível de uma VEIC (Válvula Eletromagnética Injetora de Combustível). 37

Figura 2.9 - Configuração de um sistema de ignição eletrônica. 38

Figura 2.10 - Perfil exemplar da pressão exercida pelo fenômeno de expansão termo volumétrica dos gases na câmara de combustão.

Figura 2.11 - Indicadores de torque indicado, consumo e emissões específicos resultantes da variação do disparo da centelha de ignição.

Figura 2.12 - Dois níveis de ocorrência do fenômeno de combustão anormal denominada como detonação.

Figura 2.13 - Velocidade laminar de chama resultante da relação A/C (lambda) e pressão aplicados a um combustível hidrocarboneto ciclo-hexano $\mathbf{C 6 H 1 2}$.

Figura 2.14 - Efeito da variação das relações de fornecimento do ar e do combustível em motores de combustão interna sob o trabalho efetivo we e a eficiência termodinâmica $\boldsymbol{\eta} \boldsymbol{e}$.

Figura 2.15 - Níveis de emissões para monóxido de carbono $\mathrm{CO}$, hidrocarbonetos $\mathrm{HC}$, óxido nitrosos genéricos $\mathrm{NO}_{\mathrm{x}}$ e oxigênio $\mathrm{O}_{2}$ sem implementações de póstratamento.

Figura 2.16 - Curva de "hook" do torque, consumo específico e emissões especificas em relação ao fator de excesso de oxigênio ou relação de equivalência (lambda) 49

Figura 2.17 - Modelo de controle em malha aberta (open-loop). 50

Figura 2.18 - Exemplificação dos mapas básicos para injeção e ignição. .53

Figura 2.19 - Fator adimensional para correção para os tempos de injeção e ignição em função da tensão de bateria. .55

Figura 2.20 - Modelo para controle em malha fechada (open+closed-loop) 
Figura 2.21 - Curva de resposta da saída de tensão de um sensor de oxigênio com banda estreita (EGO/HEGO)

Figura 2.22 - Exemplo de calibração da corrente de bombeamento de um sensor broad/wide band em função da relação $\lambda$ e concentração de oxigênio $\boldsymbol{O 2}$.

Figura 2.23 - Conversor catalítico de três vias (TWC) aplicado em motores de ciclo Otto.

Figura 2.24 - Representação da janela de conversão realizada por um catalisador de três vias.

Figura 2.25 - Principais etapas para o desenvolvimento de sistemas embarcados. 70 Figura 2.26 - Visão Geral do núcleo de processos para o desenvolvimento de sistema eletrônicos e software a partir do ciclo $\mathrm{V}$....

Figura 2.27 - Ciclo V aplicado às implementações de software disponibilizadas pela corporação ETAS com destaque das etapas utilizadas neste projeto.......................79

Figura 2.28 - Workflow da integração ASCET/E-HOOKS Dev.

Figura 3.1 - Modelagem de programação de tarefas de um projeto no ambiente ASCET (Advanced Simulation and Control Engineering Tool) SD (Software Design)

Figura 3.2 - Exemplo de correspondência entre os objetos no ambiente ASCET, RTOS (Real Time Operating Systems) e a linguagem de programação em código C.

Figura 3.3 - Estrutura de memória paralela da FlexECU - unidade voltada ao desenvolvimento de software no padrão automotivo.

Figura 3.4 - Cenário de experimentos do software INCA com variáveis de medição internas da ECU ETAS/Bosch MEDC17 FlexECU.

Figura 3.5 - Perfis dos sinais de rotação do motor (a) sinal de roda fônica e (b) sinal de fase.

Figura 3.6 - Diagrama de representação dos módulos presentes no ambiente do software de aplicação ASCET com a versão de firmware (projeto) Otto III.

Figura 3.7 - Identificação do dispositivo eletrônico Br-FFS (Flex-Fuel Sensor) com calibração brasileira.

Figura 3.8 - Características do perfil de sinal de saída do sensor de composição $\mathrm{Br}$ FFS.

Figura 3.9 - Representação do efeito causado pela temperatura sob a constante dielétrica

Figura 3.10 - Módulo para leitura da frequência do sinal proveniente do sensor de volume de etanol.

Figura 3.11 - Motor utilizado EA - 111 VHT (CCRA) - Flex-Fuel (etanol e/ou gasolina).

Figura 3.12 - Veículo de testes operando em um dinamômetro de chassi do IEE USP (Instituto de Energia e Ambiente da Universidade de São Paulo). 
Figura 3.13 - Vista do motor utilizado acoplado ao dinamômetro hidráulico Shenck modelo D360-1E instalado na sala 1 do Laboratório de motores do Instituto de Pesquisas Tecnológicas de São Paulo. 100

Figura 3.14 - Representação esquemática de um dinamômetro hidráulico Schenck série $D$ com comando elétrico. 100

Figura 3.15 - Aferição do erro de medida do dinamômetro hidráulico Shenck modelo D360-1E instalado na sala 1 do Laboratório de motores do Instituto de Pesquisas Tecnológicas de São Paulo. 101

Figura 3.16 - Diagrama de conexões para controle e medida de um sensor de oxigênio wide-band através de uma interface CJ125 conectada à uma ECU........103 Figura 3.17 - Módulo para leitura e controle do sensor de Banda larga LSU_OUT_V2. 104

Figura 3.18 - Hierarquia Ipump Conversion, utilizada para a conversão da corrente de bombeamento em relação de equivalência (lambda). 106

Figura 3.19 - Circuito utilizado para condicionamento da tensão Nernst proveniente do sensor de oxigênio com banda estreita.

Figura 3.20 - Principio para detecção de detonação a partir do sinal proveniente do acelerômetro denominado "Knock sensor". 108 Figura 3.21 - Representação do driver interno KnDet da ECU de desenvolvimento ETAS/Bosch MEDC17 FlexECU utilizado para interpretação do sinal do acelerômetro Knock sensor... 109

Figura 3.22 - Diagrama de cálculo de correção para avanços de ignição em função do volume de etanol do combustível.

Figura 3.23 - Diagrama de cálculo de correção para tempos de injeção em função do volume de etanol do combustível.

Figura 3.24 - Estrutura para realização do controle da relação lambda para um sistema que utiliza uma única sonda de banda larga em malha fechada.

Figura 3.25 - Resposta ao degrau simplificada para a referência lambda em um motor com 4 cilindros.

Figura 3.26 - Diagrama do módulo de controle LAMBDA_CALCv1.4. 118

Figura 3.27 - Estrutura de controle I ou PI para um único sensor com banda estreita EGO.

Figura 3.28 - Diagrama do módulo de controle LAMBDA_CALC_OnOff_v1....

Figura 3.29 - Dados de entrada e saída utilizados para identificação da planta de temperatura do sensor de banda larga.

Figura 3.30 - Comparação entre os dados medidos da planta real e a planta identificada com aproximações de $1^{\text {a }}$ (primeira) e $2^{a}$ (segunda) ordem.

Figura 3.31 - Respostas dos compensadores de $1^{\text {a }}$ (primeira) e $2^{\mathrm{a}}$ (segunda) aplicados a planta que possui $98 \%$ de índice fit. 
Figura 3.32 - Hierarquia LSU_CTRL_IN, utilizada para conversão e controle de temperatura do sensor de oxigênio de banda larga (LSU/UEGO).

Figura 3.33 - Leituras analógicas para os sensores de banda estreita (LSF/HEGO) e da saída do analisador LA4 para o sensor de banda larga (LSU/UEGO) presentes no módulo ADCv34.

Figura 3.34 - Hieraquia do módulo de injeção que exibe a possibilidade de seleção da correção lambda pelo tipo de sensor LSU(UEGO) ou LSF(HEGO/On-Off) 129 Figura 3.35 - Hieraquia utilizada para leitura de diagnose do circuito integrado CJ125 e do acionamento do aquecedor para a sonda LSU/UEGO.

Figura 3.36 - Módulo para acionamento diagnose do sinal PWM para o aquecimento da sonda de banda estreita.

Figura 4.1 - Sinal de rotação do motor durante perturbação gerada na correção da composição.

Figura 4.2 - Sinais de referência alvo e medição do sensor UEGO oriundos do controle A/C.

Figura 4.3 - Variação no teor de etanol do combustível durante a realização do teste e sinal da solicitação de torque kick down realizada através do sinal eletrônico de pedal E-GAS para o módulo de controle eletrônico de aceleração (ETC). 140 Figura 4.4 - Rotação do motor em regime de entrega de torque e referência em conjunto com o sinal de medição do sensor UEGO oriundos do controle A/C. 141 Figura 4.5 - Dinâmica dos paramêtros de correção para os períodos de injeção em função da composição do combustivel.

Figura 4.6 - (a)Sinal de rotação do motor em regime de aceleração em gradual e (b)sinais de referência alvo e medição do sensor LSU/UEGO oriundos do controle A/C.

Figura 4.7 - Período de injeção efetivo e fator de correção proveniente do controle $\mathrm{A} / \mathrm{C}$ e variação da temperatura do ar de entrante para o motor.

Figura 4.8 - Dinâmica dos paramêtros de correção para os ângulos de ignição em função da composição do combustivel.

Figura 4.9 - Sinal de rotação do motor em regime de marcha lenta, sinais de referência alvo e medição do sensor UEGO oriundos do controle $A / C$ 146 Figura 4.10 - Período de injeção efetivo, fator de correção lambda e dinâmica dos ganhos existentes no controle $\mathrm{A} / \mathrm{C}$ em malha fechada.

Figura 4.11 - Resultado do teste de comparação entre a medida da (a) corrente de bombeamento do CJ 125 e sua conversão com a (b) medida do analisador lambda LA4 148

Figura 4.12 - Variação da corrente de bombeamento medida por um sensor de oxigênio LSU/UEGO versão 4.9 em função da pressão absoluta no coletor de exaustão. 149 
Figura 4.13 - Teste de variação de temperatura do sensor LSU/UEGO realizado de forma direta através da função de comunicação com o IC CJ 125.

Figura 4.14 - Resultado do teste de comparação entre a medida da (a) tensão Nernst da sensor de oxigênio com banda estreita e (b) medida de conversão do analisador lambda LA4 com sonda de banda larga.

Figura 4.15 - Resultado do teste de referência fixa do controle da mistura A/C (lambda) (a) Resposta do sensor oxigênio com banda larga amplificada, (b) fator de correção do tempo de injeção e (c) tempo de injeção aplicado.

Figura 4.16 - Teste de variação de temperatura do sensor de banda estreita LSF/HEGO realizado de maneira indireta com a medida de tensão de sua célula Nernst. 153

Figura 4.17 - Levantamento dos avanços de ignição encontrados para a condição de MBT em função da relação de equivalência $\lambda$ (lambda) para a rotação de 2500 RPM@90 KPa.

Figura 4.18 - Exemplificação de coleta do indice de detonação durante ensaio com o combustível E27.

Figura 4.19 - Levantamento da variável de integração do sinal do acelerômetro preso ao bloco do motor (Knock sensor) para a condição de MBT em função da relação de equivalência $\lambda$ (lambda) para a rotação de 2500 RPM@90 KPa.

Figura 4.20 - Levantamento do torque encontrado para a condição de MBT em função da relação de equivalência $\lambda$ (lambda) para a rotação de 2500 RPM@90 $\mathrm{KPa}$.

Figura 4.21 - Levantamento do fluxo de combustível medido para a condição de MBT em função da relação de equivalência $\lambda$ (lambda) para a rotação de 2500 RPM@90 KPa.

Figura 4.22 - Levantamento do consumo específico de combustível medido para a condição de MBT em função da relação de equivalência $\lambda$ (lambda) para a rotação de 2500 RPM@90 KPa.

Figura 4.23 - Avanço de ignição em graus APMS no limiar de detonação para (azul) gasolina E27, (laranja) mistura entre gasolina e etanol E65, (preto) etanol hidratado e (amarelo) gasolina premium 162

Figura 4.24 - Avanço de ignição em graus APMS que produz o maior torque de saída para os seguintes combustíveis: (azul) gasolina E27, (laranja) mistura entre gasolina e etanol E65, (preto) etanol hidratado e (amarelo) gasolina premium. .....163 Figura 4.25 - Comparação entre o avanço limiar de detonação (IKT) e avanço para máximo torque (MBT) para gasolina E27. 164

Figura 4.26 - Comparação entre o avanço limiar de detonação (IKT) e avanço para máximo torque (MBT) para mistura E65.

Figura 4.27 - Comparação entre o avanço limiar de detonação (IKT) e avanço para máximo torque (MBT) para etanol hidratado E95. 
Figura 4.28 - Comparação entre o avanço limiar de detonação (IKT) e avanço para máximo torque (MBT) para gasolina premium. ................................................166 Figura 4.29 - Torque de saída do motor produzido pelo avanço de ignição no limiar de detonação para (azul) gasolina E27, (vermelho) mistura entre gasolina e etanol E65, (preto) etanol hidratado e (verde) gasolina premium.

Figura 4.30 - Torque de saída do motor produzido pelo avanço de ignição que produz o máximo torque, para (azul) gasolina E27, (vermelho) mistura entre gasolina e etanol E65, (preto) etanol hidratado e (verde) gasolina premium. 168 Figura 4.31 - Comparação entre o torque produzido pelo avanço IKT (azul) e MBT (vermelho) para etanol hidratado E95. 169 Figura 0.1 - Veículo Ford modelo T movido à "cachaça", adequação realizada na escola politécnica da Universidade de São Paulo. 179 Figura 0.2 - Licenciamento de veículos automotores leves de passeio por fonte de energia utilizada.

Figura 0.3 - Comparação da evolução da autoignição em fase gasosa para eventos de combustão com inicialização fixa para diferentes combustíveis.

Figura 0.4 - Levantamento dos avanços de ignição encontrados para a condição de MBT em função da relação de equivalência $\lambda$ (lambda) para as rotações de 1500 , 2500, 3500 e 4500 RPM@90 KPa.

Figura 0.5 - Levantamento dos índices de detonação encontrados para a condição de MBT em função da relação de equivalência $\lambda$ (lambda) para as rotações de 1500 , 2500, 3500 e 4500 RPM@90 KPa.

Figura 0.6 - Levantamento das medições de torque encontrados para a condição de MBT em função da relação de equivalência $\lambda$ (lambda) para as rotações de 1500 , 2500, 3500 e 4500 RPM@90 KPa.

Figura 0.7 - Levantamento das medições de potência encontradas para a condição de MBT em função da relação de equivalência $\lambda$ (lambda) para as rotações de 1500 , 2500, 3500 e 4500 RPM@90 KPa.

Figura 0.8 - Levantamento das medições de fluxo de combustível encontrados para a condição de MBT em função da relação de equivalência $\lambda$ (lambda) para as rotações de 1500, 2500, 3500 e 4500 RPM@90 KPa.

Figura 0.9 - Levantamento das medições de consumo específico encontrados para a condição de MBT em função da relação de equivalência $\lambda$ (lambda) para as rotações de 1500, 2500, 3500 e 4500 RPM@90 KPa. 192

Figura 0.10 - Levantamento dos avanços de ignição encontrados para a condição de IKT em função da relação de equivalência $\lambda$ (lambda) para as rotações de 1500 , 2500, 3500 e 4500 RPM@90 KPa.

Figura 0.11 - Levantamento dos índices de detonação encontrados para a condição de IKT em função da relação de equivalência $\lambda$ (lambda) para as rotações de 1500 , 2500, 3500 e 4500 RPM@90 KPa. 
Figura 0.12 - Levantamento das medições de torque encontrados para a condição de IKT em função da relação de equivalência $\lambda$ (lambda) para as rotações de 1500 , 2500, 3500 e 4500 RPM@90 KPa. 195

Figura 0.13 - Levantamento das medições de potência encontradas para a condição de IKT em função da relação de equivalência $\lambda$ (lambda) para as rotações de 1500 , 2500, 3500 e 4500 RPM@90 KPa.

Figura 0.14 - Levantamento das medições de fluxo de combustível encontrados para a condição de IKT em função da relação de equivalência $\lambda$ (lambda) para as rotações de 1500, 2500, 3500 e 4500 RPM@90 KPa.

Figura 0.15 - Levantamento das medições de consumo específico encontrados para a condição de IKT em função da relação de equivalência $\lambda$ (lambda) para as rotações de 1500, 2500, 3500 e 4500 RPM@90 KPa. 198 


\section{LISTA DE TABELAS}

Tabela 2.1 - Discriminação dos diferentes gases elementares que constituem o ar atmosférico.

Tabela 2.2 - Composição e octanagem das misturas de combustíveis comercializadas em território nacional para motores SI (ciclo Otto).

Tabela 2.3 - Propriedades físico-químicas dos combustíveis gasolina tipo A (pura) e etanol anidro.

Tabela 3.1 - Especificações do hardware da unidade de comando utilizada para o desenvolvimento ETAS/Bosch MEDC17 FlexECU Gasoline (Dedicada aos motores

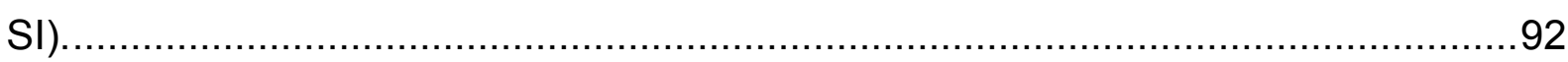

Tabela 3.2 - Especificações do motor utilizado na aplicação dos testes. .................98

Tabela 3.3 - Parâmetros de projeto para o controle em malha fechada com realimentação de um sensor de oxigênio com banda larga.

Tabela 3.4 - Mapa LAMBDA_CURVE para endereçamento de referência para o módulo de controle $L A M B D A \_C A L C$.

Tabela 3.5 - Parâmetros de projeto para o controle em malha fechada com realimentação de um sensor de oxigênio de banda estreita.

Tabela 3.6 - Mapa LambdaCurveOnOff para endereçamento de referência para o módulo de controle LAMBDA_CALC_OnOff_v1.

Tabela 3.7 - Codificação dos bits da variável de retorno da função de diagnóstico para o Heater (Aquecedor) para o sensor de banda larga LSU.

Tabela 3.8 - Identificadores de seleção para retorno da função de diagnóstico dos pinos de medição para o sensor de banda larga LSU.

Tabela 3.9 - Codificação dos bits da variável de retorno da função de diagnóstico para a comunicação com o Cl CJ 125 utilizado para o controle e medição do sensor de banda larga LSU.

Tabela 3.10 - Codificação dos bits da variável de retorno da função de diagnóstico para a saída PWM aplicada como Heater (Aquecedor) para o sensor de banda estreita LSF.

Tabela 4.1 - Calibração do mapa básico de injeção para a utilização de gasolina E27

Tabela 4.2 - Calibração do mapa básico de injeção para a utilização de etanol hidratado E95. 136

Tabela 4.3 - Calibração do mapa básico de ignição para a utilização de gasolina E27.

Tabela 4.4 - Calibração do mapa básico de ignição para a utilização de etanol hidratado E95. 


\section{LISTA DE ABREVIATURAS E SIGLAS}

$\mathrm{A} / \mathrm{C}$

Relação Ar/Combustível.

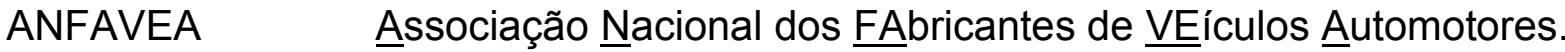

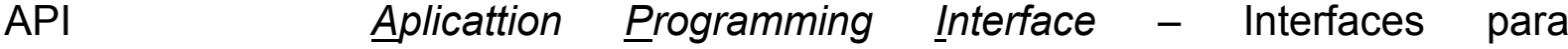
programação de aplicações.

APMS $\quad$ Antes do $\underline{\text { Ponto }}$ Morto $\underline{\text { Superior [graus }}{ }^{\circ}$ ].

AppSW $\quad$ Application SoftWare - Software de aplicação.

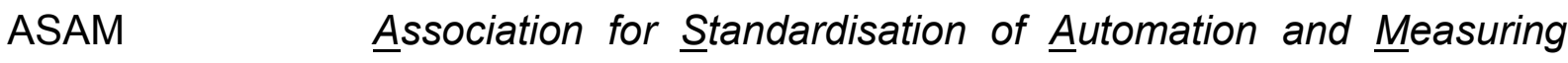
Systems - Associação para Padronização de Sistemas de Automação e Medição.

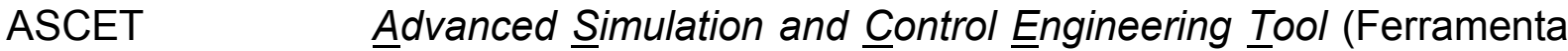
de engenharia para simulação e controle avançados).

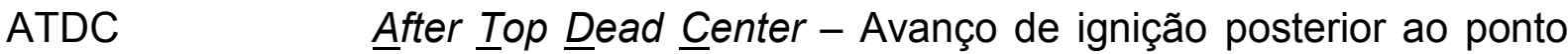
morto superior (TDC), (DPMS - Depois do Ponto Morto Superior).

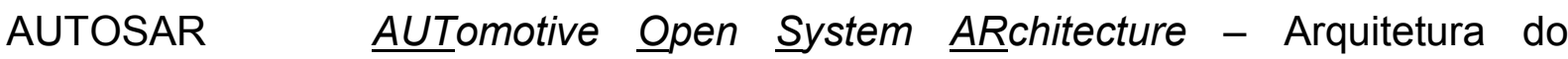
sistema aberto automotivo.

BDC

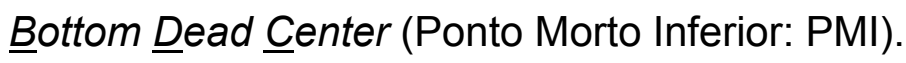

BSFC Brake Specific Fuel Consumption - Janela de consumo específico.

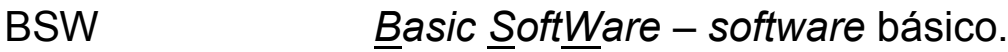

BTDC $\quad$ Before $\underline{T o p} \underline{\text { Dead }}$ Center - Avanço de ignição anterior ao ponto morto superior (TDC), (APMS - Antes do Ponto Morto Superior).

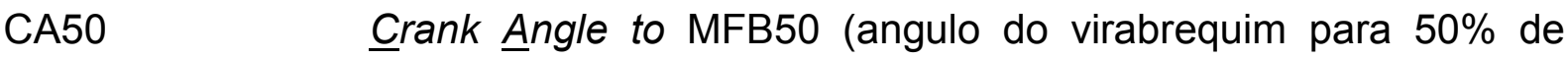
massa de combustível queimada).

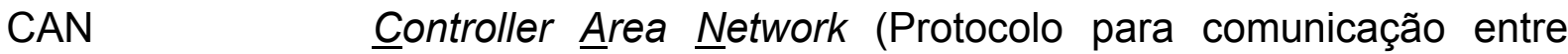
módulos de controle automotivos).

CCP $\quad \underline{C A N} \underline{\text { Calibration }}$ Protocol (Protocolo CAN destinado a calibração e controle).

$\mathrm{Cl}$ Compression Ignition - Ignição por Compressão.

E100 EEtanol Anidro o qual deve possuir pelo menos $\underline{99.6 \%}$ de Etanol puro.

E27 Gasolina com $\underline{27} \%$ de Étanol (Anidro).

E85 Gasolina com $\underline{85} \%$ de Etanol (Anidro).

E95 Combustível brasileiro com teor médio 95,1 a 96\% de Étanol e o restante de água (Hidratado). 


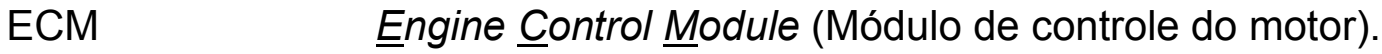

ECU Electronic Control Unit (Unidade de controle eletrônico).

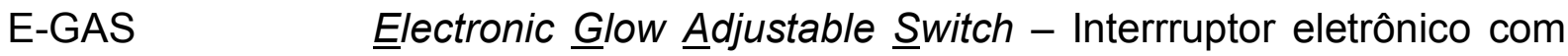
ascendência variável.

EPM Engine $\underline{P}$ osition Management - Gerenciamento posicional do motor.

ESDL Embedded Software Description Language - Linguagem de descrição para software embarcado.

ETAS Sigla do idioma inglês traduzida do alemão (Entwicklungs- und Applikationswerkzeuge für elektronische Systeme) Engineering Iools and Application Services - Ferramentas de engenharia e serviços para aplicações.

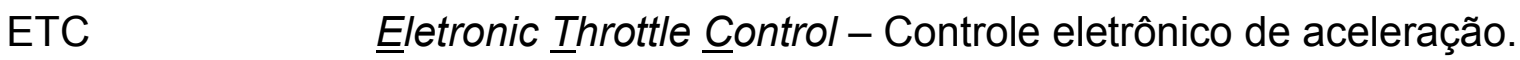

ETK Sonda para emulação de testes (do alemão: EEmulator-TestKKopf).

FFS $\quad$ Flex-ㅌuel $\underline{\text { Sensor. }}$

$\mathrm{H} 0 \quad$ idem ao E27.

H100 idem ao E95.

HEGO HEated Gas Oxygen-sensor - Sensor de oxigênio com aquecedor integrado.

IAD IÍndice Anti-Detonante.

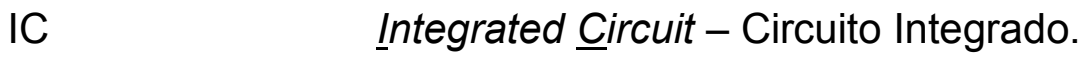

IKT Incipient Knnock iming - Avanço de detonação incipiente.

INCA INtegrated Calibration and Application-Tool - Ferramenta integrada de aplicação e calibração.

LA4

LLSW

LSU

MAF

MAP

MBT

$\mathrm{MCl}$

MFB50
Lambda Analyzer 4- Analisador Lambda versão 4.

Low Level SoftWare (Programa de baixo nível).

do alemão Lambda Sonde Universal - Sonda Lambda Universal.

Manifold $\underline{\text { Air }}$ Flow (Fluxo de ar no coletor).

Manifold $\underline{A} b s o l u t$ Pressure (Pressão Absoluta no coletor).

Maximum Break Torque - Janela de Torque Máximo.

Motor de Combustão Interna.

$50 \%$ of Mass Fraction Burned (Fração de massa de combustível queimada).

MiL

Model-in-the-Loop. 
MON

Motor O-ctane Number (Número de octanas para método de calibração de motores).

OSEK do idioma alemão Arbeitskreis Offene Systeme und deren Schnittstellen für die Elektronik in Kraftfahrzeugen - Sistemas Abertos e suas Interfaces para a Eletrônica em Veículos Motorizados.

PCM

Powertrain Control Module (Módulo de controle do "trem de força").

PFI

Port Fuel Injection.

PI

Proporcional Integral.

PWM

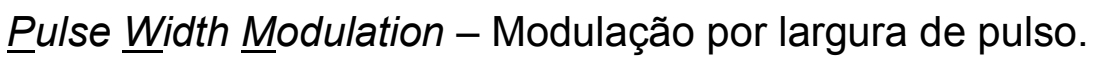

RON

$\underline{R}$ esearch $\underline{\text { Octane }}$ Number (Número de Octanas para método de pesquisa).

RPM

Rotações Por Minuto [ $\left.\mathrm{min}^{-1}\right]$.

RTE

Run Time Environment - ambiente para tempo de execução.

RTOS

Real Time Operating System (Sistema operacional de tempo real).

SI

Sparked Ignition (Ignição por centelha).

SiL

Software-in-the-Loop.

SPI

Serial Peripherical Interface - Interface serial para periféricos.

TDC

Top Dead Center (Ponto Morto Superior: PMS).

TWC

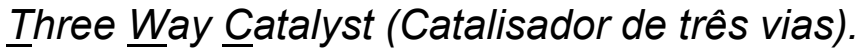

UEGO

Universal Exxhaust Gas Oxygen Sensor (Sensor universal para os gases de exaustão).

UML

Unified Modeling Language - Linguagem de Modelagem Unificada.

VDX

Vehicle Distributed eX ecutive - execução veicular distribuída.

VEIC

Válvula Eletromagnética Injetora de Combustível.

VFB

Virtual Functional B $u s$ - barramento funcional virtual.

VHT

Very $\underline{\text { High }}$ Torque - Nomenclatura comercial dada a família de motores EA 111 que receberam uma série de aprimoramentos da VW do Brasil em meados de 2008 a 2009. 


\section{SUMÁRIO}

AGRADECIMENTOS

RESUMO

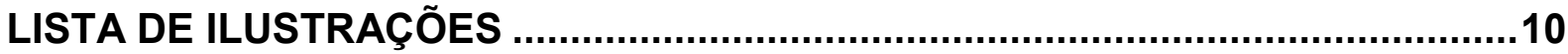

LISTA DE TABELAS

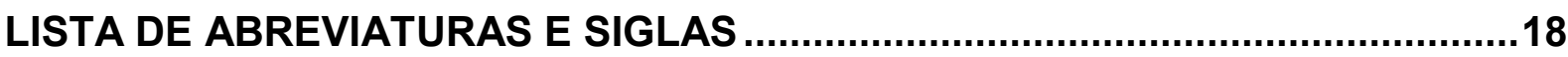

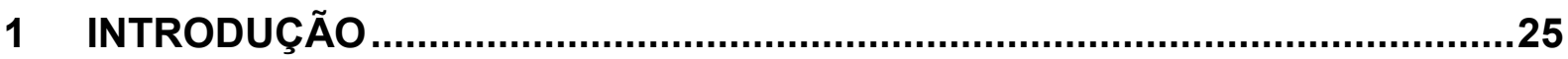

1.1 RELEVÂNCIA ECONÔMICA E AMBIENTAL DA TECNOLOGIA FLEXFUEL 26

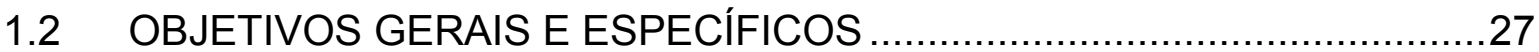

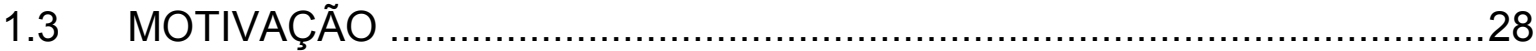

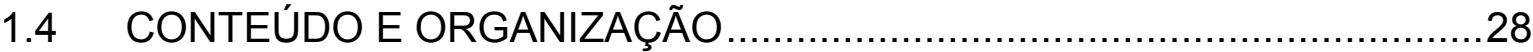

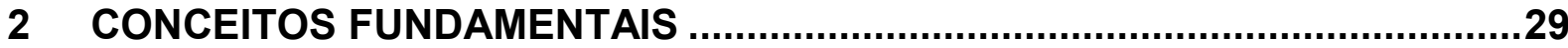

2.1 MOTOR DE COMBUSTÃO INTERNA POR CENTELHA _.......................29

2.1.1 Motor SI (Otto) com deslocamento em 4 tempos ................................29

2.1.2 Definições geométricas para a câmara de combustão ...........................30

2.1.3 Arquitetura de gerenciamento do motor baseada no torque ...................32

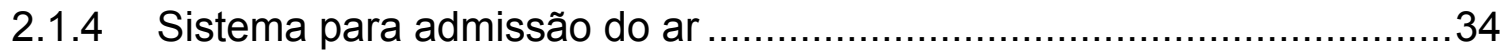

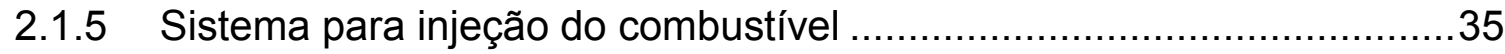

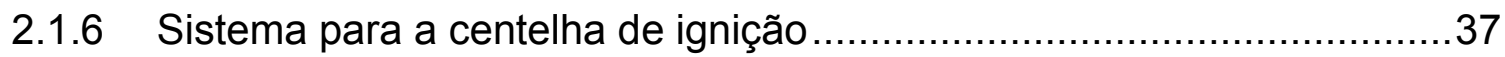

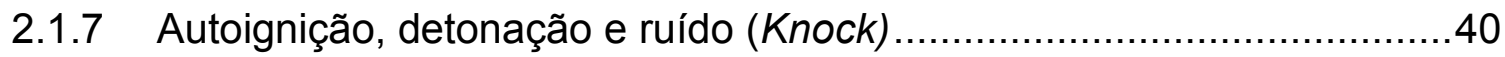

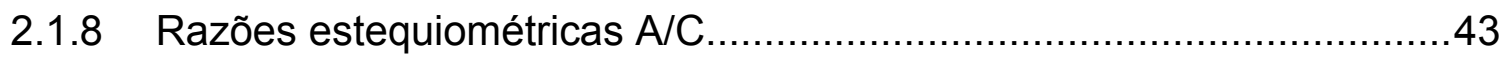

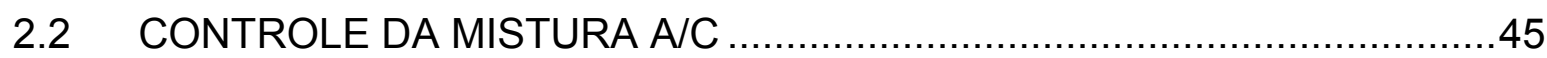

2.2.1 Definição da relação de equivalência $\lambda$ (lambda) .................................46

2.2.2 Emissões de gases nocivos à atmosfera...........................................47

2.2.3 Sistema em malha aberta (open-loop/feedforward) .............................50

2.2.4 Cálculo de combustível para a quantidade de ar................................52

2.2.5 Sistema em malha fechada (closed loop/feedback) .............................55

2.3 SENSORES DE OXIGÊNIO (SONDAS LAMBDA) …............................57

2.3.1 Sensor de oxigênio (sonda lambda) planar de banda estreita

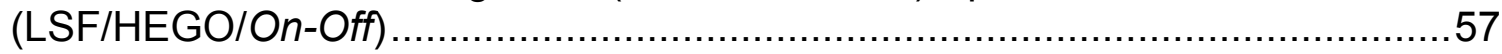

2.3.2 Sensor de oxigênio (sonda lambda) planar com banda larga amplificada

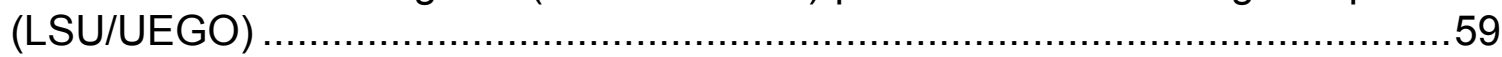

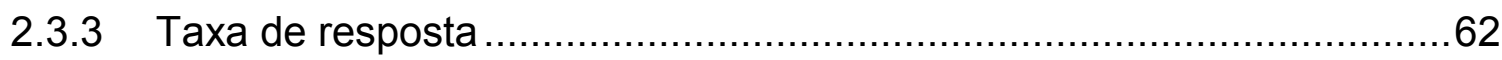

2.4 SISTEMA DE PÓS-TRATAMENTO E CONTROLE A/C ..........................63

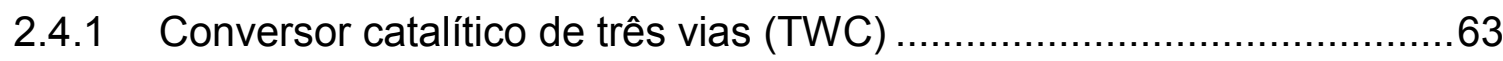

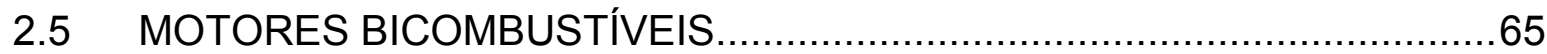

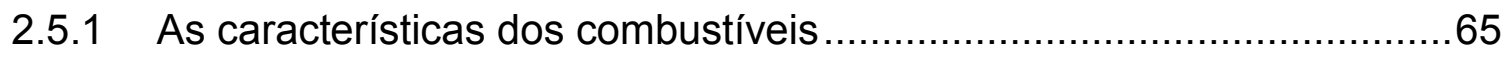


2.5.2 Método indireto para identificação do combustível ...............................67

2.5.3 Taxas de compressão em motores bicombustíveis ...............................68

2.6 O AMBIENTE DE DESENVOLVIMENTO EMBARCADO …......................69

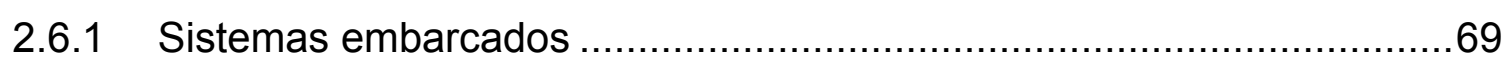

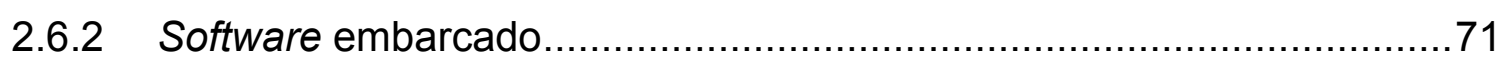

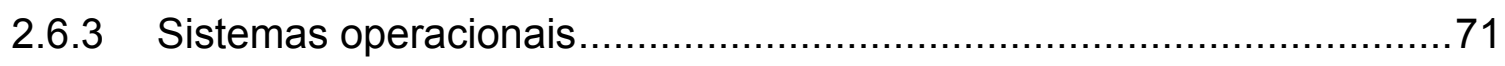

2.6.4 Sistemas operacionais de tempo real (RTOS) …............................. 72

2.6.5 Escalonamento de tarefas .............................................................

2.7 ESTRATÉGIAS PARA O DESENVOLVIMENTO EMBARCADO AUTOMOTIVO .76

2.7.1 O esforço da indústria automotiva para criação de arquiteturas para o

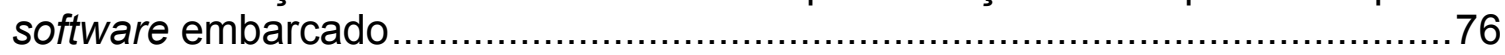

2.7.2 Aspectos da engenharia de software embarcado ..................................77

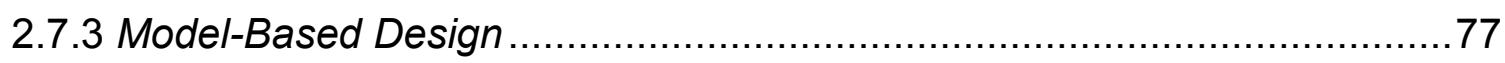

2.8 ETAPAS PARA O DESENVOLVIMENTO DO SOFTWARE AUTOMOTIVO...78

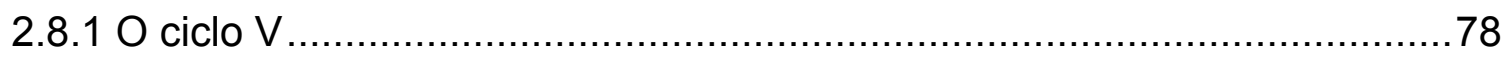

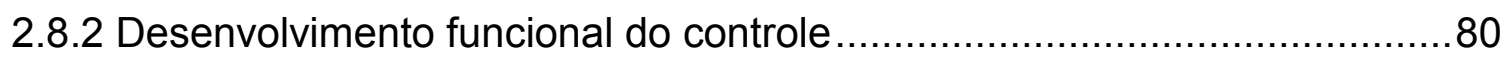

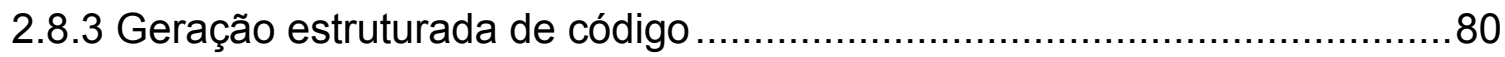

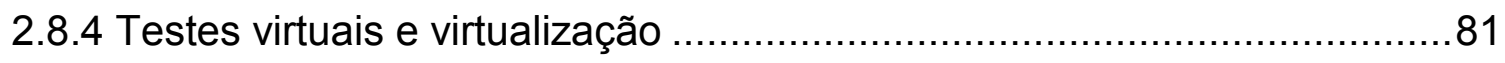

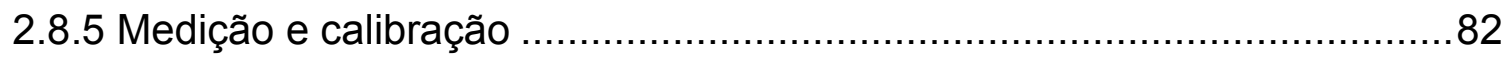

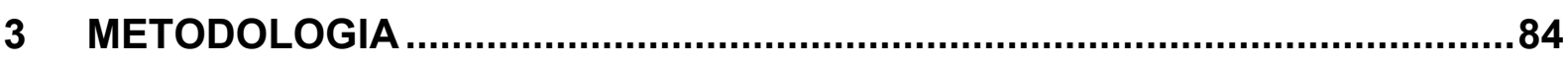

3.1 FERRAMENTAS PARA O SOFTWARE EMBARCADO …........................84

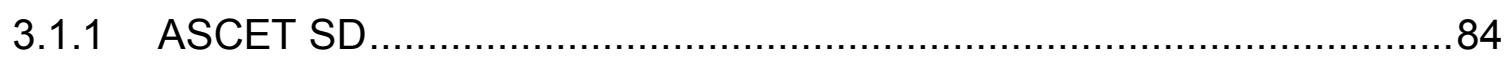

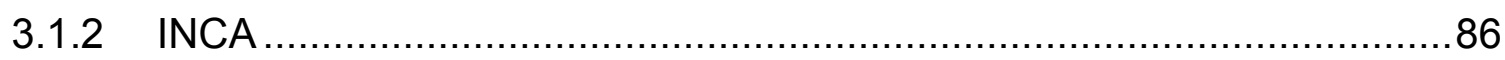

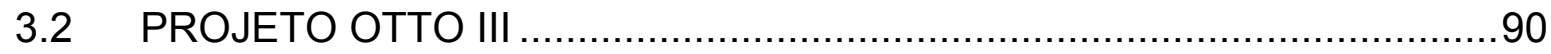

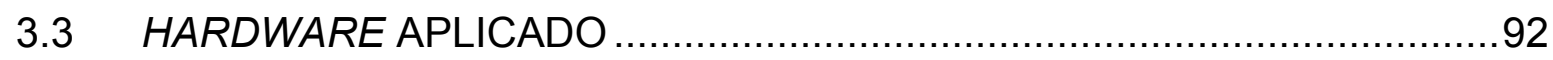

3.3.1 Unidade de Comando dedicada ao Desenvolvimento ..........................92

3.3.2 Utilização de um medidor de composição comercial .............................93

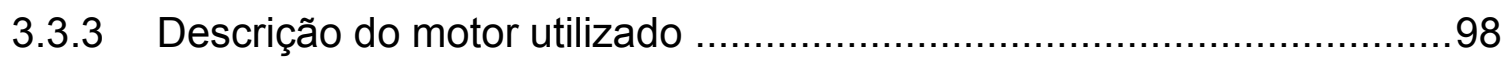

3.3.4 Freios dinamométricos utilizados...................................................99

3.4 MÉTODOS UTILIZADOS NA OBTENÇÃO DO SINAL DE RELAÇÃO LAMBDA E DO ÍNDICE DE DETONAÇÃO PROVENIENTE DO ACELERÔMETRO 102

3.4.1 Utilização inicial de uma interface de testes Lambda 102

3.4.2 Obtenção e conversão da medida da corrente de bombeamento em um sensor de banda larga ............................................................................102

3.4.3 Monitoramento da tensão Nernst em um sensor de banda estreita ....107

3.4.4 Utilização de um driver para a detecção remota de detonação ...........108 
3.5.1 Controle da mistura $A / C$ realizado em malha aberta

3.5.2 Controle da mistura A/C (lambda) realizado em malha fechada para um sensor de oxigênio com banda larga (LSU/UEGO). 114

3.5.3 Controle da mistura A/C (lambda) realizado em malha fechada para um sensor de oxigênio com banda estreita (LSF/HEGO/On-Off).... 119

3.5.4 Controle para o aquecimento do sensor de banda larga (LSU/UEGO) em malha fechada. 122

3.5.5 Características comuns às rotinas de controle e diagnose

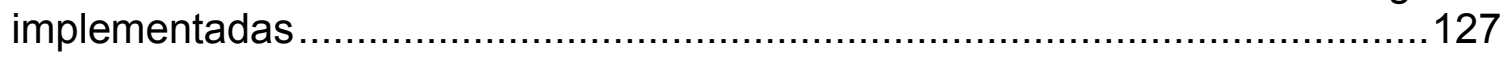

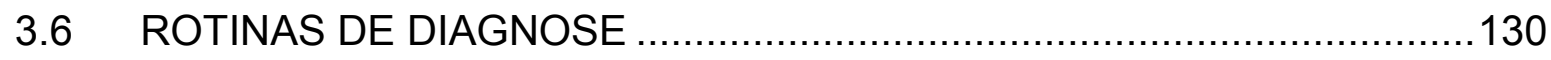

3.6.1 Diagnose da comunicação CJ125, aquecedor e do sensor de banda larga (LSU/UEGO) 130

3.6.2 Diagnose do acionamento PWM do aquecedor do sensor de banda estreita LSF(HEGO/On-Off) ...................................................................133

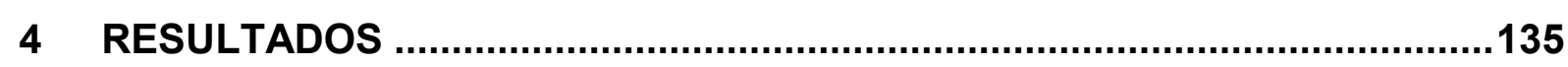

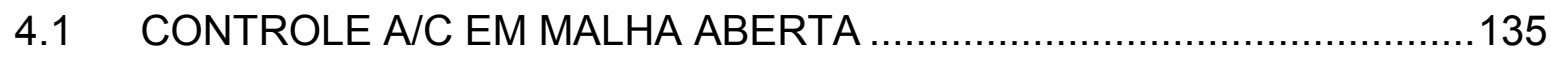

4.1.1 Ajuste dos mapas básicos de injeção e ignição ................................135

4.2 CONTROLE A/C EM MALHA FECHADA PARA UM SENSOR DE OXIGÊNIO DE BANDA LARGA (LSU/UEGO) ........................................138

4.2.1 Correção por composição do combustível.......................................138

4.2.2 Enriquecimento da mistura A/C durante aceleração brusca (kick down) e aceleração gradual. 139

4.2.3 Manutenção da relação estequiométrica durante regime de marcha lenta e conversão da corrente de bombeamento para a relação de equivalência lambda 145

4.2.4 Regulação da temperatura de operação do sensor LSU/UEGO .........149 4.3 CONTROLE A/C EM MALHA FECHADA PARA UM SENSOR DE OXIGÊNIO DE BANDA ESTREITA (LSF/HEGO/On-OFF)...............................150

4.3.1 Conversão da Tensão Nernst e manutenção da relação estequiométrica

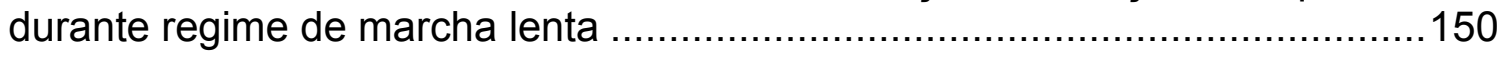

4.3.2 Regulação da temperatura de operação do sensor LSF/HEGO ..........153

4.4 OBSERVAÇÃO DOS FENÔMENOS DEPENDENTES DA RELAÇÃO DE EQUIVALÊNCIA $\lambda$ (LAMBDA) PARA A CONDIÇÃO DE MBT...........................154

4.4.1 Busca dos avanços de ignição para o MBT ......................................154

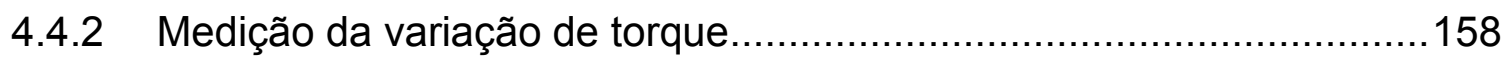

4.4.3 Medição da variação do fluxo de combustível ...................................159

4.4.4 Medição da variação do consumo específico de combustível ..............160

4.5 COMPARAÇÃO DOS RESULTADOS ENCONTRADOS NAS METAS MBT E IKT 160 
APÊNDICE A - BREVE HISTÓRICO DO DESENVOLVIMENTO FLEX-FUEL ...179

Os primórdios do combustível etanol .......................................................179

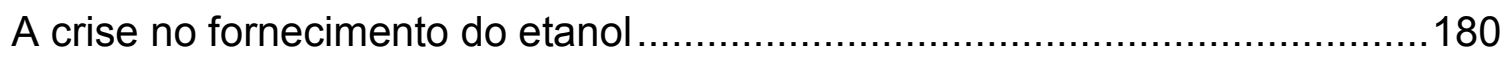

A ascensão da tecnologia Flex-Fuel .......................................................180

APÊNDICE B - RELEVÂNCIA DA CARACTERIZAÇÃO DA COMPOSIÇÃO DO COMBUSTIVVEL EM MOTORES FLEX-FUEL COM SOBREALIMENTAÇÃO E

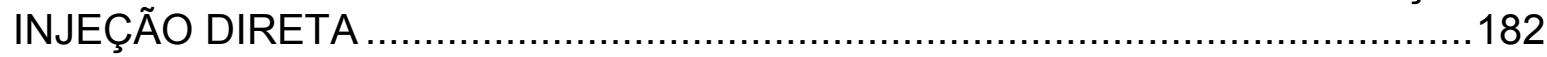

APÊNDICE C - DETERMINAÇÃO ONLINE DA COMPOSIÇÃO DO COMBUSTIVVEL 185

Princípios estimado a partir da medida da constante dielétrica e resistividade

(síntese simplificada) 185

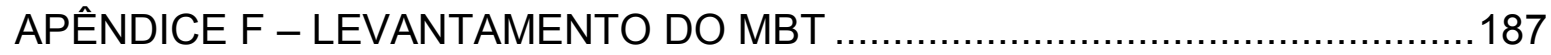

Buscas dos avanços de ignição para as condições de MBT...........................187

Medições dos índices de detonação para as condições de MBT .....................188

Medições de torque para as condições de MBT ........................................189

Medições de potência para as condições de MBT ………............................190

Medições de fluxo de combustível para as condições de MBT ........................191

Medições de consumo específico para as condições de MBT ........................192

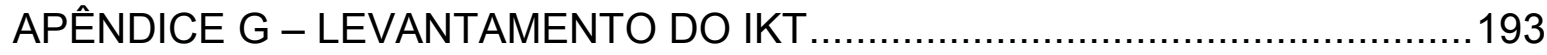

Buscas dos avanços de ignição para a condições de IKT ………………......193

Medições do índice de detonação para as condições de IKT ...........................194

Medições de torque para as condições de IKT ..........................................195

Medições de potência para as condições de IKT ........................................196

Medições de fluxo de combustível para as condições de IKT .........................197

Medições de consumo específico para as condições de IKT ...........................198 


\section{INTRODUÇÃO}

Por milênios, a humanidade tem feito o uso de biomassas como fonte de energia, tendo começado a ser substituído há apenas 200 anos atrás por carvão e óleo. Por isto, a discussão sobre a utilização primária de energia tem sido algo recorrente nos últimos dois séculos. A combustão proveniente de energia fóssil representa mais de dois terços da utilização primária de energia do mundo (SARATHY, et al., 2014).

O crescente emprego de energia não renovável tornou visível o cenário de que num futuro próximo haveria o fim das reservas de energia derivadas do petróleo. Uma das opções que passaram a ser seriamente consideradas é a utilização da bioenergia sob novos conceitos e tecnologias (NOGUEIRA HORTA, et al., 2013), e por esta razão uma das principais alternativas consideradas é o aumento do emprego de combustíveis alternativos de fontes renováveis como é o caso dos combustíveis álcoois provenientes de plantas, buscando-se também o aumento de eficiência em sua utilização.

Nos veículos que utilizam o motor de combustão interna, a eficiência energética é alcançada ao utilizar-se um módulo de controle da mistura ar/combustível, função a qual considera-se como a mais essencial do gerenciamento eletrônico do motor (ASHOK, ASHOK e KUMAR, 2016).

Até a década de 1960, o controle de um motor a combustão interna era executado através de uma combinação de sistemas mecânicos, pneumáticos ou hidráulicos. Então, na década de 1970, os sistemas de controle eletrônico foram introduzidos (RIBBENS, 2012), objetivando, dentre outros aspectos, a redução dos impactos ambientais e econômicos ligados ao uso da energia fóssil nos veículos automotivos, e também ao atendimento das legislações vigentes da época.

Nas últimas duas décadas, graças a eletrônica, os microcontroladores foram sistematicamente incorporados em sistemas automotivos, a fim de melhorar o funcionamento de uma série de funcionalidades, em termos de controle do motor, conforto e segurança dos passageiros e sistemas de infotainment. (DE A DIAS, et al., 2015).

A inserção da eletrônica permitiu, também, a evolução de todos os outros sistemas automotivos, aumentando a eficiência, o conforto e a confiabilidade, pela introdução de funções microprocessadas e controladas. Atualmente, 
aproximadamente $90 \%$ de todas as inovações na área automotiva estão associadas a sistemas eletrônicos baseadas em software (CHEN, et al., 2013).

Em apenas 30 anos, a quantidade de linhas de código existentes nos softwares automotivos foi de zero a dezenas de milhões. Um veículo premium atual, por exemplo, tem tipicamente implementadas cerca de 270 funções para interação de um único usuário, implantadas em cerca de 70 módulos comunicantes, (BROY, et al., 2007) números estes que tendem a aumentar com o passar dos anos.

Este fato aponta notavelmente para que o desenvolvimento possua um padrão estrutural que a longo prazo possa ser aprimorado, afim de conduzir esse processo evolutivo sem que se perca o legado previamente estabelecido reduzindo o tempo de entrega de novas soluções em aplicações de software. O desenvolvimento de software de maneira padronizada se faz necessário para que haja harmonia no controle e comunicação dos vários sistemas atuantes em um veículo de maneira refinada e controlada, com a finalidade do projeto ser replicado em larga escala.

O sistema de controle do motor é a parte mais significativa em veículos modernos, sendo também uma das tarefas mais importantes no campo de controle automotivo. O gerenciamento eletrônico do motor é um sistema embarcado de sinais mistos que interagem com o mundo físico através de sensores e atuadores. Comparado com outros sistemas embarcados, possui rigorosas demandas de confiabilidade (da ordem de $10^{-8}$ falhas/hora/carro) com compartilhamento de recursos e custos de modo eficiente. (HUANG, HUANG e ZHANG, 2010)

\subsection{RELEVÂNCIA ECONÔMICA E AMBIENTAL DA TECNOLOGIA FLEX-FUEL}

Ao contrário do que muitos pensam, a utilização do etanol ainda deve ser tratada como um tema tecnológico atual, e cada vez mais a comunidade cientifica mundial têm se convencido disto. Em 2002, o denominado pai dos polímeros condutores, o físico laureado com o prêmio Nobel de química nos anos 2000, Alan Graham MacDiarmid, afirmou em suas próprias palavras: "O Brasil é líder mundial em tecnologia de biocombustíveis, mas não se dá conta. O mundo precisa da expertise brasileira em combustíveis renováveis, pois, eles são a melhor resposta para os três maiores problemas da humanidade nos próximos anos - energia, água e alimentos - e contribuem também para solucionar outros problemas tão 
importantes, como meio ambiente, pobreza, doenças, educação, terrorismo e guerra".

Assim como o meio acadêmico, o ambiente industrial enxerga na utilização do etanol oportunidades promissoras para o país, assim como destaca em sua fala o Gerente experimental da FCA da América Latina Robson Cotta: "O etanol é um elemento fundamental no desenvolvimento da indústria automotiva brasileira, mas os próprios brasileiros não dão valor a ele. Somos o único país do mundo com uma alternativa viável e consolidada ao petróleo sendo utilizada em larga escala. O Brasil precisa estimular uma evolução ainda maior do etanol antes de pensar em híbridos e elétricos".

Além dos fatores destacados, a utilização do etanol não resulta em emissões significativas de gases do efeito-estufa (principalmente o gás carbônico $\mathrm{CO}_{2}$ ). Isto se deve ao fato do $\mathrm{CO}_{2}$ proveniente da queima de etanol e seu bagaço ${ }^{1}$ (utilizado em caldeiras) ser reabsorvido pela fotossíntese durante o crescimento da cana na estação seguinte. As necessidades de energia para sua produção (calor e eletricidade) provêm do próprio bagaço e a sobra deste material pode ser usada para geração de eletricidade (GOLDEMBERG, COELHO e GUARDABASSI, 2008).

\subsection{OBJETIVOS GERAIS E ESPECÍFICOS}

O presente trabalho teve como objetivos gerais o aprimoramento de um gerenciamento monocombustível para a operação bicombustível, com o emprego de técnicas de controle da mistura ar/combustível em uma abordagem de desenvolvimento real time, e contribuir com outras pesquisas que necessitem de um gerenciamento eletrônico com esta funcionalidade dentro deste ambiente open source que é referência em sistemas embarcados por facilitar os processos de criação, compartilhamento e manutenção de software.

Para alcance dos objetivos gerais, foram definidas as seguintes metas a serem alcançadas:

(i) Solução para identificação de combustíveis em tempo real, com o objetivo de eliminar estratégias reativas para a identificação de combustível.

(ii) Implementação do controle da mistura A/C (lambda) em malha fechada com 2 (duas) principais tecnologias de sensores de oxigênio:

\footnotetext{
${ }^{1}$ Resíduo do esmagamento da cana-de-açúcar.
} 


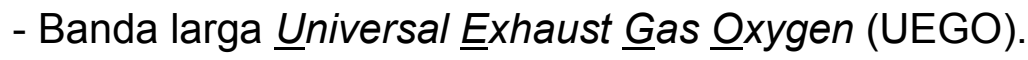

- Banda estreita Exhaust Gas Oxygen (EGO).

(iii) Contribuir modularmente para o domínio de novas tecnologias no gerenciamento eletrônico de um motor a combustão interna ciclo Otto bicombustível um ambiente de desenvolvimento profissional, o qual suporta as principais nuances de engenharia de software embarcado automotivo.

\subsection{MOTIVAÇÃO}

Existe uma grande oportunidade pedagógica na eletrônica embarcada automotiva, já que permite implementar uma série de aplicações reais. O crescimento da produção automotiva exige grandes equipes de engenheiros eletrônicos, especializados em eletrônica embarcada (DE A DIAS, et al., 2015). Ao atacar-se diferentes aspectos de um mesmo problema, realiza-se o desenvolvimento, por isto, este trabalho tem a principal motivação de contribuir a um propósito maior, que é o compartilhamento e valorização do conhecimento e desenvolvimento acerca do gerenciamento eletrônico de motores bicombustíveis.

\subsection{CONTEÚDO E ORGANIZAÇÃO}

O presente trabalho está organizado da seguinte maneira: o capítulo 2 revisa conceitos fundamentais relacionados ao motor de ciclo Otto, a relevância do avanço de ignição e relação de equivalência $\lambda$ (lambda) para o aproveitamento da combustão, os sensores e atuadores empregados, as particularidades dos motores bicombustíveis, características geométricas, gerenciamento eletrônico, e uma breve intordução aos sistemas e softwares embarcados, sistemas operacionais de tempo real, e o cenário autotomotivo para desenvolvimento. O capítulo 3 expõe a metodologia e arquitetura do software embarcado, as ferramentas e técnicas aplicadas para o tratamento do problema em questão, como os softwares e hardwares empregados e os respectivos controles utilizados neste projeto. $\mathrm{O}$ capítulo 4 discute os resultados dos experimentos e validação das rotinas de software. O capítulo 5 contém conclusões sobre resultados obtidos e propõe as metas a serem realizadas para otimização dos objetivos deste trabalho. 


\section{CONCEITOS FUNDAMENTAIS}

\subsection{MOTOR DE COMBUSTÃO INTERNA POR CENTELHA}

\subsubsection{Motor SI (Otto) com deslocamento em 4 tempos}

Por definição, motor é um conjunto de peças fixas e móveis que emprega determinado tipo de energia para que seja aproveitada em uma disposição cinética, no motor Otto, a expansão volumétrica dos gases é aproveitada em movimentos alternativos através dos pistões, que são mecanicamente transformados em movimentos rotacionais. $\mathrm{O} \mathrm{MCl}$ Otto opera em quatro fases, que ocorrem durante duas voltas de sua árvore de manivelas (HEYWOOD, 1988). Essas fases são chamadas de "tempos", correspondentes aos processos de (a) admissão, (b) compressão, (c) expansão e (d) exaustão, conforme ilustrado na Figura 2.1.

Figura 2.1 - Períodos de trabalho de um motor de combustão interna de quatro tempos SI (ciclo Otto).

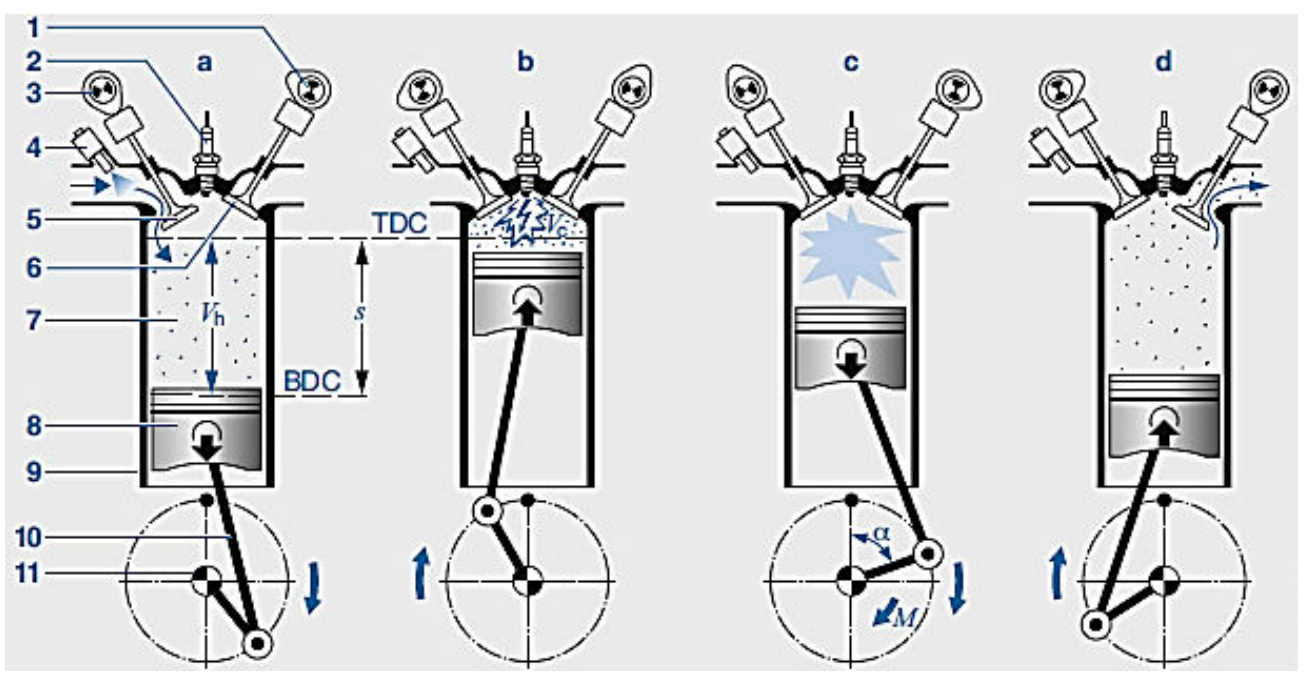

1. Eixo de comando para a válvula de saída (exaustão); 2. Vela de ignição; 3 . Eixo de comando para a válvula de entrada (admissão); 4. Injetor de combustível; 5. Válvula de entrada (admissão); 6. Válvula de saída (exaustão); 7. Volume da mistura admitida; 8. Pistão (êmbolo); 9. Cilindro; 10. Biela; 11. Eixo de manivela ou virabrequim; (a) admissão; (b) compressão; (c) expansão e; (d) exaustão. FONTE: Adaptado de (BOSCH PROFESSIONAL INFORMATION, 2015).

Para melhor compreensão, toma-se o exemplo de um $\mathrm{MCl}$ monocilíndrico, o ciclo Otto completa-se a cada duas revoluções do eixo de manivelas (virabrequim) totalizando $720^{\circ}$, levando em consideração que uma volta do motor possui $360^{\circ}$ de deslocamento. A partir do momento em que o motor está parado, é necessário que haja ação de uma fonte externa de torque para que entre em regime de funcionamento, um motor elétrico utilizado apenas para esse fim (partida). No 
processo de partida o motor elétrico rotaciona o eixo de manivelas (virabrequim) de maneira que este movimento rotativo $M$ com deslocamento angular $\alpha$ seja transmitido através do conjunto biela-manivela ao pistão em um curso linear $s$ dando início ao processo de (a) admissão.

No processo de admissão, a válvula de entrada é movimentada pelo came ${ }^{2}$ do eixo de comando de válvulas abrindo a passagem de entrada do cilindro e o

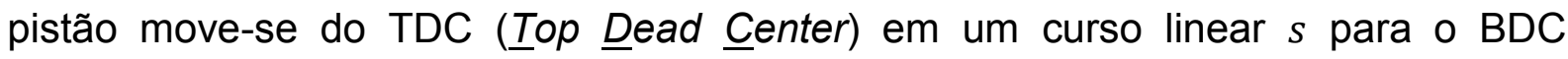

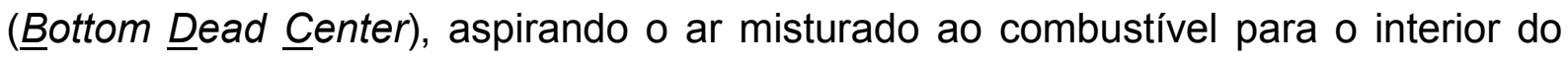
cilindro. No processo de (b) compressão, a válvula de admissão se fecha e o pistão passa a comprimir a mistura de ar e combustível durante o deslocamento do pistão de BDC a TDC em um curso $s$. Em um instante anterior ao do pistão atingir o TDC, o sistema de ignição descarrega uma centelha na vela de ignição que inicia a queima da mistura ar/combustível. Com a combustão, o motor entra no processo do tempo de (c) expansão a partir da pressão interna do cilindro, forçando o pistão a se deslocar do TDC ao BDC, e o conjunto biela-manivela transforma esse movimento de curso linear $s$ em movimento rotativo $M$ com deslocamento angular $\alpha$. Como a combustão ocorre somente neste tempo, esta é a única fase em que o trabalho é gerado, e os demais processos (tempos) ocorrem devido à inércia de giro de todo o conjunto. Finalmente, no processo de (d) exaustão, as válvulas para exaustão se abrem, liberando os gases queimados para a saída do cilindro com um deslocamento do pistão por inércia, indo do BDC para o TDC força os gases da queima a saírem do cilindro para o escapamento e depois para a atmosfera. Cada tempo do motor dura $180^{\circ}$ de deslocamento na árvore de manivelas, resultando em $720^{\circ}$ para o ciclo de quatro tempos.

\subsubsection{Definições geométricas para a câmara de combustão}

A câmara de combustão é formada pelo conjunto pistão (êmbolo), cilindro e cabeçote. A seguir são destacadas as principais definições geométricas a serem observadas.

${ }^{2}$ Came ou lobe: É o ressalto excêntrico do eixo de comando de válvulas que converte seu movimento rotacional em deslocamento alternativo para abertura e fechamento da válvula de admissão ou de escape. 
Figura 2.2 - Definições das dimensões geométricas do virabrequim, da biela e do cilindro de um motor.

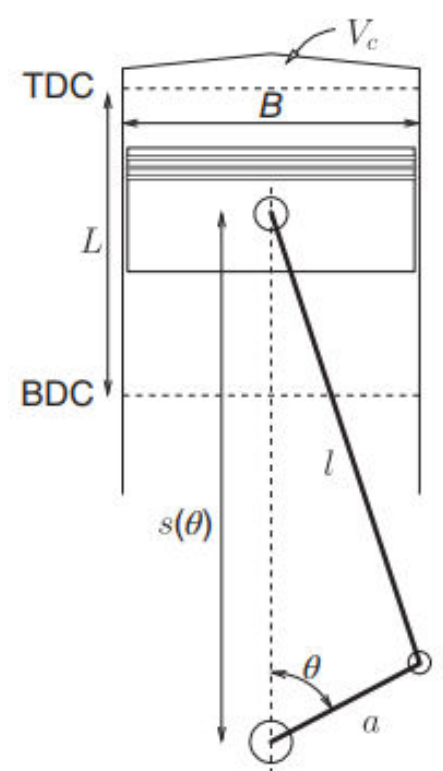

Fonte: Adaptado de (ERIKSSON e NIELSEN, 2014).

O volume deslocado dentro da câmara de combustão $V_{h}$ é dado pela Eq. (2.1).

$$
V_{h}=\frac{\pi \cdot B^{2} \cdot L}{4}
$$

onde $B$ é o diâmetro do cilindro, $a$ o raio do eixo de manivelas, $L=2 a$ curso do pistão, $V_{c}$ o volume mínimo do cilindro, $\theta$ ângulo do eixo de manivelas e $l$ o comprimento da biela.

Outro aspecto geométrico que influi no comportamento da combustão é a relação de compressão $R_{C}$ entre as medidas volumétricas internas ao cilindro do motor. A Figura 2.3 mostra o volume deslocado pelo cilindro (destacado pela elipse de maior circunferência) $\left(V_{h}\right)$ e o volume da câmara de combustão (destacado pela elipse de menor circunferência) $\left(V_{c}\right)$. 
Figura 2.3 - Representação ilustrativa dos volumes internos do cilindro referentes à relação de compressão do mesmo.

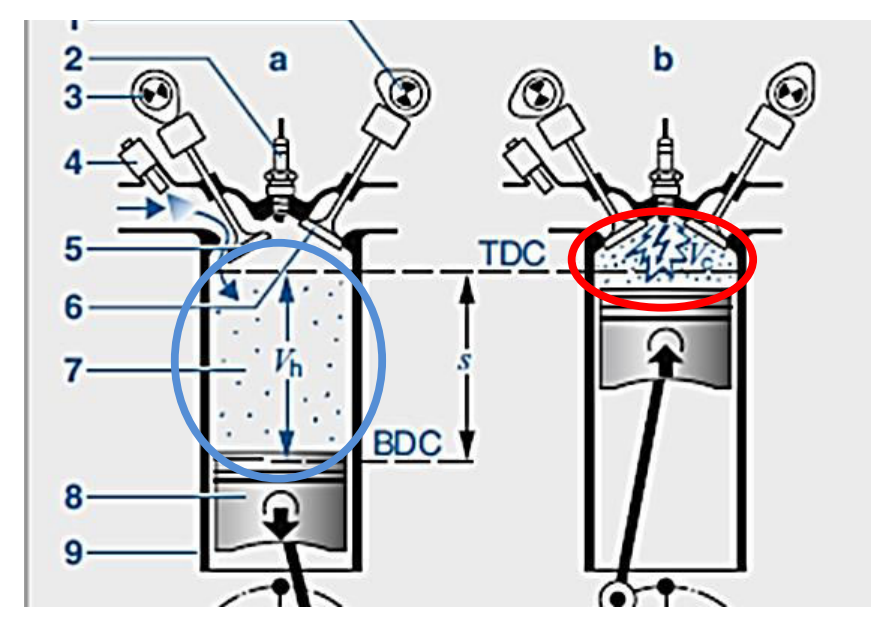

FONTE: Adaptado de (BOSCH PROFESSIONAL INFORMATION, 2015).

A relação de compressão pode ser compreendida como uma grandeza que indica quantas vezes a mistura $A / C$ é comprimida dentro da câmara de combustão antes do processo de queima, e pode ser expressa pela Eq. (2.2).

$$
R_{c}=\frac{\text { volume do cilindro }_{\text {máximo }}}{\text { volume do cilindro } \text { mínimo }_{\text {vili }}}=\frac{V_{h}+V_{c}}{V_{c}}
$$

Do ponto de vista termodinâmico, a relação de compressão pode ser proporcional ao rendimento térmico do motor. Assim, quanto maior for a taxa de compressão, melhor poderá ser o aproveitamento energético do combustível consumido (KIENCKE e NIELSEN, 2005). Entretanto, este efeito não possui uma dinâmica tão simples, pois existe um ponto ótimo para o ganho de trabalho na pressão exercida pela combustão, como é relatado nos experimentos realizados por (SERDAR, et al., 2006) e (BALKI e SAYIN, 2014).

\subsubsection{Arquitetura de gerenciamento do motor baseada no torque}

A arquitetura de controle mais recomendada para motores SI é a estrutura baseada na solicitação torque. O sistema baseado em torque pode interagir facilmente com interfaces externas que também demandam torque durante suas operações (transmissão, controle de tração, entre outros), ou seja, a maioria das exigências para o funcionamento dos sistemas periféricos ao $\mathrm{MCl}$ é que este gere torque. O módulo de controle EMS (Engine Management System) baseado em torque converte as variáveis de entrada em variáveis de torque para o motor, que 
são utilizadas como principal interface entre a unidade de controle do motor e demais funções dentro do sistema de controle do veículo. Através dessas variáveis de torque, realiza-se também a coordenação entre os sistemas de controle referentes ao motor, transmissão e freio, dentre outros. Assim, com base em uma aproximação física do torque, todas as demandas podem ser coordenadas antes que a conversão ideal para os respectivos valores de controle do motor seja estabelecida. À medida que as solicitações de torque são originadas do operador (motorista), formam-se também as funções estratégicas para a operação do motor (por exemplo, inicialização do motor, controle da marcha lenta, aquecimento do catalisador) e subsistemas externos, como a unidade de controle de transmissão e os sistemas de controle de cruzeiro e de tração, dentre outros, como exemplificado na Figura 2.4. (GUENTHER e GERHARDT, 2000) (HEINTZ, et al., 2001)

Figura 2.4 - Arquitetura de gerenciamento do motor baseada no torque.

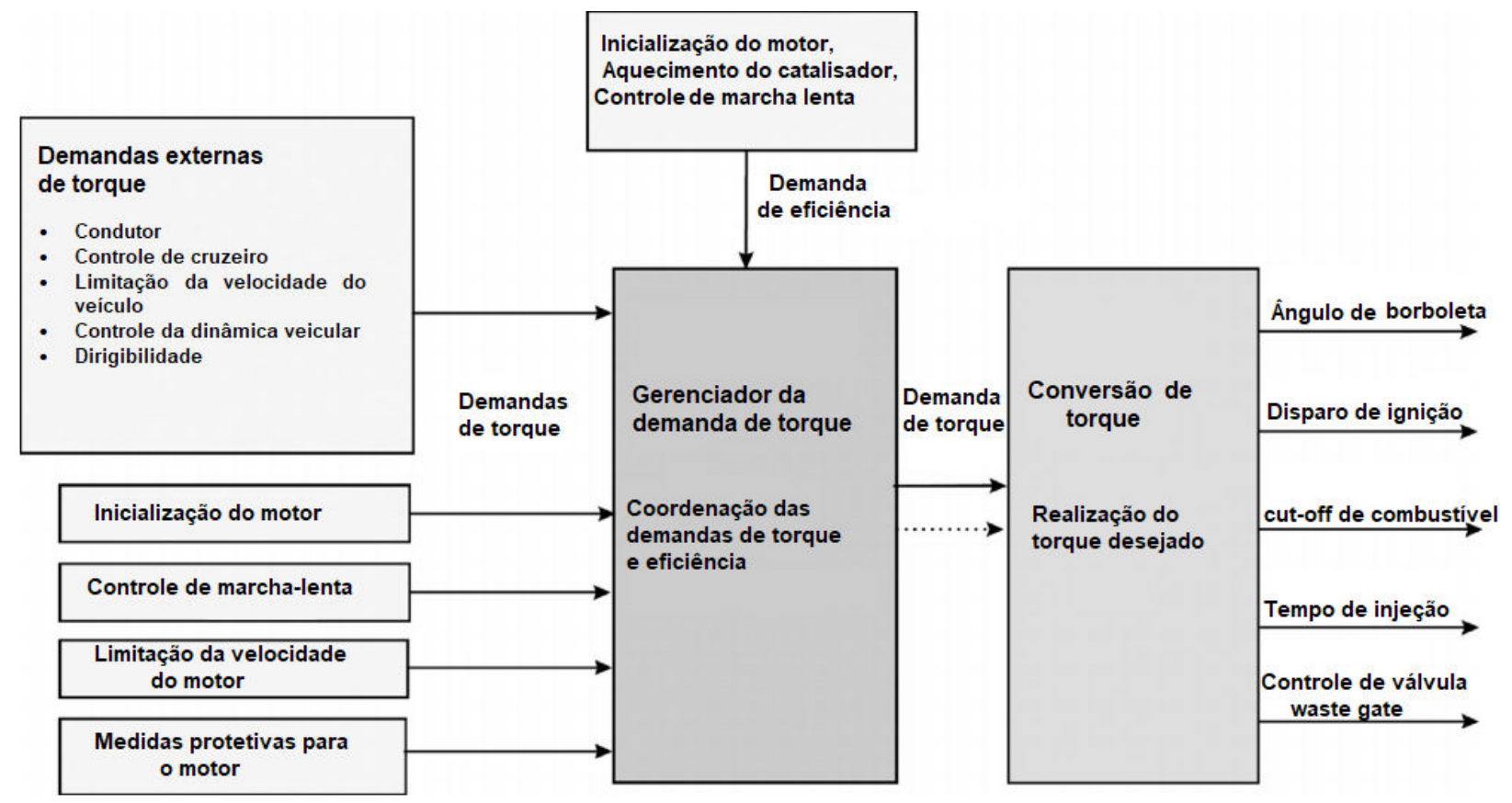

Fonte: Adaptado de (ASHOK, ASHOK e KUMAR, 2016).

O gerenciamento eletrônico baseado no torque para um motor naturalmente aspirado pode ser dividido basicamente em três subsistemas de controle, que gerenciam os seguintes elementos: combustível, ar e ignição. Isto se deve ao fato de que para a ocorrência da combustão são necessários três reagentes: o combustível, o comburente que é oxigênio presente no ar e o calor produzido da centelha desprendida na vela de ignição. Esses três reagentes são respectivamente gerenciados pelos subsistemas de dosagem do combustível, admissão de ar e 
sincronia de ignição. A Figura 2.5 representa a aplicação realizável do torque no gerenciamento eletrônico para um motor naturalmente aspirado realizado pelo ECM

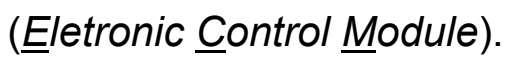

Figura 2.5 - Modelo de controle para realização do torque desejado em um motor SI naturalmente aspirado e seus subsistemas de controle.

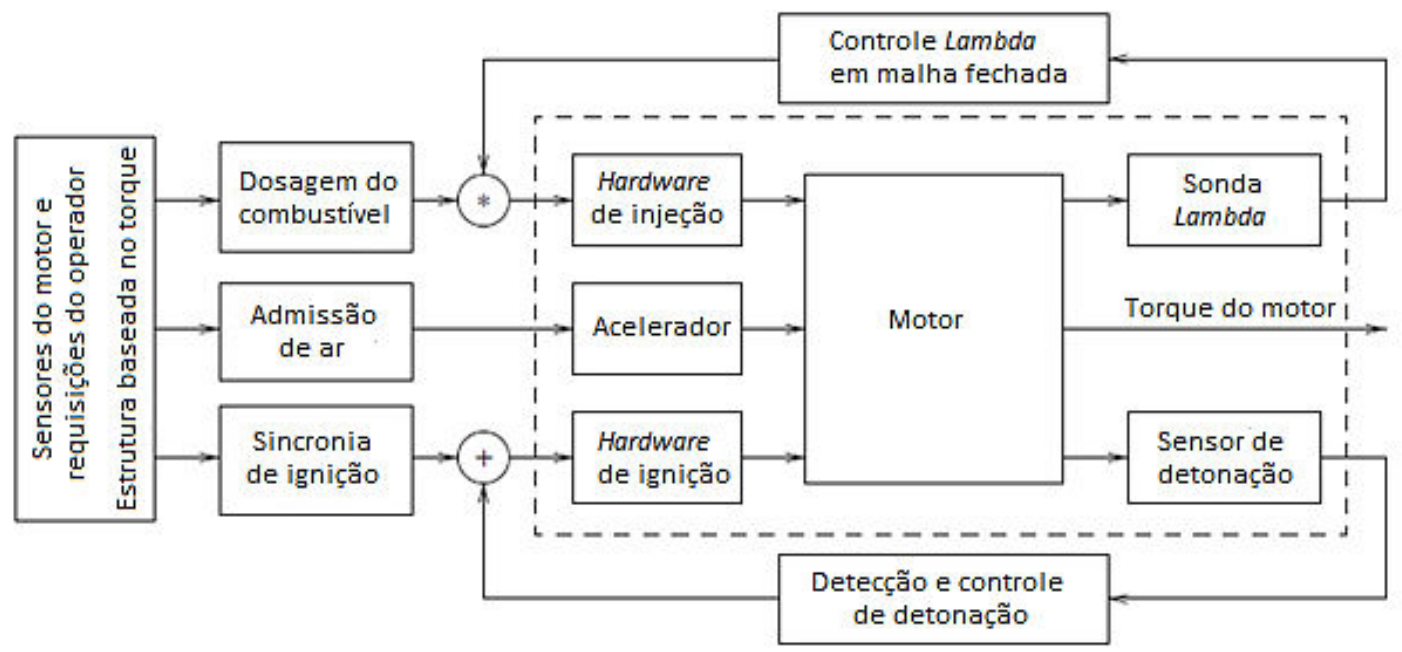

FONTE: Adaptado de (ERIKSSON e NIELSEN, 2014).

Os subsistemas precisam operar de forma sincronizada com a finalidade de se obter os indicadores do bom funcionamento, evitando desperdícios de energia, seja na forma química, cinética ou eletroeletrônica, entregando o melhor desempenho em função do aproveitamento do torque, economia de combustível e adicionalmente garantir que o veículo emita a menor quantidade de poluentes possível, e esta afirmação pode ser naturalmente compreendida pelo entendimento do delineamento dos subsistemas descritos a seguir.

\subsubsection{Sistema para admissão do ar}

O subsistema para a admissão de ar é o responsável por estimar e restringir a massa de ar admitida pelos cilindros do motor através de um atuador principal. A estimação é realizada através de sensores e estratégias para medida do fluxo ou massa de ar que é consumida pelo motor. A restrição é realizada através do movimento de uma válvula de estrangulamento que controla a passagem de ar através de seu ângulo de abertura. Se a vazão do ar admitido pelos cilindros

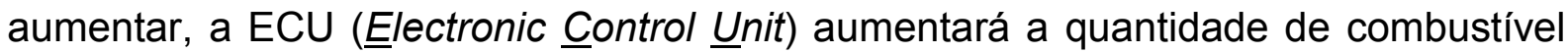
entregue e, assim, aumentará a força elástica de expansão dos gases promovendo o aumento do torque e, consequentemente, o trabalho entregue pelo $\mathrm{MCl}$. 
A partir do conceito drive by wire ${ }^{3}$, o controle de aceleração eletrônico ETC (Electronic Throttle Control) realiza o estrangulamento do ar para o motor, exemplificado na Figura 2.6.

Figura 2.6 - Esquemático simples do funcionamento de uma válvula para estrangulamento do fluxo de ar com controle eletrônico (ETC).

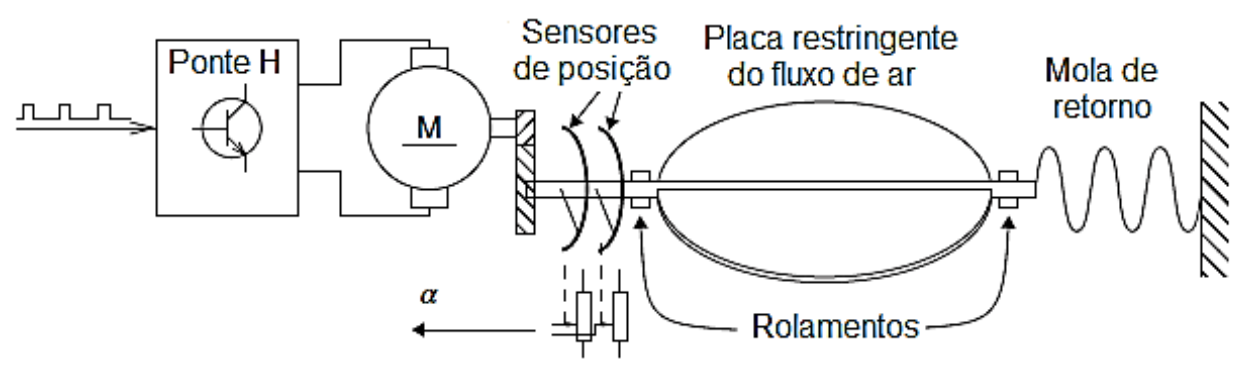

Fonte: Adaptado de (ERIKSSON e NIELSEN, 2014).

O ângulo de abertura da válvula é controlado pelo sistema de gerenciamento do motor com base na estrutura de realização do controle de torque para a demanda requerida pelo condutor, através de sinais dos sensores de posição do pedal do acelerador e outros requisitos do sistema.

\subsubsection{Sistema para injeção do combustível}

O controle da quantidade necessária de combustível que deve ser entregue à entrada (admissão) é realizado pela atuação das válvulas eletromagnéticas injetoras de combustível (VEIC's). A VEIC é o principal atuador empregado para o controle de dosagem de combustível, a partir do uso da válvula solenoide, conforme Figura 2.7.

${ }^{3}$ Drive by wire ou $x$-by-wire é a aplicação do controle eletrônico para a realização de funções que foram primordialmente idealizadas para serem controladas de uma maneira puramente mecânica. 
Figura 2.7 - (a) Representação funcional de uma válvula injetora, (b) sinal do pulso de acionamento da válvula.

(a)

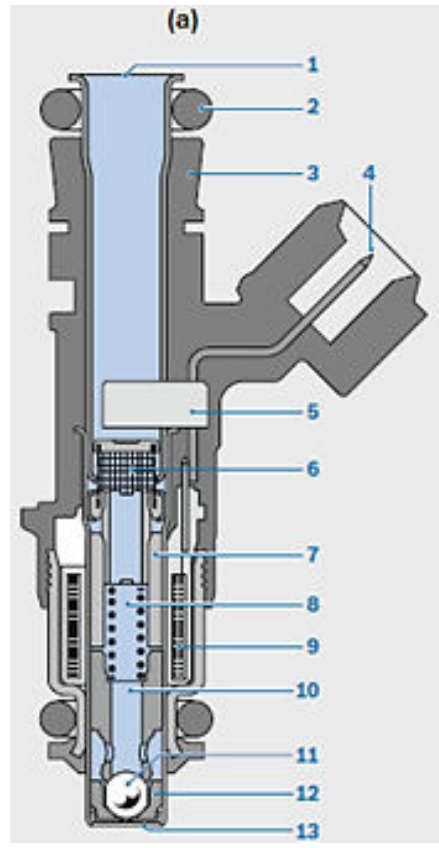

(b)

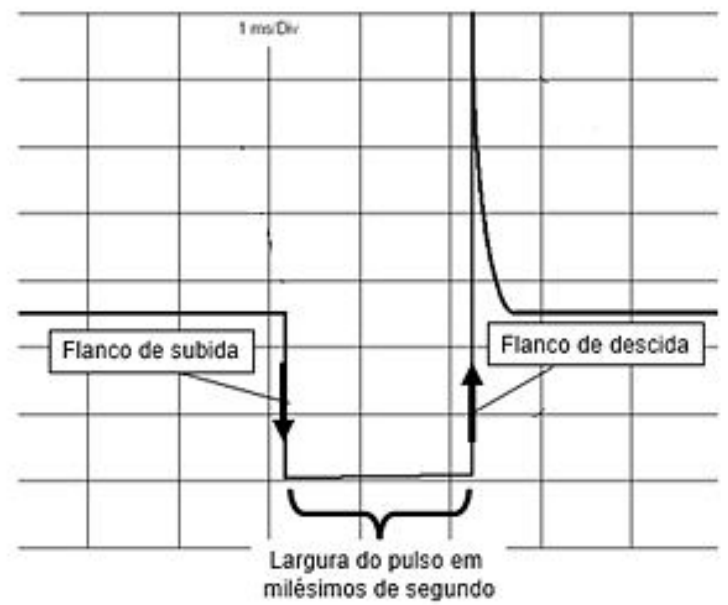

1. Acesso hidráulico; 2. Anel de vedação; 3. Invólucro do conjunto; 4. Conexões elétricas; 5 . Grampo plástico com os pinos elétricos injetados; 6 . Filtro de retenção; 7 . Polo interno; 8 . Mola do conjunto válvula; 9 . Bobina solenoide; 10 . Agulha do conjunto válvula e armadura; 11 . Esfera do conjunto válvula; 12. Acento do conjunto válvula e; 13. Placa com orifício de injeção. Fonte: Adaptado de (BOSCH PROFESSIONAL INFORMATION, 2015).

Durante o estado de repouso, não há fluxo de corrente na bobina, nesse instante não há f.e.m (força eletromotriz), então a força da mola de retorno mantém o conjunto válvula-armadura pressionado, não permitindo a passagem do combustível. Com a excitação gerada pelo circuito de potência, o enrolamento da bobina solenoide é energizado e a f.e.m. desloca o conjunto válvula-armadura no sentido contrário à pressão exercida pela mola, liberando a passagem para o fluxo de combustível.

A quantidade de combustível injetada será proporcional à largura de pulso aplicada no injetor, visto que de maneira geral a VEIC pode ser tratada como uma válvula solenóide que após aberta possuirá em seu estado de regime permanente uma vazão estática como exemplificado na Figura 2.8. 
Figura 2.8 - Parâmetros básicos da vazão de combustível de uma VEIC (Válvula Eletromagnética Injetora de $\underline{\text { Combustível). }}$

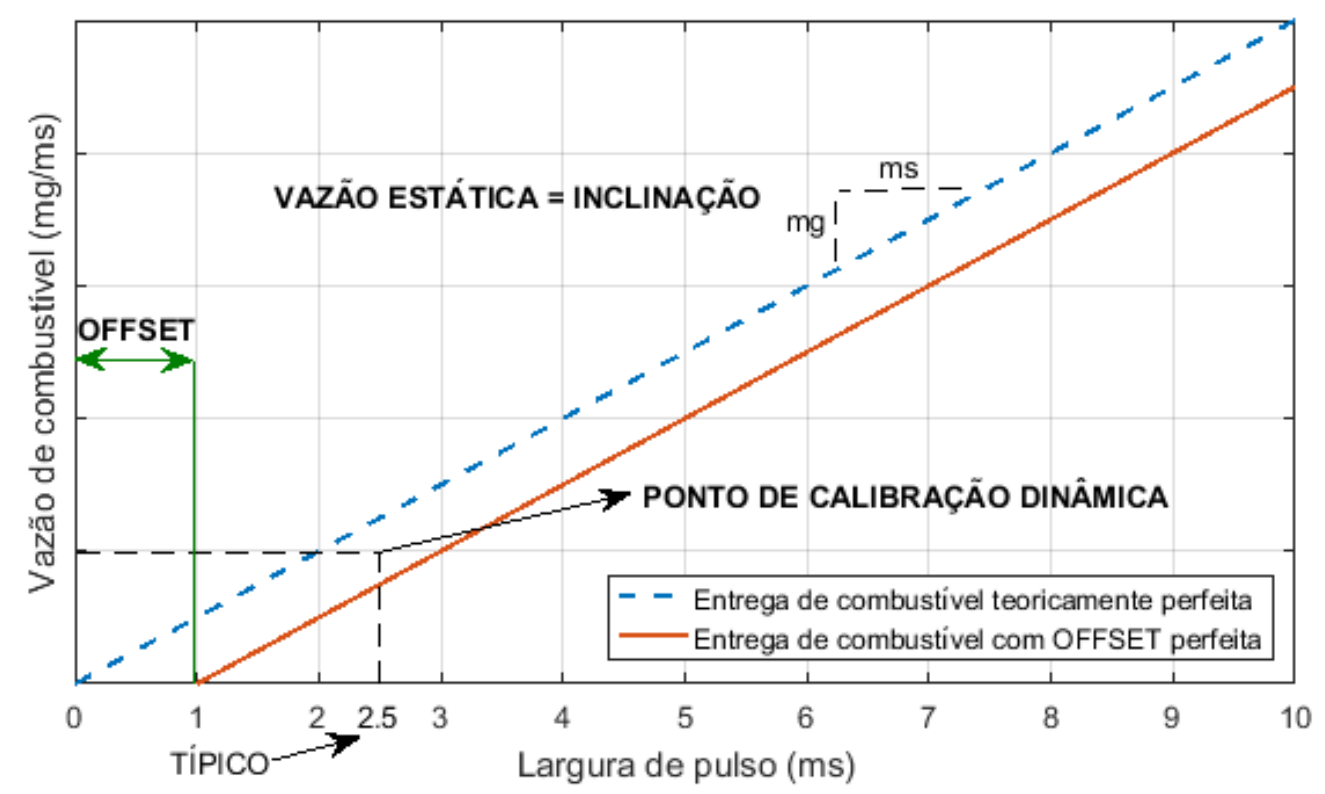

Fonte: Adaptado de (PASSARINI, 1993).

Observa-se que devido á existência, de um atraso entre o início e fim do pulso de controle eletrônico e o início e fim real da vazão de combustível, o ponto de entrega 0 (zero) sempre estará deslocado em relação ao ponto de prigem, sobre o eixo temporal. Esse deslocamento é definido com OFFSET da VEIC. O delta entre o pulso de largura mais curta e o OFFSET é chamada de duração de injeção linear mínima (PASSARINI, 1993).

A vazão estática, inclinação da curva de vazão em conjunto a um único ponto da vazão dinâmica estabelece todo o plano da válvula injetora. O ponto de calibração dinâmica e a inclinação de vazão estática são as duas únicas carcterísticas ajustáveis diponíveis para o controle do fluxo de combustível em sistemas nos quais o sinal de controle é apenas um pulso elétrico ON-OFF.

\subsubsection{Sistema para a centelha de ignição}

O subsistema dedicado à ignição é responsável por gerar a centelha na câmara de combustão do motor, com base nas medições dos sensores de posição do motor, fluxo de ar de massa ou pressão do coletor e RPM (Rotações Por Minuto). O controlador eletrônico calcula o avanço de ignição correto para cada cilindro. No momento apropriado, o controlador envia um sinal de disparo para o circuito de potência (driver), iniciando assim a ignição. Antes que ocorra a centelha, o driver aplica uma corrente relativamente alta através do primário $(P)$ da bobina. Para que ocorra a centelha, um pulso de disparo é enviado ao driver a fim de interromper a 
corrente no primário. Uma tensão muito alta é induzida nesse momento no secundário (S) da bobina. Esta alta tensão é aplicada às velas de ignição, fazendo com que disparem. Nos casos em que uma bobina está associada a dois cilindros, um dos dois cilindros estará no curso de compressão. A combustão ocorrerá neste cilindro, resultando na entrega de energia durante o seu ciclo de potência. $O$ outro cilindro estará em seu curso de escape e a faísca não terá efeito. A maioria dos motores tem um número par de cilindros e pode haver um circuito de acionamento separado e bobina para cada par de cilindros. Por esta razão, tais sistemas de ignição são denominados como centelha perdida, e está exemplificado na Figura 2.9 .

Figura 2.9 - Configuração de um sistema de ignição eletrônica.

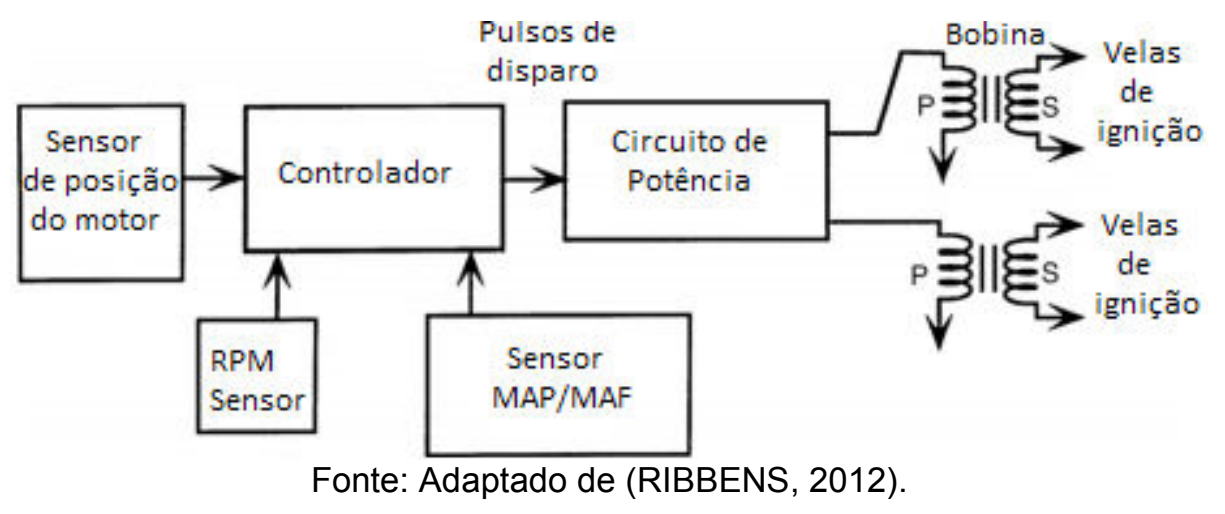

O controle de ignição atua para que a centelha ocorra no momento oportuno e a combustão transmita o máximo de torque disponível, sendo que o ângulo de ignição geralmente é calculado por uma função dos parâmetros de velocidade, carga relativa e temperatura do motor. O pico de compressão ocorre quando o pistão atinge o ponto mais alto de seu curso. Nesse breve momento, a velocidade do pistão é considerada 0 (zero), instante em que o êmbolo atinge o TDC. Para que se obtenha o máximo de eficiência da combustão e, consequentemente, maior torque e potência do motor, a pressão causada pela queima do combustível deve atingir seu máximo em um tempo imediatamente posterior ao TDC, como mostrado na Figura 2.10 . 
Figura 2.10 - Perfil exemplar da pressão exercida pelo fenômeno de expansão termo volumétrica dos gases na câmara de combustão.

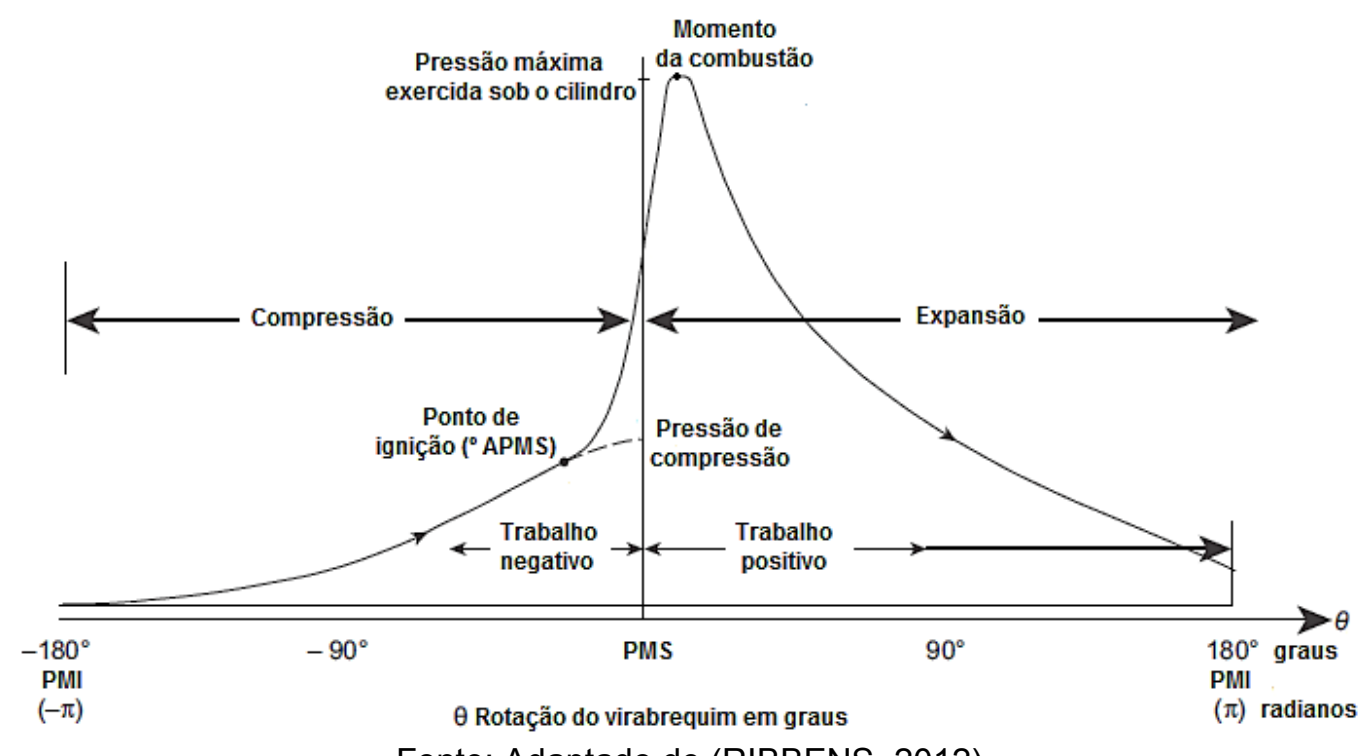

Fonte: Adaptado de (RIBBENS, 2012).

A centelha gerada pela vela leva um pequeno tempo para se propagar por toda a mistura e, portanto, deve ocorrer em um momento anterior ao que o pistão chega ao TDC. Essa variação de tempo é medida em graus (considerando o movimento de rotação do eixo virabrequim). Assim, define-se o ponto em que a centelha da vela é iniciada antes do ponto de TDC, ou seja, o ângulo de antecipação da centelha, denominado avanço de ignição medido em graus [ ${ }^{\circ} \mathrm{BTDC}$ (B efore $\underline{T}$ op

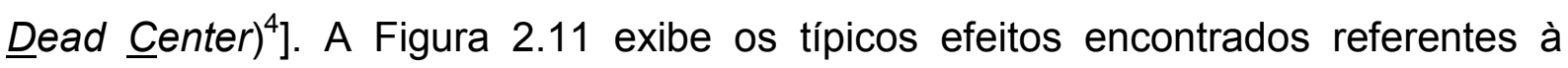
variação do ponto de disparo denominado ângulo de ignição.

Figura 2.11 - Indicadores de torque indicado, consumo e emissões específicos resultantes da variação do disparo da centelha de ignição.

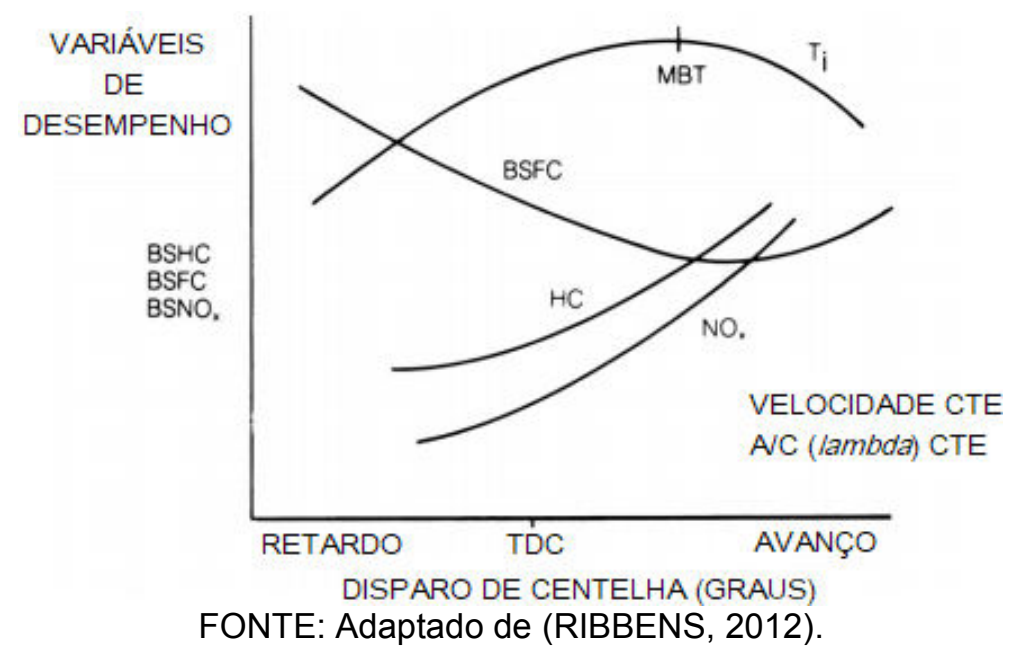

${ }^{4}$ Avanço de ignição anterior ao ponto morto superior (TDC), (APMS - Antes do Ponto Morto Superior). 
As velocidades de propagação da chama variam com a relação de equivalência $\lambda$ (lambda) da mistura, quando ocorre aumento da velocidade de rotação do motor (RPM) em qualquer relação $\lambda$ que possa ser alcançada. $O$ avanço de ignição deverá ser aumentado, adiantando-se o ponto de disparo da centelha para que o momento de máxima pressão aconteça de maneira oportuna ao melhor aproveitamento da energia cinética do conjunto alternativo do motor. Com o êxito desta meta, alcança-se o melhor aproveitamento do torque gerado pela combustão, ou seja, o ponto de MBT (Maximum Break $\underline{\text { Torque }}{ }^{5}$ ). Além disso, a economia de combustível e os níveis de emissões tem sua taxa reduzida quando os eventos de combustão são situados próximos a esse ponto.

Outras aproximações recorrentes podem ser utilizadas para referenciar o ponto de operação denominado MBT, como a medição angular da taxa de desenvolvimento da chama, a qual é analisada através da taxa de liberação de calor do combustível.

Esta teoria baseia-se na função de Wiebe, e é usual em todos os motores de combustão interna. A partir das análises teóricas e experimentais, foi indicado que os melhores ajustes da combustão se dão quando a velocidade de queima do combustivel possui uma taxa de $50 \%$ em um período angular médio entre 6 a 12 graus. Via de regra, o cálculo médio sob a contagem de ciclos do motor fica em torno de 8 a 9 graus do ponto em que a centelha foi disparada em motores SI. Esta medida angular é denominada como MFB50 ou CA50 (BLAIR, 1999). A função de wiebe é amplamente utiizada e é aplicada na grande maioria de softwares simuladores para a combustão como GTpower, AVLBoost, entre outros.

\subsubsection{Autoignição, detonação e ruído (Knock)}

A combustão pode ocorrer como um fenômeno típico ou atípico, sendo dependente de certas condições de operação. A maneira normal e controlada é aquela iniciada exclusivamente por uma centelha sincronizada, que gera a frente de chama e se espalha no volume do cilindro de maneira uniforme a uma velocidade constante. O distanciamento do disparo da ignição da região ótima para iniciação da frente de chama para a combustão a torna ineficiente.

\footnotetext{
${ }^{5}$ Janela máxima de torque.
} 
As combustões atípicas podem causar detonação devido à criação de pontos quentes na área de mistura não queimada da câmara de combustão, principalmente da temperatura e da pressão finais da combustão proposital, bem como da taxa de desenvolvimento da chama.

A detonação pode ser definida como um fenômeno de combustão anormal que envolve a autoignição dos gases pós-combustão (mistura não queimada de combustível, ar e gás residual) diante do avanço regular das frentes de chama, acompanhada de liberação de energia extremamente rápida e descontrolada, o que resulta em oscilações de pressão em alta frequência dentro do cilindro. Essas oscilações de pressão produzem vibrações de amplitude substancial, propagadas através da estrutura do motor, causando um ruído acústico agudo denominado knock $^{6}$ (HEYWOOD, 1988). A Figura 2.12 exemplifica 3 (três) situações de combustão: a normal em que não há evento de detonação, a que possui detonação leve que pode ser caracterizada como trivial e a detonação intensa que deve ser constantemente evitada.

Figura 2.12 - Dois níveis de ocorrência do fenômeno de combustão anormal denominada como detonação.

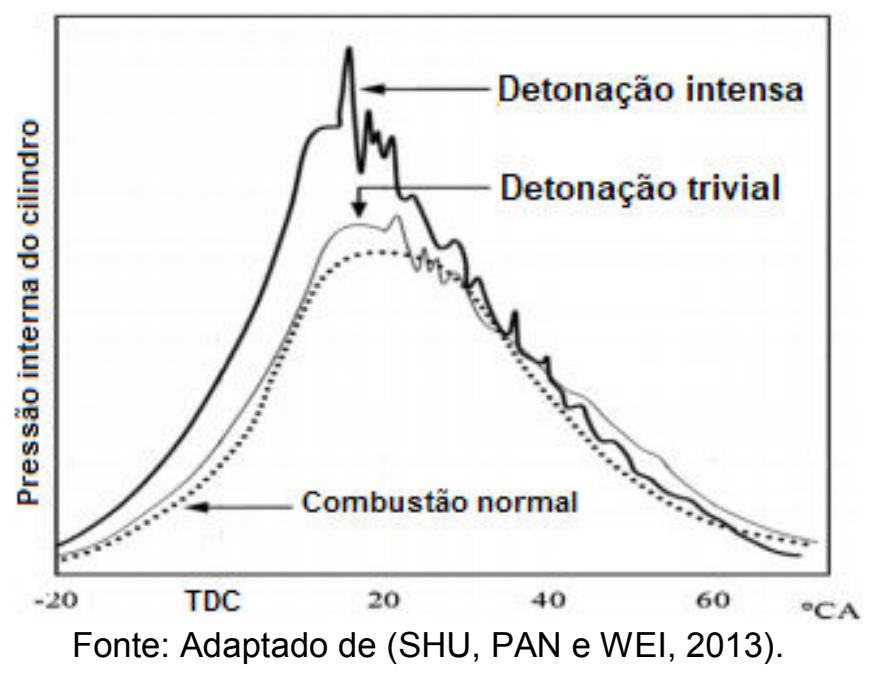

A detonação é um dos elementos fundamentais que obstruem a melhoria da eficiência térmica do motor SI, e ocorre quando a temperatura do gás final é alta 0 suficiente para promover uma autoignição (ERIKSSON e NIELSEN, 2014). Portanto, é importante desenvolver sensores novos e confiáveis que possam fornecer

${ }^{6}$ Palavra do idioma inglês que pode ser traduzida como batida ou pancada, utilizado no jargão técnico da área de motores para caracterizar o momento em que ocorre um dos eventos anormais de combustão conhecido como detonação. 
melhores diagnósticos do motor e identificar vários fenômenos importantes. Por exemplo, a detonação pode ser identificada ao medir-se diretamente variações de pressão dentro da câmara de combustão, instalando-se um sensor óptico na câmara de combustão, ou ainda de maneira remota utilizando-se um sensor piezoelétrico para medir as vibrações no bloco estrutural do motor. Alternativamente, a detonação poderia ser identificada medindo a ionização da mistura $A / C$ também rotulada como corrente iônica (LAGANA, et al., 2018).

As detonações de alta amplitude são classificadas como intensas, e se ocorrerem durante um longo período de tempo, trarão efeitos desfavoráveis como danos materiais ao motor: Além da detonação causar estas avarias de maneira potencial, o mesmo é uma fonte geradora de ruídos em motores. (ZHEN, et al., 2012).

De maneira geral, os eventos de autoignição podem ser evitados através da regulação do ângulo de ignição. Os parâmetros de referência para que o disparo da centelha seja ajustado em função de um ângulo referente ao ponto TDC (denominado de avanço da ignição) são a velocidade do motor e a carga de ar admitida, pois, com o aumento destas grandezas de entrada, maiores serão a temperatura e a pressão finais internas ao cilindro. Entretanto, deve-se perceber que a velocidade laminar de queima do combustível possui relação direta com a relação de equivalência lambda $(\lambda)$, conforme demonstrado na Figura 2.13.

Figura 2.13 - Velocidade laminar de chama resultante da relação A/C (lambda) e pressão aplicados a um combustível hidrocarboneto ciclo-hexano $\boldsymbol{C}_{6} \boldsymbol{H}_{12}$.

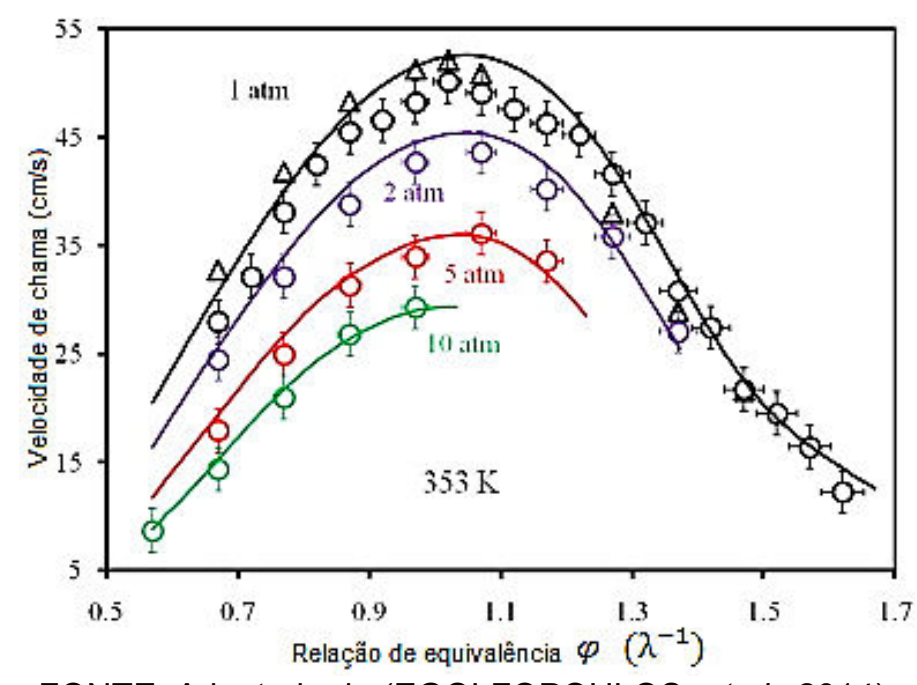

FONTE: Adaptado de (EGOLFOPOULOS, et al., 2014). 
É possível constatar que, além do controle da sincronia (avanço) de ignição, a proporção entre ar e combustível pode moderar fenômenos como autoignição, detonação e Knock. A relação de equivalência lambda influi diretamente na velocidade de queima, além de reduzir a temperatura do interior do cilindro, podendo eliminar o surgimento de pontos quentes.

A taxa de compressão está diretamente relacionada à tendência de detonar, por conta de sua influência na temperatura dos gases não queimados. Em virtude disto, é esperado que motores com taxa de compressão elevada trabalhem com significativa quantidade de eventos detonantes com baixa amplitude classificadas como triviais, as quais começam a ocorrer com um avanço de ignição classificado

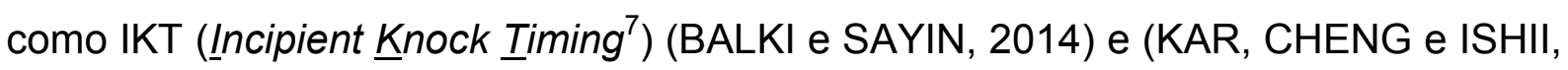
2009).

\subsubsection{Razões estequiométricas A/C}

Uma visão simplista da operação de um motor a combustão interna é que o motor realize a mistura entre ar e combustível. Essa mistura $A / C$ é queimada liberando energia e trabalho através da expansão volumétrica dos gases e, como consequência desta produção de trabalho, tem-se as emissões de gases na atmosfera após o processo da combustão. A medida da mistura ar/combustível é importante tanto para a produção do trabalho quanto para o controle dos níveis de emissões.

$O$ ar é constituído por diferentes gases, tais como oxigênio, nitrogênio, argônio, dióxido de carbono, dentre outros. O oxigênio é essencial em um $\mathrm{MCl}$, o processo de reação com o gás libera energia na forma de combustão. Os outros gases são inertes e possuem efeitos mínimos na combustão, porém, ocupam espaço e ajudam na expansão elástica dos gases. A proporção de distribuição em volume e em massa estão listadas na Tabela 2.1.

Tabela 2.1 - Discriminação dos diferentes gases elementares que constituem o ar atmosférico.

\begin{tabular}{|c|c|c|c|}
\hline Elemento & Símbolo químico & Volume [\%] & Massa [\%] \\
\hline Oxigênio & $\mathrm{O}_{2}$ & 20.95 & 23.14 \\
\hline Nitrogênio & $\mathrm{N}_{2}$ & 78.09 & 75.53 \\
\hline Argônio & $\mathrm{Ar}$ & 0.93 & 1.28 \\
\hline Dióxido de carbono & $\mathrm{CO}_{2}$ & 0.03 & 0.05 \\
\hline
\end{tabular}

\footnotetext{
${ }^{7}$ Avanço de detonação incipiente.
} 
A proporção entre ar e combustível é muito importante para o processo de combustão. Ocorrem vários efeitos que causam variações na massa de ar $m_{a}$ que chega ao cilindro, tais como aceleração do fluxo de ar pela válvula borboleta, resistência aerodinâmica e ressonâncias presentes no coletor de admissão, rebote dos gases já queimados do cilindro nos dutos de entrada para a câmara, dentre outras causas. A massa de ar que teoricamente oxida uma molécula de combustível é denotada por $m_{a, t e o}$. A proporção entre os valores reais e teóricos é igual ao fornecimento de ar $\lambda_{a}$ :

$$
\lambda_{a}=\frac{m_{a}}{m_{a, t e o}}
$$

Similarmente, a proporção entre a massa de combustível medida $m_{c}$ e a massa de combustível teórica $m_{c, t e o}$ é equivalente ao fornecimento relativo de combustível $\lambda_{c}$ :

$$
\lambda_{c}=\frac{m_{c}}{m_{c, t e o}}
$$

A massa teórica de combustível $m_{c, t e o}$ equivale à massa necessária para uma combustão que seja estequiométrica com o oxigênio e outros gases inertes presentes na massa de ar teórica $m_{a, t e o}$, assim, as Eqs. (2.3) e (2.4) são dependentes e relativas entre si (esta relação é abordada na seção 2.2.1).

A estequiometria é importante na combustão, pois expressa se toda a massa de combustível que entrou no cilindro foi consumida, ou seja, todos os hidrocarbonetos foram convertidos durante a combustão, juntamente com o oxigênio, em $\mathrm{H}_{2} \mathrm{O}$ (água) e $\mathrm{CO}_{2}$ (dióxido de carbono) em uma transformação ideal, expresso na Eq. (2.5).

$$
C_{a} H_{b}+\left(a+\frac{b}{4}\right)\left(O_{2}+3.773 N_{2}\right) \rightarrow a C O_{2}+\left(\frac{b}{2}\right) H_{2} O+3.773\left(a+\frac{b}{4}\right) N_{2}
$$

Então, para uma molécula do combustível $\mathrm{C}_{8} \mathrm{H}_{15}$ (gasolina tipo A) ou $\mathrm{C}_{2} \mathrm{H}_{5} \mathrm{OH}$ (etanol anidro), a reações químicas de combustão devem ser:

$$
\mathrm{C}_{2} \mathrm{H}_{5} \mathrm{OH}+3 \mathrm{O}_{2}+13,2 \mathrm{~N}_{2} \rightarrow 2 \mathrm{CO}_{2}+3 \mathrm{H}_{2} \mathrm{O}+13,2 \mathrm{~N}_{2}+\text { calor }_{\text {combustão }}
$$




$$
\mathrm{C}_{8} \mathrm{H}_{15}+11,75 \mathrm{O}_{2}+44,33 \mathrm{~N}_{2} \rightarrow 8 \mathrm{CO}_{2}+7,5 \mathrm{H}_{2} \mathrm{O}+44,33 \mathrm{~N}_{2}+\text { calor }{ }_{\text {combustão }}
$$

De acordo com o balanceamento, para uma molécula de gasolina ser queimada são necessárias 11.75 moléculas de oxigênio. Desta forma, a razão, ou mistura estequiométrica para este combustível seria 11.75. Porém, o ar atmosférico é utilizado na relação, e este possui aproximadamente $21 \%$ de oxigênio, $78 \%$ de nitrogênio e $1 \%$ de gases como argônio e dióxido de carbono, sendo que os 3 (três) últimos gases são inertes à transformação química, porém, também participam da expansão volumétrica no momento da combustão. Segundo (HEYWOOD, 1988), a relação estequiométrica pode ser aproximada através da Eq. (2.8).

$$
A / C_{\text {esteq. }\left(C_{x} H_{x}\right)}=138,8 \cdot\left[\frac{\left(\frac{y}{4}\right)+1-\left(\frac{z}{2}\right)}{12+y+16 z}\right]
$$

onde $y$ e $z$ representam consecutivamente as relações $\mathrm{H} / \mathrm{C} \mathrm{e} / \mathrm{C}$.

Segundo (SARATHY, et al., 2014) e (POLICARPO, et al., 2018), as relações $A / C$ estequiométricas para gasolina tipo $A$, gasolina tipo $C$ e o etanol anidro são respectivamente representadas pelas Eqs. (2.9), (2.10) e (2.11):

$$
\begin{gathered}
A /_{C_{\text {esteq. Gasolina A (E0) }}}=\frac{m_{a, \text { teo }}}{m_{c, \text { teo }}} \cong 14.58 \\
A /_{C_{\text {esteq. Gasolina C (E27) }}}=\frac{m_{a, t e o}}{m_{c, \text { teo }}} \cong 13.1 \\
A /_{C_{\text {esteq. Etanol Anidro (E100) }}}=\frac{m_{a, \text { teo }}}{m_{c, \text { teo }}} \cong 8.98
\end{gathered}
$$

Em motores bicombustíveis, as referências estequiométricas são utilizadas como alvo do controle de variação da proporção $A / C$ em função da composição do combustível administrado ao motor. $\mathrm{O}$ alvo de controle da mistura nem sempre deverá ser estequiométrico, pois, isto poderá depender fortemente da faixa natural de operação, como abordado na seção 2.2.1, e estratégia funcional para o $\mathrm{MCl}$.

\subsection{CONTROLE DA MISTURA A/C}

A relação $A / C$ é um fator decisivo que afeta o desempenho do motor SI. Com uma compensação imprecisa da relação $\mathrm{A} / \mathrm{C}$, o desempenho dinâmico e a economia de combustível do motor serão atenuados, enquanto as emissões de gases nocivos 
se elevarão (CHEN, et al., 2013). A fim de satisfazer às exigências rigorosas que garantem o bom funcionamento e baixas emissões dos gases de escape, a mistura A/C para cada ciclo deve ser composta com precisão de acordo com uma proporção adequada, que geralmente tem a finalidade de atingir a mistura $\mathrm{A} / \mathrm{C}$ estequiométrica em regimes de rotação constante.

\subsubsection{Definição da relação de equivalência $\lambda$ (lambda)}

Segundo os autores (KIENCKE e NIELSEN, 2005), para uma combustão estequiométrica ideal, existe uma razão entre os fornecimentos de ar e combustível, que forma a relação $\mathrm{A} / \mathrm{C}$, que exerce grande impacto no trabalho efetivo do motor $\omega_{e}$ e na eficiência termodinâmica $\eta_{e}$, podendo ser decomposta em duas formas diferentes pela variação dos fornecimentos de ar $\lambda_{a}$ ou de combustível $\lambda_{c}$, como representado na Figura 2.14.

Figura 2.14 - Efeito da variação das relações de fornecimento do ar e do combustível em motores de combustão interna sob o trabalho efetivo $\omega_{e}$ e a eficiência termodinâmica $\boldsymbol{\eta}_{\boldsymbol{e}}$.

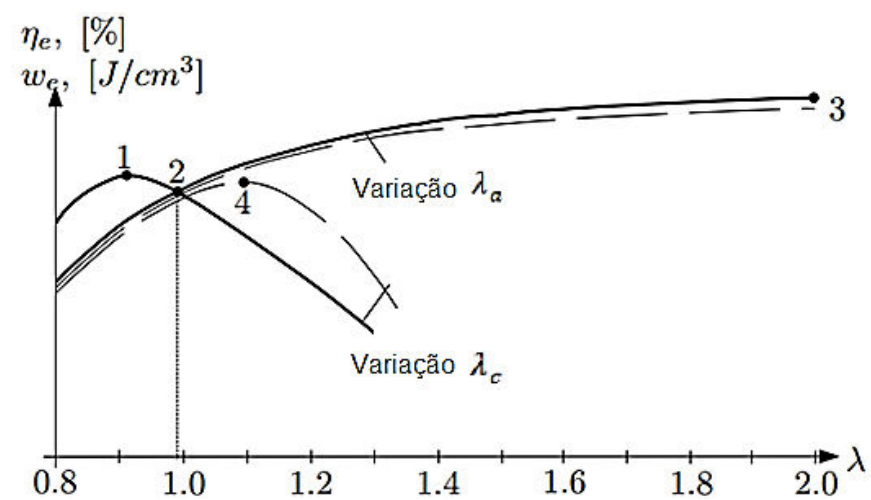

1. Região de máxima potência em motores SI (Otto); 2. Motores SI em região estequiométrica; 3. Motores Diesel e lean burn (queima pobre); 4. Motores SI de queima sutilmente pobre. Fonte: Adaptado de (KIENCKE e NIELSEN, 2005).

Nota-se que no caso dos motores SI (ou Otto), a realização do controle normalmente é aplicada ao fornecimento relativo de combustível $\lambda_{c}$ com base na entrada do fornecimento relativo de ar $\lambda_{a}$, e para motores Diesel e lean burn, o processo é inverso, assim como pode ser aplicável aos motores SI de queima sutilmente pobre. Assim, entende-se que para a aplicação deste trabalho destina-se a seguinte relação de controle:

\section{Variação de $\lambda_{c}$ para um dado $\lambda_{a}$ :}

Esta é uma aplicação típica para os motores SI convencionais que operam próximo à região estequiométrica, o fornecimento relativo de ar $\lambda_{a}$ é determinado pelo motorista. 
Mistura pobre $(\lambda<1.0)$ : Ao injetar-se menos combustível que o necessário para uma combustão estequiométrica ( $\lambda_{c}$ menor), e devido à pressão de trabalho reduzida, o trabalho efetivo diminui. No intervalo $1.0<\lambda<1.1$, a eficiência termodinâmica aumenta, contudo, isto gera picos de temperatura na combustão, elevando as emissões de óxido nitroso $N O_{x}$. Se $\circ$ fator $\lambda$ aumentar mais ainda, a eficiência volumétrica irá diminuir, pois a pressão de trabalho efetiva diminuirá tanto que a pressão média de trabalho também será reduzida.

Mistura rica $(\lambda>1.0)$ : Injeta-se mais combustível que o necessário para uma combustão estequiométrica ( $\lambda_{c}$ maior), o excedente de combustível aumenta, assim como a pressão e o trabalho efetivo. Relações $\lambda<0.7$ podem resultar em combustões incompletas e, consequentemente, elevar os níveis das emissões de hidrocarbonetos $H C$ nos gases de exaustão e causando redução do trabalho efetivo.

Assim, com base no fornecimento relativo de ar $\lambda_{a}$, o gerenciamento eletrônico deve controlar o fornecimento relativo de combustível $\lambda_{c}$. Portanto, para a finalidade de comparação da referência para controle de relação de mistura $A / C$ que se deseja, convencionou-se a razão de equivalência lambda entre as relações $A / C$ medida e estequiométrica, conforme Eq. (2.12):

$$
\lambda=\frac{\lambda_{a}}{\lambda_{c}}=\frac{A / C_{\text {medida }}}{A / C_{\text {esquiométrica }}}
$$

A relação de equivalência lambda é, portanto, uma medida importantíssima e fundamental para o controle de um $\mathrm{MCl}$ em todos os seus regimes de funcionamento, sobretudo para priorização do torque, economia do combustível e redução de emissões.

\subsubsection{Emissões de gases nocivos à atmosfera}

Segundo o balanceamento químico referente a combustão, equações (2.9) e (2.11), a transformação da queima de um combustível com o oxigênio teoricamente deveria ser completa, pois, após esta reação química restariam apenas água, dióxido de carbono e outros gases constituintes do ar que são inertes à combustão. $\mathrm{Na}$ realidade, devido à ocorrência de fenômenos físicos, químicos e elétricos e à 
impossibilidade de medida em tempo real dentro da câmara de combustão, a queima total de combustível não acontece e, consequentemente, surgem gases nocivos e poluentes para o meio ambiente, como resíduo da combustão.

A taxa de poluentes emitidos a cada combustão depende diretamente da relação de equivalência $\lambda$ (lambda), pois em cada pequena variação de $\lambda$ a emissão de algum poluente aumenta devido à deficiência ou excesso de ar, combustível e calor internos à câmara de combustão.

Conforme a Figura 2.15 , com uma mistura rica $(\lambda<1.0)$, os níveis de emissões se tornam elevados, devido a uma combustão imperfeita, com sobra de hidrocarbonetos (combustível não convertido) e monóxido de carbono (resultante de uma combustão incompleta). Já em situação inversa, onde existe a falta de combustível, a emissão dos dois gases citados acima diminui, porém, eleva-se o índice de emissão de $\mathrm{NO}_{x}$ que também é nocivo ao meio ambiente, possuindo picos de emissão com misturas levemente empobrecidas $(1.05<\lambda<1.1)$.

Figura 2.15 - Níveis de emissões para monóxido de carbono $\mathrm{CO}$, hidrocarbonetos $\mathrm{HC}$, óxido nitrosos genéricos $\mathrm{NO}_{x}$ e oxigênio $\mathrm{O}_{2}$ sem implementações de pós-tratamento.

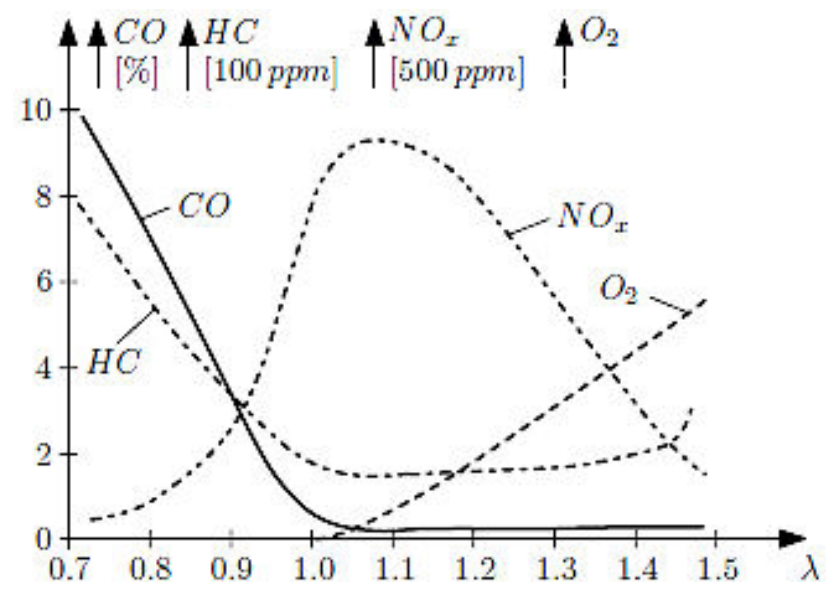

FONTE: Adaptado de (KIENCKE e NIELSEN, 2005).

Ao se atingir a mistura estequiométrica, apesar do elevado nível de emissão de $N O_{x}$, também é atingida a máxima eficiência de conversão da mistura $\mathrm{A} / \mathrm{C}$ na combustão (menos resíduos de combustível $H C$ e menos resíduo de oxigênio) e máxima eficiência de conversão do dispositivo catalítico (abordado na seção 2.4.1), ou seja, em motores de ciclo Otto, $\lambda=1.0$ é o melhor ponto de operação para emissões. 
A relação $\lambda$ instantânea exerce grande influência no funcionamento de um $\mathrm{MCl}$, principalmente no torque e potência gerados para o veículo. Além disso, o consumo de combustível também está ligado a essa relação. Portanto, $\lambda$ é um fator determinante para o desempenho e autonomia. A Figura 2.16 representa o efeito da variação de mistura $A / C$ sobre o torque indicado, consumo específico e emissões de gases, enquanto o fornecimento de ar, sincronismo da ignição e a velocidade do motor forem mantidos de maneira constante.

Figura 2.16 - Curva de "hook" do torque, consumo específico e emissões especificas em relação ao fator de excesso de oxigênio ou relação de equivalência (lambda).

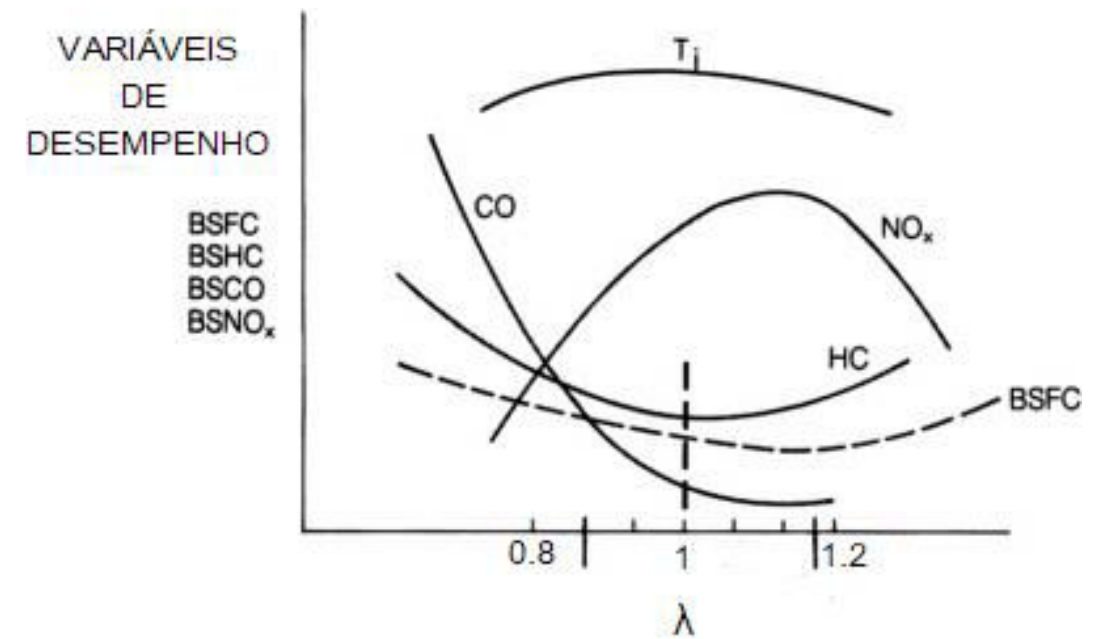

Fonte: Adaptado de (RIBBENS, 2012).

Segundo (ERIKSSON e NIELSEN, 2014) e (RIBBENS, 2012), os parâmetros frequentemente usados para comparações de desempenho e eficiência são analisados de maneira intrínseca ao trabalho produzido. Um exemplo disto é o consumo específico BSFC (Brake Specific Fuel Consumption), que é definido como a quantidade de combustível em massa $m_{c}$ por unidade de trabalho $W$, ou equivalente ao fluxo de combustível $\dot{m}_{c}$ pela potência $\dot{W}$, conforme a Eq. (2.13).

$$
B S F C=\frac{m_{c}}{W}=\frac{\dot{m}_{c}}{\dot{W}}
$$

Assim, a comparação do consumo é analisada especificamente a partir de sua geração de trabalho. O mesmo princípio é empregado para medir as concentrações de $\mathrm{HC}, \mathrm{CO}$ e $\mathrm{NO}_{x}$, os principais componentes da emissão em um motor de combustão interna conforme as Eqs. (2.14), (2.15) e (2.16). 


$$
\begin{gathered}
B S H C=\frac{H C}{\dot{W}} \\
B S C O=\frac{C O}{\dot{W}} \\
B S N O_{x}=\frac{N O_{x}}{\dot{W}}
\end{gathered}
$$

\subsubsection{Sistema em malha aberta (open-loop/feedforward)}

Sistemas de controle em malha aberta são aqueles nos quais as saídas não causam efeitos nas ações de controle. Isto é, em um sistema de controle em malha aberta, a saída é medida somente para fins de monitoramento e não para um ajuste automático da entrada para um determinado setpoint. Portanto, neste tipo de controle aplica-se o laço de ação direta (open-loop/feedforward), como exemplificado na Figura 2.17.

Figura 2.17 - Modelo de controle em malha aberta (open-loop).

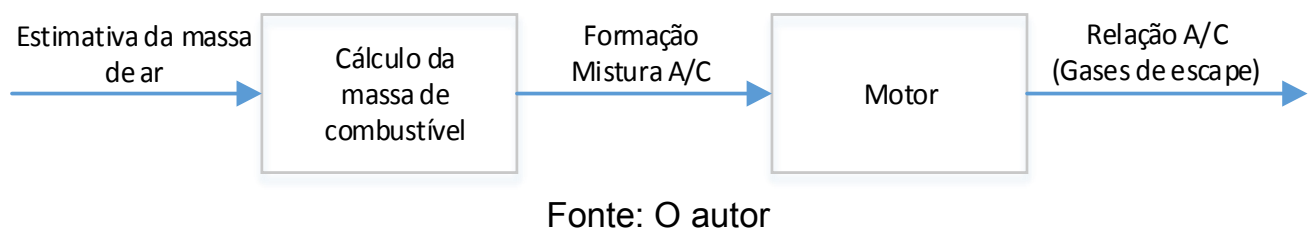

O controle feedforward da mistura $\mathrm{A} / \mathrm{C}$, de forma geral, utiliza a estimativa do fornecimento de ar demandado pelo operador $m_{a}$ como entrada para que o gerenciamento possa controlar a massa de combustível a ser injetada $m_{c}$, de modo a atingir uma referência $\lambda_{0}$, sem que haja a influência de uma realimentação obtida pelo sensor de oxigênio para que se mantenha automaticamente uma determinada relação lambda. A Eq. (2.17) exemplifica o cálculo da massa de combustível realizado por este controle.

$$
m_{c}=m_{a} \frac{1}{\lambda_{0} \cdot A / C_{\text {estequiométrica }}}
$$


onde $m_{a}$ (massa de ar) pode ser medida diretamente através de um sensor do fluxo de massa de ar MAF (Manifold $\underline{\text { Air }}$ Flow $^{8}$ ) ou indiretamente com as medidas de pressão e temperatura do ar no coletor de entrada (admissão) provenientes do sensor MAP ( Manifold $\underline{A}$ bsolut $\underline{\text { Pressure }}{ }^{9}$ ) em conjunto da estratégia speed density.

A estratégia speed density relaciona as pressões e temperaturas no coletor de entrada com o rendimento volumétrico conhecido, que é característico a um determinado $\mathrm{MCl}$. O cálculo da eficiência volumétrica é realizado em função do volume de deslocamento interno, densidade do ar e velocidade do motor. Desta forma, estima-se a densidade do ar presente no coletor de admissão a partir da pressão e temperatura, usando a lei de Clapeyron para os gases perfeitos, representada na Eq. (2.18).

$$
p \cdot V=n \cdot R \cdot T
$$

onde $p$ é a pressão exercida sob o gás em questão; $V$ o volume ocupado pelo gás em questão; $n$ é o número de moles do gás definido como a razão da massa $m$ total em relação à massa molar do gás em questão $M_{m o l}$, sendo assim $n=\frac{m}{M_{m o l}} ; R$ a constante universal dos gases; e $T$ a temperatura do gás em Kelvin.

A densidade do ar $\rho$ é diretamente proporcional à pressão e inversamente proporcional à temperatura conforme Eq. (2.19).

$$
\rho=\frac{m}{V}=\frac{n / n}{\frac{R \cdot T}{p} / n}=\frac{p}{R \cdot T}
$$

O que torna possível uma medida indireta da massa de ar, em função da eficiência volumétrica $\eta_{v o l}$ que é função da rotação do motor. Segundo (ERIKSSON e NIELSEN, 2014), a Eq. (2.20) exibe uma possível estimativa do fluxo médio da massa de ar realizada com speed density para um ciclo do motor.

$$
\dot{m}_{a}=\eta_{v o l}\left(\rho_{c a}, N, T_{c a}\right)=\frac{p_{c a} \cdot V_{h} \cdot N}{R \cdot T_{c a} \cdot n_{c i l}}
$$

\footnotetext{
${ }^{8}$ Sensor do fluxo de ar presente no coletor de admissão (entrada).

${ }^{9}$ Sensor de pressão absoluta do coletor de admissão (entrada).
} 
onde $\rho_{c a}$ é a densidade do ar na entrada; $m_{a}$ é o fluxo de massa de ar; $n_{c i l}$ é o número de cilindros do motor em questão; $p_{c a}$ a pressão no coletor de admissão; $V_{h}$ o volume máximo do cilindro, $N$ a velocidade do motor em revoluções por segundo.

O sensor MAP possui um medidor de temperatura do ar integrado, que é utilizado para correções da densidade na estratégia speed density.

\subsubsection{Cálculo de combustível para a quantidade de ar}

O fornecimento de combustível $\lambda_{c}$, demonstrado pela Eq. (2.4) na seção 2.1.8 e Eq. (2.12) na seção 2.2.1, é controlado através do tempo de injeção $t_{i n j}$, que é comandado para abertura da válvula injetora. Assim, a quantidade de combustível por injeção em um cilindro pode ser calculada usando-se uma relação para um fluxo constante de massa de $\operatorname{ar} \dot{m}_{a}$ de forma a atingir uma relação $\lambda_{0}$ de referência, como exibido na Eq. (2.21) .

$$
m_{c}=\frac{m_{a}}{\frac{A}{\bar{C}_{\text {estequiométrica }}}}=\overbrace{\frac{1}{\bar{C}_{\text {estequiométrica }}}}^{\lambda_{0}} \frac{m_{a}}{N} \frac{2}{n_{\text {cil }}}
$$

onde $\frac{A}{C_{\text {estequiométrica }}}=14.58$ (gasolina tipo A) ou $\frac{A}{C}_{\text {estequiométrica }}=8.98$ (etanol anidro); a rotação do motor em RPS é denotada por $N$; e $n_{c i l}$ representa a quantidade de cilindros do motor.

A quantidade de combustível injetado $m_{c}$ é proporcional ao tempo de injeção $t_{i n j}$, e a raiz quadrada da diferença de pressão $\Delta p$ entre a galeria de combustível e o coletor de admissão (injeção indireta) ou entre a galeria de combustível e a câmara de combustão (injeção direta), conforme a Eq. (2.22) .

$$
m_{c} \sim \rho_{c} \cdot A_{e f e} \cdot \sqrt{2 \frac{\Delta p}{\rho_{c}}} \cdot t_{i n j}
$$

onde a densidade combustível $\rho_{c}$ e a área de abertura efetiva da válvula injetora $A_{\text {efe }}$ são consideradas constantes (exceto se houver condições de pressão constante na linha de alimentação e não existam mudanças na composição do combustível ou impurezas que obstruam o fluxo através da eletroválvula, pois a área de abertura da válvula não muda durante o tempo de abertura). Em modos de injeção indireta, a diferença de pressão $\Delta p$ varia em torno de 5 bar. Para modos de 
injeção direta, $\Delta p$ poderá possuir valores acima de 400 bar e de 2000 bar para motores diesel (KRACKE, 1992). Então, o tempo de injeção pode ser calculado considerando a vazão estática nominal das VEIC's injetores através da Eq. (2.23).

$$
t_{i n j}=m_{c} \cdot \text { flux }_{\text {injetor }}
$$

Assim, fica claro que a relação lambda pode e deve ser utilizada como fator de correção do tempo de injeção em regimes de rotação aproximadamente constante, com o objetivo do ajuste da relação $A / C$.

Mapas de calibração são frequentemente usados nos sistemas de controle para representação de parâmetros, controle e geração de setpoints. Quando os mapas são usados para controle, a ideia básica é usar quantidades medidas, como a velocidade do motor e a pressão do coletor de admissão (carga), como entradas que endereçam a ação de controle como saída do mapa. Esses mapas podem, por exemplo, implementar controladores de open-loop/feedforward. A Figura 2.18 mostra uma estrutura simples baseada em mapas para injeção de combustível e avanço de ignição básicos.

Figura 2.18 - Exemplificação dos mapas básicos para injeção e ignição.

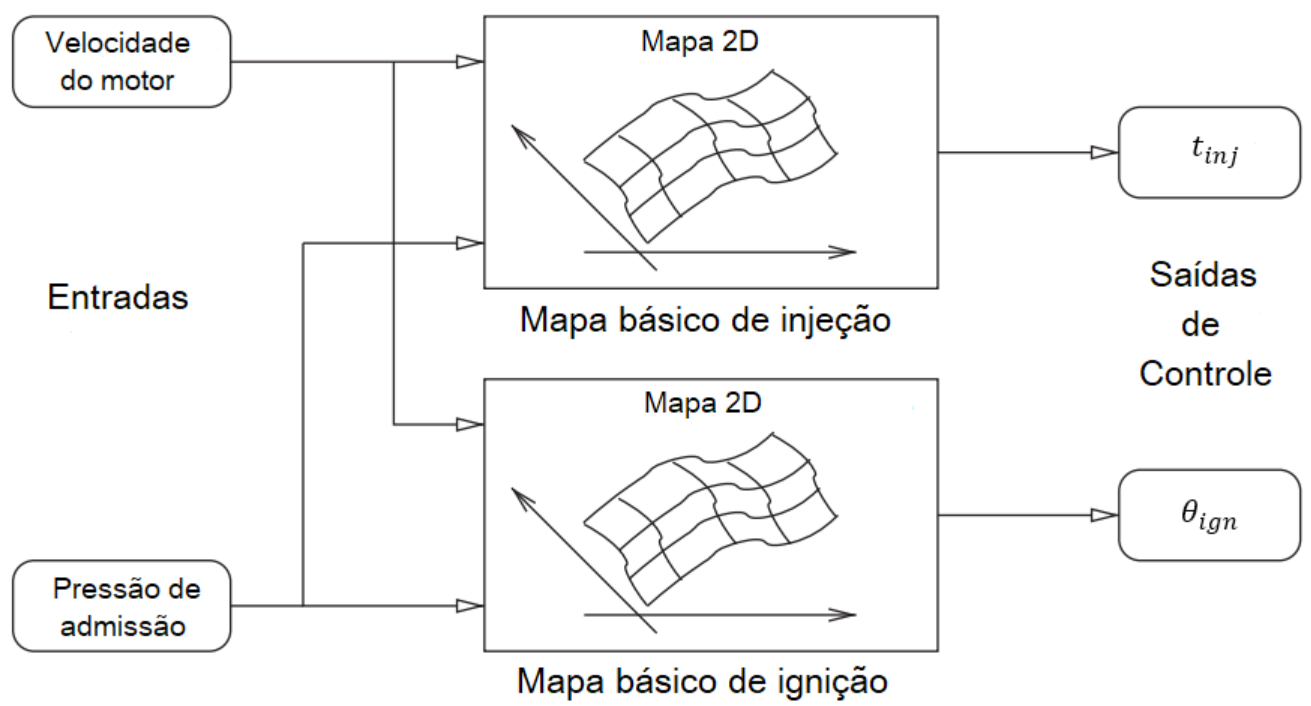

Fonte: Adaptado de (ERIKSSON e NIELSEN, 2014).

Esses mapas são obtidos através de calibração em bancada de testes de motores. O procedimento é simples e oferece boa precisão, mas o procedimento pode ser demorado. Durante a calibração, o motor é controlado no ponto de ajuste desejado, por exemplo, em velocidade e carga, e as saídas de controle são 
ajustadas para atingir as metas alvo. A saída de controle desejada é então armazenada no mapa e o procedimento vai para o próximo ponto.

Um procedimento muito comum dentro do gerenciamento de motores é refinar o sistema de controle, após os controladores básicos serem sintonizados, através da adição de mapas que lidam com efeitos como, por exemplo, partida a frio, clima quente/frio e compensações para alta altitude. As vantagens dos mapas são que eles são computacionalmente eficientes, fáceis de implementar e simples de obter, se a instrumentação estiver disponível. A principal desvantagem é que eles não oferecem extrapolação; quando um equipamento (sistema) for re-projetado, os mapas poderão precisarem ser recalibrados, o que é um processo demorado.

Além disso, o período de injeção pode ser influenciado pelo nível de tensão fornecido ao sistema, caso ocorram quedas de tensão devido a aumentos expressivos da demanda de energia elétrica por sistemas consumidores (sistemas de entretenimento, iluminação, entre outros).

O tempo de carregamento em uma bobina elétrica como o transformador de ignição, ou o offset de abertura de uma válvula eletromagnética injetora (solenoide) está diretamente relacionado ao perfil transitório de carregamento da corrente elétrica em um indutor $i_{L}(t)$.

$$
i_{L}(t)=i_{m a ́ x} \cdot\left(1-e^{-t / \tau_{c}}\right)
$$

onde $i_{\text {máx }}$ representa a máxima corrente disponível, a qual será $\frac{V_{\text {bat }}}{R_{\text {primário }}}$ para o transformador de ignição, e $\frac{V_{\text {bat }}}{R_{\text {injetor }}}$ para a válvula eletromagnética injetora; $\tau_{c}$ representa a constante de tempo como a razão entre a indutância e a resistência da bobina $\frac{L}{R}$.

As variações na tensão de alimentação do sistema elétrico $V_{b a t}$ são supridas por um gerador trifásico de eletricidade (alternador), o qual opera de maneira síncrona ao motor. Quedas significativas do nível da tensão de excitação $V_{b a t}$ geram desvios de offset e consequentemente no tempo de abertura das VEIC's, assim como no time dwell (tempo de carregamento ) das bobinas de ignição, e devem ser compensados por correções aditivas de tempo para minimizar as variações do time dwell e do tempo de abertura efetivos.

A partir do resultado de testes práticos realizados em seu trabalho, (PEREIRA, 2017) levantou uma curva característica de correção multiplicativa a 
partir da tensão de alimentação do sistema elétrico aplicada originalmente em um veículo por sua montadora. A função está exibida graficamente na Figura 2.19.

Figura 2.19 - Fator adimensional para correção para os tempos de injeção e ignição em função da tensão de bateria.

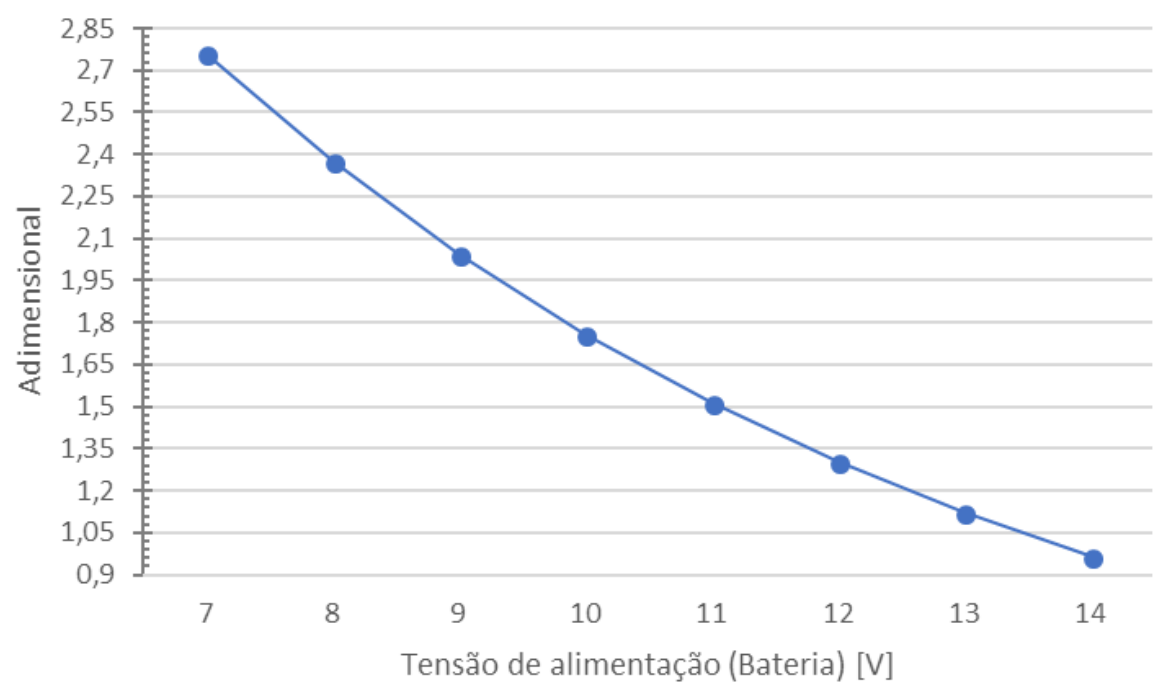

Fonte: Adaptado de (PEREIRA, 2017).

A função demonstrada na Figura 2.19 também pode ser expressa pela Eq. (2.25), como segue:

$$
y=7,8985 \cdot e^{-0,15 x}
$$

onde $y$ representa o fator de correção e $x$ a tensão de alimentação de todo o sistema de gerenciamento do motor. É de fundamental importância a observação dos fenômenos citados, pois, existem duas situações diferentes de teste neste trabalho, a primeira é a do motor instalado em uma sala dinamométrica com fornecimento de alimentação proveniente de uma fonte ligada a rede elétrica, e a segunda é a do motor esteve montado no veículo, possuindo alimentação elétrica independente própria proveniente de seu alternador. A transição entre os dois ambientes de testes aumenta a necessidade da utilização de um fator de correção para o nível de tensão de bateria/alimentação.

\subsubsection{Sistema em malha fechada (closed loop/feedback)}

O objetivo de um sistema de controle é modificar a dinâmica de modo a satisfazer critérios de estabilidade e desempenho. O bloco referente ao controle da mistura $A / C$ é uma das subdivisões de controle mais importantes no sistema de gerenciamento do motor. $A$ relação $A / C$ deve ser estrategicamente estabelecida 
para que o motor possa suprir demandas energéticas originadas da estrutura de controle em função do torque, intrínsecas do motor (partida à frio, aquecimento de catalisador, ar-condicionado, dentre outros), e extrínsecas ao motor, referentes a dinâmica do veículo (controle de cruzeiro, controle de transmissão, dentre outros).

Um sistema de controle que emprega a realimentação do sinal é denominado como sistema em malha fechada, no qual o sinal de saída possui um efeito direto na ação de controle. Isto é, sistemas de controle em malha fechada são dispositivos de ajuste automático realimentados pela diferença entre o sinal de entrada e o sinal realimentado (podendo ser o sinal de saída ou alguma derivação do mesmo), o que constitui o sinal de erro atuante, que é utilizado pelo controlador de modo a realizar compensações automáticas, a fim da estabilização da saída de um sistema em um valor desejado. Em outras palavras, o termo malha fechada implica o uso de ação de realimentação com a finalidade de reduzir a variação de erro do sistema, o que é extremamente interessante para realizar correções no controle da mistura A/C. Considerando que não é possível atingir a mistura exatamente estequiométrica, o melhor que se pode fazer é mantê-la próxima da região estequiométrica, quando isto não implica com outra estratégia aplicada para o bom funcionamento do motor (aquecimento após partidas a frio) ou para bruscas transições de regimes de rotação (aceleração e desaceleração do motor).

A vantagem de se utilizar a realimentação no controle da relação lambda é a possibilidade de detectar os desvios de uma relação $A / C$ específica e corrigi-los através da massa de combustível injetada. $O$ teor de oxigênio residual nos gases de escape, medido com sensores de oxigênio lambda, é utilizado como grandeza na aplicação de métodos para a correção de composição da mistura A/C.

O loop feedforward é essencialmente composto pela estimativa de ar e a relação $A / C_{\text {estequiométrica }}$ do combustível em conjunto com um dado valor de referência $\lambda$. A realimentação do loop feedback é usada para mitigar as variações de do ar entrante com o combustível injetado em comparação com a $A / C_{\text {medida }}$ para garantir que a relação $\lambda$ seja mantida em uma faixa restrita em torno de $\lambda=1.0$ ou outro determinado ponto de operação lambda.

O controle em malha fechada realiza correções na quantidade de massa de combustível a ser injetada, após o controle de ação direta (malha aberta), como uma combinação entre o controle open-loop/feedforward e o controle closed- 
loop/feedback, caso em que a realimentação é feita posteriormente à ação de controle direta, exemplificado na Figura 2.20.

Figura 2.20 - Modelo para controle em malha fechada (open+closed-loop).

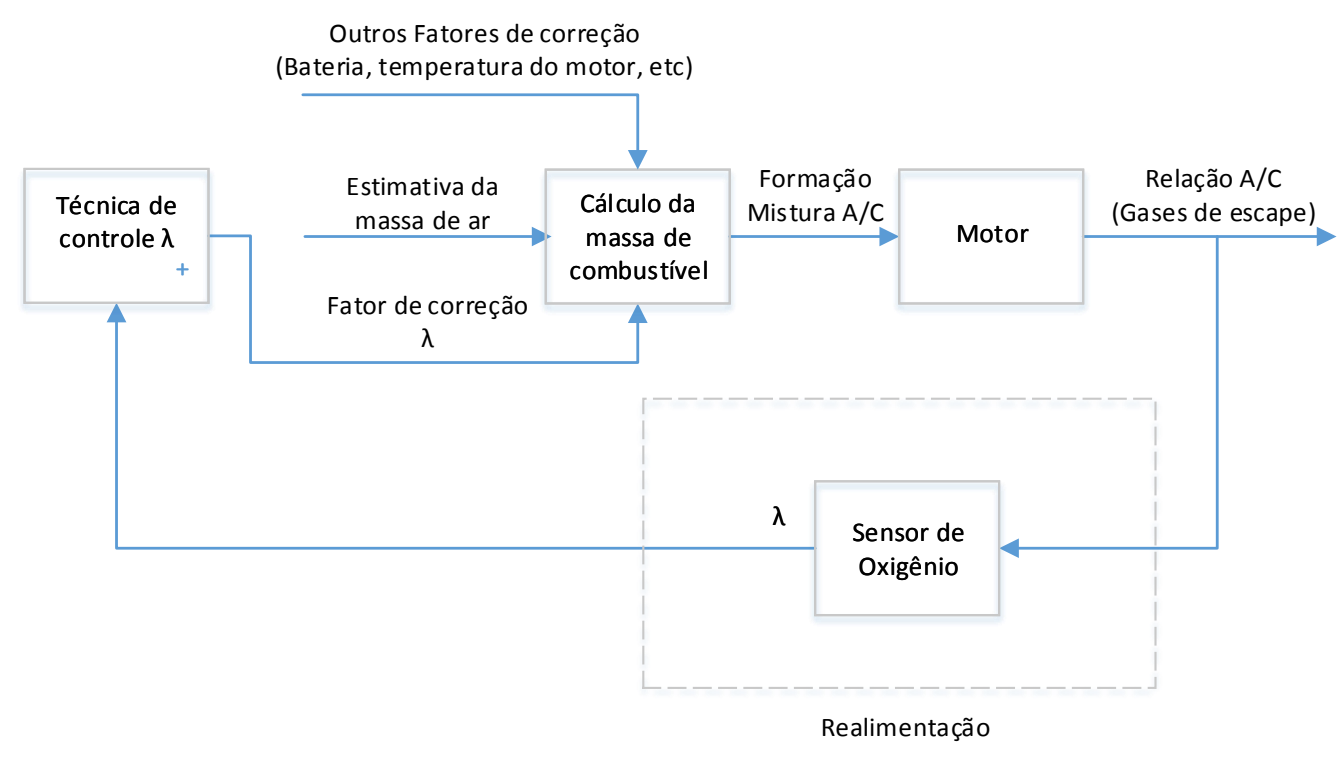

Fonte: O autor

Nessa abordagem de tratamento feedback, o foco está na determinação e parametrização da técnica de controle a ser utilizada. Com a utilização de uma sonda On-Off (sensor EGO (Exxhaust G Gas Oxxygen), como descrito na seção 2.3.1) para o controle em malha fechada haverá uma limitação devido à característica binária do sensor, que indica somente se a mistura resultante da combustão está rica ou pobre. Assim, o ponto estequiométrico $(\lambda=1.0)$ é alcançado pela variação média, ou seja, para a relação lambda ser igual a 1, o sinal tem de estar sempre em transição de rico para pobre e/ou vice-versa.

No caso do sensor de oxigênio de banda larga, a resultante da mistura é estimada com maior linearidade e precisão, possibilitando um controle de maior precisão e pontos diferentes de referência, que podem ser endereçados de acordo com diferentes estratégias de funcionamento aplicadas ao motor.

\subsection{SENSORES DE OXIGÊNIO (SONDAS LAMBDA)}

\subsubsection{Sensor de oxigênio (sonda lambda) planar de banda estreita (LSF/HEGO/On-Off)}

Os sensores empregados no monitoramento da relação $A / C$ medem 0 conteúdo de oxigênio nos gases de exaustão, para o qual é estabelecida uma 
relação $\lambda$. Para isto, a célula de Nernst é usada como elemento sensor. Um experimento prático apontou que a partir da ionização das moléculas de oxigênio, ocorrerá a transferência de elétrons da extremidade catodo para a extremidade anodo denominada corrente de bombeamento de oxigênio (LEE, 2003), conforme as transformações (2.26) e (2.27).

$$
\begin{gathered}
2 O^{2-} \leftrightarrow O_{2}+4 e^{-} \text {(catodo) } \\
O_{2}+4 e^{-} \leftrightarrow 2 O^{2-} \text { (anodo) }
\end{gathered}
$$

Este é o princípio de medida universal para sensores de oxigênio e consiste na observação da condutividade elétrica de diferentes gases, tendo como principal referência o oxigênio.

O sensor mais utilizado atualmente é o HEGO (HEated Gas Oxygen-sensor) de estrutura planar, também conhecido como sonda lambda On Off ou sensor lambda de banda estreita com aquecimento, apresentado na subseção 2.3.2. O sensor lambda de banda estreita compara o teor de oxigênio residual nos gases de escape com o oxigênio atmosférico (referência de ar presente no sensor) e indica uma mistura rica $(\lambda>1.0)$ ou pobre $(\lambda<1.0)$ presente nos gases de escape. $O$ sensor possui um eletrodo exposto aos gases de exaustão e outro à atmosfera (utilizado como referência). Entre os eletrodos, utiliza-se um material cerâmico com capacidade de transferir íons de oxigênio entre eles, geralmente dióxido de zircônio, $\mathrm{ZrO}_{2}$.

Segundo (LEE, 2003), a célula eletroquímica, denominada célula de Nernst, utiliza a diferença de pressão parcial do oxigênio entre dois eletrodos, onde um está exposto à referência do ar atmosférico e o outro exposto aos gases de exaustão. Com isto, o sensor gera uma força eletromotriz (tensão) que é empregada como a medida da concentração de oxigênio dos gases residuais da combustão, conforme a Eq. (2.28).

$$
U_{\lambda B E}=t_{i o n} \cdot \frac{R T}{4 F} \cdot \ln \left(\frac{p_{O_{2}(\text { ambiente })}}{p_{O_{2}(\text { exaustão })}}\right)
$$

onde $t_{i o n}$ é o número de transferência iônica do elemento cerâmico, que tem valor máximo igual a 1 no momento em que o sensor alcança sua temperatura ideal de operação, $R$ a constante universal dos gases, $T$ a temperatura absoluta em Kelvin, $F$ 
a constante de Faraday, $p_{\mathrm{O}_{2} \text { (ambiente) }}$ a pressão parcial de oxigênio do ambiente e $p_{O_{2(\text { exaustão) }}}$ a pressão parcial do oxigênio presente no coletor de exaustão. A Figura 2.21 exibe as características do sinal de um sensor de banda estreita EGO/HEGO.

Figura 2.21 - Curva de resposta da saída de tensão de um sensor de oxigênio com banda estreita (EGO/HEGO).

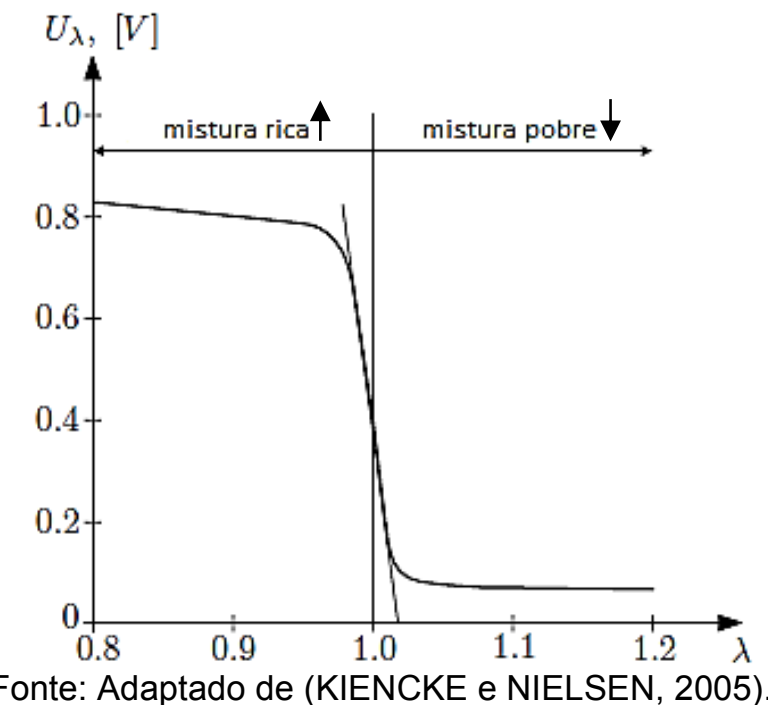

A mudança abrupta na curva característica deste tipo de sensor permite que o controle de mistura $\mathrm{A} / \mathrm{C}$ seja efetuado somente para o ponto estequiométrico, ou seja, o alvo desejado no uso aplicado deste sensor será o ponto de transição de um estado a outro, a fim de que se atinja o ponto médio de operação $(\lambda=1.0)$.

Devido a esta característica de transição entre dois estados, pode-se considerar que este sensor possui uma resposta característica binária, conforme as expressões

$\lambda<1.0=1$ (nível lógico um)(800 900 mV)

$\lambda>1.0=0$ (nível lógico zero) $(100 \sim 200 \mathrm{mV}$ ), que representam a associação entre o sinal gerado por este tipo de sensor e a relação lambda correspondente em dois estados, conforme exposto na Figura 2.21.

\subsubsection{Sensor de oxigênio (sonda lambda) planar com banda larga amplificada (LSU/UEGO)}

Controlar a relação $\mathrm{A} / \mathrm{C}$ em uma região empobrecida com o sensor de banda estreita torna-se uma tarefa extremamente difícil devido às características distintivas de seu sinal serem mínimas entre os pontos de mistura rica e pobre. Desta forma, com esse tipo de sensor é possível aferir se a mistura está rica ou pobre, mas com precisão limitada da medida lambda apenas para o ponto estequiométrico. Como 
consequência das características do sensor de oxigênio binário, não é possível aplicá-lo em operações sob faixas de misturas empobrecidas, onde há a intenção da correta e precisa indicação para a concentração de oxigênio presente nos gases de escape. Por essa razão, foram desenvolvidos sensores de oxigênio com maiores faixas de medida, conhecidos com sondas lambda lineares. Destas sondas, destacam-se a sonda lambda de banda larga (Wide-band) medindo relações de equivalência $0.8 \geq \lambda \leq 1.6$, e as de banda larga amplificada (Broad-Band Lambda Sensor) medindo relações de equivalência $0.7 \geq \lambda \leq \infty$, onde infinito representa a medida do ar atmosférico contendo aproximadamente $21 \%$ de oxigênio.

Este sensor pode ser utilizado no gerenciamento de motores, não somente para o ponto estequiométrico $(\lambda=1.0)$, caso da sonda binária de banda estreita, como em gerenciamentos que operam motores em misturas altamente empobrecidas. Em razão da abrangência de sua banda de medição, é utilizável em diversos tipos de motores a combustão interna, não somente aqueles que empregam princípios de funcionamento Otto, mas também os motores lean burn, Diesel, a gás, dentre outros. Esta vasta aplicabilidade justifica a atribuição de sensor

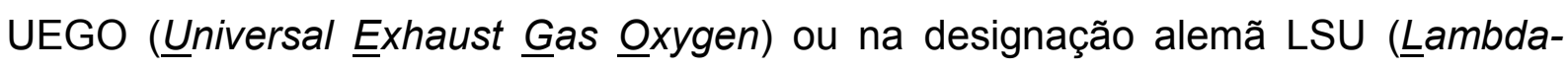
Sonde-Universal).

O sensor LSU/UEGO utiliza um princípio de detecção de oxigênio $O_{2}$, para isto, emprega uma célula de medida constituída de dióxido de zircônio $\mathrm{ZrO}_{2}$ cerâmico, sendo uma combinação da célula de concentração Nernst (mesmo princípio aplicado no sensor lambda de banda estreita) e uma célula para bombeamento de oxigênio, utilizada para transporte dos íons de oxigênio.

Segundo (LEE, 2003), um sensor de banda larga, que utiliza o princípio de corrente limitante, gera força eletromotriz medida como tensão, de acordo com a Eq. (2.29).

$$
U_{\lambda B L}=\mathrm{I}_{p} \cdot \mathrm{R}_{b}+\frac{R T}{4 F} \cdot \ln \left(\frac{p_{O_{2}(\text { ambiente })}}{p_{O_{2}(\text { exaustão })}}\right)
$$

onde $\mathrm{I}_{p}$ representa a corrente de bombeamento do oxigênio, $\mathrm{R}_{b}$ a resistência da célula de medição que varia com a temperatura do elemento cerâmico, $R$ a constante universal dos gases, $T$ a temperatura absoluta em Kelvin, $F$ a constante 
de Faraday, $p_{O_{2} \text { (ambiente) }}$ a pressão parcial de oxigênio do ambiente e $p_{O_{2(\text { exaustão) }}}$ a pressão parcial do oxigênio presente no coletor de exaustão.

O sensor broad-band possui como pré-requisito um circuito eletrônico que determine sua referência de oxigênio e regule a sua temperatura de medida. Um aquecedor integrado eleva a temperatura do sensor de modo que ele alcance os pontos ideais de operação, tais temperaturas podem variar entre 650 e $900{ }^{\circ} \mathrm{C}$, este controle é importante para que haja a maior confiança na validade da medição. O controle de temperatura do aquecedor é realizado através da tensão de alimentação $U_{H}$ que de maneira geral é modulada por $\mathrm{PWM}^{10}$.

Os gases de escape entram na câmara de medição (lacuna de difusão) da célula de concentração de Nernst através da pequena passagem de acesso ao gás da célula de bombeamento. Para que o fator de excesso de ar $\lambda$ possa ser ajustado no intervalo de difusão, a célula de concentração de Nernst compara o gás no espaço de difusão com o ar ambiente na passagem de ar de referência.

O processo completo consiste em aplicar a tensão de bombeamento $U p$ através dos eletrodos de platina de sua célula. O oxigênio dos gases de escape pode ser bombeado através da barreira de difusão para dentro ou para fora da lacuna de difusão. Com o auxílio da célula de concentração de Nernst, um circuito eletrônico na ECU controla a tensão $(U p)$ através da célula de bombeamento para que a composição dos gases no espaço de difusão permaneça constante em $(\lambda=1.0)$. Se o gás de escape está pobre, a célula de bombeamento leva o oxigênio para o exterior (corrente de bombeamento positiva). Alternadamente, à medida que o gás de escape está rico (devido à decomposição de $\mathrm{CO}_{2}$ e $\mathrm{H}_{2} \mathrm{O}$ no eletrodo dos gases de escape), o oxigênio é bombeado a partir do gás de escape ambiente para dentro da lacuna de difusão (corrente de bombeamento negativa). $\operatorname{Em}(\lambda=1.0)$, ocorre a ausência de oxigênio sendo transportado, portanto, a corrente de bombeamento é zero.

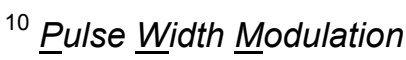


Figura 2.22 - Exemplo de calibração da corrente de bombeamento de um sensor broad/wide band em função da relação $\lambda$ e concentração de oxigênio $\boldsymbol{O}_{2}$.

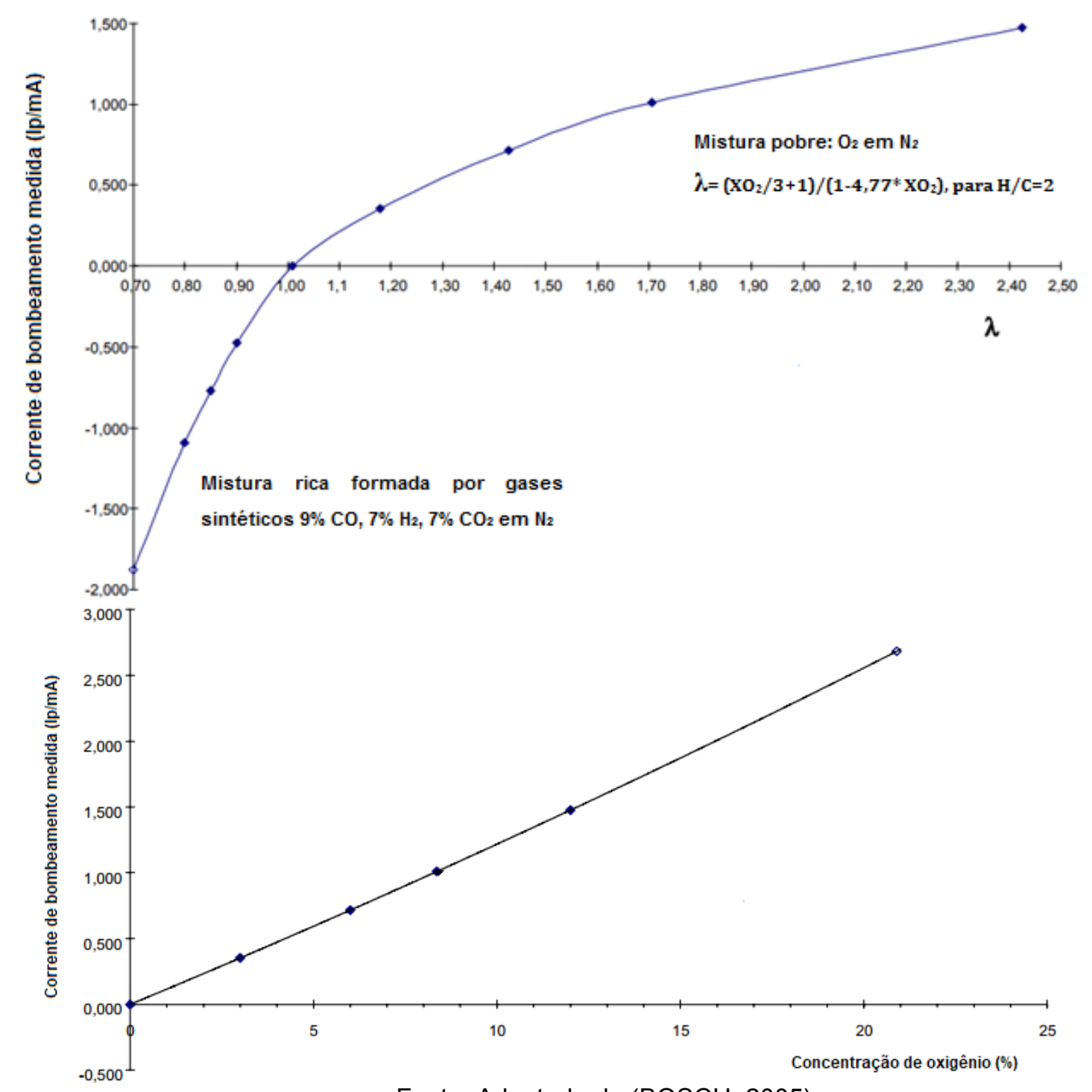

Fonte: Adaptado de (BOSCH, 2005).

A Figura 2.22 mostra os pontos de calibração do sensor, que é realizada com gases específicos, sendo a função $f(x)$ uma interpolação linear que representa a relação de equivalência ou fator de excesso de ar $\lambda$ entre estes pontos medidos. Assim, a corrente de bombeamento também é proporcional à concentração de oxigênio nos gases de escape e, portanto, o sensor de oxigênio de banda larga amplificada provê uma medida linear do oxigênio presente nos gases de escape.

\subsubsection{Taxa de resposta}

A medida realizada por um sensor de oxigênio (sonda lambda) possui um atraso relativo ao seu princípio de medição que pode ser expresso por uma aproximação de primeira ordem no domínio de Laplace conforme a Eq. (2.30): 


$$
G_{L S}(s)=\frac{1}{1+\tau_{L S} \cdot S}
$$

onde $\tau_{L S}$ é uma constante de tempo que varia de 10 a 20 milissegundos (ms) para os sensores de banda larga (ERIKSSON e NIELSEN, 2014) e de 20 a $30 \mathrm{~ms}$ para sensores de banda estreita (KIENCKE e NIELSEN, 2005).

\subsection{SISTEMA DE PÓS-TRATAMENTO E CONTROLE A/C}

\subsubsection{Conversor catalítico de três vias (TWC)}

O conversor catalítico de três vias converte os poluentes que são gerados durante a combustão em componentes menos tóxicos, sendo eles: hidrocarbonetos $\left(H C^{\prime} s\right)$, monóxido de carbono $(\mathrm{CO})$ e óxidos nitrosos $\left(\mathrm{NO}_{x}\right)$. Os produtos após a conversão devem resultar em vapor de água $\left(\mathrm{H}_{2} \mathrm{O}\right)$, dióxido de carbono $\left(\mathrm{CO}_{2}\right)$ e nitrogênio $\left(N_{2}\right)$. A configuração do conversor catalítico no sistema de exaustão está apresentada na Figura 2.23.

Figura 2.23 - Conversor catalítico de três vias (TWC) aplicado em motores de ciclo Otto.

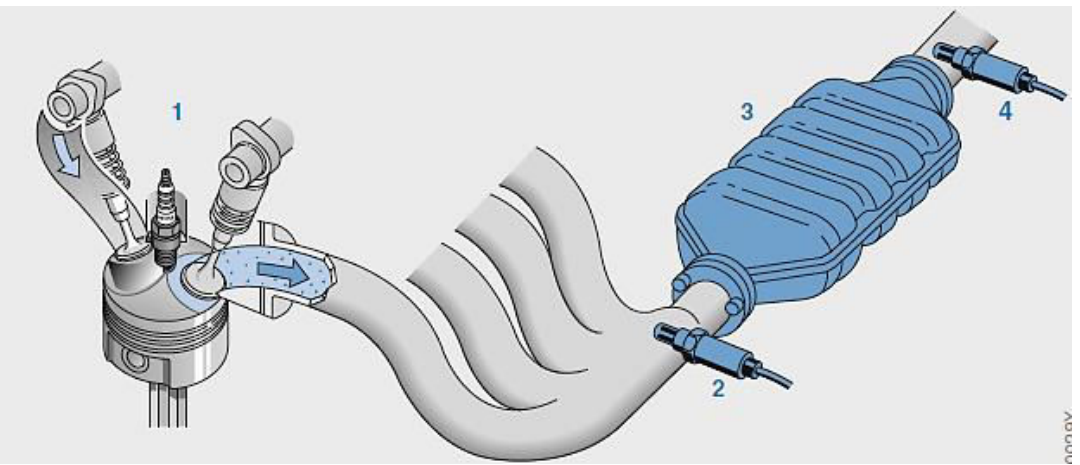

1. Motor SI (Otto); 2. Sensor de oxigênio (sonda lambda) pré-catalítico(a) (On-Off Wide-band ou Broad-band); 3. Catalisador de três vias (TWC); 4. Sensor de oxigênio (sonda lambda) précatalítico(a) (On-Off). Fonte: Adaptado de (BOSCH PROFESSIONAL INFORMATION, 2015).

Os poluentes lançados na atmosfera são originados dos gases de escape não tratados e da taxa de conversão catalítica, isto é, da proporção que pode ser convertida no catalisador. A liberação desses poluentes é fortemente dependente da relação de equivalência (fator de excesso de ar) $\lambda$ ajustado. A melhor taxa de conversão possível para os três componentes poluentes requer um fator de mistura estequiométrico de $(\lambda=1.0)$. Consequentemente, a janela estequiométrica em que a relação $\lambda$ deve estar situada é muito pequena. O cumprimento do objetivo de manutenção do regime estequiométrico depende, portanto, do controle da mistura 
em malha fechada, a fim de reduzir os pequenos desvios gerados pelo funcionamento do motor.

A Figura 2.24 exibe a característica de eficiência de conversão do TWC

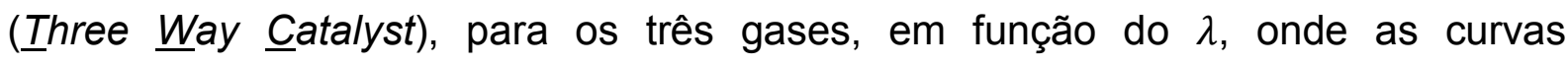
tracejadas representam os gases antes da conversão feita pelo catalisador de três vias e as linhas contínuas representam os mesmos gases após o a conversão catalítica do TWC.

Figura 2.24 - Representação da janela de conversão realizada por um catalisador de três vias.

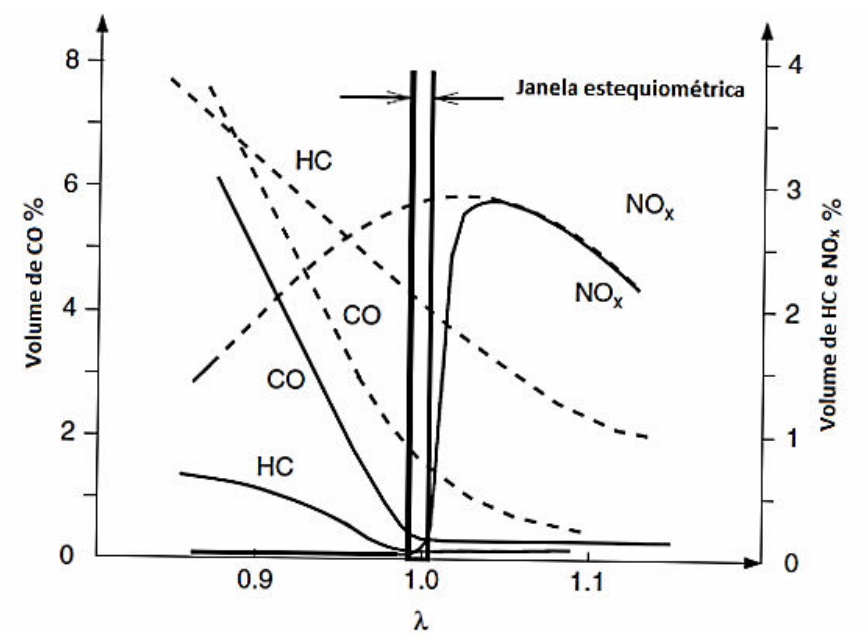

Fonte: Adaptado de (ERIKSSON e NIELSEN, 2014).

Observa-se que quando a mistura é pobre $(\lambda>1.0)$, o excesso de oxigênio favorece a oxidação de $C O$ e de $H C$, enquanto a redução do $N O_{x}$ fica prejudicada. Já no momento em que a mistura é rica $(\lambda<1.0)$, a ausência de oxigênio favorece a redução do $\mathrm{NO}_{x}$ e prejudica a oxidação de $\mathrm{CO}$ e $\mathrm{HC}$.

A noção de que a catálise realizada pelo TWC ocorre principalmente em função de um bom controle de mistura atesta novamente o quanto esta função é importante dentro do gerenciamento eletrônico do motor. $\operatorname{Em}(\lambda=1.0)$, ocorre o estado de equilíbrio entre as reações de oxidação e de redução. O teor de oxigênio residual nos gases de escape em $(\lambda=1.0)$ (com tolerância aproximada de $\pm 0,5 \%$ ) e o oxigênio ligado no óxido nitroso permitem que $\mathrm{HC}^{\prime} \mathrm{s}$ e $\mathrm{CO}$ oxidem completamente; os óxidos nitrosos são simultaneamente reduzidos. Deste modo, $H C^{\prime}$ 's e $C O$ atuam como agentes redutores para os óxidos nitrosos. 


\subsection{MOTORES BICOMBUSTÍVEIS}

Um motor bicombustível tem a capacidade de operar em um modo relativamente eficiente em qualquer combinação entre gasolina e etanol. No entanto, é necessária uma estratégia para que a combustão do motor seja rapidamente adaptada às mudanças de proporção dessa combinação, que podem ocorrer após um evento de reabastecimento, para que se garanta a combustão ideal do combustível (MCKAY, et al., 2012).

O gerenciamento eletrônico de um motor a combustão interna busca um compromisso entre performance, eficiência e baixos índices de emissões. O controle da proporção entre ar e combustível, presente na mistura a ser consumida na combustão, afeta diretamente o trabalho realizado pelo motor, emissões de poluentes e consumo de combustível. Esse aspecto tem ainda maior impacto para aplicações bicombustíveis, que dispõem de parâmetros operacionais que variam com a troca e mistura do combustível (gasolina/etanol). Para isto, é necessário que se estabeleça com precisão a proporção entre os combustíveis. Geralmente, a estratégia usa a sonda lambda para detecção dos gases queimados variantes entre os combustíveis, realizando assim um reconhecimento indireto.

Os motores flex-fuel compartilham os mesmos princípios operacionais básicos de motores SI convencionais monocombustíveis. Entretanto, eles podem operar com qualquer razão entre gasolina e etanol, em variações de $0 \%$ a 100\% em volume geralmente notado na escala ( $E x)$ para etanol anidro ou ainda na escala (Hy) para etanol hidratado, representando uma mistura de gasolina contendo $x$ ou $y \%$ de teor em etanol. A seleção entre uma das duas escalas se dá para a consideração do volume de água presente nas diferentes misturas entre os combustíveis gasolina/etanol e classifica os combustíveis álcoois como etanóis anidro e hidratado.

\subsubsection{As características dos combustíveis}

Nos dias atuais, estão à disposição dos consumidores brasileiros o etanol hidratado e três tipos de gasolina: tipo $\mathrm{C}$ (comum), tipo $\mathrm{C}$ aditivada e premium. 
Tabela 2.2 - Composição e octanagem das misturas de combustíveis comercializadas em território nacional para motores SI (ciclo Otto).

\begin{tabular}{|c|c|c|c|c|c|}
\hline Característica & $\begin{array}{c}\text { Etanol } \\
\text { Hidratado }\end{array}$ & $\begin{array}{l}\text { Gasolina } \\
\text { Comum }\end{array}$ & $\begin{array}{c}\text { Mistura } \\
\text { Centromédia }\end{array}$ & $\begin{array}{l}\text { Gasolina } \\
\text { Premium }\end{array}$ & $\begin{array}{c}\text { Método } \\
\text { Analítico } \\
\end{array}$ \\
\hline $\begin{array}{c}\text { Massa Específica } \\
@ 20^{\circ} \mathrm{C}\left(\mathrm{Kg} / \mathrm{m}^{3}\right)\end{array}$ & 805 & 753.2 & 778.4 & 745.4 & $\begin{array}{l}\text { ASTM D4052 e } \\
\text { NBR } 15639 \\
\text { (E95) }\end{array}$ \\
\hline $\begin{array}{c}\text { Etanol anidro } \\
\text { [Vol. \%] }\end{array}$ & 94.7 & 27 & 65 & 25 & $\begin{array}{l}\text { ABNT } \\
13992 \\
\end{array}$ \\
\hline Água [Vol. \%] & 5.3 & $0.5-0$ & 2.3 & $0.5-0$ & - \\
\hline $\begin{array}{c}\text { Índice } \\
\text { antidetonante }[\mathrm{AKI}]\end{array}$ & 100 & 88 & 97 & 92.2 & $\begin{array}{c}\text { ASTM D2699 } \\
\text { D2700 }\end{array}$ \\
\hline Escala H & $\mathrm{H} 100$ & $\mathrm{HO}$ & $\mathrm{H} 50$ & $\mathrm{HO}$ & - \\
\hline $\begin{array}{c}\text { Relação A/C } \\
\text { estequiométrica }\end{array}$ & 9 & 13.1 & 10 & 13.2 & - \\
\hline
\end{tabular}

Fonte: Resultados levantados pelo Laboratório de Combustíveis Líquidos (LCL) do Instituto de Pesquisa Tecnológica de São Paulo.

O número de octanos ou octanagem do combustível é uma característica que indica o quanto a mistura $A / C$ resiste às altas temperaturas e pressões formadas dentro da câmara de combustão momentos antes da queima no instante da combustão. A octanagem é indicada a partir da comparação do combustível em questão com a mistura de dois tipos de hidrocarbonetos. $O$ iso-octano $\left(C_{8} H_{18}\right)$ possui número de octano igual a 100 e n-heptano $\left(n-C_{7} H_{16}\right)$ ou heptano normal possui número de octano igual a zero. Por exemplo, determinado combustível apresentará uma octanagem igual a $80 \mathrm{se}$, durante o teste, ocorrer a detonação semelhante à de uma mistura que contenha $80 \%$ de iso-octano e $20 \%$ de $n$-heptano em volume. A avaliação da octanagem do combustível se justifica pela necessidade de garantir que o produto atenda às exigências dos motores nos tempos de compressão e de expansão (quando ocorrem elevações de pressão e temperatura) sem que o mesmo entre em autoignição. Para avaliação da octanagem dos combustíveis automotivos foram desenvolvidos os métodos MON e RON descritos a seguir:

O Método MON (Motor $\underline{\text { Octane }}$ Number) examina a resistência da gasolina à auto inflamação ao ser consumida em uma condição de operação ligeiramente severa, como ocorre em tráfego parado, com velocidade levemente maior e temperatura do ar de admissão elevada. Parâmetros: velocidade $=900$ RPM, sincronismo da ignição $=19{ }^{\circ} \mathrm{BTDC}$, temperatura de admissão $=149^{\circ} \mathrm{C}\left(300^{\circ} \mathrm{F}\right)$, pressão de admissão $=1 \mathrm{~atm}$, humidade do ar $=0.0036-0.0072 \mathrm{Kg} / \mathrm{Kg}$ de ar seco, temperatura do liquido de arrefecimento $=100{ }^{\circ} \mathrm{C}$, relação $\mathrm{a} / \mathrm{c}=$ Ajustada para a máxima ocorrência de knock. (ERIKSSON e NIELSEN, 2014) 
O Método RON (ㄹesearch $\underline{\text { OCctane }}$ Number) observa a resistência da gasolina à detonação sob uma condição menos exigente de trabalho, em um regime de rotação menor da que é avaliada pelo método MON, e com temperatura de admissão reduzida.

Parâmetros: velocidade $=600$ RPM, sincronismo da ignição $=13$ BTDC, temperatura de admissão $=52^{\circ} \mathrm{C}\left(125^{\circ} \mathrm{F}\right)$, pressão de admissão $=1 \mathrm{~atm}$, humidade do $\operatorname{ar}=0.0036-0.0072 \mathrm{Kg} / \mathrm{Kg}$ de ar seco, temperatura do liquido de arrefecimento = $100{ }^{\circ} \mathrm{C}$, relação a/c = Ajustada para a máxima ocorrência de knock. (ERIKSSON e NIELSEN, 2014)

Atualmente, adota-se $\mathrm{O} \mathrm{AKI}^{11}$ como representante do desempenho antidetonante do combustível. O AKI é definido como a média entre as octanagens medidas pelos métodos RON e MON, ou seja, $A K I=\frac{M O N+R O N}{2}$. A Tabela 2.3 exemplifica as propriedade físico-químicas observadas nos combustíveis de maneira geral.

Tabela 2.3 - Propriedades físico-químicas dos combustíveis gasolina tipo A (pura) e etanol anidro.

\begin{tabular}{|c|c|c|}
\hline PROPRIEDADE & GASOLINA tipo A (pura) & ETANOL ANIDRO \\
\hline $\begin{array}{c}\text { Concentração de carbono/oxigênio } \\
(\%)\end{array}$ & $86 / 0$ & $52 / 35$ \\
\hline Densidade a $15^{\circ} \mathrm{c}\left(\frac{\mathrm{Kg}}{\mathrm{m}^{3}}\right)$ & 747 & 789 \\
\hline $\begin{array}{l}\text { Resistência à detonação } \\
\text { (RON/MON) }\end{array}$ & $88-98 / 80-88$ & $109 / 90$ \\
\hline Calor de combustão $\left(\frac{\mathrm{KJ}}{\mathrm{m}^{3}}\right)$ & 42.4 & 26.8 \\
\hline Relação a/c estequiométrica & 14.58 & 8.98 \\
\hline Ponto de ebulição $\left({ }^{\circ} \mathrm{C}\right)$ & $27-225$ & 78 \\
\hline Constante dielétrica $(\varepsilon)$ & 2.0 & 24.3 \\
\hline Geração de energia (MW) & 111.19 & 46.06 \\
\hline
\end{tabular}

O combustível misto de etanol e gasolina é oferecido nos postos de gasolina nos EUA e Brasil, designados por "Flex-Fuel" (p. ex. E27 $=27 \%$ de etanol $+73 \%$ de gasolina e E85 $=85 \%$ de etanol $+15 \%$ de gasolina). (ROBERT BOSCH GMBH, 2005)

\subsubsection{Método indireto para identificação do combustível}

Uma técnica muito usual em motores bicombustíveis com aspiração natural é a detecção da concentração de etanol através da medida reativa do teor de oxigênio existente após a queima do combustível. O etanol contém aproximadamente $35 \%$ de

\footnotetext{
${ }^{11}$ Anti-Knock Index - Índice AntiDetonante.
} 
oxigênio em sua composição, o que aumenta proporcionalmente o teor de oxigênio no escape do motor após a queima dos gases (MCKAY, et al., 2012). A tecnologia flex-fuel empregou o algoritmo de aprendizado para detectar mudanças no teor de oxigênio residual dos gases restantes da combustão. Com o objetivo de isolar medições errôneas, normalmente, esta estratégia é iniciada a partir da detecção do evento de um reabastecimento, momento em que existe uma potencial possibilidade de alteração no teor de etanol do combustível para que se evite a classificação errada de variações no teor de etanol e outras inconstâncias, como discrepância do funcionamento de atuadores e/ou envelhecimento de componentes ( $A H N, 2011)$.

A partir do evento de reabastecimento, a unidade de controle do motor (ECU), começa a monitorar todas as mudanças representativas do sinal proveniente do sensor EGO. As variáveis do mapa de injeção de combustível são mantidas fixas desde a configuração anterior de reabastecimento, então, se o volume de etanol aumentar, consequentemente aumentar-se-á o teor de oxigênio nos gases de escape. A medida do sensor lambda mostrará que o teor de oxigênio do combustível mudou, então, para a ECU isto será interpretado como um aumento do teor de etanol e a partir disso, então, a referência para relação $A / C$ estequiométrica será compensada para uma maior quantidade de combustível.

Essa estratégia do algoritmo de aprendizado da tecnologia flex-fuel generalizou-se na indústria, se tornando consideravelmente robusta e eficaz, com acurácia entre 5 e 10 por cento para estimativas de concentração de etanol. Porém, o período de aprendizado geralmente demoraria de 5 a 10 minutos para ser finalizado dependendo das condições de aceleração demandadas pelo operador. Além disso, o sinal originado do sensor lambda é sensível a ruídos, mais particularmente em modos de operação de transiente de velocidade do motor. Sistemas sofisticados de alimentação do motor, como os de injeção direta de combustível e turbo-alimentação, são duramente penalizados, pois, com pressões e temperaturas de trabalho elevadas, têm maior variabilidade com ruídos causados pela estratégia de aprendizado (MCKAY, et al., 2012).

\subsubsection{Taxas de compressão em motores bicombustíveis}

Em relação às taxas de compressão para a câmara de combustão do motor, os desenvolvedores de motores bicombustíveis possuem caminhos alternativos. $O$ caminho conservador é aplicar a relação de compressão que esteja próxima à ideal 
para a utilização da gasolina (fixando-a em torno de 9:1 a 10.5:1) desprezando-se o desempenho para o etanol em prol da redução de ocorrências de autoignição. $\mathrm{Na}$ busca de um desempenho intermediário de ambos os combustíveis, são empregadas taxas de compressão fixas em torno de (10.5:1 a 12:1). Para otimização do desempenho do etanol na operação do motor Flex-Fuel, utilizam-se elevadas taxas de compressão (acima de 13:1), o que demanda maior atenção ao dimensionamento de sistemas e estratégias na fase de operação com gasolina a fim de minimizar os efeitos de detonação como, por exemplo, reconfiguração do sistema de gerenciamento do motor e de componentes de sistemas gerenciais do motor (ignição, injeção, arrefecimento, dentre outros) (NASCIMENTO, et al., 2010).

\subsection{O AMBIENTE DE DESENVOLVIMENTO EMBARCADO}

\subsubsection{Sistemas embarcados}

Segundo Rodrigo (BORGES, 2011), sistemas embarcados, assim como outros sistemas computacionais, consistem de software, hardware e do ambiente onde estão inseridos, com a ressalva de apresentarem restrições físicas de computação tornando necessária a separação entre o software e o componente físico.

Estas características de desenvolvimento requerem uma abordagem holística que integre consistentemente os paradigmas de desenvolvimento do hardware, software e da teoria de controle. As principais etapas do desenvolvimento de um sistema embarcado consistem em: definição de requisitos, especificação, arquitetura, componentes e integração do sistema (BORGES, 2011). Neste aspecto, duas abordagens diferentes podem ser adotadas como exemplificadas na Figura 2.25 . 
Figura 2.25 - Principais etapas para o desenvolvimento de sistemas embarcados.

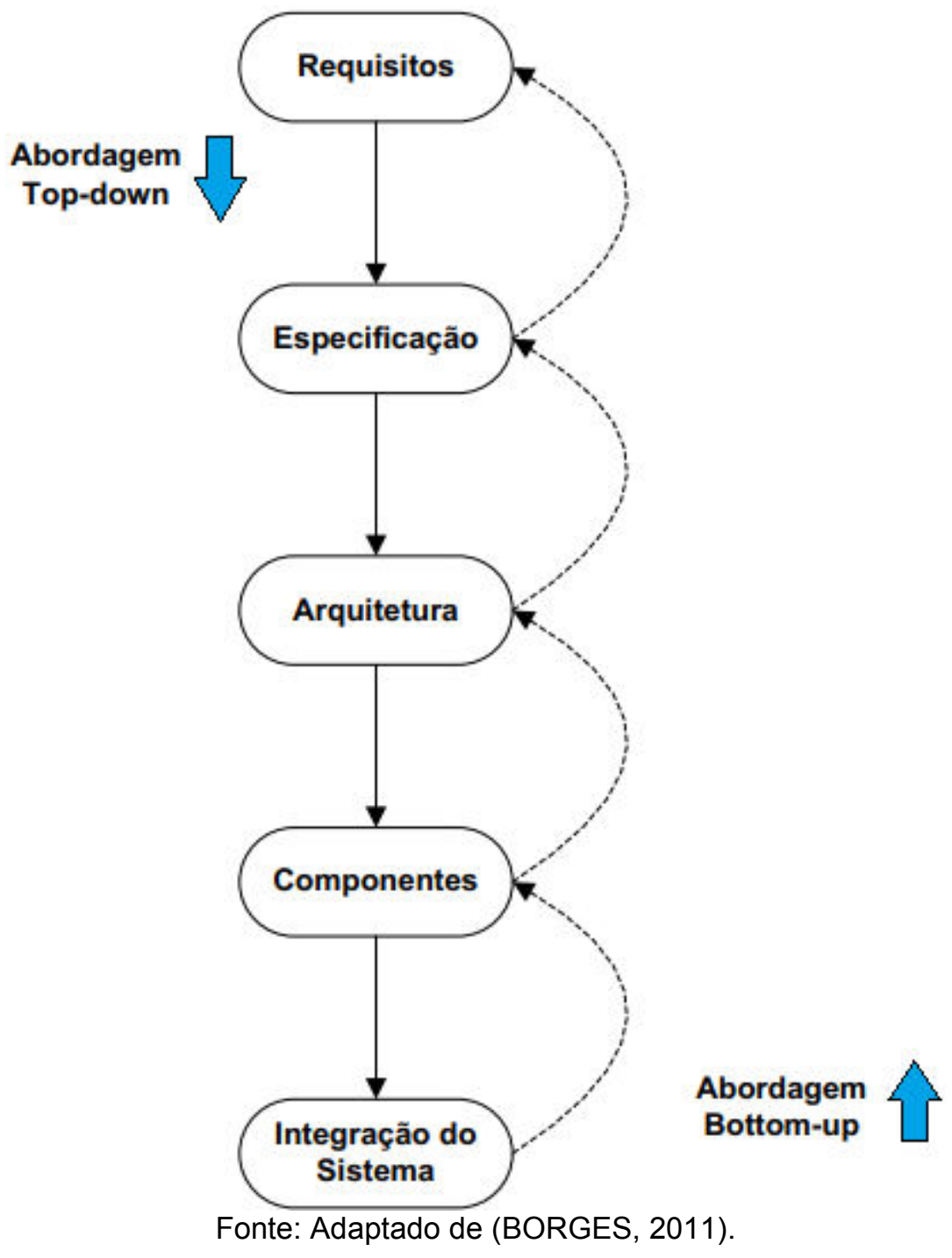

Berger (BERGER, 2002) descreve praticamente as mesmas etapas, porém, destaca as etapas de teste, refinamento, manutenção e atualizações, como segue:

- Especificação do produto.

- Divisão de desenvolvimento em componentes de software e hardware.

- Iteração e refinamento da divisão.

- Desenvolvimento independente de hardware e software.

- Integração dos componentes de hardware e software.

- Teste e lançamento do produto.

- Atualizações e manutenções.

De acordo com Wolf, o uso de uma metodologia de desenvolvimento é importante, pois, permite que o desenvolvimento seja acompanhado, garantindo a execução de todas atividades. Além disso, a utilização de uma metodologia permite a automatização de etapas, o uso de ferramentas de auxílio ao desenvolvimento e melhoria na comunicação e coordenação do time de projeto. 
Segundo Ganslee (GANSSLEE, 2008), quando desenvolve-se um produto, balanceia-se requisitos de cronograma, qualidade e funcionalidades, onde 0 desequilíbrio dessa tríplice coloca o densenvolvimento do produto em risco.

\subsubsection{Software embarcado}

O software tornou-se o componente chave no desenvolvimento de sistemas embarcados, e os produtos controlados puramente por hardware passam a ser cada vez mais raros e obssoletos. A extensão de softwares em produtos eletrônicos cresce em grande escala, nos automóveis atuais empregam-se cerca de milhões de linhas de código (BORGES, 2011).

A computação embarcada não baseia-se apenas na administração de timers e contadores, pois, muitos recursos de computação com natureza incomum a computação tradicional são envolvidos. Logo, a função determinante do software embarcado torna-se a interação com o ambiente físico e não somente a pura transformação de dados (WOLF, 2005).

Segundo (LEE, 2002), o software embarcado não se trata apenas de um código em um pequeno computador que possui características como:

- Precisão temporal.

- Concorrência.

- Operação contínua.

- Heterogeneidade.

- Reatividade.

Wolf (WOLF, 2005) destaca mais algumas características do software embarcado como:

- Restrições de tempo real.

- Baixo consumo de energia.

- Balanço entre hardware e software.

Além disso, Knight (KNIGHT, 2002) destaca que o software em si, exerce papel importante na confiabilidade, segurança, integridade, manutenção e confidencialidade do sistema embarcado.

\subsubsection{Sistemas operacionais}

Os sistemas operacionais (OS's) surgiram com o desenvolvimento da computação, como base para sistemas computacionais, promovendo desenvolvimentos mais modulares e a abstração entre hardware e código de aplicação (LI e YAO, 2003). Segundo (NOEGAARD, 2006) e (BORGES, 2011), os 
OS's podem ser definidos como um conjunto de bibliotecas de software que buscam atender dois propósitos principais:

- Prover uma camada de abstração, tornando o software mais independente do hardware, facilitando o desenvolvimento do software de aplicação.

- Gerenciar os vários recursos de software e hardware garantindo confiabilidade e eficiência na operação do sistema.

O sistema operacional junto com o hardware associado suporta a estrutura de tarefas de programas, o paralelismo (concorrência de operações), o uso de recursos aleatórios em tempo pré-determinados, a implementação e abstração de tarefas sem conhecimento do hardware, com a finalidade de que as tais tarefas sejam implementadas como unidades independentes (BORGES, 2011).

As tarefas consitem em um conjunto de processos que juntos provém funcionalidade ao sistema. Uma tarefa pode ser descrita como conjunto básico de instruções em um software ao utilizar-se RTOS's, e é definida pelos seus parâmetros e estrutura de dados tais como: nome, identificação (prioridade), nível de prioridade, bloco de controle (TCB), pilha (stack) e rotina.

(LIU, NARAYANAN e BAI, 2000) e (BORGES, 2011) propuseram três modelos de tarefas:

Tarefas periódicas: compostas por processos executados em intervalos regulares ou semi-regulares para prover uma funcionalide do sistema.

Tarefas esporádicas: compostas por processos com restrições hard real time liberados aleatoriamente para execução.

Tarefas aperiódicas: compostas por processos com restrições soft real time liberados aleatoriamente para execução.

Os processos formam as tarefas, e por isto, compartilham tanto as carascterísticas estáticas quanto os requisitos temporais. O processo é a menor undidade de trabalho agendada e executada pelo sistema, sendo caracterizado por parâmetros temporais, funcionais, de interconexão e de recursos (BORGES, 2011).

\subsubsection{Sistemas operacionais de tempo real (RTOS)}

O RTOS tem por função escalonar a execução de tarefas temporalmente, a fim de gerenciar recursos em uma base consistente para códigos de aplicação (LI e YAO, 2003). Sua essência é garantir a execução de processos dentro de limites rígidos de tempo, sem o risco da aplicação ficar comprometida. Dentro da área 
embarcada, a utilização de RTOS aumentou muito devido a ampliação do volume e complexidade de software (BORGES, 2011).

(VETROMILLE, et al., 2006) destaca sem qualquer hesitação que o sistema oprecional sem dúvida é o software mais importante em um sistema embarcado de tempo real, pois um RTOS que possa gerenciar tanto tarefas críticas e não-críticas é excepcionalmente fundamental para que seja garantida a eficiência do sistema.

Ganslee (GANSSLEE, 2008) afirma que OS's bem elaborados descomplicam o desenvolvimento na execução conflitante de múltiplas tarefas, eliminando disfunções geradas por variáveis globais com as devidas estruturas de sincronização (mailboxes, lista de mensagens ou métodos set and get - linguagem C). Contudo sem uma arquitetura de desenvolvimento com a certificação adequada, - RTOS embarcado pode gerar disparidades como alto consumo de memória, o que se torna um maleficio dentro do ambiente embarcado.

Os principais benefícios dos RTOS's são:

- Otimização do desenvolvimento de software

- Melhor sincronização e robustez das tarefas

- Gerenciamento de recursos com utilização de API's

- Gerenciamento de tempo

Existem incontáveis vantagens no emprego de um sistema operacional embarcado ainda mais quando aumenta-se a complexidade do software, por isto, é imprescindível uma escolha cautelosa do RTOS que será utilizado, pois, deverá suportar pressões como time to market, custo e qualidade no ambiente industrial (BORGES, 2011).

O RTOS é composto por um kernel (núcleo) que executa o escalonamento, gerenciamento de recursos com lógicas minimas, sistemas de arquivos, protocolos de comunicação, além de componentes de aplicações particulares (LI e YAO, 2003). Ainda que os sistemas operacionais possam variar muito em relação a sua composição, todos devem ser compostos por, no mínimo, um kernel (NOEGAARD, 2006) . Os kernel's (núcleos) de escalonadores podem ser classificados como nãopreemptivos ou preemptivos.

O termo preempção pode ser definido como a capacidade de um sistema operacional interromper um processo em execução e substituí-lo por um outro 


\subsubsection{Escalonamento de tarefas}

Nos sistemas de tempo real, os processos são escalonados e têm recurso alocados de acordo com algoritmosde escalonamento e protocolos de controle de acesso a recursos (LIU, NARAYANAN e BAI, 2000).

O Escalonamento de tarefas é um dos tópicos de sistemas de tempo real que é mais amplamente pesquisado, devido à crença de que o problema básico de sistemas de tempo real é garantir que as restrições de tempo das tarefas sejam atendidas (NERY, 2009). Segundo (BORGES, 2011) podemos destacar 3 (três) abordagens gerais:

Abordagem dirigida por tempo (Clock-driven/time-driven): Nesta abordagem, decisoes relativas ao escalonamento são realizadas em instantes especificos de tempo. Tipicamente em sistemas que usam essa abordagem, todos os parâmetros hard real time são fixos e conhecidos. Nesse sistemas geralmente a escala é computada offline e armazenada para utilização durante o tempo de execução.

Abordagem de compartilhamento (round-robin): a abordagem round-robin é comumente utilizada para escalonar aplicações de tempo compartilhado, sendo o algortimo também conhecido como compartilhamento do processador. Nesta abordagem, cada processo recebe uma fatia de tempo (unidade básica de tempo) igual para execução. O período equivalente a todas as fatias dos processos, prontos para execução, é denominado round.O algoritmo weihted round robin, segue o mesmo principio de algoritmo tradiconal. Porém, o procesador não é dividido igualmente entre os processsos. Processos diferentes recebem diferentes pesos (weights). Nesse caso, o round é igual À soma dos pesos. O ajuste dos pessos permite acelerar ou desacelerar o progresso dos processos.

Abordagem dirigida por prioridade (priority driven):Os algoritmos dirigidos por prioridade compõem uma grande classe de algoritrmos de escalonamento que maximizam a utilização de recursos. Nesse algoritmos, os processos com maior prioridade são escalonados e executados nos recursos disponíveis. As prioridades usualmente são atribuídas baseando-se nos parâmetros temporais como tempo de chegada, caso do algoritmos FIFO (First-in-First-out) e LIFO (Last-in-First-out), e deadline como nos algoritmos EDF (Earliest-deadline-first) e DM (deadlinemonotonic), ou no período como algoritmo RM (Rate Monotonic)

Os algoritmos de escalonamento pode ser classificados ainda quanto as suas carcterísitcas de: 
Em relação a análise do método de escalonabilidade:

Estáticos: a escalonabilidade é realizada de modo estático baseado no conhecimento prévio das propriedades relevantes das requisições (NERY, 2009).

Dinâmicos: projetados para trabalhar com requisições imprevisíveisde tempo e chegada, e por isto podem ter um tempo de execução desconhecido (NERY, 2009).

Em relação a preempção:

Preemptivos:permitem que uma tarefa seja temporariamente suspensa para a execução de outra com maior prioridade Nery (2009).

Não-preemptivos:impedem que a execução de uma tarefa seja interrompida até sua conclusão (NERY, 2009).

Em relação a execução:

Offl-line:o escalonamento é pré-computado antes da execução do sistema (LIU, NARAYANAN e BAI, 2000).

On-line: o escalonamento é realizado durante o tempo de execução, onde as decisões relativas a tarefas são tomadas sem conhecimento das tarefas futuras (LIU, NARAYANAN e BAI, 2000).

Em relação ao sincronismo:

Time driven:As decisões sobre qual requissição executar são tomadas de acordo com instantes previamente estabelelcidos (NERY, 2009).

Event driven : As decisões de escalonamentosão baseadas em eventos (NERY, 2009).

O produto do escalonaodr é a escala, que consiste no agendamento ded todos os processos de um sistema em um ou mais processadores (BORGES, 2011). 


\subsection{ESTRATÉGIAS PARA O DESENVOLVIMENTO EMBARCADO AUTOMOTIVO}

\subsubsection{O esforço da indústria automotiva para criação de arquiteturas para o software embarcado}

O padrão aberto OSEK ${ }^{12}$ foi fruto de uma convenção criada para estabelecer normas e especificações de software para serem utilizadas no desenvolvimento de unidades de controle eletrônico (ECU's) embarcadas. Criada em 1993 por um Consórcio entre a universidade de Karlsruhe e empresas automotivas de origem alemã (BMW, Robert Bosch GmbH, DaimlerChrysler, Opel, Siemens e Volkswagen). Em 1994, o grupo automotivo francês (Renault e PSA Peugeot Citroën) desenvolveu um projeto similar chamado VDX ( Vehicle Distributed eX $\underline{X}$ ecutive ${ }^{13}$ ), e posteriormente juntaram-se ao consórcio alemão, que passou a se chamar OSEK/VDX.

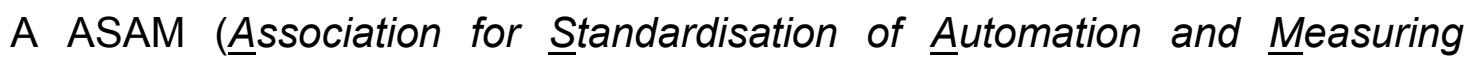
Systems) é uma associação incorporada sob a legislação alemã, formada por fabricantes internacionais de automóveis, fornecedores e prestadores de serviço de engenharia da indústria automotiva, responsável por coordenar a elaboração de padrões técnicos, que são desenvolvidos por grupos de trabalho compostos por especialistas de suas empresas associadas. A principal ideia defendida pela associação alemã é a visão de que as ferramentas de uma cadeia de processos de desenvolvimento podem ser interconectadas livremente e permitir uma troca contínua de dados. Os padrões definem protocolos, modelos de dados, formatos de arquivos e API's para o uso no desenvolvimento e teste de unidades de controle eletrônico automotivo. A ASAM cooperou para o desenvolvimento do AUTOSAR (AUTomotive Open System $\underline{A R}$ chitecture), incorporando arquiteturas de software, padrões e arquivos de configuração para aplicativos e BSW ( $\underline{B}$ asic $\underline{\text { SoftWware), que }}$ permite interações entre os módulos do software. Estes módulos de aplicação são executados num RTE (ㅁun $\underline{\text { Time Environment }}{ }^{14}$ ) através de um VFB (Virtual Functional Bus ${ }^{15}$ ). Uma grande quantidade de ferramentas populares nas áreas de

12 Arbeitskreis Offene Systeme und deren Schnittstellen für die Elektronik in Kraftfahrzeugen - Sistemas Abertos e suas Interfaces para a Eletrônica em Veículos Motorizados

${ }^{13}$ Execução veicular distribuída.

${ }^{14}$ Ambiente de execução temporal.

${ }^{15}$ Barramento funcional virtual. 
simulação, medição, calibração e automação de teste são compatíveis com as normas ASAM.

Para atender às demandas do design do sistema de controle embarcado, a indústria automotiva desenvolveu uma extensão padronizada do OSEK/VDX, que recebeu o nome de AUTOSAR. O AUTOSAR permite a especificação de componentes que implementam funções complexas, potencialmente distribuídas, em um veículo. Os principais objetivos de toda esta elaboração de métodos é proporcionar à indústria automotiva benefícios como modularidade, escalabilidade, transmissibilidade e reutilização de software entre projetos, variantes, fornecedores, clientes, sem a necessidade de reconfigurar, abrir e reconstruir o código e principalmente, aumentar o foco no desenvolvimento de novas estratégias de controle, sem perder estruturas lógicas já consolidadas.

\subsubsection{Aspectos da engenharia de software embarcado}

O desenvolvimento de softwares é um grande desafio devido à sua alta complexidade e inexistência física. Geralmente os problemas derivam de deficiências humanas, tais como: acurácia ineficiente ou baixa capacidade de visualização de interações complexas. A discussão científica para superar tais problemas foi denominada como engenharia de software. O código orientado foi concebido para eliminar as complicações iniciais de criação, e por isto, tem se tornado cada vez mais expressivo para o desenvolvimento de softwares (FUCHS, et al., 1998).

O modelo tradicional do desenvolvimento de softwares de engenharia sugere uma realização em fases sucessivas. Na fase primária, os requisitos são analisados, então a estrutura fundamental é projetada pela divisão em componentes do modelo. Esses componentes são implementados e testados individualmente antes de serem integrados e testados como um todo, para que em uma última fase seja realizada a adequação do software gerado a padrões normativos (SCHÄUFFELLE e ZURAWKA, 2005).

\subsubsection{Model-Based Design}

O design baseado em modelo emergiu como uma solução para os problemas de desenvolvimento de software integrado, encontrados tanto em ambientes acadêmicos quanto nos industriais. O princípio básico desta metodologia é afastarse da codificação manual e de especificações informais de código, ao capturar 
requisitos incorporados de funcionalidades funcionais e não funcionais de modelos matemáticos abstratos. Claramente, um modelo matemático oferece um terreno comum para uma integração sistemática e coerente de diversos esforços na especificação do sistema, design, síntese (geração de código), análise (validação), execução (suporte de tempo de execução) e manutenção (evolução do design). Hoje, não existe nenhum modelo pronto que seja acordado para o desenvolvimento integrado de software, e os fluxos são baseados em diferentes ferramentas e modelos (e.g. no domínio automotivo, os modelos baseados em UML ( $\underline{\text { Unified }}$ Modeling Language ${ }^{16}$ ), Simulink e ASCET são usualmente aplicados para representar projetos em diferentes níveis de abstração como a estrura real time, model based e object oriented) (BALEANI, et al., 2005).

A atuação orientada das funcionalidades divide os encargos (modelados como protagonistas) das incumbências de interação de componentes (modeladas como frameworks) e fornece escopos bem definidos para aprimoramento do modelo e realização do sistema (HUANG, HUANG e ZHANG, 2010). Este desenvolvimento como um todo se torna possível porque o SW automotivo é baseado no RTOS (Real Time Operating Systems) automotivo (neste caso o RTA-OSEK). Em níveis de abstração, o software só acessa o RTA-OSEK e o Basic Software (BSW) que contém os drivers (software no lugar de hardware) de entrada e saída, além de drivers sofisticados (injetores de alta pressão - $G D I^{17}$ ). Isso permite que um AppSW possa ser desenvolvido focando-se apenas no sistema operacional em conjunto com os drivers, com isenção do HW, que torna o hardware alvo para aplicação modular e independente.

\subsection{ETAPAS PARA O DESENVOLVIMENTO DO SOFTWARE AUTOMOTIVO}

\subsubsection{O ciclo $\mathrm{V}$}

O conceito referencial mais difundido para o desenvolvimento automotivo em geral é o ciclo $V$ que visa a integração entre inspeção de qualidade e procedimentos de testes, especificando o cenário de componentes dentro de um determinado sistema. Um modelo $\mathrm{V}$, de maneira geral, conforme a Figura 2.26, exemplifica quais passos guiam o desenvolvimento de um software automotivo, com o intuito de se empregar uma validação robusta do software de aplicação, este conceito tem sido

\footnotetext{
${ }^{16}$ Linguagem de Modelagem Unificada.

${ }^{17}$ Gasoline Direct Injection
} 
amplamente utilizado na indústria automotiva, por propiciar segurança e qualidade na evolução de aplicações automotivas, pois, compreende os cuidados a serem considerados em estratégias que deverão ser reproduzidas em massa.

Figura 2.26 - Visão Geral do núcleo de processos para o desenvolvimento de sistema eletrônicos e software a partir do ciclo $\mathrm{V}$.

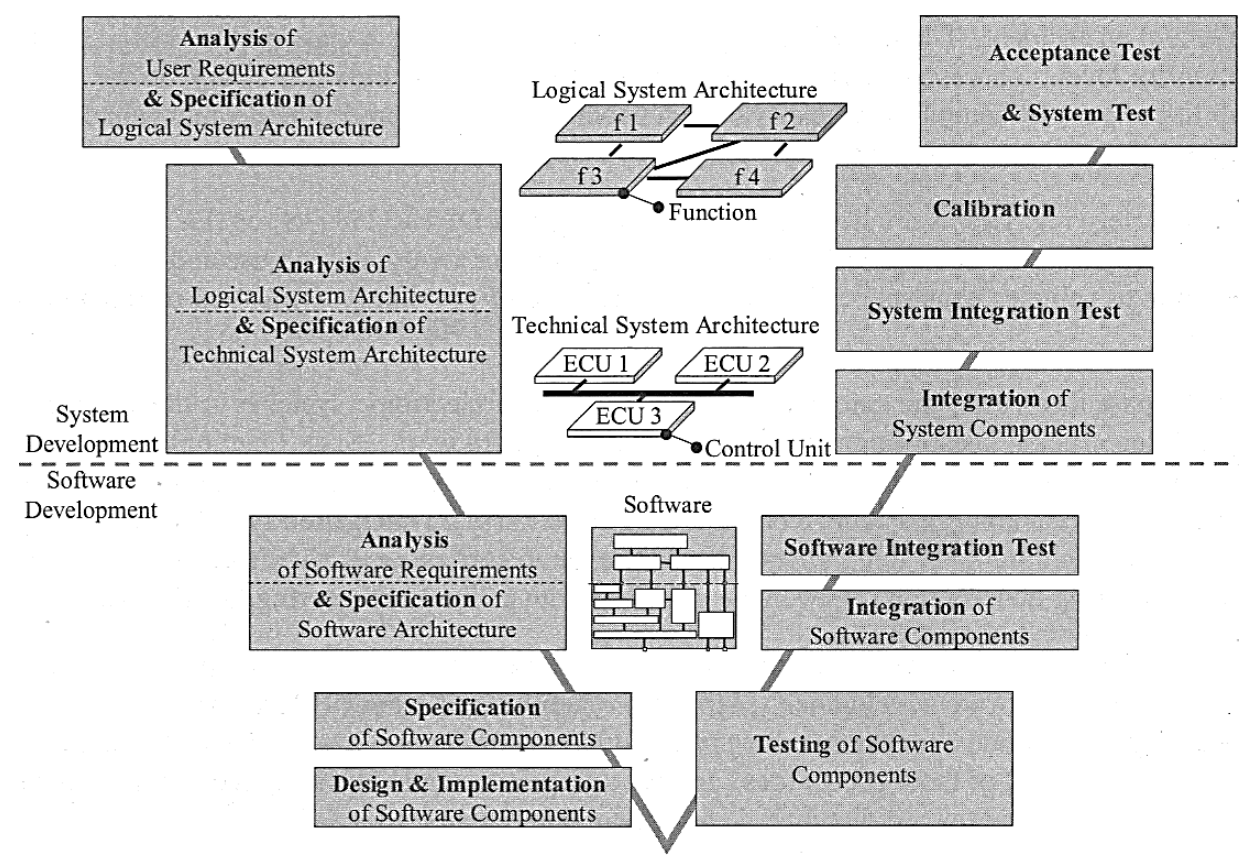

Fonte: Extraído de (SCHÄUFFELLE e ZURAWKA, 2005).

A Figura 2.27 exibe o $\mathrm{V}$-model mais específico aplicado a este projeto, com a inclusão de algumas das ferramentas computacionais empregadas no model-based software engineering conforme determinações regidas pela ASAM e implementada comercialmente pela corporação ETAS (Engineering Iools and Application Services). 
Figura 2.27 - Ciclo V aplicado às implementações de software disponibilizadas pela corporação ETAS com destaque das etapas utilizadas neste projeto.

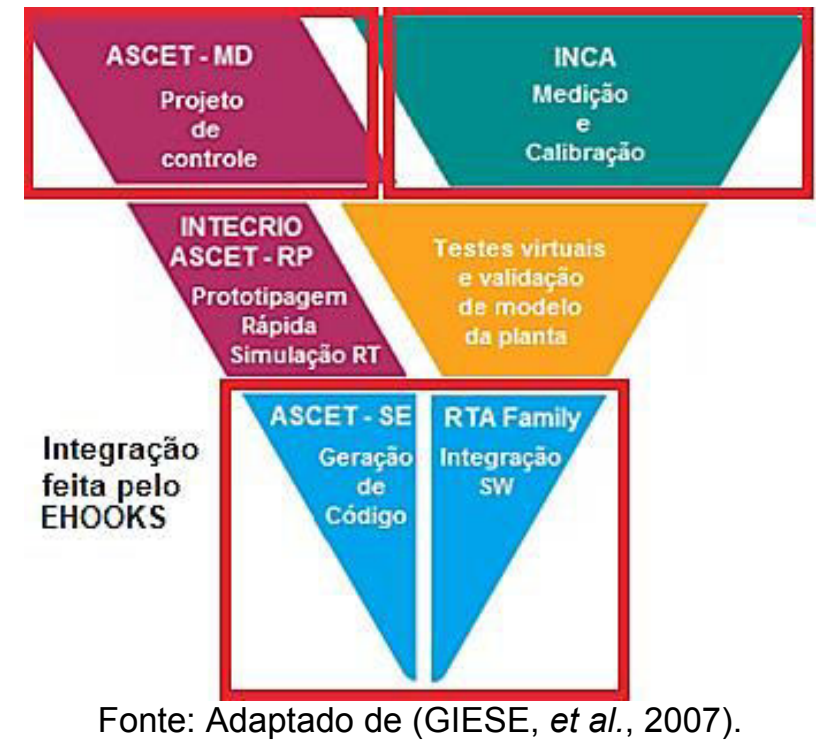

Independentemente do processo clássico de design do sistema de controle ou do processo de desenvolvimento do ciclo $\mathrm{V}$, o processo de projeto do sistema de controle é dividido em 4 etapas.

\subsubsection{Desenvolvimento funcional do controle}

Com base em uma descrição conceituada do objetivo de controle, realiza-se a seleção dos algoritmos de controle baseados em modelos de planta de alto nível, uma plataforma de execução idealizada e requisitos de desempenho simplificados. As leis de controle geralmente são validadas por uma combinação de provas matemáticas e simulações de tempo contínuo e/ou digital. O desenvolvimento do controle a ser introduzido na ECU, considerando apenas as entradas e saídas da estratégia trata-se do ponto de partida representado na extremidade superior esquerda da Figura 2.27, onde não há a necessidade de consideração do hardware em que será implementado (este ponto é tratado posteriormente pelo software). Desta maneira, a estratégia de controle do AppSW pode ser desenvolvida de maneira abstraída do código fonte, ou seja, através das seguintes interfaces: diagrama de blocos, linguagem C, ESDL (Embedded Software Description Language) ou máquina de estados e, desta maneira, a integração do software é realizada automaticamente com o código objeto a partir destes diagramas e/ou linguagens.

Para a finalização desta fase, são realizados testes com entradas e saídas virtuais, que podem ser realizados em tempo real e/ou virtual. No caso do real-time, 
há a necessidade de um $\mathrm{HW}^{18}$ de prototipagem, que é um dispositivo dedicado para rodar o $\mathrm{AppSW}^{19}$ de controle e este, por ser dedicado, consegue rodar não só o AppSW como também o sistema operacional real-time que será utilizado na ECU final, neste caso, um sistema operacional automotivo chamado RTA-OSEK que é uma implementação dos padrões estabelecidos pelo consórcio OSEK.

\subsubsection{Geração estruturada de código}

A geração do código objeto a ser implementado na ECU de desenvolvimento, trata-se da compilação das linhas de código $\mathrm{C}$ ou blocos de diagramas lógicos desenvolvidos no ambiente de trabalho e base de dados serem associadas ao hardware/software alvo que neste projeto, trata-se do LLSW da Flex-ECU. A compilação e associação dos componentes é implementada através do uso integrado do software E-HOOKS Dev.

Figura 2.28 - Workflow da integração ASCET/E-HOOKS Dev.

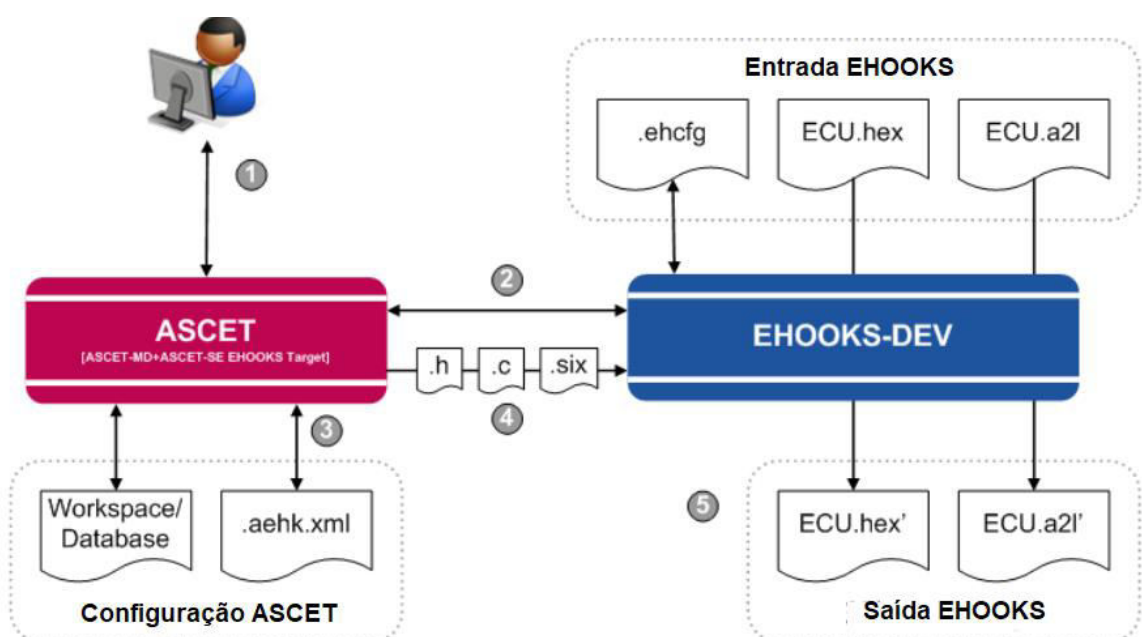

1. Operador; 2. "Link"de integração; 3. ASCET - Model Development + ASCET Software Engineering; 4. Extensões de código do AppSW; 5. Objetos gerados pelo EHOOKS Dev. Fonte: Adaptado de (ETAS INC).

O processo de compilação integrada resulta em dois arquivos essenciais fundamentados pela norma ASAM $^{20}$, os arquivos ASAM-MCD-2MC (ASAP2) de extensão $A 2 L$ e o código objeto extensão HEX. $O$ formato $A 2 L$ explicita nome de variáveis e respectivos endereços, fórmulas de conversão, e especificações da interface de hardware. O código hexadecimal (HEX) armazena as instruções de software e os dados utilizados na calibração, esta divisão é fundamental para

\footnotetext{
${ }^{18}$ HardWare

19 Application SoftWare - Software de aplicação.

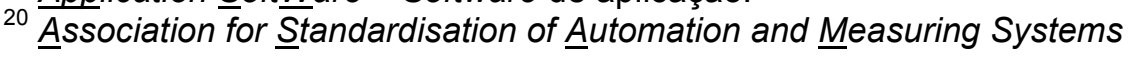


garantir o pré-requisitos de rastreabilidade e segurança previstos dentro da engenharia de software embarcado.

\subsubsection{Testes virtuais e virtualização}

O processo do ajuste ideal de parâmetros para a ECU deve ser feito desde a primeira fase, onde se desenha e define as funções que vão gerenciar o sistema. Contudo, quanto mais distante da planta real e de um teste em malha fechada, mais complicado será definir os valores das variáveis de calibração e mais distantes estarão estas dos valores que terão ao finalizar a etapa de medição e calibração.

Portanto, quanto antes o AppSW, o SW e a ECU forem testadas em closed loop, mais rápido se encontram e se resolvem os problemas. Além disso, é possível iniciar um trabalho de medição e calibração muito mais representativo desde a primeira etapa, tornando o desenvolvimento de uma unidade de controle mais eficiente, formando um laço de repetição condicional com base nos resultados desejados.

Nesta etapa, adota-se um modelo da planta para que seja possível emulá-la em um $P C$ com sistema operacional real-time que estimule a ECU com sinais elétricos idênticos aos existentes em uma conexão com a planta real, como se esta estivesse realmente conectada à planta, permitindo que se faça testes e validações de maneira completa sem o viés de perdas ou danos materiais oriundos de testes práticos.

A partir da consideração deste conceito, o MBD permite interações entre suas etapas através de diversos recursos de ferramentas como: SiL ( Software-in-theLoop), MiL (Model-ịn-the-Loop), Prototipagem Rápida, External By-pass e On-Target $B y$-pass para os mais variados fins de projeto automotivo, como o relatado por (SANTOS, et al., 2015) aplicando este método desenvolvimento para o controle de iluminação veicular.

\subsubsection{Medição e calibração}

A fase final do ciclo $V$ corresponde à validação e teste na planta real (motor ou veículo), onde a ECU é conectada ao veículo real e o trabalho de calibração dos parâmetros é realizado.

$O$ recente aumento nos requisitos de largura de banda redes automotivas levaram a CAN ao seu limite. A fim de atender a esses requisitos, CAN-FD, que foi recentemente desenvolvido, permite taxas e cargas mais altas. Este novo protocolo 
possui controladores que também executam comunicação CAN padrão, representando uma nova alternativa para futuros sistemas automotivos. As motivações que levam a esse novo protocolo incluem: (i) atender à crescente demanda por largura de banda de comunicação; (ii) fornecer um protocolo que preencha a lacuna entre o barramento CAN de baixa velocidade e econômico com largura de banda máxima de $1 \mathrm{Mbps}$ e o FlexRay de alta velocidade, mas caro, com largura de banda máxima de 10 a $20 \mathrm{Mbps}$; (iii) para evitar o dispendioso esforço de portabilidade envolvido na migração do CAN para o FlexRay ou Ethernet (DE ANDRADE, et al., 2018).

A calibração é feita acessando a ECU através de protocolos automotivos de medição e calibração como, por exemplo, acesso XCP (Calibration Protocol) via

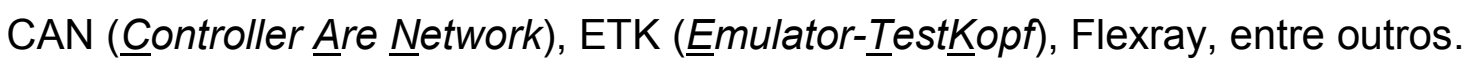

Estes protocolos permitem um acesso à unidade de comando, para coleta dos conteúdos das variáveis de medição e para alteração de mapas e parâmetros de calibração de maneira online o PC de trabalho, ou seja, alterando estes mapas enquanto a planta real (por exemplo, o motor) está em funcionamento, sem que haja necessidade de parada do motor para realização de uma nova gravação de flash na ECU. Nesta fase, ajustes relativos a combustíveis, sensores, dirigibilidade, economia de combustível e conforto podem ser realizados sem a necessidade da geração e compilação de um novo SW, desde que sejam previstos na confecção lógica do software de aplicação. 


\section{METODOLOGIA}

Nesse capítulo são abordados os métodos envolvidos no projeto, bem como os componentes de hardware utilizados.

\subsection{FERRAMENTAS PARA O SOFTWARE EMBARCADO}

Esta seção revisa sobre as ferramentas de software utilizadas neste trabalho.

\subsubsection{ASCET SD}

A ferramenta avançada de engenharia para simulação e controle ASCET

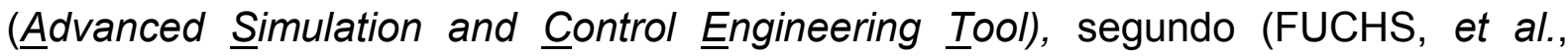
1998)foi concebida em 1997 para oferecer suporte às condições desafiadoras de mercado que motivaram processos de produção de software mais inteligentes para desenvolvimento, conforme as arquiteturas, citadas na seção A ASCET-SD favorece uma separação rigorosa dos aspectos funcionais e temporais, sendo os componentes as unidades de modularidade e reutilização. A especificação do sistema segue um conceito de três camadas. Um único componente no nível superior, chamado de projeto, representa um sistema de controle incorporado com todos os aspectos de tempo dinâmicos contidos na especificação do sistema operacional. Estâncias funcionais maiores, considerando aspectos de temporização estática, são modeladas com componentes da segunda camada chamados módulos que trocam informações através de mensagens. O terceiro e último nível inferior é composto de classes, fornecendo funcionalidades menores e especializadas (HONEKAMP, et al., 1999). 
Figura 3.1 - Modelagem de programação de tarefas de um projeto no ambiente ASCET (

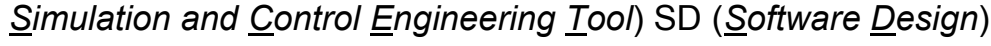

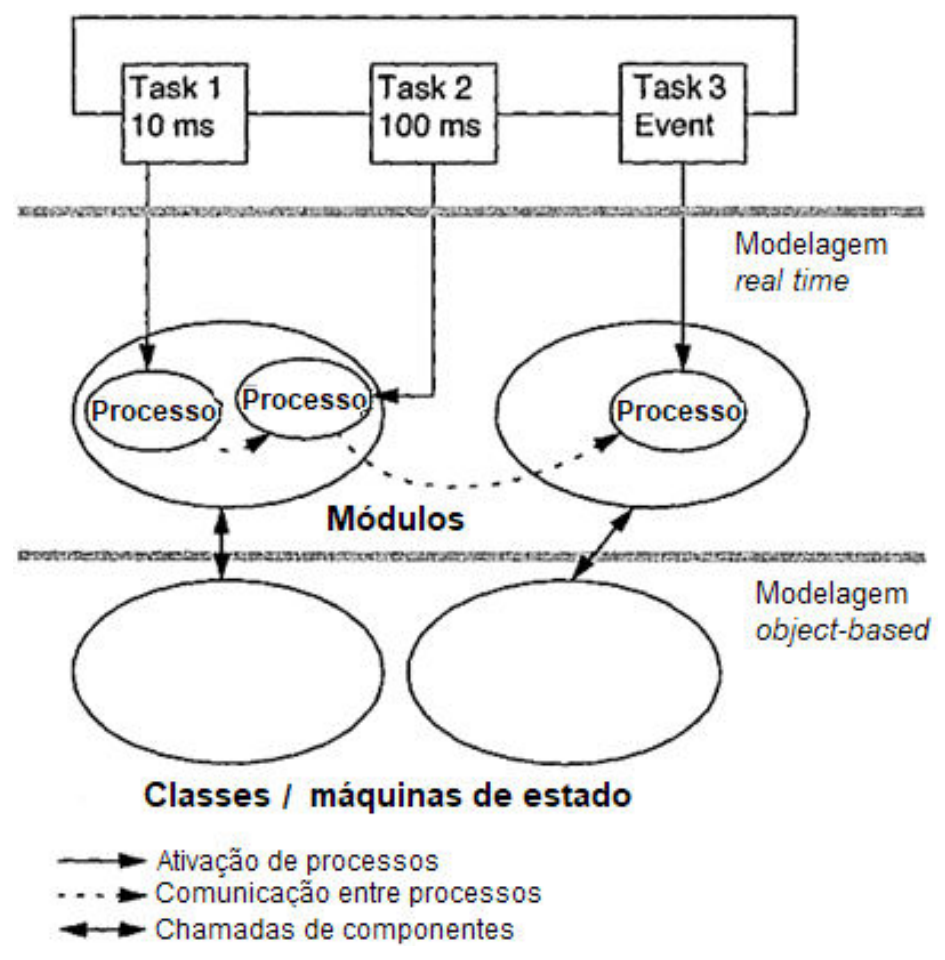

Fonte: Extraído de (HONEKAMP, et al., 1999)

A ASCET SD oferece principalmente suporte ao paradigma do Modelo de Programação de Tarefas (MPT) para implementações de processamento singular em controladores com software integrado. De acordo com o MPT, as especificações do sistema são dadas como uma coleção de componentes de software denominadas tasks (tarefas) e uma política de escalonamento apropriada.

A especificação do sistema no ASCET é chamada de projeto e consiste em um conjunto de módulos que criam instâncias e definem processos. As classes são componentes reutilizáveis que consistem em variáveis e métodos. O estado do componente é mantido por variáveis. As saídas de componentes podem ser calculadas e medidas através de métodos de chamada. Os processos são métodos definidos em módulos, e podem chamar os métodos definidos pelas classes alocadas dentro do módulo, que se comunicam através de mensagens, que são variáveis compartilhadas protegidas por cópia local: cada processo funciona em uma cópia local de suas mensagens de entrada/saída. 
Os procedimentos de segurança e proteção são garantidos pelo sistema operacional subjacente RTOS ( arquitetura OSEK (ㅁfene Systeme und deren Schnittstellen für die Elektronik in Kraftfahrzeugen ${ }^{21}$ ). Os processos são agendados com tarefas escalonadas (agendadas) pelo RTOS, seja por base de tempo ou evento. A técnica de agendamento é baseada em prioridade estática com preempção (BALEANI, et al., 2005).

Pode-se estabelecer uma relação de analogia entre a linguagem de alto nível gráfica do ASCET, sistemas operacionais de tempo real (que é como o programa foi idealizado para funcionar) e a linguagem de código $C$ gerada no nível mais baixo de código (Figura 3.2).

Figura 3.2 - Exemplo de correspondência entre os objetos no ambiente ASCET, RTOS (Real Time Operating Systems) e a linguagem de programação em código $C$.

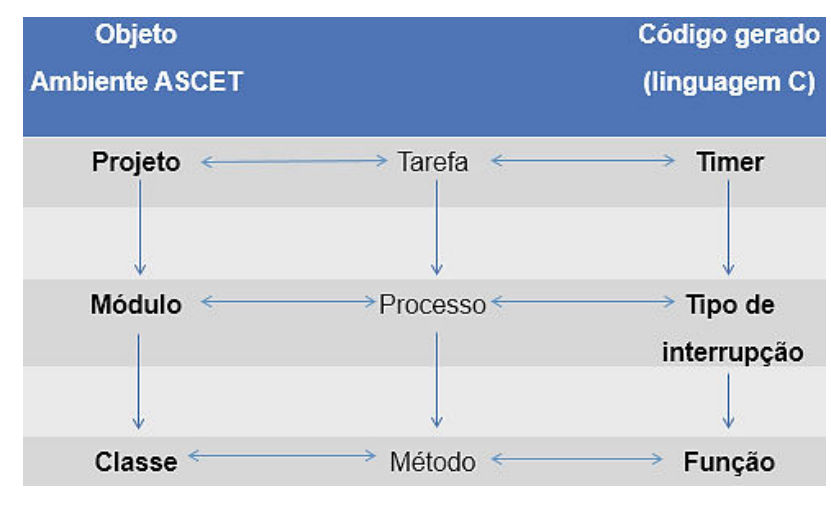

Fonte: $\mathrm{O}$ autor.

As rotinas são executadas a partir do conceito on target by pass que consiste em um desvio de tarefas em função da rotina "alvo", tendo como principais vantagens a modularização de rotinas, desconsiderando o efeito da integração entre elas e o compartilhamento do raciocínio lógico dos módulos sem a necessidade do compartilhamento e/ou compreensão de todo o projeto.

\subsubsection{INCA}

O trabalho de calibração foi realizado através da ferramenta integrada de medição e calibração INCA (INtegrated Calibration and Acquisition Systems), permitindo tarefas como:

${ }^{21}$ Sistemas Abertos e suas Interfaces para a Eletrônica em Veículos Motorizados. 
- Ambiente de experimentos: Configuração de hardware, inteface para bancadas de testes, gravação do desempenho do powertrain ${ }^{22}$ com suporte a testes automatizados. Conversão de sinais internos da ECU em tensões analógicas, medição de sensores que não estão diretamente conectados à ECU (disponíveis através de algum protocolo: Flexray, ETK, CAN, Ethernet, Lin, etc);.

- Análise de dados medidos: avaliação de resultados.;

- Gerenciamento de dados de calibração: Gravação do software e dados da ECU, bem como a administração de diferentes versões softwares sem necessidade de mudança de controladores ou chips de memória;

Além de diferentes padrões de comunicação automotiva, o espaço de memória da unidade possui uma distribuição característica, sendo dividida em páginas funcionais. A funcionalidade destas páginas é dividida em três: Calibration Data - armazenada na página de calibração (Calibration Page) situada na memória flash; Software Code (instruções) - armazenada na página de códigos (Code Page) também situada na memória flash; Measured Data and Operands - armazenada na página de dados medidos (Measure Data Page) situada na memória RAM, como exibido na Figura 3.3.

Figura 3.3 - Estrutura de memória paralela da FlexECU - unidade voltada ao desenvolvimento de software no padrão automotivo.

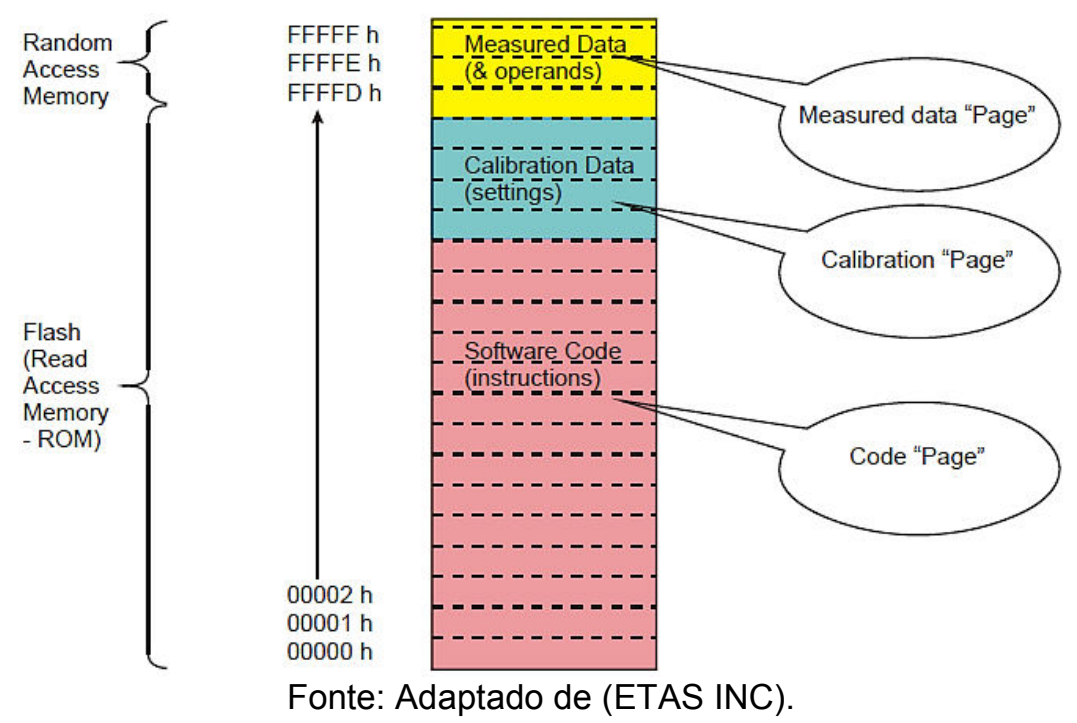

A realização da leitura e gravação de páginas de memória é implantada

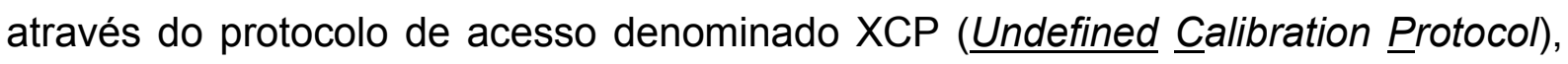
esse acesso ocorre de modo paralelo, e possui a vantagem de não interferir nas ações do microcontrolador enquanto for realizado. O XCP é um protocolo utilizado

${ }^{22}$ Expressão da língua inglesa formada pela palavra power, força ou potência, em conjunto com a palavra train, trem. Portanto a expressão "powertrain" significa trem de força, referindo-se ao conjunto motor e câmbio do veículo, que transmitem o torque gerado pelo motor para as rodas. 
para calibração e aquisição de dados da ECU. Seu principal foco é a compatibilidade entre diferentes tipos de hardware e software. Em sua camada de aplicação, o XCP pode ser configurado em diferentes procolos de comunicação automotiva (Flexray, ETK, CAN, Ethernet, Lin, etc) e disponibiliza as seguintes funcionalidades:

- Leitura e escrita para a memória da ECU;

- Aquisição de dados cíclica e síncrona da ECU;

- Manipulação de acesso e escrita ao barramento;

Neste trabalho, foi selecionada camada de aplicação CAN 2.0 B (identificadores de mensagem com 11/29 bits), portanto o XCP foi implementado como CCP ( $\underline{\text { Can }} \underline{\text { Calibration }}$ protocol).O CAN é um protocolo de transmissão de mensagens multi-mestre usado na maioria dos automóveis, com uma taxa máxima de sinal de $1 \mathrm{Mbps}$. Ao contrário das redes tradicionais, como USB e Ethernet, o CAN não envia grandes blocos de dados ponto-a-ponto sob a supervisão de um mestre de barramento central. Em uma rede CAN, muitas mensagens curtas são transmitidas para toda a rede, o que fornece consistência de dados em todos os nós do sistema (DE ANDRADE, et al., 2018).

O INCA possui em sua janela principal, um ambiente de experimentos, com um cenário de seleção e configuração representativa das variáveis de medição. configuração e seleção do hardware utilizado, alteração de variáveis de calibração internas da ECU. 
Figura 3.4 - Cenário de experimentos do software INCA com variáveis de medição internas da ECU ETAS/Bosch MEDC17 FlexECU.

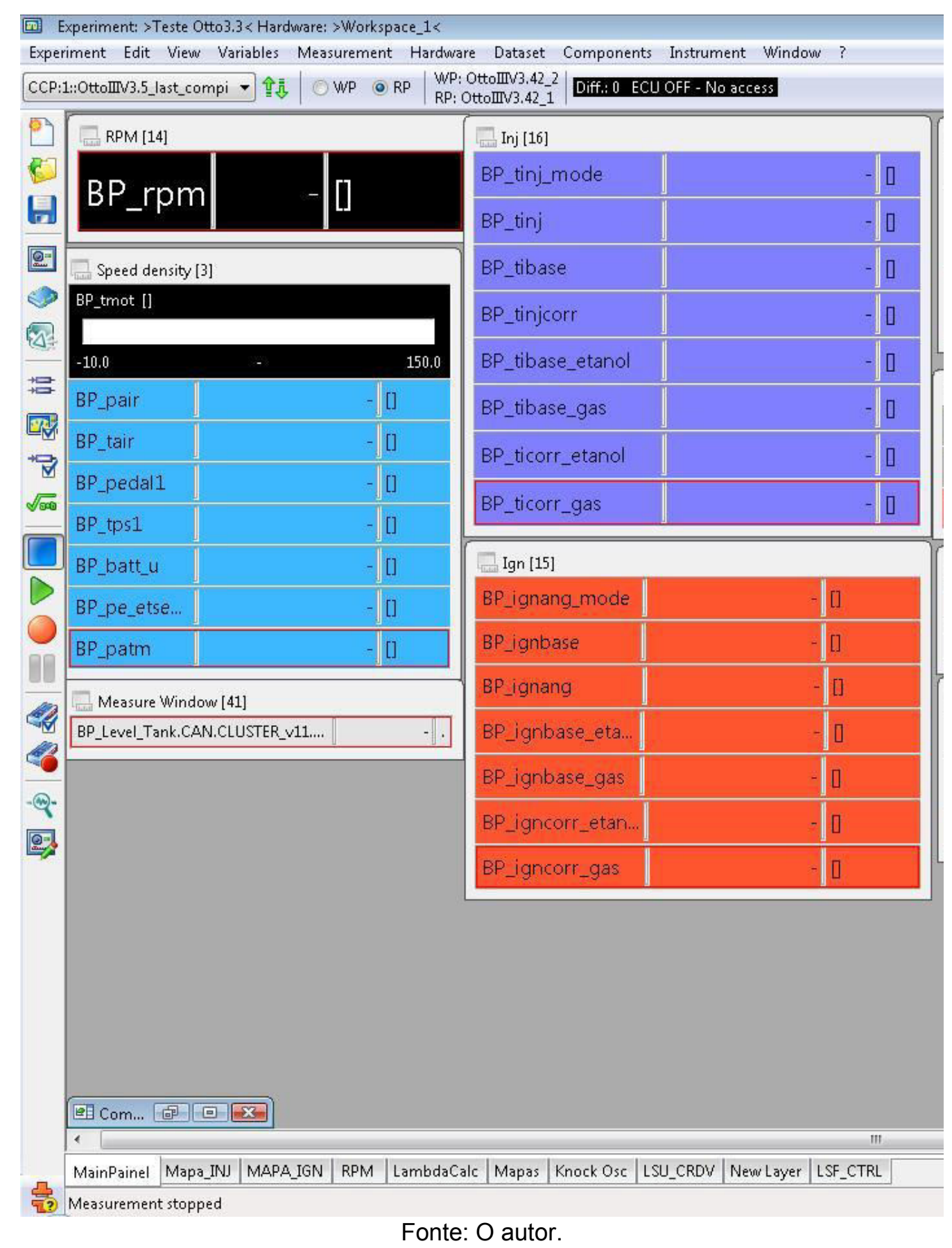

Neste cenário, os parametros de medição podem ser exibidos como valores diretos, cluster (representação por medidores analógicos), como temperatura, contagiros etc; ou ainda como curvas em osciloscópios. As variáveis de calibração podem ser utilizadas virtualmente como se fossem chaves seletoras ou simples botões binários. Para a gravação destas variáveis é possível estabelecer-se por rasters ${ }^{23}$

${ }^{23}$ Caixas de seleção para amostragens pré-definidas. 
amostragens individuais para a gravação dos dados medidos. Ao final de uma gravação serão salvos sempre uma versão .dat e também no formato selecionado pelo usuário (ASCII, csv, etc.).

\subsection{PROJETO OTTO III}

Com a utilização do conceito V-Model, alunos do grupo de eletrônica automotiva desenvolveram, para um motor 1.6I 14, um firmware de controle ou AppSW (Application SoftWare), denominado Otto III, empregando a ferramenta ASCET no gerenciamento eletrônico do motor, com o hardware profissional de desenvolvimento FlexECU. A fase inicial do projeto foi aplicar o gerenciamento em um funcionamento monocombustível (J. P. F. SANTOS, 2015).

A ECU possui um bloco de instruções dedicado ao sincronismo do motor chamada EPM (Engine Position Management), onde são determinados à ECU os pontos de TDC dos pistões e sincronia do sinal de rotação do comando de válvulas (sinal de fase) e o sinal de rotação do virabrequim (sinal de roda fônica), exemplificados na Figura 3.5.

Figura 3.5 - Perfis dos sinais de rotação do motor (a) sinal de roda fônica e (b) sinal de fase.

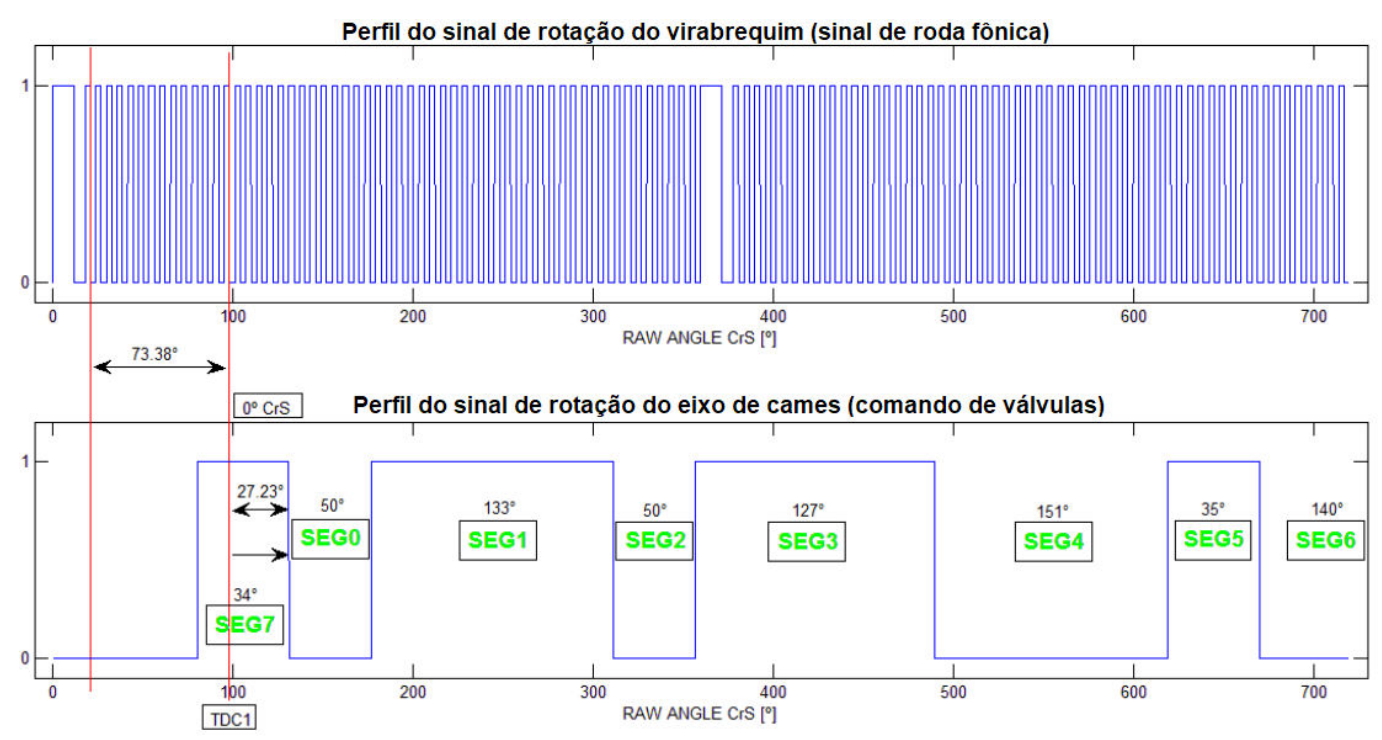

Fonte: Adaptado de (J. P. F. SANTOS, 2015).

Todas as rotinas síncronas com a velocidade do motor são dependentes deste bloco. A Figura 3.6 exibe o projeto de AppSW, onde cada módulo possui 
funções e periodicidades distintas dentro do RTOS em que opera o software de aplicação.

Figura 3.6 - Diagrama de representação dos módulos presentes no ambiente do software de aplicação ASCET com a versão de firmware (projeto) Otto III.

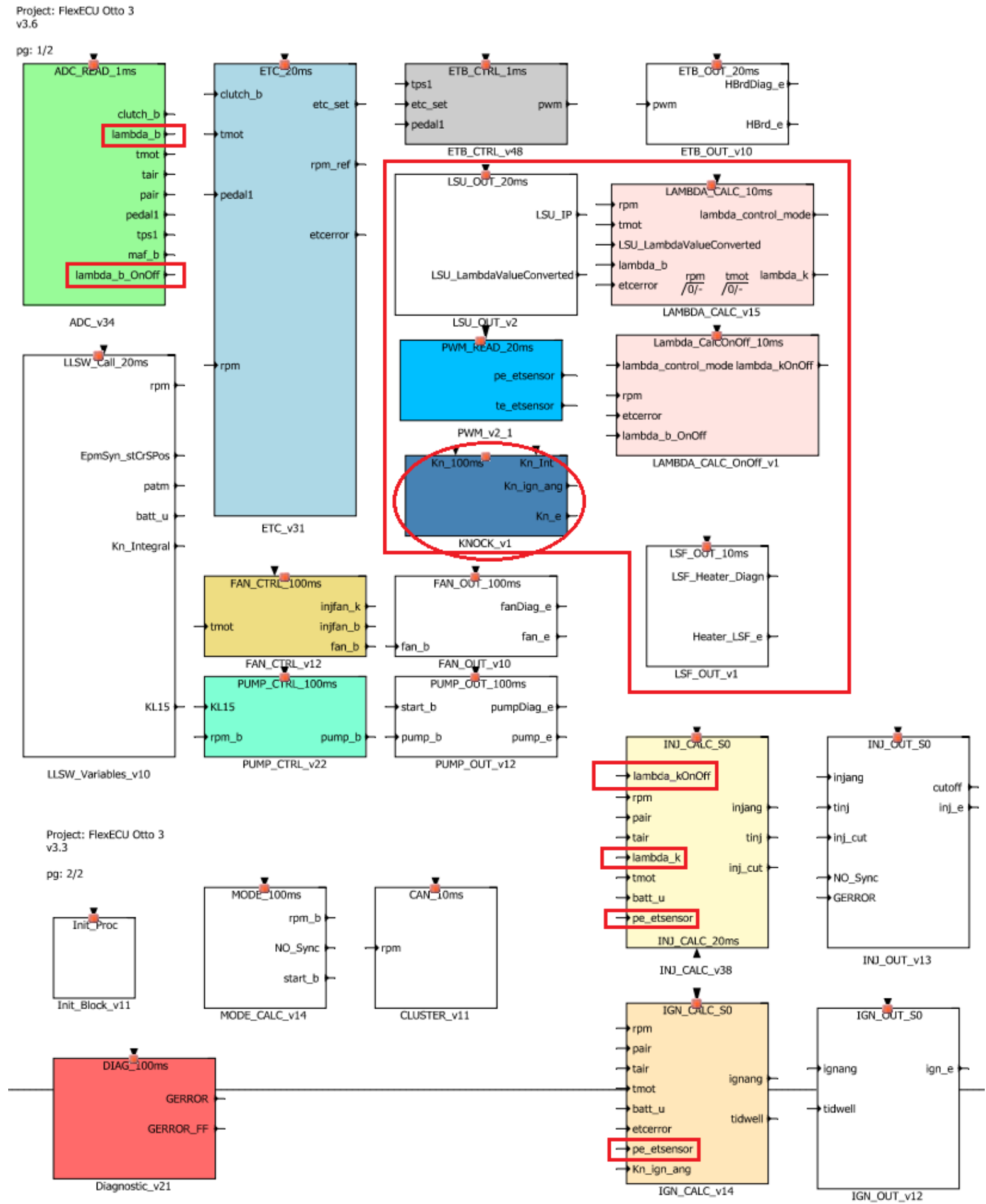

As alterações adicionadas para o funcionamento Flex-Fuel no controle A/C (lambda) em malha fechada realizado neste trabalho, estão destacadas pelas marcações retangulares, com exceção do bloco destacado por uma elipse, o qual tem a função de detectar detonações aplicado por (HAYASHIDA, 2018).

Fonte: $\mathrm{O}$ autor. 
No desenvolvimento deste trabalho, o software de aplicação recebeu o incremento de módulos lógicos de controle necessários para a inserção do funcionamento bicombustível e controle da estequiometria do combustível (A/C) em malha fechada. Tais módulos serão delineados de maneira descritiva na seção 3.4.4.

\subsection{HARDWARE APLICADO}

\subsubsection{Unidade de Comando dedicada ao Desenvolvimento}

O hardware alvo neste trabalho é uma unidade dedicada ao desenvolvimento eletrônico de motores denominada Flex-ECU, que possui programação em código open source, conforme descrito na seção 3.1.1. Atribui-se o termo "flexível" ao nome da ECU devido à sua grande abrangência de controle, concebida para simulação e desenvolvimento de estratégias automotivas. As especificações de hardware da plataforma de desenvolvimento descrita acima estão exibidas na Tabela 3.1.

Tabela 3.1 - Especificações do hardware da unidade de comando utilizada para o desenvolvimento ETAS/Bosch MEDC17 FlexECU Gasoline (Dedicada aos motores SI).

\begin{tabular}{|c|c|c|}
\hline \multicolumn{3}{|c|}{ FlexECU - versão “Gasolina”, possui hardware projetado para motores de ignição por centelha (SI Otto) } \\
\hline Núcleo da ECU & Microcontrolador & Infineon Tri-Core Tc1797 - 32 bits \\
\hline \multirow{4}{*}{ Memória } & Frequência de clock & $180 \mathrm{MHz}$ \\
\hline & Flash & 1.8 MB Código; 215KB Dados \\
\hline & RAM & $43 \mathrm{~KB}$ \\
\hline & EEPROM & 2KB (emulação) \\
\hline \multirow{7}{*}{ Entradas } & Tensão de alimentação & $8-16 \mathrm{~V}$ \\
\hline & Digitais & 8 (+2 dedicadas à IGN e Flash) \\
\hline & Frequência & 4 \\
\hline & $\begin{array}{l}\text { Entradas para leitura de deslocamento do } \\
\text { virabrequim e comando de válvulas }\end{array}$ & Hall \\
\hline & Entradas analógicas & 30(11 passivas e 19 ativas) \\
\hline & Sensor de oxigênio (Sonda Lambda) & 2 LSU \\
\hline & Sensores de detonação (Knock) & Até 4 \\
\hline \multirow{7}{*}{ Saídas } & PWM (ㅁulse Width Modulation) & 20 Low-Side ${ }^{24} ; 1$ High-Side ${ }^{25}$ \\
\hline & Digitais & 11 Low-Side \\
\hline & Drivers ponte $\mathrm{H}$ & 3 \\
\hline & Drivers válvulas de fluxo de massa & 2 \\
\hline & Relés principais de energia & Externo \\
\hline & Drivers de ignição & Até 8 (bobina externa) \\
\hline & Drivers de injetores & Até 8 (GDI ou PFI) \\
\hline Comunicação & CAN & 3 canais CAN \\
\hline $\begin{array}{l}\text { Medição e } \\
\text { Calibração }\end{array}$ & Protocolo CAN & $\mathrm{XCP}$ \\
\hline
\end{tabular}

Fonte: Adaptado de (ETAS, INC).

\footnotetext{
${ }^{24}$ Termo da língua inglesa utilizado para se referir à modulação por largura de pulso em que o ciclo de trabalho tem a comutação realizada para potencial negativo.

25 Idem ao anterior, porém voltado para o potencial positivo.
} 
Seu hardware foi previsto para o comando de um conjunto de motores, sendo esta dedicada aos que empregam o princípio do ciclo Otto, que podem possuir diferentes subsistemas, por exemplo, que contenham maior quantidade de cilindros, sobrealimentação (compressores e turbo-compressores) e/ou injeção direta de combustível.

Toda a programação de acesso ao hardware à nível de máquina da FlexECU é feita de forma detalhada por um programa chamado LLSW (Low Level SoftWare), que não é acessível para edição, mas apenas para parametrização (Medição e/ou controle). Nele também está contido o sistema operacional de tempo real RTOS chamado RTA-OSEK. A comunicação com o LLSW realiza-se a partir da utilização de funções API's (Aplicattion Programming Interface), estas funções realizam chamadas para leitura de sinais e envio dos parâmetros necessários no acionamento de atuadores. O software de aplicação (ASCET) tem a função de controlar todo o comportamento do LLSW e seus respectivos drivers.

\subsubsection{Utilização de um medidor de composição comercial}

Para realização do primeiro gerenciamento do motor com a ECU de desenvolvimento, aplicando-se o combustível E95 (etanol hidratado com até 5\% de água), adotou-se uma estratégia conservadora, que consistiu em buscar minimamente os parâmetros originais de tempo de injeção e ângulo de ignição, minimamente e não precisamente, pois, seria uma árdua tarefa de engenharia reversa realizar este trabalho de maneira precisa e fiel. Para isto, foi preciso um levantamento de dados, a partir de um ensaio realizado em dinamômetro com o

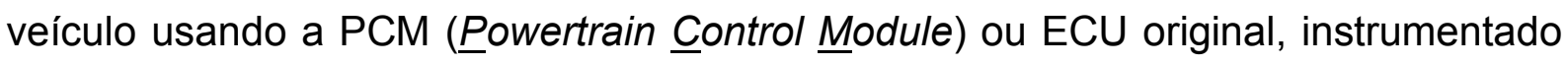
para aquisição de tais sinais como parâmetros iniciais. O propósito deste experimento foi gerar uma referência de operação segura para a integridade do motor do veículo utilizado. Com isto, uma ligeira adequação para estratégia speed density pôde ser realizada de maneira indireta, pois tal ajuste depende ainda da conservação das condições de pressão atmosférica em que foi realizada a calibração.

Com a busca de uma estratégia de controle de avanço direto, foi desenvolvido um FFS (Flex-Fuel Sensor.) integrado, o qual está representado na Figura 3.7. 
Figura 3.7 - Identificação do dispositivo eletrônico Br-FFS (Flex-Fuel Sensor) com calibração brasileira.
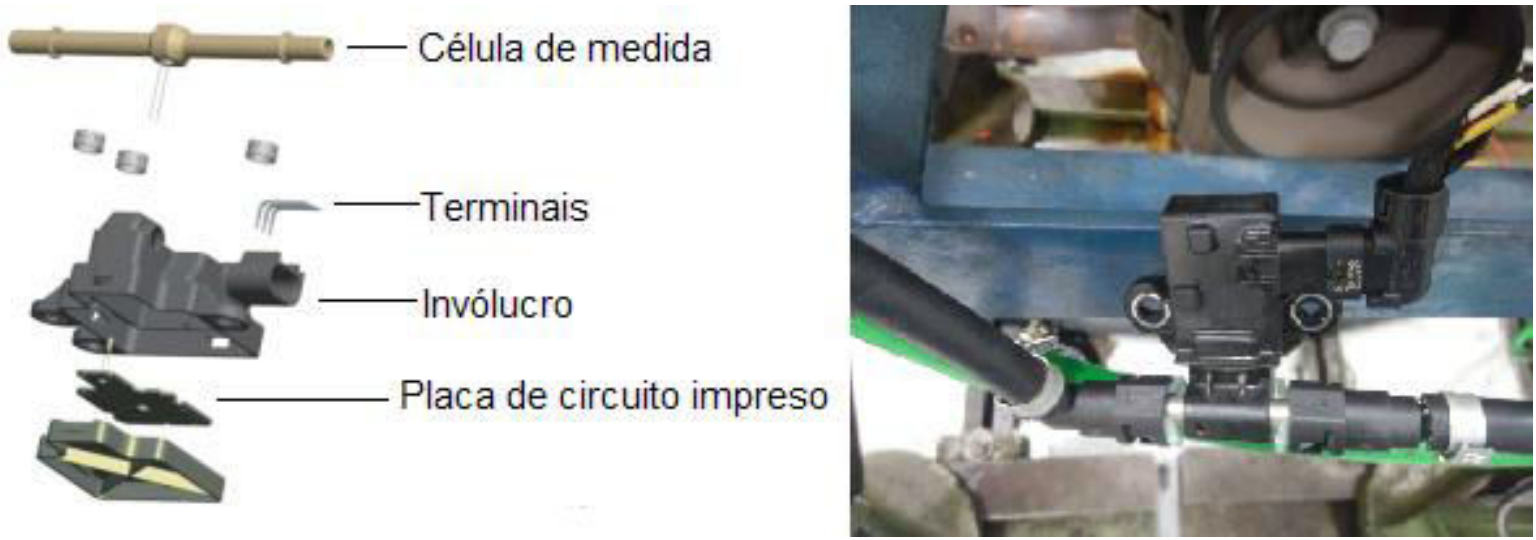

Fonte: Adaptado de (CONTINENTAL, 2014).

O FFS pode ser instalado diretamente na linha de alimentação entre o reservatório de combustível e o injetor para medir a concentração do tipo do combustível antes que este atinja o injetor e seja liberado à câmara de combustão. O sensor FFS estima a concentração de etanol no combustível em tempo real usando uma correlação baseada na permissividade, condutividade e temperatura do combustível que flui por sua célula de medida (MCKAY, et al., 2012). Além disso, geralmente o controle da mistura $\mathrm{A} / \mathrm{C}$ não explora bem a flexibilidade do ponto de referência do sensor de oxigênio, pois, um dos sensores mais empregados no controle $\mathrm{A} / \mathrm{C}$ em motores SI é o de banda estreita, o qual possui um comportamento binário.

O FFS é um dispositivo eletrônico que mede a porcentagem de etanol e a temperatura do combustível antes que ele atinja a galeria de distribuição (flauta). O sensor possui um circuito oscilador que gera uma onda quadrada em sua saída. $\mathrm{O}$ tempo de saturação (Figura $3.8, \mathrm{~A}$ ) varia com a temperatura e o período total do sinal varia com a porcentagem do teor de etanol.

Figura 3.8 - Características do perfil de sinal de saída do sensor de composição Br-FFS. 
PERFIL DO SINAL PROVENIENTE DO FFS
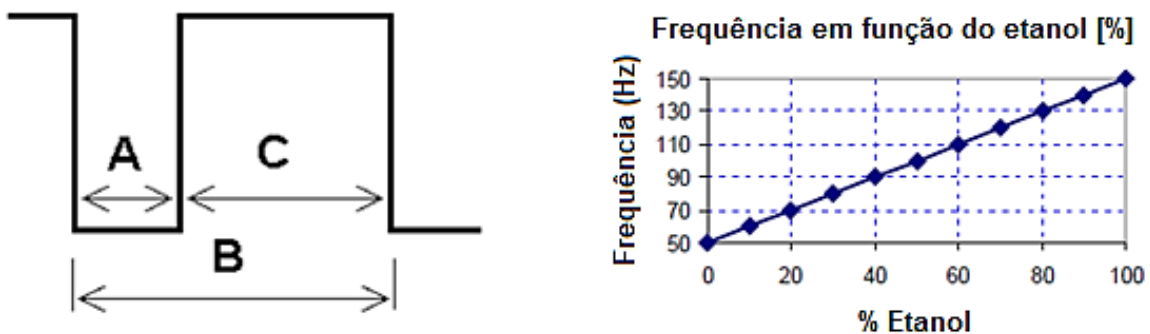

A - Tempo de saturação do ciclo de trabalho (temperatura)

B - Período total do ciclo de trabalho (\% Etanol)

C - Tempo de corte do ciclo de trabalho

Fonte: Adaptado de (CONTINENTAL, 2014).

A concentração do volume de etanol é uma função da frequência do período total $T_{\text {total }}$ (Figura 3.8, B) do sinal do sensor, dado pela Eq. (3.1).

$$
\text { volume }[\%]_{\text {etanol }}=\frac{1}{T_{\text {total }}}-50=\text { Freq }_{\text {Total }}-50
$$

Assim, um sinal de frequência igual a $145 \mathrm{~Hz}$ indica o combustível E95, e aproximadamente $77 \mathrm{~Hz}$ denota o uso da gasolina comum E27. Como a constante dielétrica varia diretamente com a temperatura, conforme abordado na APÊNDICE C - DETERMINAÇÃO ONLINE DA COMPOSIÇÃO DO COMBUSTÍVEL, este aspecto também deve ser levado em consideração na estimação do teor de etanol. A Figura 3.9 exibe o efeito que a temperatura exerce sob a constante dielétrica.

Figura 3.9 - Representação do efeito causado pela temperatura sob a constante dielétrica.

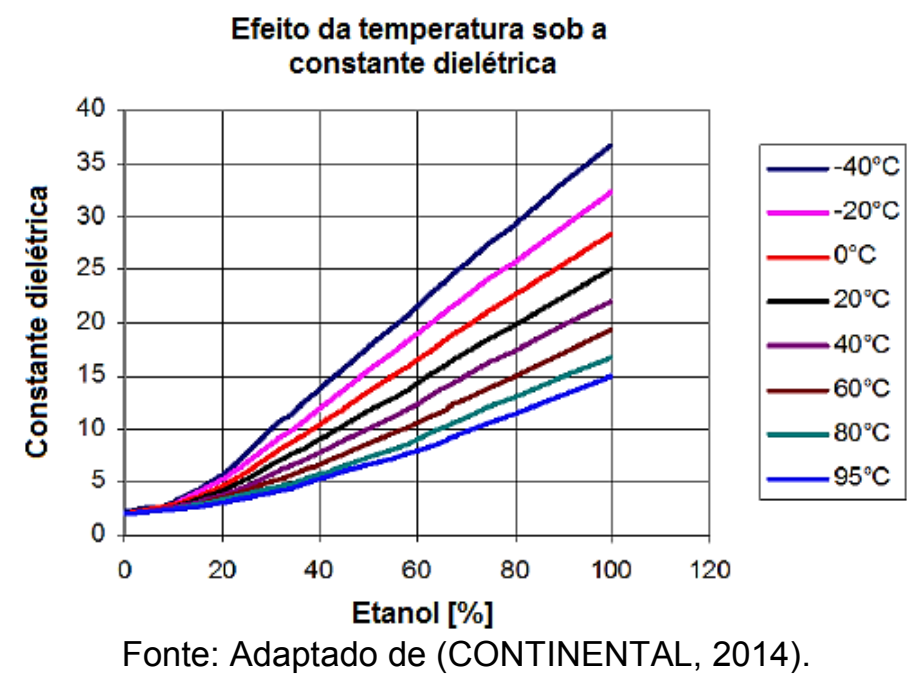

Para a medida da temperatura do combustível que flui através do sensor, realiza-se o cálculo de conversão descrito pela Eq. (3.2). 


$$
\text { Temp } \text { combustivel }=\left[\left(T_{\text {Sat }}-1 \cdot 10^{-3}\right) \cdot 41.25\right]-40
$$

onde Temp combustivel é medida em ${ }^{\circ} \mathrm{C}, T_{\text {Sat }}$ o período de saturação do ciclo de trabalho (nível baixo do sinal), e outros fatores de ajuste para correção em função do tempo (CONTINENTAL, 2014).

O sensor dielétrico de composição do combustível foi inserido na linha de baixa pressão do combustível anteposto ao tubo da galeria de distribuição aos injetores. A vantagem principal de utilizar o sensor é a disponibilidade de leitura da concentração de etanol em tempo real para a ECU. O sinal de medida do sensor permite uma estratégia em malha aberta de interseção dos mapas utilizados para o controle de avanço de ignição e duração do pulso de injeção. O sensor realiza a medição em um ponto imediatamente próximo à galeria de distribuição do combustível, de onde o mesmo é injetado para se misturar com o ar durante a admissão. Isto elimina a necessidade de um algoritmo com técnicas de aprendizado reativo empregado anteriormente para estimação da composição do combustível utilizado, como descrito por (AHN, 2011) e (MCKAY, et al., 2012).

A partir da utilização da API para leitura de sinais de frequência Get_PWM_in, foi selecionado para a leitura da porcentagem de volume de etanol, o pino I_F_DF22 na variável de calibração etsensor_pin. Esta API possibilita o acesso aos seguintes parâmetros:

tiPer como endereço da variável de aplicação do LLSW que armazena o período do sinal lido no pino I_F_DF22.

rduty como endereço da variável de aplicação do LLSW que armazena o ciclo de trabalho do sinal lido no pino I_F_DF22.

stErr como endereço da variável de aplicação do LLSW que armazena a string de erro de leitura no pino I_F_DF22.

A Figura 3.10 mostra o diagrama de blocos do módulo desenvolvido para a leitura de sinais do FFS com a API descrita e um pseudo-código para uma melhor compreenssão. 
Figura 3.10 - Módulo para leitura da frequência do sinal proveniente do sensor de volume de etanol.

Module:PWM_READ

v2

pg $1 / 1$

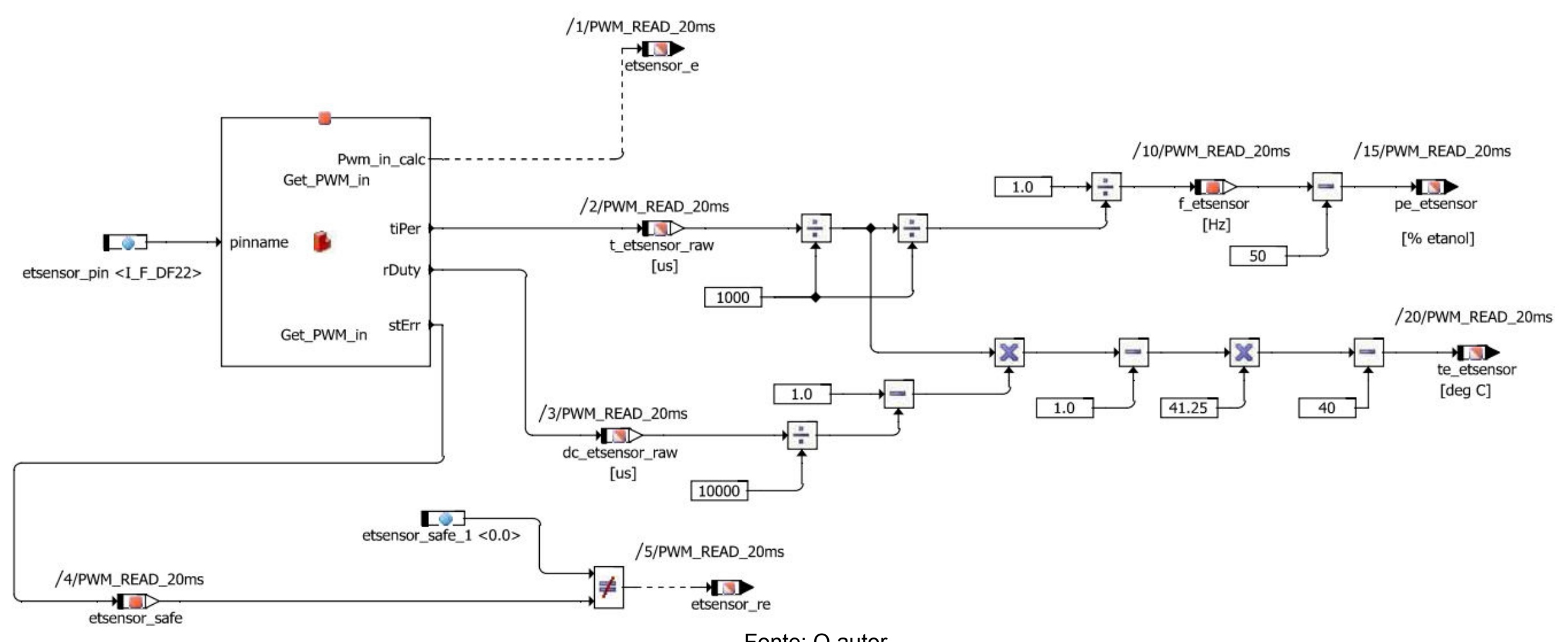

Fonte: $\mathrm{O}$ autor.

t_etsensor_raw = tiPer(us); dc_etsensor_raw = rduty(us); etsensor_safe=stErr; //

f_etsensor $(\mathrm{Hz})=1 /\left(t \_\right.$etsensor_raw/1000000); pe_etsensor $=f$ _etsensor $-50 ; / /$

te_etsensor $=\{[(1-$ dc_etsensor_raw/1000) * (t_etsensor_raw/1000) - 1] * 41.25\}-40;// 


\subsubsection{Descrição do motor utilizado}

O motor utilizado funciona por aspiração natural e é um modelo de produção

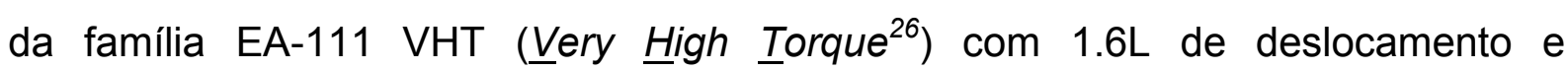
disposição cilíndrica $14^{27}$, conforme a Figura 3.11.

Figura 3.11 - Motor utilizado EA - 111 VHT (CCRA) - Flex-Fuel (etanol e/ou gasolina).

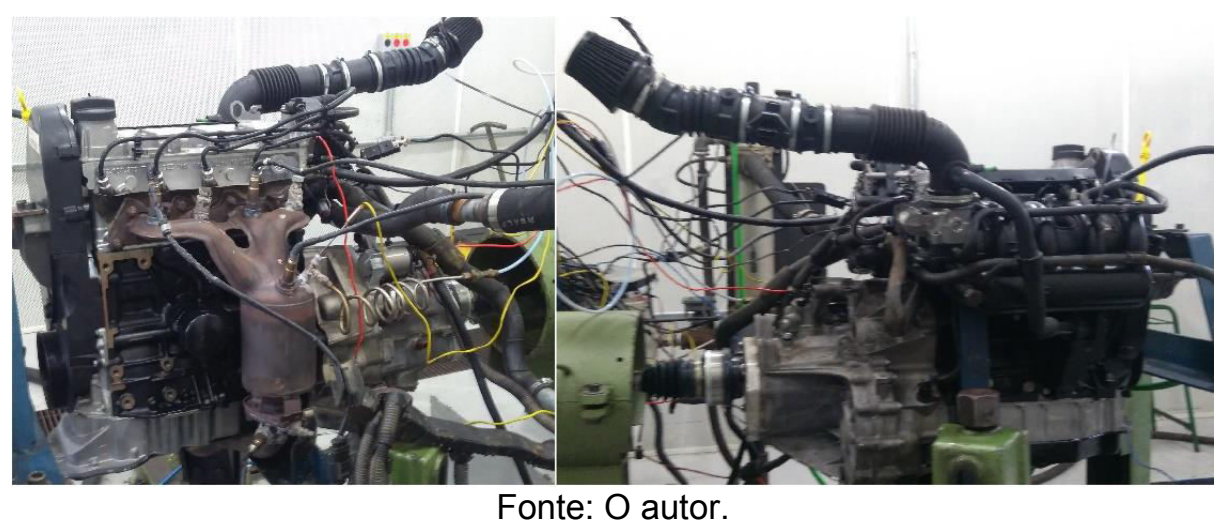

O motor apresentado é originalmente Flex-Fuel e possui taxa de compressão 12.1:1, isto evidencia um projeto voltado para a utilização de combustíveis com maiores concentrações de etanol, em função da legislação brasileira impor que a concentração desse combustível na gasolina comum seja de praticamente $30 \%$. Assim sendo, mesmo quando a opção da gasolina é realizada, existe a presença significativa do combustível originário da cana-de-açúcar. As demais especificações do motor descrito estão listadas na Tabela 3.2.

Tabela 3.2 - Especificações do motor utilizado na aplicação dos testes.

\begin{tabular}{|c|c|}
\hline Nomenclatura & EA - 111 VHT (CCRA) - etanol e/ou gasolina \\
\hline Quantidade de cilindros & 4 (quatro) em linha \\
\hline Quantidade de válvulas & 8 (oito), 2 (duas) por cilindro \\
\hline Eixo de comando & $12,1: 1$ \\
\hline Taxa de compressão & $1598 \mathrm{~cm}$ \\
\hline Deslocamento volumétrico & SOHC (comando de válvulas simples situado no cabeçote) \\
\hline Potência Máxima (a nível do mar) & $104 \mathrm{cv}(\mathrm{A})$ e 101cv (G) @ 5250 RPM \\
\hline Torque Máximo (a nível do mar) & $76,6 \mathrm{kgfm}(\mathrm{A})$ e 15,4 kgfm (G) @ 2500 RPM \\
\hline Diâmetro x Curso do êmbolo & Multiponto Bosch ME 7.5.30 \\
\hline ECU Original & Indireta multiponto sequencial 1-3-4-2 (MPFI) \\
\hline Modo de injeção & Acionamento banco a banco - 2 (duas) bobinas de ignição dupla acionando \\
simultaneamente os cilindros 1-4 e 2-3(centelha perdida)
\end{tabular}

Fonte: Adaptado do manual do fabricante.

${ }^{26}$ Nomenclatura comercial dada a família de motores EA 111 que receberam uma série de aprimoramentos da VW do Brasil em meados de 2008 a 2009.

27 Termo utilizado para se referir à disposição e a quantidade de cilindros do motor em questão, neste caso, um motor de 4 (quatro) cilindros dispostos em linha. 
Esta taxa de compressão intermediária fixada em 12,1:1 é uma das características construtivas do motor que permite o melhor aproveitamento da aplicação do gerenciamento bicombustível.

\subsubsection{Freios dinamométricos utilizados}

Os resultados deste trabalho foram levantados em dois freios dinamométricos diferentes. Durante a primeira fase, o motor encontrava-se integrado a um veículo VW modelo Gol, ano 2008, e os testes foram realizados no dinamômetro de chassis do IEE (Instituto de Energia e Ambiente) USP, Figura 3.12.

Figura 3.12 - Veículo de testes operando em um dinamômetro de chassi do IEE USP (Instituto de Energia e Ambiente da Universidade de São Paulo).

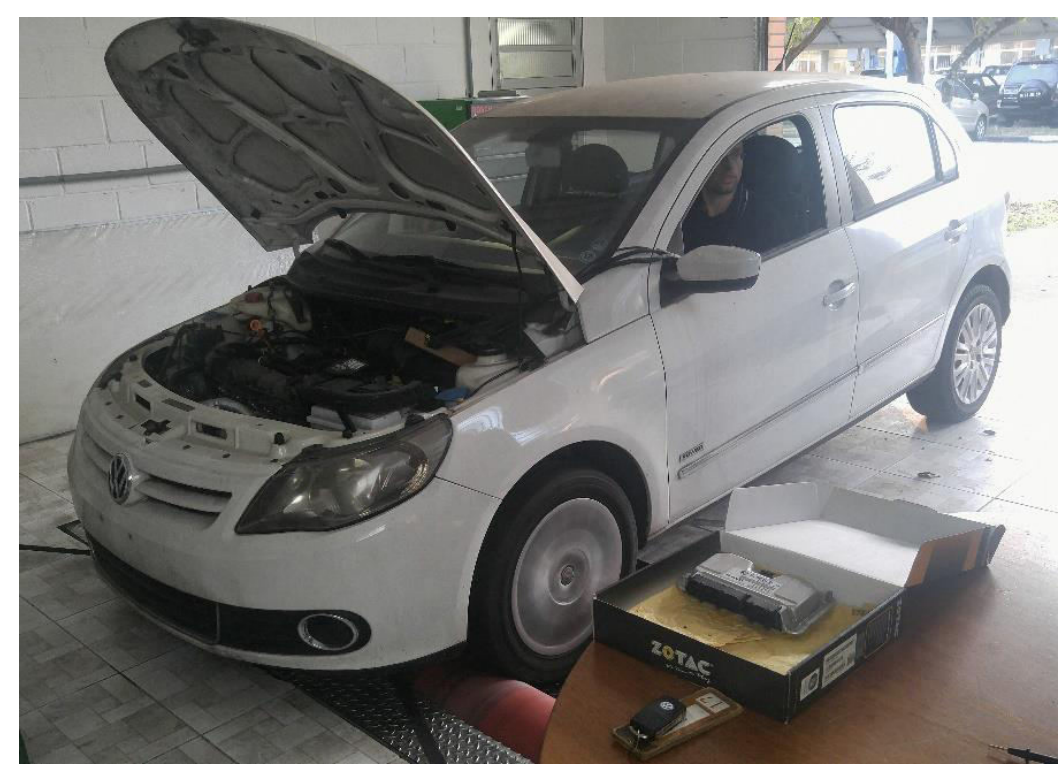

Fonte: $\mathrm{O}$ autor.

Este dinamômetro possui um sistema de controle $\mathrm{NAPRO}^{\mathrm{TM}}$ e utiliza uma aplicação eletromagnética para frenagem do rolo.

Os últimos resultados foram realizados em um banco de testes dinamométrico hidráulico Shenck ${ }^{\mathrm{TM}}$ modelo D360-1E com controlador elétrico automático sptronic ${ }^{\mathrm{TM}}$ ECAT do Instituto de Pesquisas Tecnológicas (IPT) do Estado de São Paulo, Figura 3.13 . 
Figura 3.13 - Vista do motor utilizado acoplado ao dinamômetro hidráulico Shenck modelo D360-1E instalado na sala 1 do Laboratório de motores do Instituto de Pesquisas Tecnológicas de São Paulo.

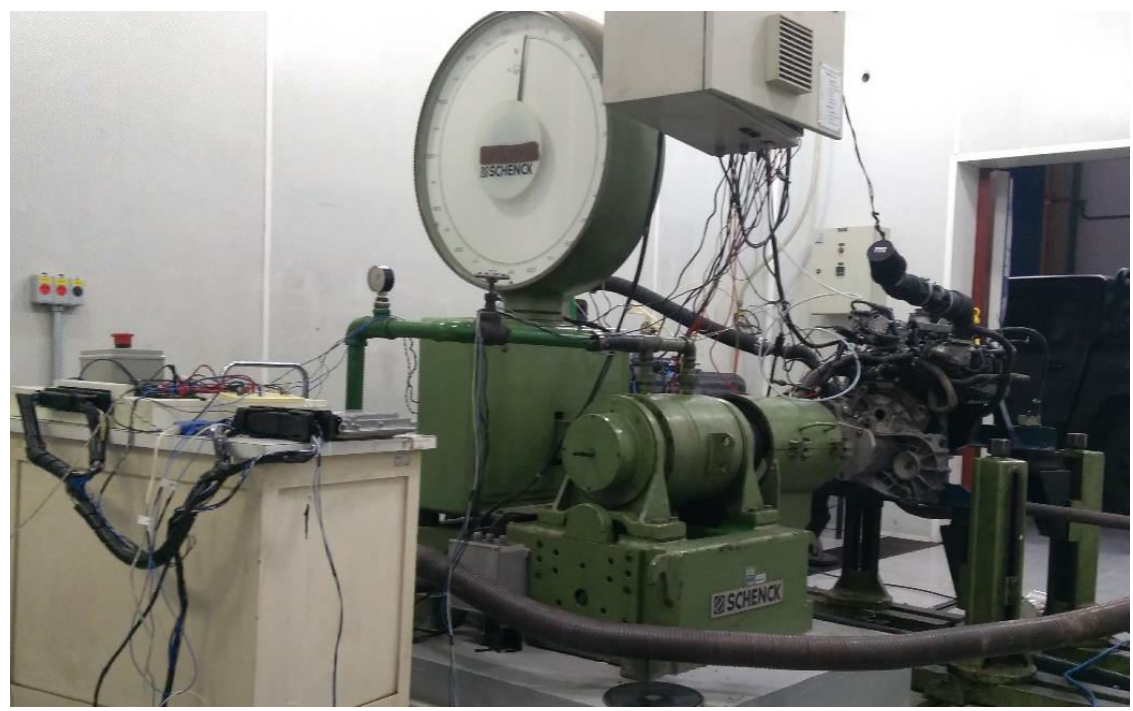

Fonte: $\mathrm{O}$ autor.

O banco dinamométrico apresentado utiliza a água como fluido de aplicação para frenagem do motor, possuindo como medida a reposta de um transdutor do tipo célula de carga. Os componentes funcionais deste dinamômetro são representados na Figura 3.14.

Figura 3.14 - Representação esquemática de um dinamômetro hidráulico Schenck série D com comando elétrico.

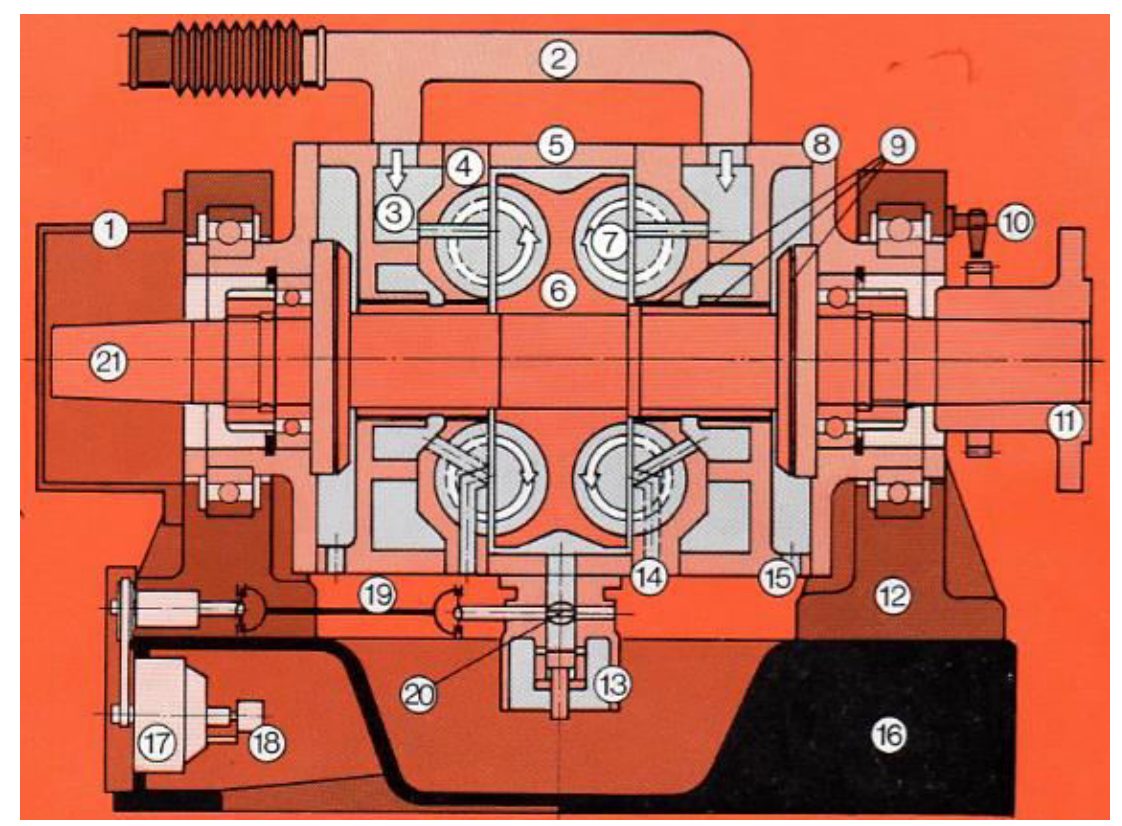

1 Tampa; 2 Entrada de água; 3 Câmara circular; 4 Estator; 5 Carcaça; 6 Rotor duplo; 7 Câmara de turbilhonamento; 8 Flange; 9 Galerias de retenção; 10 Medidor de rotação; 11 Flange de acoplamento; 12 Suporte; 13 Válvula de controle; 14 Orifício de aeração; 15 ;16 Rack de máquina;17 Válvula motorizada; 18 Sensor de posição; 19 Eixo-cardã; 20 Válvula de regulagem; 21 Ponta de eixo utilizada para equilíbrio de apoio das flanges de acoplamento. Fonte: Adaptado do manual do fabricante. 
Por se tratar de um dinamômetro de construção e concepção antiga, encontrou-se a necessidade de aferição e levantamento da incerteza de medida para o torque indicado pelo dinamômetro hidráulico Shenck modelo D360-1E instalado na sala 1 do Laboratório de motores do Instituto de Pesquisas Tecnológicas de São Paulo. Os resultados do levantamento após aaferiação e calibração estão representados na Figura 3.15.

Figura 3.15 - Aferição do erro de medida do dinamômetro hidráulico Shenck modelo D360-1E instalado na sala 1 do Laboratório de motores do Instituto de Pesquisas Tecnológicas de São Paulo.

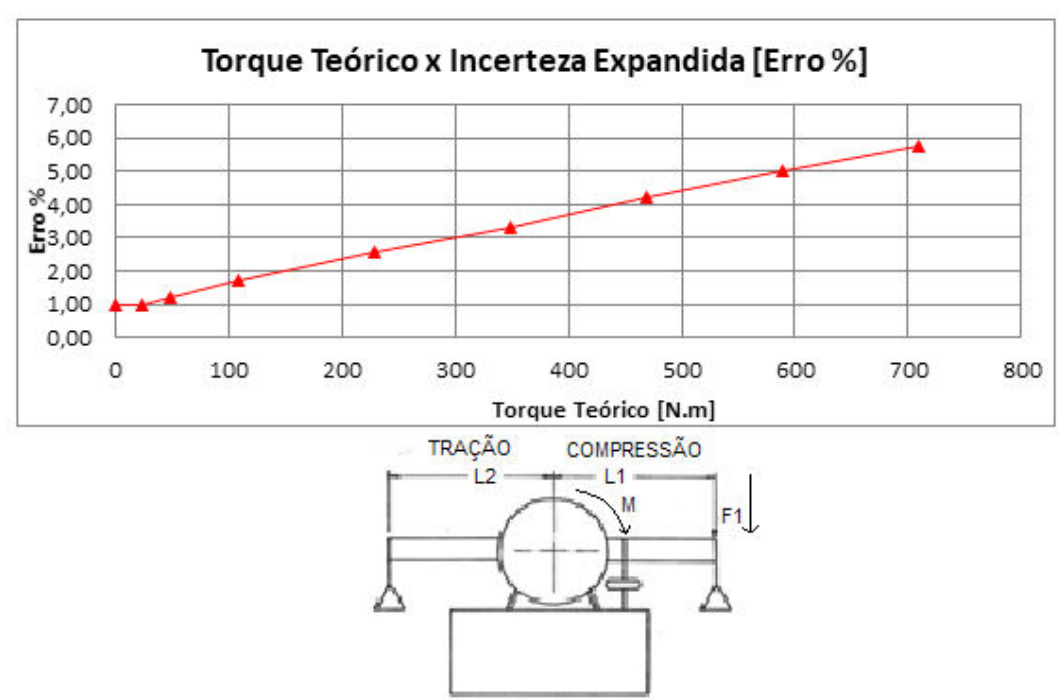

\begin{tabular}{|c|c|c|}
\hline $\begin{array}{c}\text { TORQUE } \\
\text { Teórico } \\
{[\text { N.m] }}\end{array}$ & $\begin{array}{c}\mathbf{U} \\
{[\mathrm{N} . \mathrm{m}]}\end{array}$ & $\begin{array}{c}\mathbf{U} \\
{[\%]}\end{array}$ \\
\hline 0,00 & 0,98 & 0,00 \\
\hline 24,02 & 0,96 & 4,01 \\
\hline 48,04 & 1,22 & 2,55 \\
\hline 108,08 & 1,72 & 1,59 \\
\hline 228,17 & 2,57 & 1,13 \\
\hline 348,25 & 3,34 & 0,96 \\
\hline 468,34 & 4,20 & 0,90 \\
\hline 588,43 & 5,00 & 0,85 \\
\hline 708,51 & 5,73 & 0,81 \\
\hline
\end{tabular}

Fonte: Colaboradores do Instituto de Pesquisas Tecnológicas (IPT) de São Paulo.

O torque teórico foi calculado com a utilização de braços de apoio que tem por função aplica os prinicpios inerciais de Newton, onde o desequilibrio de forças nos dará o momento resultante entre elas $M_{\text {teórico }}$ expresso pela eq. (3.3), com a finalidade de aferir-se a conversão do deslocamento da célula de carga para a calibração do torque convertido no sistema eletrônico sptronic ${ }^{\mathrm{TM}}$.

$$
M_{\text {teórico }}=(m \cdot g) \cdot L_{x}[N m]
$$

onde $m$ representa a massa colocada para aplicar a força de compressão, $g$ a aceleração da gravidade e $L$ o comprimento do braço em questão. 


\subsection{MÉTODOS UTILIZADOS NA OBTENÇÃO DO SINAL DE RELAÇÃO LAMBDA E DO ÍNDICE DE DETONAÇÃO PROVENIENTE DO ACELERÔMETRO}

\subsubsection{Utilização inicial de uma interface de testes Lambda}

A sonda lambda universal, descrita na seção 2.3.2, requer um hardware que controle sua referência de oxigênio para medição com base na relação estequiométrica do combustível utilizado e que também efetue o controle de aquecimento do sensor. Para esta função, primeiramente foi utilizada a interface LA4

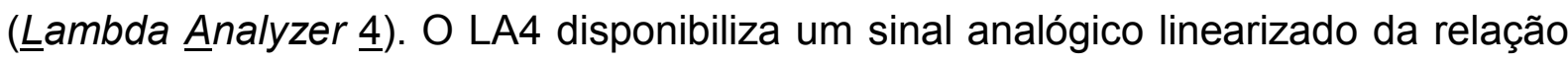
lambda medida através de um sensor de oxigênio de banda larga amplificada (LSU/UEGO).

O dispositivo pode operar de maneira stand alone e possibilita monitorar tanto a relação de equivalência $\lambda$ (lambda), como a corrente de bombeamento do sensor de oxigênio via display, também disponibiliza um sinal de saída com opção de ajustes de ganho e offset. Este parâmetro foi utilizado como principal medida para o controle A/C (lambda) em malha fechada nas fases iniciais do projeto, sendo monitorada na ECU de desenvolvimento via conversão A/D (ㅁnalógica/Digital). Além disso, é possível ajustar as correções de tratamento para a corrente de bombeamento proveniente de sensores de oxigênio com banda larga com em função das características do combustível utilizado, possibilitando maiores afinações de medida.

\subsubsection{Obtenção e conversão da medida da corrente de bombeamento em um sensor de banda larga}

A plataforma de desenvolvimento utilizada também possui de forma integrada (contido no mesmo invólucro) o hardware necessário para medição e controle do

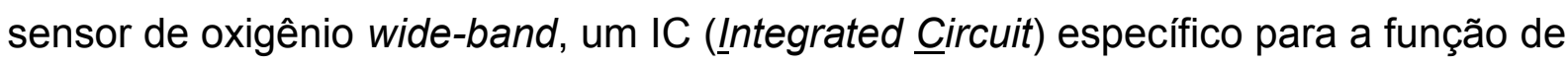
medida para versões recentes de sonda com banda larga (LSU 4.2/ 4.9) denominado CJ125, que é controlado pela unidade de comando via comunicação SPI (Serial Peripheral Interface ${ }^{28}$ ). O aquecimento da sonda também pode ser controlado pela ECU através da modulação PWM. O diagrama de conexões entre o IC e a ECU está representado na Figura 3.16.

\footnotetext{
${ }^{28}$ Interface serial periférica.
} 
Figura 3.16 - Diagrama de conexões para controle e medida de um sensor de oxigênio wide-band através de uma interface CJ125 conectada à uma ECU.

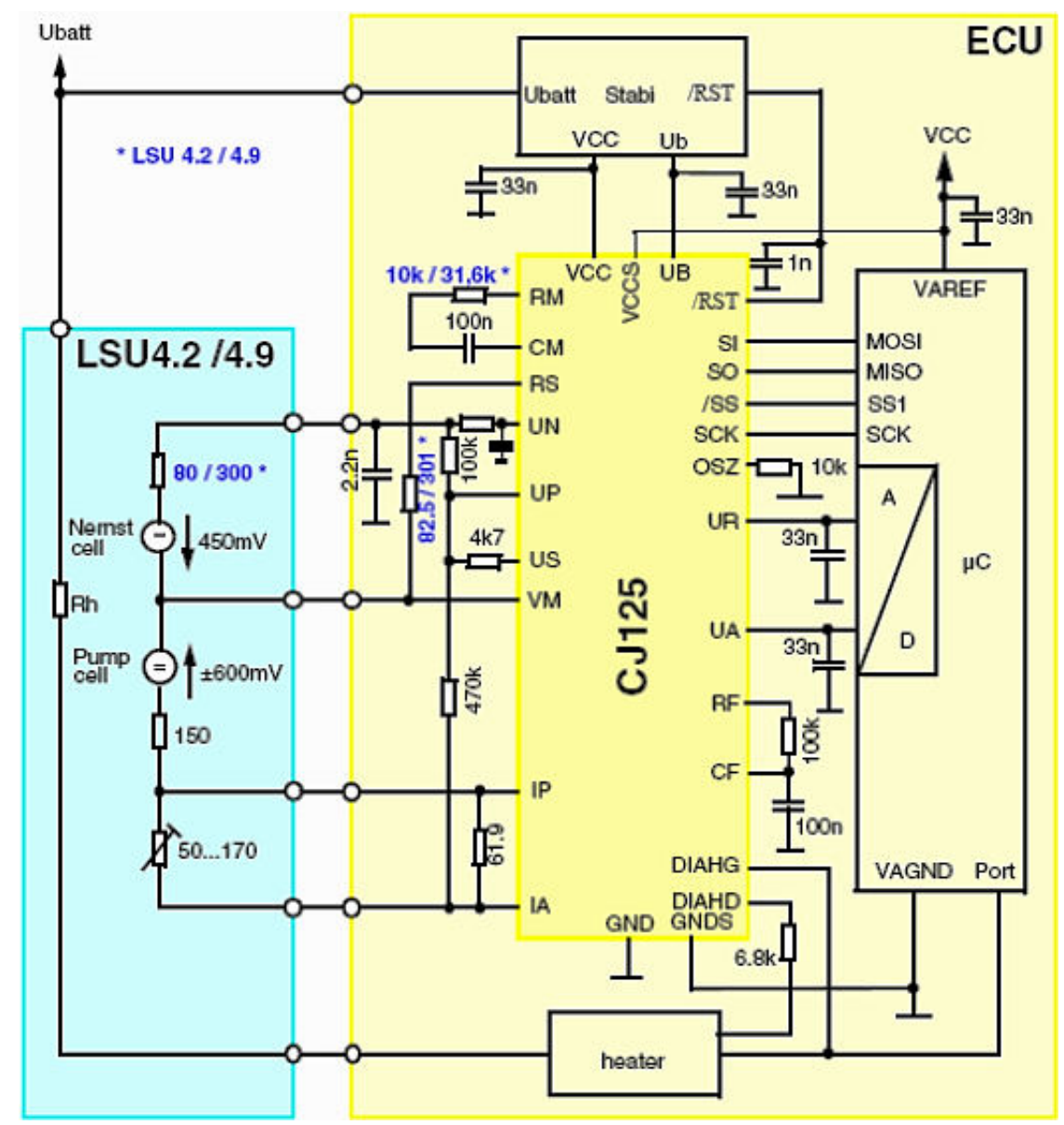

Fonte: Extraído de (ROBERT BOSCH GMBH, 2006).

A FlexECU possui no seu invólucro o hardware para medição e controle de sensores de oxigênio wide-band. O aquecimento da sonda é controlado pela ECU por modulação PWM aplicada à sua resistência de aquecimento. A utilização desse hardware integrado da unidade de comando possibilita o objetivo de tornar o projeto independente da medida realizada pelo analisador lambda LA4 ao utilizar-se um sensor de oxigênio com banda larga. Foi desenvolvido um módulo de software para efetuar o aquecimento da LSU, controle, comunicação e leitura da corrente de bombeamento medida através do CJ 125 e diagnose do mesmo, ilustrado na Figura 3.17 . 
Figura 3.17 - Módulo para leitura e controle do sensor de Banda larga LSU_OUT_V2.

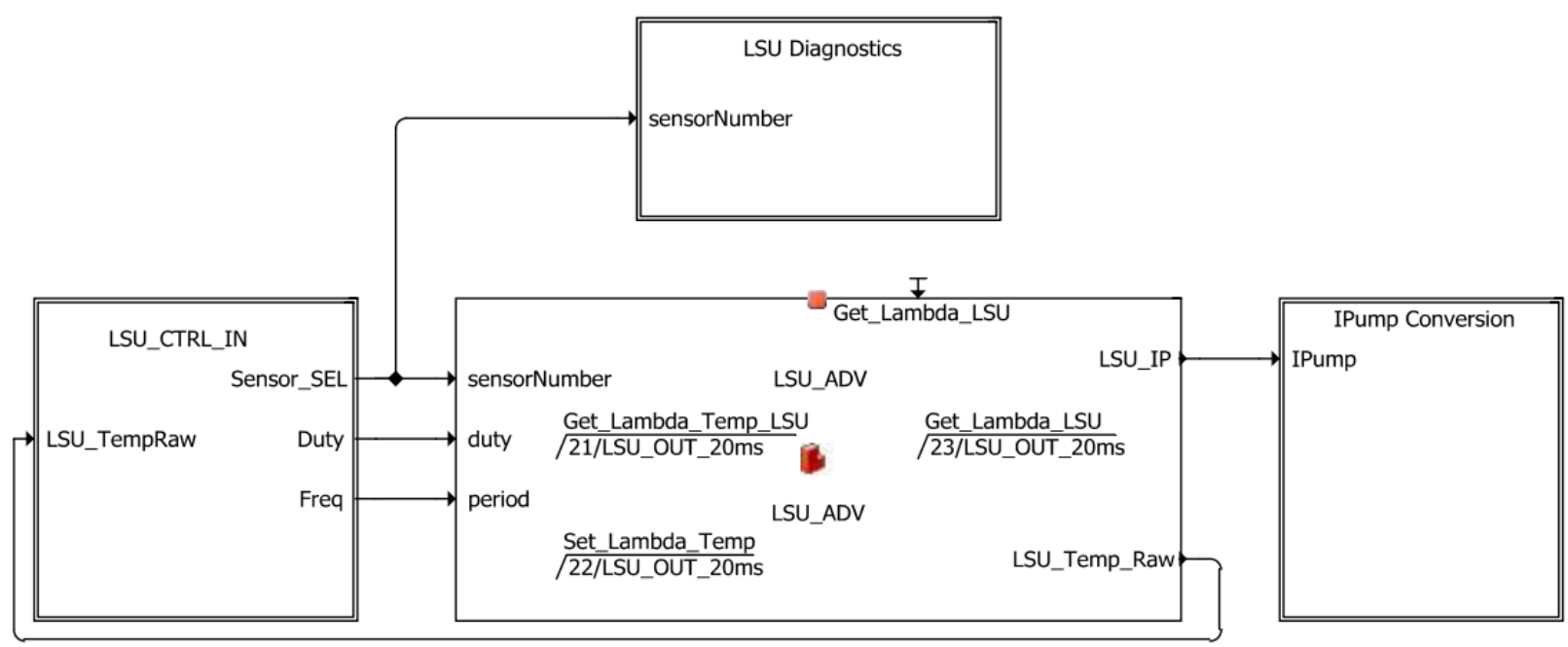

Fonte: O autor.

O bloco central denominado LSU_ADV é uma classe criada para coordenar 3 (três) funções API's que realizam as rotinas de leitura da temperatura do sensor (Get_Lambda_Temp_LSU), acionamento de seu aquecedor integrado (Set_Lambda_Temp) e da corrente de bombeamento sem tratamento (Get_Lambda_LSU).

A hierarquia LSU_CTRL_IN (destacada na seção 3.5.4) trata a medida LSU_Temp_Raw e ajusta a temperatura do sensor através de uma malha PID (Proporcional Integral Derivativa) na qual é configurado o setpoint desejado, controlando também a frequência e o duty cycle do PWM para o aquecedor integrado da célula de medida da sonda.

A segunda hierarquia denominada LSU Diagnostics (destacada na seção 3.6.1) realiza as leituras das funções de diagnose do CJ 125 , disponibilizando o status dos pinos de medida do sensor e dos pinos de acionamento PWM em seu aquecedor integrado.

A terceira e última hierarquia Ipump Conversion recebe o valor da corrente de bombeamento colhida do sensor de oxigênio através da classe LSU_ADV e o converte em relação de equivalência lambda a ser utilizada como referência para o controle A/C (lambda) em malha fechada.

Esta hierarquia foi criada com 4 opções de conversão para a corrente de bombeamento. Segundo o manual do LLSW, para a sonda LSU modelo ADV, 
existem dois mapas específicos de conversão utilizados para o combustível E85 e para a gasolina E0. Implementou-se também a curva de conversão lambda da corrente de bombeamento para o sensor de oxigênio LSU modelo 4.9 que independe do combustível aplicado. No total são 3 mapas de conversão: 2 (dois) para a utilização da LSU ADV e 1 para a da LSU4.9, a quarta opção vem da interpolação média entre os dois mapas utilizados para a LSU ADV. Foi implementada ainda uma tabela IPTAbleMultiplier_1 para aplicação posterior da correção da corrente de bombeamento lida em função da pressão absoluta dos gases de escape. Aplicou-se uma tabela de compensação da corrente de bombeamento, na qual foi realizado um ajuste empírico referenciado pela medida simultânea proveniente do analisador lambda LA4. O diagrama de blocos da hierarquia Ipump Conversion está ilustrado pela Figura 3.18. 
Figura 3.18 - Hierarquia Ipump Conversion, utilizada para a conversão da corrente de bombeamento em relação de equivalência (lambda).

HIERACHY: IPUmp Conversion

pg: $1 / 1$

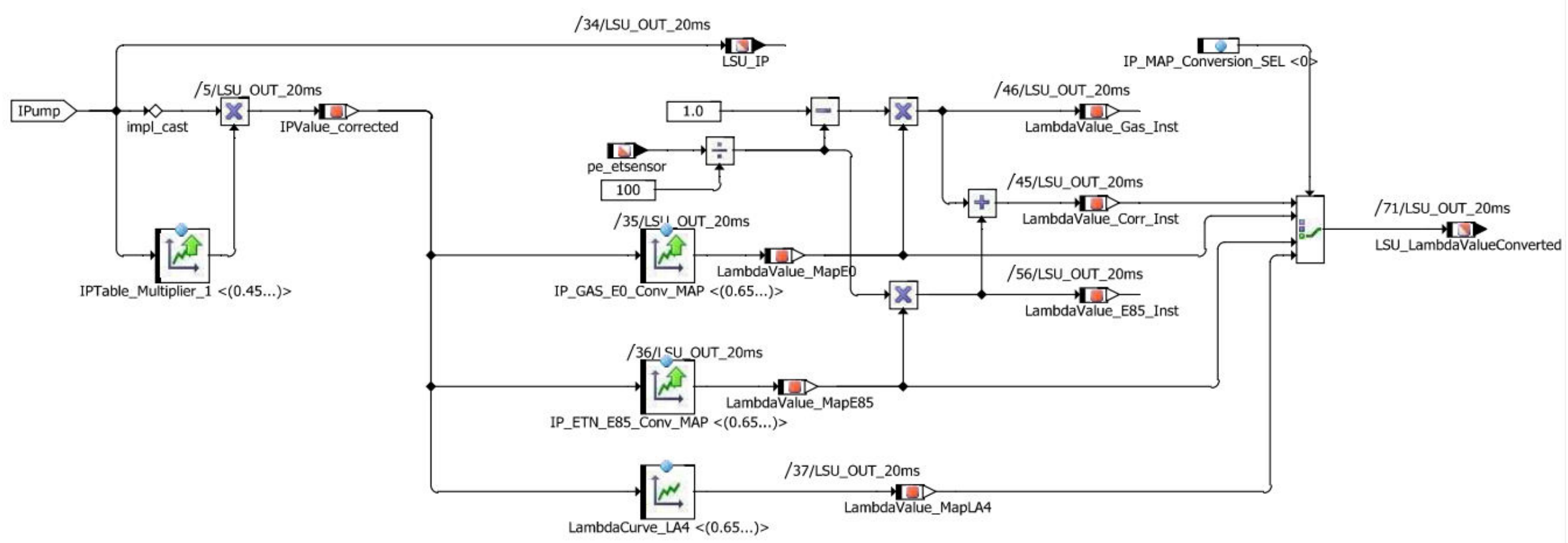

Fonte: O autor. 


\subsubsection{Monitoramento da tensão Nernst em um sensor de banda estreita}

O sensor de oxigênio de banda estreita não requer cuidados tão complexos como o sensor de banda larga. Por esta razão, é possível medir a relação de equivalência lambda diretamente através da tensão da célula Nernst do sensor, medindo sua tensão de saída através de uma entrada analógica da Flex-ECU, levando em conta apenas o tempo de amostragem e resolução de sinal necessários.

Ao utilizar-se apenas uma entrada passiva para leitura, não é possível determinar, de forma precisa, se o sinal do sensor pode ser considerado válido, pois, neste caso é inexistente a indicação da temperatura de sua célula de medida. Para contornar este problema, foi introduzido um circuito divisor de tensão, como mostra a Figura 3.19.

Figura 3.19 - Circuito utilizado para condicionamento da tensão Nernst proveniente do sensor de oxigênio com banda estreita.

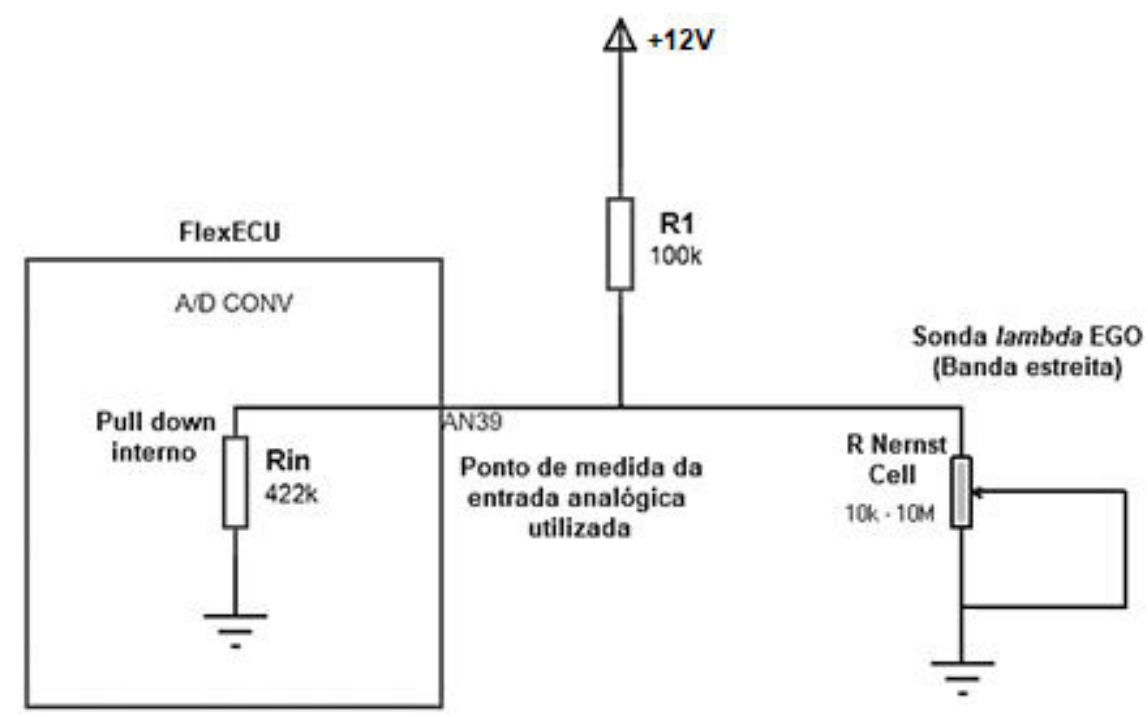

Fonte: O autor.

Segundo (TEXAS INSTRUMENTS, 2013), normalmente um sensor de oxigênio com banda estreita terá uma impedância menor que $10 \mathrm{~K} \Omega$ quando estiver operando em temperaturas entre $300^{\circ} \mathrm{C}$ e $500^{\circ} \mathrm{C}$. Quando um sensor Lambda está abaixo dessas temperaturas, sua impedância pode ser maior que $10 \mathrm{M} \Omega$.

O momento em que o sensor estiver frio a sua resistência será alta como a de um circuito aberto para o conversor A/D da ECU. Desta maneira, a queda de tensão causada pela mudança de resistência do sensor pode ser interpretada pela ECU como confirmação da validade de medida do mesmo, com a certeza de que este esteja adequadamente aquecido. 


\subsubsection{Utilização de um driver para a detecção remota de detonação}

O papel fundamental do detector de detonação é disponibilizar uma interpretação detonação que permite a discriminação entre o ruído vibracional normal do motor do ruído característico que ocorre em eventos de combustão descontrolada como o da detonação. Por exemplo, a intensidade das detonações pode ser detectada remotamente em função das vibrações no bloco do motor medidas por um acelerômetro, ou ainda, de maneira direta por um sensor de pressão no cilindro, sendo que o último é impraticável fora do cenário de testes. Neste trabalho, a intensidade da detonação foi medida remotamente a partir da interpretação de sinal de um acelerômetro piezoelétrico, o qual necessita ser condicionado por um hardware com lógica de interpretativa do sinal semelhante a que está representada na Figura 3.20.

Figura 3.20 - Principio para detecção de detonação a partir do sinal proveniente do acelerômetro denominado "Knock sensor".

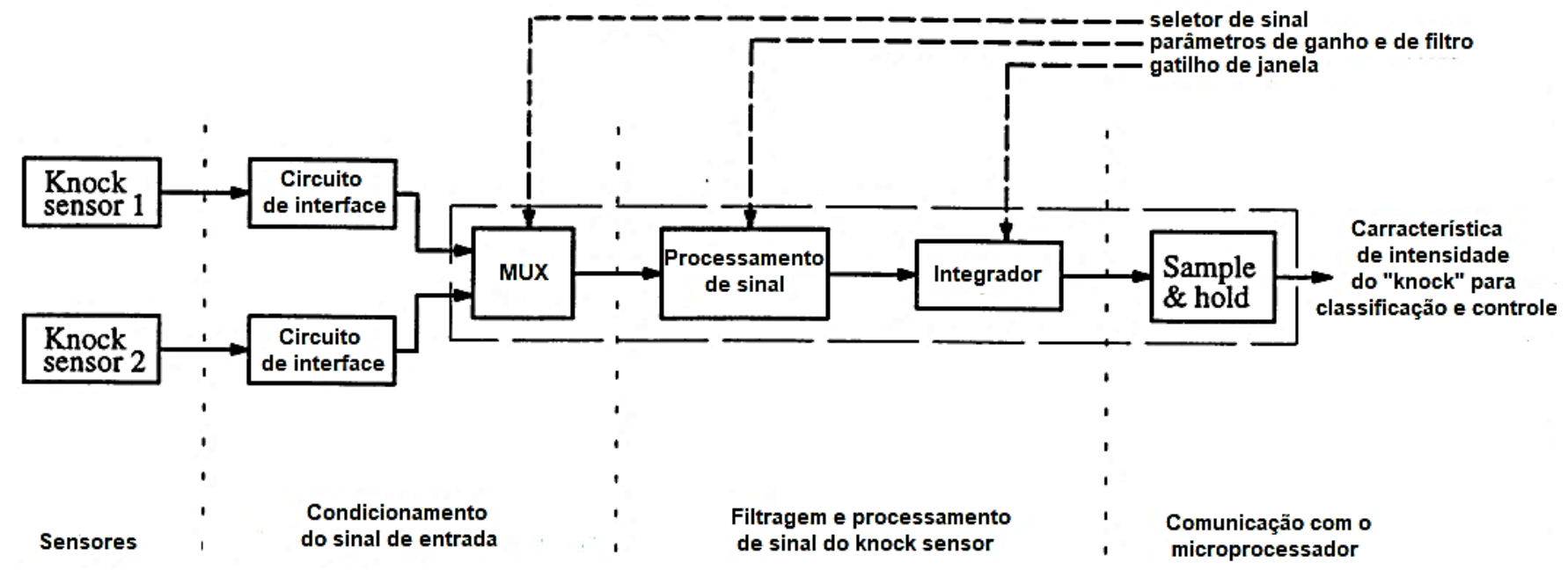

Fonte: Adaptado de (WAGNER, et al., 1998).

Emprega-se um multiplexador analógico sob comando microprocessado para a seleção/alternância de leitura dos sensores (normalmente motores com mais de uma bancada de cilindros) para que se obtenha a leitura adequada para o cilindro ativo. No processo de filtragem do sinal, aplica-se um filtro passa-faixa para isolar a leitura do acelerômetro de ruídos de frequência mais elevada e outras possíveis vibrações do motor que estejam fora do espectro de frequência em que ocorre a detonação, pois, a frequência nominal da detonação pode ser calculada em função do diâmetro do cilindro do motor. 
Utiliza-se um seletor para ajuste do ganho variável da leitura do sinal analógico que será convertido digitalmente, a conversão $A / D$ do sinal e filtragem discreta compõem o condicionamento necessário para a integração, que fornecerá a intensidade da detonação. A variedade de características dos filtros discretos permite a programação do hardware para diferentes aplicações de motores, onde a estrutura eletrônica do filtro, sua frequência central e ganho são selecionados para que se obtenha as frequências da detonação mais representativas.

Os limites de integração são estabelecidos por janelas de duração angular com a finalidade de registar-se a leitura a partir do ângulo de disparo da centelha até o final da ocorrência da combustão, esta característica é fundamentalmente importante, pois, a duração temporal desta janela de medição varia com a velocidade do motor.

A unidade de comando para desenvolvimento ETAS/Bosch MEDC17 FlexECU possui um hardware para detecção remota de eventos de detonação que possui os princípios citados, o qual está representado na Figura 3.21.

Figura 3.21 - Representação do driver interno KnDet da ECU de desenvolvimento ETAS/Bosch MEDC17 FlexECU utilizado para interpretação do sinal do acelerômetro Knock sensor.

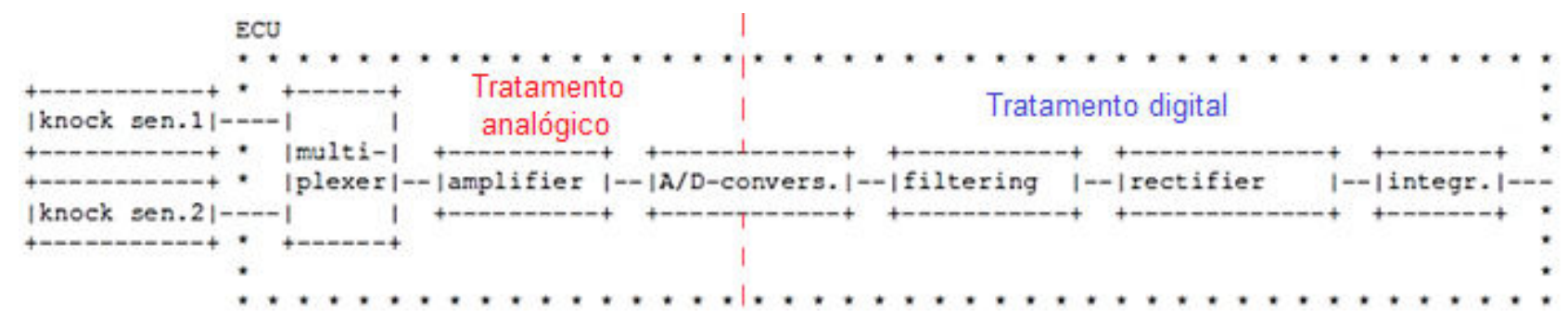

Fonte: Adaptado de (ETAS, INC)

O driver detector de detonação KnDet possui 4 (quatro) fatores para amplificação, 1 (um) filtro equi_ripple e 9 (nove) filtros butterworth com frequências centro diferentes. A aproximação utilizada para seleção da frequência nominal é dada pela eq. (3.4).

$$
\text { Frequência nominal }_{\text {detonação }}=\frac{900}{\pi \cdot 0,5 \cdot B}
$$

onde $B$ representa o diâmetro do cilindro em milímetros [mm].

A amplitude do sinal de referência livre de detonação varia, uma vez que as vibrações mecânicas do motor variam em função da velocidade do mesmo. O sinal medido do sensor de detonação será comparado com o nível de ruído de fundo do 
motor para determinar se existe uma detonação. Um esquema de classificação simples pode ser usado para comparar o valor atual da intensidade da detonação com um múltiplo calibrado por média móvel dos ciclos não detonantes, pois, limiares (referências) fixos(as) não permitem a adaptação imediata a níveis variados de vibração de fundo das diferentes velocidades de operação e ao longo do desgaste mecânico de componentes do motor.

\subsection{ROTINAS DE CONTROLE IMPLEMENTADAS}

\subsubsection{Controle da mistura $\mathrm{A} / \mathrm{C}$ realizado em malha aberta}

A primeira proposição foi estabelecer uma parcela de correção para a estratégia speed density (citada na seção 2.2.2) em função da composição do combustível em uma abordagem feedforward. A malha feedforward aplica um método de interpolação linear para a determinação dos parâmetros base do tempo de injeção $t_{i n j}$ referentes ao funcionamento monocombustível para o etanol e para a gasolina E27. Para o avanço de ignição $\theta_{i g n}$ adotou-se o mesmo método como referência. Devido a imposições governamentais vigentes, o menor teor de etanol encontrado na gasolina nacional é normalizado pontualmente em 27,5\%. Por esta razão, utiliza-se um pré-filtro para ajuste da faixa de variação entre a gasolina tipo $C$ (comum) e o etanol hidratado, que são combustíveis disponibilizados comercialmente no Brasil. O pré-filtro é exemplificado pela Eq. (3.5).

$$
\text { Fuel }_{\text {Range }_{B R}}=\left[\left(\frac{\%_{\text {etanol }}}{100}\right)-0.275\right] \cdot 1,48
$$

Com este ajuste de faixa, cria-se um método que emprega a soma ponderada entre os mapas base do avanço de ignição e do tempo de injeção baseado na quantidade de etanol presente no combustível injetado. Tal referência é medida a partir de um sensor de composição de combustível. Desta forma, é aplicado um método de interpolação linear entre os padrões de funcionamento do motor referentes às proporções de mistura variantes entre os dois combustíveis, expressa pelas Eqs. (3.6) e (3.7).

$$
\theta_{\text {ign }}=\left[\left(\frac{\%_{\text {etanol }}}{100}\right) \cdot \theta_{\text {ign } H 100}\right]+\left[\left(1-\frac{\%_{\text {etanol }}}{100}\right) \cdot \theta_{\text {ign E27 }}\right]
$$




$$
t_{\text {inj }}=\left[\left(\frac{\%_{\text {etanol }}}{100}\right) \cdot t_{\text {inj } H 100}\right]+\left[\left(1-\frac{\%_{\text {etanol }}}{100}\right) \cdot t_{\text {inj E27 }}\right]
$$

A Figura 3.22 exibe o AppSW em diagrama de blocos que realiza a correção do avanço de ignição correspondente à Eq. (3.6). 
Figura 3.22 - Diagrama de cálculo de correção para avanços de ignição em função do volume de etanol do combustível.

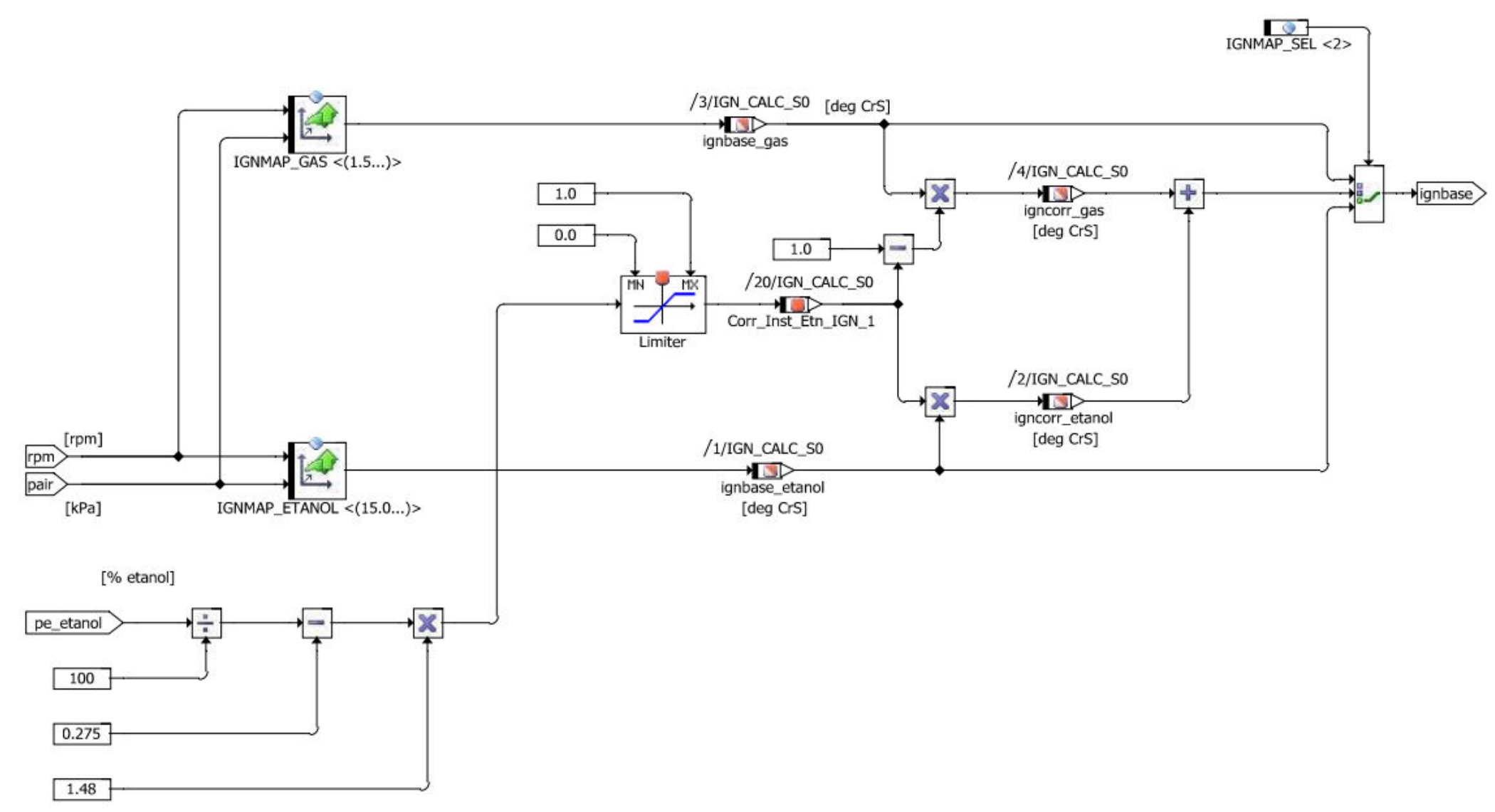

Fonte: O autor. 
De forma semelhante, a Figura 3.23 exibe o AppSW em diagrama de blocos que efetua a correção linear do tempo de injeção correspondente à Eq. (3.5).

Figura 3.23 - Diagrama de cálculo de correção para tempos de injeção em função do volume de etanol do combustível.

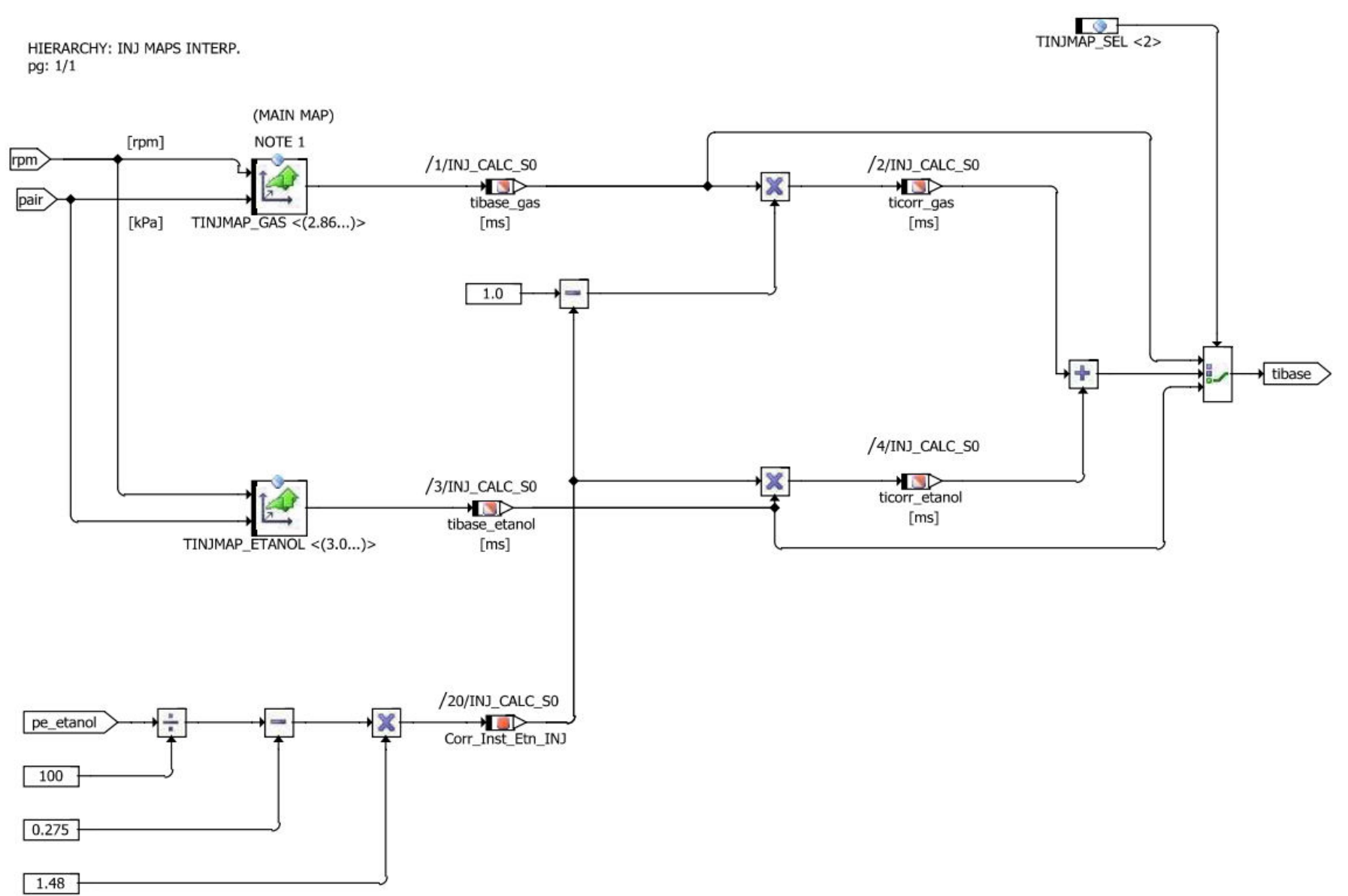

Fonte: O autor. 
As duas rotinas de correção por volume de etanol presente no combustível possuem periodicidade síncrona a velocidade de rotação do motor, onde foram inseridos parâmetro de seleção em que é possível ignorá-las durante a os processos de medição e calibração, através da plataforma de aquisição de dados INCA (INtegrated Calibration and Application-Tool).

\subsubsection{Controle da mistura A/C (lambda) realizado em malha fechada para um sensor de oxigênio com banda larga (LSU/UEGO)}

A utilização de um sensor UEGO permite a aquisição de valores lambda absolutos durante todo o regime de operação de um motor SI convencional. O fato de não haver retransmissão em um ponto de comutação permite que se imponha uma referência de entrada que não necessite ser apenas da relação lambda igual a 1. A opção do controlador foi realizada em proveito da simplicidade computacional, aplicabilidade prática e relativa robustez de funcionamento. Em virtude desses requisitos, tomou-se a decisão de utilizar um tipo de controle clássico e eficiente. Segundo (ERIKSSON e NIELSEN, 2014), o controle de A/C (lambda) em malha fechada para diferentes alvos de relação de equivalência pode ser aplicado pelo emprego de um único sensor UEGO de banda larga com um compensador I (puramente integral) ou PI (Proporcional Integral), como exemplificado na Figura 3.24 .

Figura 3.24 - Estrutura para realização do controle da relação lambda para um sistema que utiliza uma única sonda de banda larga em malha fechada.

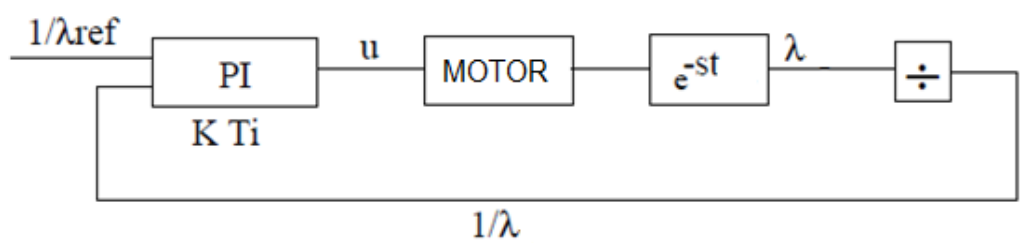

Fonte: Adaptado de (BEGGREN e PERKOVIC, 1996).

Utiliza-se $\frac{1}{\lambda}$ como sinal de entrada e realimentação, por esta relação ser proporcional à massa de combustível para um fornecimento "aproximadamente ${ }^{29,}$ constante de ar, expresso na Eq. (3.8).

${ }^{29}$ O termo aproximadamente surge entre aspas para lembrar que o perfil da pressão de admissão de um $\mathrm{MCl}$ Otto é pulsativo, devido a abertura e fechamento de suas válvulas, assim sendo, a massa de ar deve possuir um comportamento similar. 
$\frac{1}{\lambda}=\frac{\left(\frac{m_{a}}{m_{c}}\right)_{\text {estequiométrica }}}{\left(m_{a} / m_{c}\right)_{\text {instantânea }}}=\frac{\left(\frac{m_{a}}{m_{c}}\right)_{\text {estequiométrica }} \cdot m_{a_{\text {instantânea }}}{ }^{-1}}{m_{\text {cinstantânea }}} \cong \frac{K}{m_{c_{\text {nstantânea }}}}$

Para identificar o sistema, foi utilizada uma aproximação de $1^{\text {a }}$ ordem para a resposta ao degrau da referência lambda, um método utilizado por (KIENCKE e NIELSEN, 2005). A Figura 3.25 representa a técnica de identificação aplicada.

Figura 3.25 - Resposta ao degrau simplificada para a referência lambda em um motor com 4 cilindros.

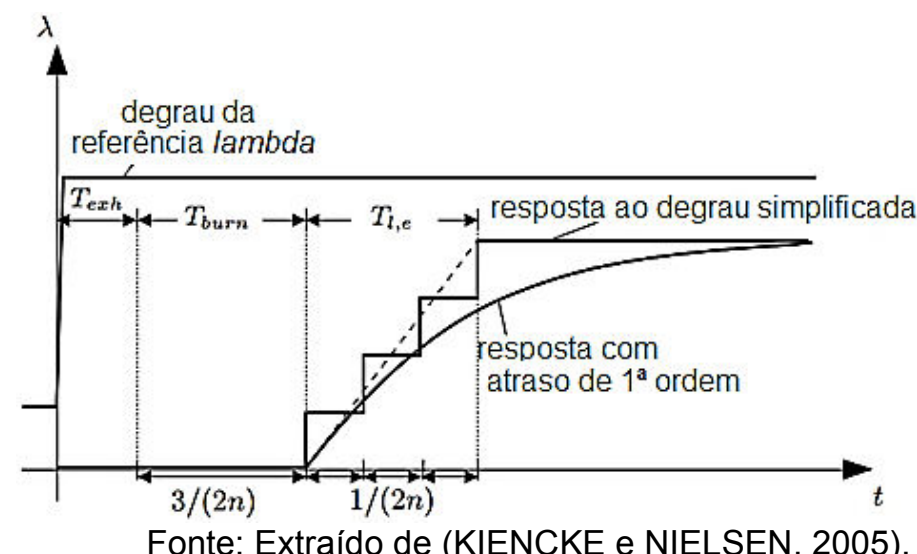

Nesta abordagem, o segmento do transiente de resposta $T_{l, e}$ é calculado com base na quantidade de cilindros do motor, conforme Eq. (3.9).

$$
T_{l, e}=\frac{2 \cdot\left(n_{c i l}-1\right)}{N \cdot n_{c i l}}
$$

onde $N$ é a rotação em RPS; e $n_{c i l}$ é a quantidade de cilindros do motor. Desta maneira para $n_{c i l}=4$, o atraso $T_{l, e}$ será $\frac{3}{2 N}$, então, neste caso particular do motor de 4 cilindros o parâmetro $T_{b u r n}$ será igual ao $T_{l, e}$, ou seja, para $n_{c i l}=4, T_{b u r n}=T_{l, e}$. Um caso diferente seria em um motor com 5 cilindros onde o $T_{l, e}$ seria igual a $\frac{8}{5 \mathrm{~N}}$.

A parcela $t_{d, e}$ como a soma do período de queima $T_{b u r n}$ e do transiente de resposta da referência lambda ao degrau $T_{l, e}$, de acordo com a Eq. (3.10).

$$
T_{d, e}=T_{b u r n}+T_{l, e}
$$

Como o projeto é aplicado em um motor de 4 cilindros, a parcela pode ser aproximada como $2 T_{l, e}$. O parâmetro de tempo de resposta desejado foi denominado 
como $T_{c}$, segundo os testes realizados por (PEREIRA, 2015) demostraram melhor precisão de controle e menor influência na operação do motor com um $T_{c}=2 \mathrm{~s}$.

A estrutura do compensador é expressa na Eq. (3.11) no domínio digital z, e seus parâmetros de ajuste nas Eqs. (3.12) e (3.13):

$$
C_{L S U}(z)=1+\left(P_{L S U}+I_{L S U} \cdot T_{S} \frac{1}{z-1}\right) \cdot e(z)
$$

onde $P$ o ganho proporcional do controlador; $I$ o ganho integral do controlador; $T_{S}$ o período de integração; e $e(z)$ o sinal de erro.

A definição da proporcional $P_{L S U}$ do ganho é parametrizada pela Eq. (3.12).

$$
P_{L S U}=\frac{1}{K} \frac{T_{l, e}}{T_{d, e}+T_{c}}
$$

onde $K$ é o parâmetro de ajuste ao qual foi atribuído um valor unitário (1).

A parcela integral $I_{L S U}$ do ganho é definida em função da parcela proporcional $P$ pelo tempo de resposta do sistema $T_{l, e}$, como dado pela Eq. (3.13).

$$
I_{L S U}=\frac{P_{L S U}}{T_{l, e}}
$$

Como os ganhos são dependentes do termo $t_{l, e}$, construíram-se mapas para os ganhos $P_{L S U}$ e $I_{L S U}$ calculados em função da rotação do motor. Os ganhos exemplificados na Tabela 3.3 foram calculados com base nas equações (3.9), (3.10), (3.11), (3.12) e (3.13).

Tabela 3.3 - Parâmetros de projeto para o controle em malha fechada com realimentação de um sensor de oxigênio com banda larga.

\begin{tabular}{|c|c|c|c|c|c|c|c|}
\hline $\begin{array}{c}\text { Rotação } \\
\text { (RPM) }\end{array}$ & $\begin{array}{c}\text { Tl,e } \\
(\mathbf{m s})\end{array}$ & $\begin{array}{c}\text { Td,e } \\
(\mathbf{m s})\end{array}$ & $\begin{array}{c}\text { Ts } \\
(\mathbf{m s})\end{array}$ & $\begin{array}{c}\text { Tc } \\
(\mathbf{s})\end{array}$ & $\mathbf{K}$ & P_LSU & I_LSU \\
\hline 600 & 150 & 300 & 200 & 2 & 1 & 0,065217 & 0,434783 \\
\hline 700 & 128,571 & 257,143 & 171,43 & 2 & 1 & 0,056962 & 0,443038 \\
\hline 800 & 112,5 & 225 & 150 & 2 & 1 & 0,050562 & 0,449438 \\
\hline 900 & 100 & 200 & 133,33 & 2 & 1 & 0,045455 & 0,454545 \\
\hline 1000 & 90 & 180 & 120 & 2 & 1 & 0,041284 & 0,458716 \\
\hline 2000 & 45 & 90 & 60 & 2 & 1 & 0,021531 & 0,478469 \\
\hline 3000 & 30 & 60 & 40 & 2 & 1 & 0,014563 & 0,485437 \\
\hline 4000 & 22,5 & 45 & 30 & 2 & 1 & 0,011002 & 0,488998 \\
\hline 5000 & 18 & 36 & 24 & 2 & 1 & 0,008841 & 0,491159 \\
\hline 6000 & 15 & 30 & 20 & 2 & 1 & 0,007389 & 0,492611 \\
\hline 6500 & 13,846 & 27,692 & 18,46 & 2 & 1 & 0,006829 & 0,493171 \\
\hline
\end{tabular}

Fonte: $\mathrm{O}$ autor. 
A rotina do módulo de controle lambda é realizar a correção no tempo de injeção a partir da realimentação do sensor de oxigênio wide-band. Foram estipuladas condições inicias de teste para que a função do controle da relação lambda pudesse ser ativada, sendo: a medida da temperatura do liquido de arrefecimento ser superior a $50^{\circ} \mathrm{C}$, para que os períodos de injeção não sejam encurtados, evitando que o motor perca estabilidade de marcha-lenta ou apague, e consequentemente, não alcance aquecimento e lubrificação adequadas para o seu funcionamento, pois, o bombeamento do óleo é feito por um dispositivo rotacionado solidariamente ao motor. Outro pré-requisito é que a rotação necessita ser igual ou superior a 600 RPM, liberando que o motor também seja alimentado com uma quantidade de combustível necessária no instante em que o eixo de manivelas for rotacionado pelo motor de arranque durante o momento de partida. A Figura 3.26 exibe a estrutura de blocos utilizada do módulo lógico para controle da mistura $A / C$ em malha fechada, denominado LAMBDA_CALCv1.4.

O target da relação lambda pode ser fixado em um dado valor desejado durante calibração ou endereçado em função do sinal de erro do modulo de controle de rotação pelo mapa LAMBDA_CURVE, exemplificado na Tabela 3.4.

Tabela 3.4 - Mapa LAMBDA_CURVE para endereçamento de referência para o módulo de controle $\angle A M B D A \_C A L C$.

\begin{tabular}{|c|c|c|c|c|c|c|c|}
\hline Rotação (RPM) & -6000 & -3000 & -1000 & 0 & 3000 & 6000 & 12000 \\
\hline Referência $(\boldsymbol{\lambda})$ & 2,0 & 1,3 & 1,2 & 1,0 & 0,95 & 0,9 & 0,85 \\
\hline
\end{tabular}

Os elementos deste mapa passam por um saturador que limita a excursões máxima e mínima da referência utilizada para o compensador PI. Além da referência gerada pelo mapa $L A M B D A \_C U R V E$, o setpoint pode ser alterado manualmente durante experimentos através da mudança do seletor da referência LAMBDA_SEL e da inserção do valor desejado na variável de calibração F_LAMBDAK. A saída é o ganho de ajuste da relação de equivalência alvo denominada lambda_k ${ }^{30}$ que é um dos principais fatores corretivos para o tempo de injeção.

30 Identificador da variável que contém o ganho de saída que é proveniente da malha de controle lambda, utilizada para correção multiplicativa da quantidade massa de combustível que é injetada. 
Figura 3.26 - Diagrama do módulo de controle LAMBDA_CALCv1.4.

MODULE: LAMBDA_CALC

v1.4

pg: $1 / 1$

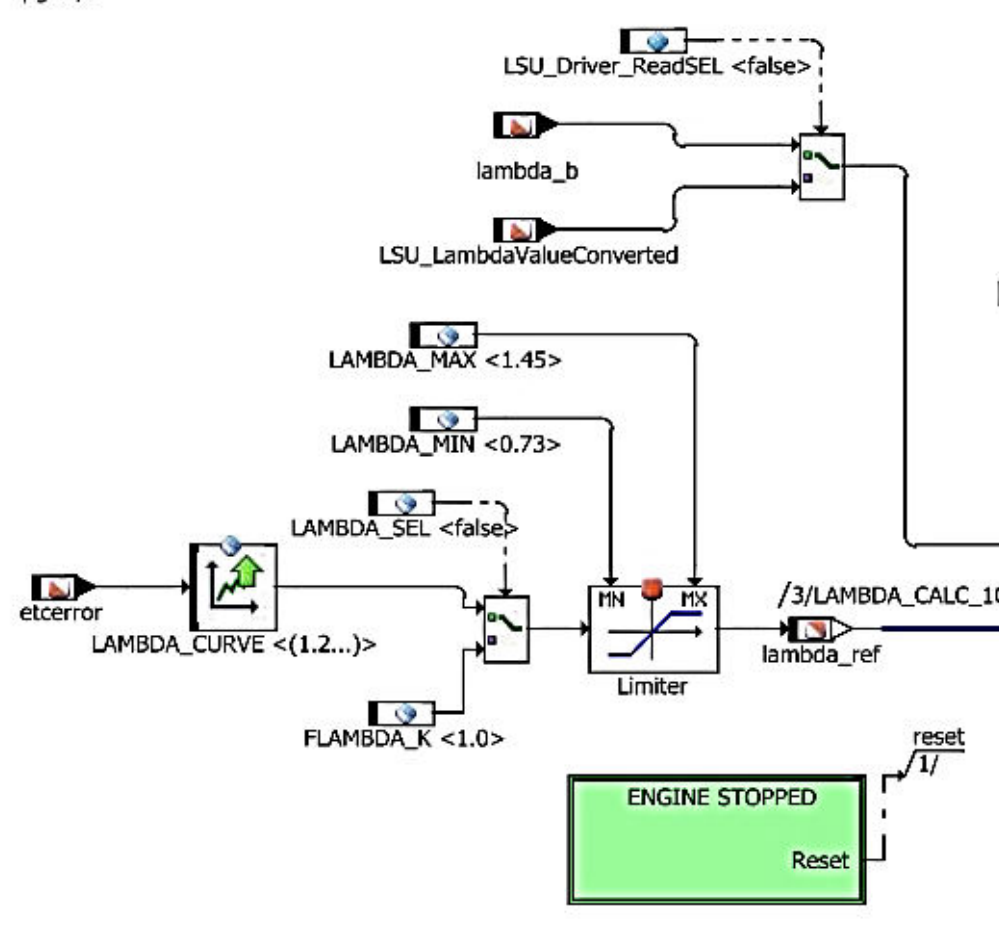

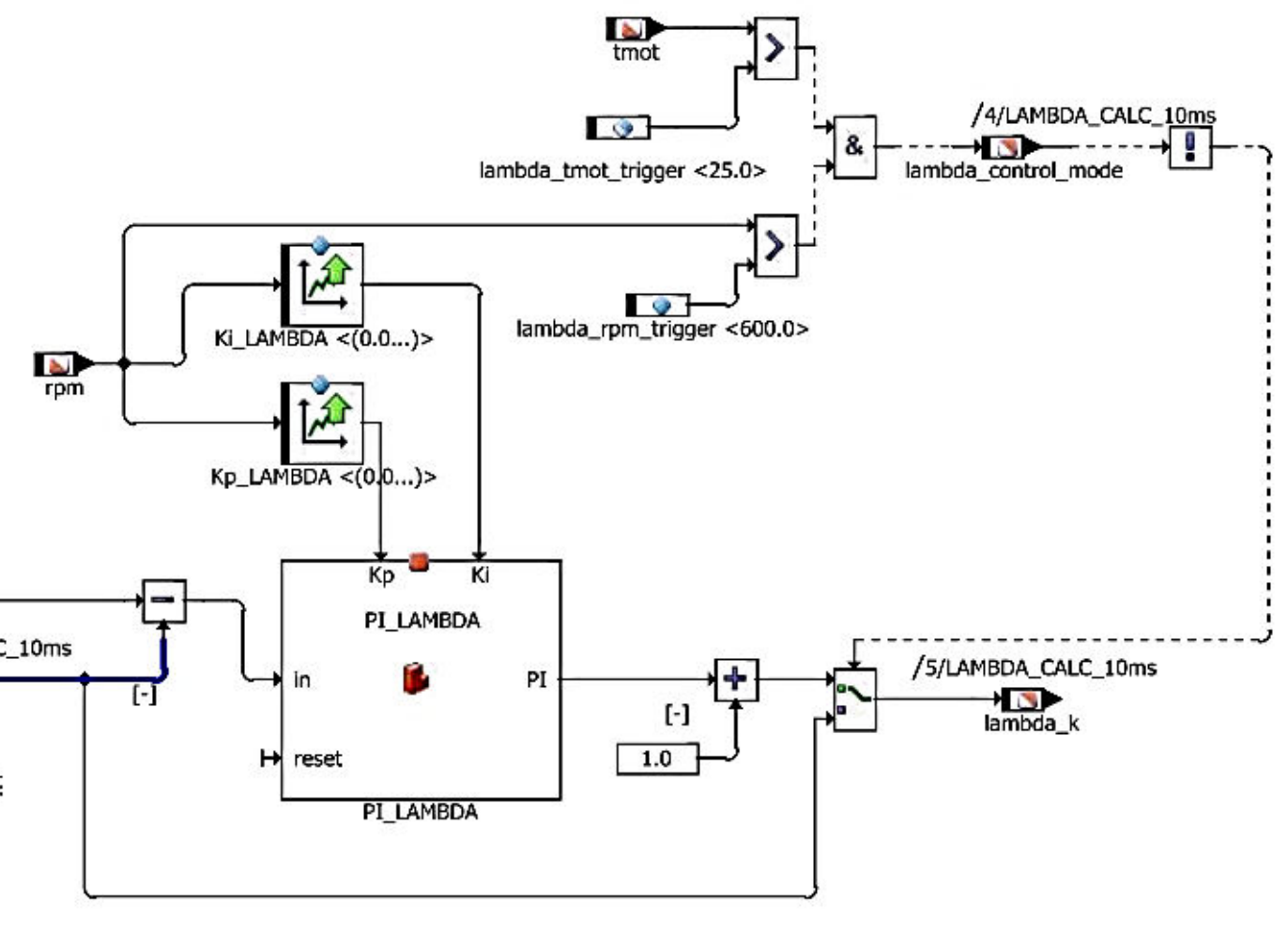

Fonte: $\mathrm{O}$ autor. 


\subsubsection{Controle da mistura A/C (lambda) realizado em malha fechada para um sensor de oxigênio com banda estreita (LSF/HEGO/On-Off)}

A utilização do sensor de oxigênio de banda estreita (HEGO/EGO) possui particularidades, pois possui um sinal de característica binária em que o controle busca uma instabilidade marginalmente estável. A estrutura de controle utilizada em seu exemplo é exibida na Figura 3.27.

Figura 3.27 - Estrutura de controle I ou PI para um único sensor com banda estreita EGO.

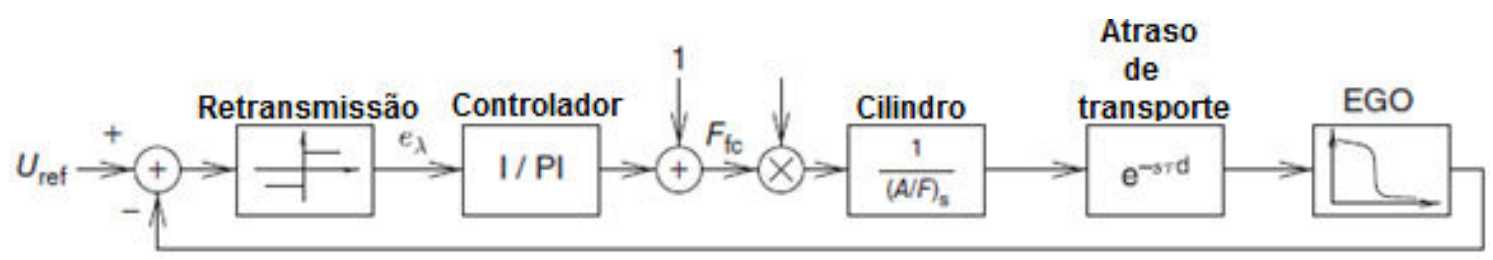

FONTE: Adaptado de (ERIKSSON e NIELSEN, 2014).

A referência $U_{\text {ref }}$ define a tensão de comutação, em torno de $450 \mathrm{mV}$, e a retransmissão presente na entrada condiciona o sinal $e_{\lambda}$ para mudar de 0 (pobre) a 1 (rico), correlacionando mistura rica e pobre para o controlador. A lei de controle aplicada é expressa pela equação (3.14) no domínio de Laplace.

$$
C_{L S F}(s)=1+\left(P_{L S F}+I_{L S F} \cdot T_{s} \cdot \frac{1}{Z-1}\right) \cdot e(s)
$$

Neste compensador o ganho $P_{L S F}$ possui valor fixo de 0,01 . O ganho $I_{L S F}$ é endereçado pela rotação do motor com o escalonamento da Eq. (3.15).

$$
I_{L S F}=T_{l, e}=\frac{2\left(n_{c i l}-1\right)}{N \cdot n_{c i l}}
$$

O ganho $I_{L S F}$ é dependentes do termo $t_{l, e}$, portanto, construiu-se o mapa de ganho endereçado pela rotação do motor o qual está exemplificado na Tabela 3.5. 
Tabela 3.5 - Parâmetros de projeto para o controle em malha fechada com realimentação de um sensor de oxigênio de banda estreita.

\begin{tabular}{|c|c|c|c|c|c|}
\hline $\begin{array}{c}\text { Rotação } \\
\text { (RPM) }\end{array}$ & $\begin{array}{c}\text { TI,e } \\
(\mathbf{m s})\end{array}$ & $\begin{array}{c}\text { Ts } \\
(\mathbf{m s})\end{array}$ & $\begin{array}{c}\text { Tc } \\
(\mathbf{s})\end{array}$ & P_LSF & I_LSF \\
\hline 600 & 150 & 200 & 2 & 0,01 & 0,15 \\
\hline 700 & 128,571 & 171,43 & 2 & 0,01 & 0,12857 \\
\hline 800 & 112,5 & 150 & 2 & 0,01 & 0,1125 \\
\hline 900 & 100 & 133,33 & 2 & 0,01 & 0,1 \\
\hline 1000 & 90 & 120 & 2 & 0,01 & 0,09 \\
\hline 2000 & 45 & 60 & 2 & 0,01 & 0,045 \\
\hline 3000 & 30 & 40 & 2 & 0,01 & 0,03 \\
\hline 4000 & 22,5 & 30 & 2 & 0,01 & 0,0225 \\
\hline 5000 & 18 & 24 & 2 & 0,01 & 0,018 \\
\hline 6000 & 15 & 20 & 2 & 0,01 & 0,015 \\
\hline 6500 & 13,846 & 18,46 & 2 & 0,01 & 0,01385 \\
\hline
\end{tabular}

Fonte: $\mathrm{O}$ autor.

O alvo da relação lambda pode ser definido de maneira estática por calibração, ou endereçado em função do sinal de erro do modulo de controle de rotação, através mapa LambdaCurveOnOff, destacado na Tabela 3.6.

Tabela 3.6 - Mapa LambdaCurveOnOff para endereçamento de referência para o módulo de controle LAMBDA_CALC_OnOff_v1.

\begin{tabular}{|c|c|c|c|}
\hline Rotação (RPM) & -6000 & 0 & 6000 \\
\hline Referência ( $\boldsymbol{\lambda}$ ) & 1,5 & 1,0 & 0,5 \\
\hline
\end{tabular}

Fonte: $\mathrm{O}$ autor.

De maneira similar ao módulo LAMBDA_CALCv1.4, os elementos deste mapa possuem um saturador que tem a função de limitar a excursões máxima e mínima da referência utilizada para o compensador PI e possui como saída o ganho lambda_kOnOff ${ }^{31}$ sendo um dos principais fatores corretivos para a saída do tempo de injeção. O módulo LAMBDA_CALCOnOffv1 está exemplificado na Figura 3.28.

${ }^{31}$ Identificador da variável que contém o ganho de saída que é proveniente da malha de controle lambda, utilizada para correção multiplicativa da quantidade massa de combustível que é injetada a partir de realimentação de um sensor de banda estreita. 
Figura 3.28 - Diagrama do módulo de controle LAMBDA_CALC_OnOff_v1.

MODULE: LAMBDA_CALC_OnOff_v1

$\mathrm{pg}: 1 / 1$

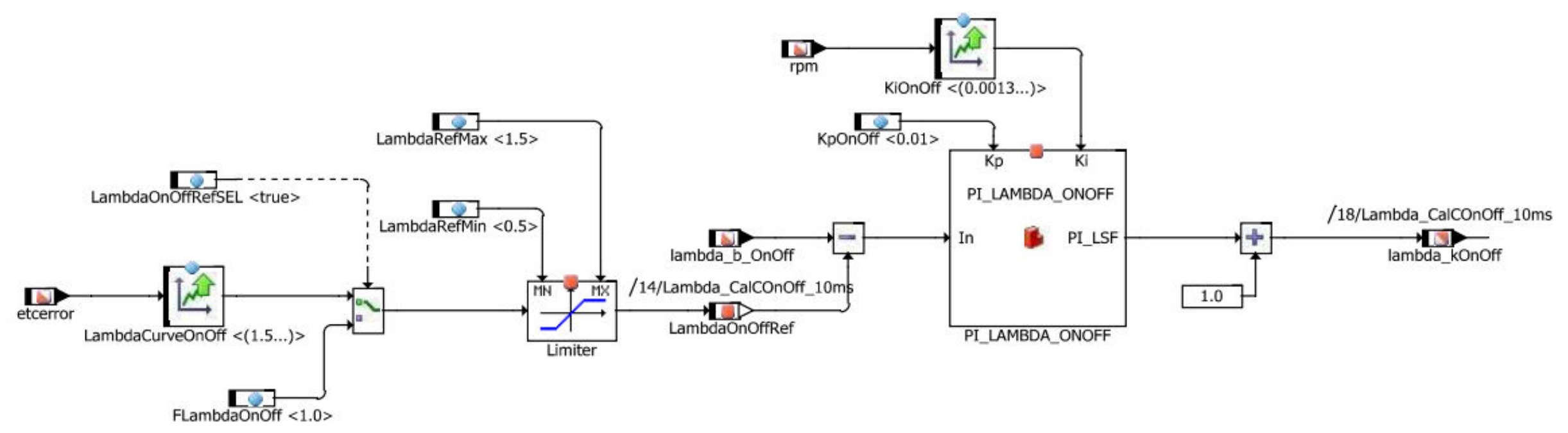

Fonte: O autor. 


\subsubsection{Controle para o aquecimento do sensor de banda larga (LSU/UEGO) em malha fechada \\ Aplicando-se um ensaio empírico, sinais de entrada e saída são} periodicamente registrados para que possam ser submetidos a análise de dados posteriores, de maneira a obter-se um modelo virtual com comportamento próximo ao da planta real. Este processo recebe o nome de identificação de sistemas, e o modelo gerado a partir dele recebe a designação de caixa preta. (LJUNG, 1998)

$\mathrm{Na}$ construção dos modelos empíricos, alterações são provocadas nas variáveis de entrada em torno de uma certa condição nominal de operação, de modo que a resposta dinâmica a estas excitações possibilite a determinação de um modelo para o sistema. (AGUIRRE, 2004)

A hierarquia LSU_CTRL_IN recebe 0 retorno da função Get_Lambda_Temp_LSU() na variável LSU_Temp_Raw e a escalona com a conversão da Eq. (3.16).

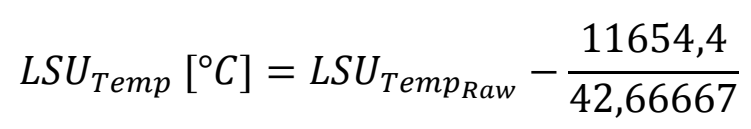

Com o intuito de realizar simulações da planta de controle, implantou-se um processo de modelagem para identificar a função de transferência entre a modulação PWM de entrada e a temperatura de saída do sensor, como ilustrado pela Figura 3.29. 
Figura 3.29 - Dados de entrada e saída utilizados para identificação da planta de temperatura do sensor de banda larga.

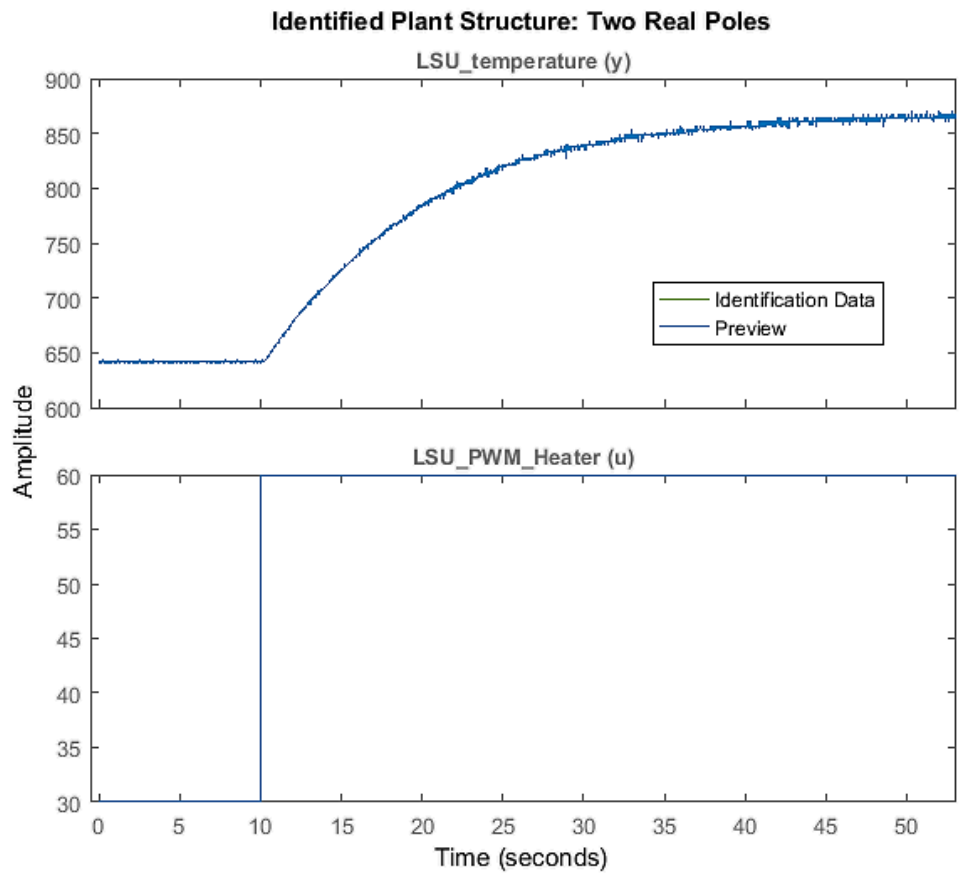

(a)temperatura do sensor de oxigênio $\left[{ }^{\circ} \mathrm{C}\right]$, (b) ciclo de trabalho do PWM [\%].

Fonte: $\mathrm{O}$ autor.

Empregando-se a INCA, foi possível medir a curva de resposta da temperatura do aquecimento do sensor de banda larga a partir de um degrau com variação de $30 \%$ em PWM ( Pulse Width Modulation) @ $250 \mathrm{~Hz}$ no instante t=10s. Com a introdução desses dados de entrada/saída em um aplicativo de identificação de sistemas através do software Matlab, foi possível estabelecer duas aproximações de identificação da planta no controle de temperatura do sensor LSU(UEGO), exibidos na Figura 3.30. 
Figura 3.30 - Comparação entre os dados medidos da planta real e a planta identificada com aproximações de $1^{\mathrm{a}}$ (primeira) e $2^{\mathrm{a}}$ (segunda) ordem.

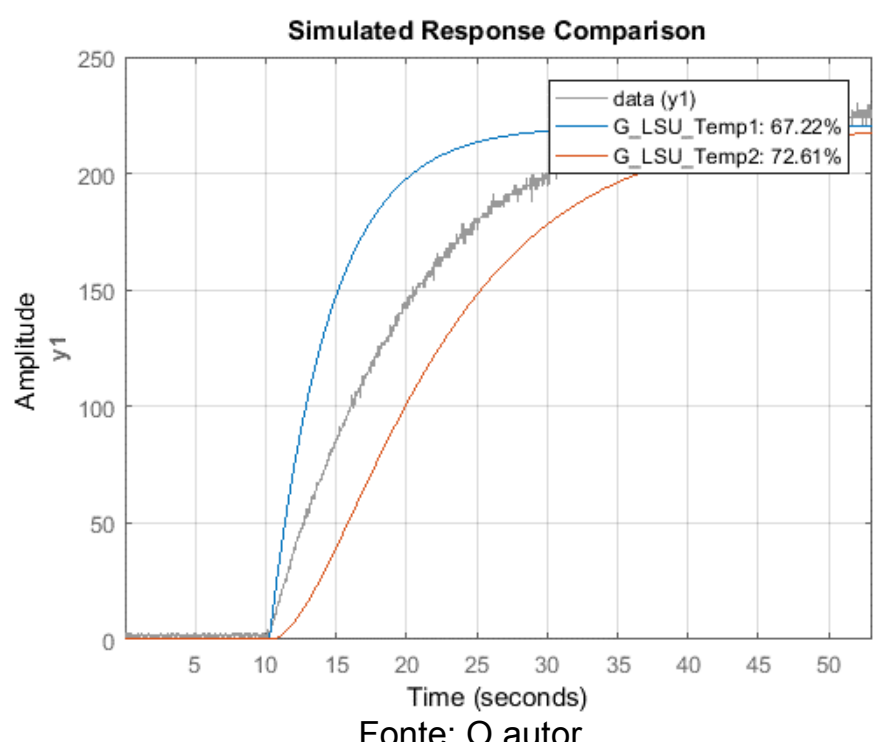

Com a utilização do toolbox para identificação de sistemas foi possível identificar duas plantas de tempo contínuo para o controle da temperatura do sensor, exemplificadas na Eqs. (3.17) e (3.18).

$$
\begin{gathered}
G_{\text {LSU Temp } 1}(s)=\frac{7,3488}{4,281 s+1} \\
G_{\text {LSU Temp } 2}(s)=\frac{7,3496}{37,100498 s^{2}+12,921 s+1}
\end{gathered}
$$

Com as plantas identificadas definiu-se dois compensadores, um PI Eq. (3.19) e outro PID Eq. (3.20) ambos na forma paralela:

$$
\begin{gathered}
C_{\text {LSU Temp } 1}(s)=0,142+0,0994 \cdot \frac{1}{S} \\
C_{L S U T e m p 2}(s)=0,27+0,0306 \cdot \frac{1}{S}+0.518 . s
\end{gathered}
$$

Os compensadores propostos aplicados a uma terceira planta com índice fit acima de $98 \%$ apresentaram desempenho satisfatório, com repostas ao degrau exibidas na Figura 3.31.

Foi utilizada a conversão para o domínio digital, pois, o controle foi implementado em um microcontrolador que opera de maneira discreta. A amostragem utilizada na conversão foi a mesma aplicada a periodicidade de sua rotina no sistema operacional RTOS (ㅁeal Iime Operating System). 
Figura 3.31 - Respostas dos compensadores de $1^{\text {a }}$ (primeira) e $2^{\mathrm{a}}$ (segunda) aplicados a planta que possui $98 \%$ de índice fit.

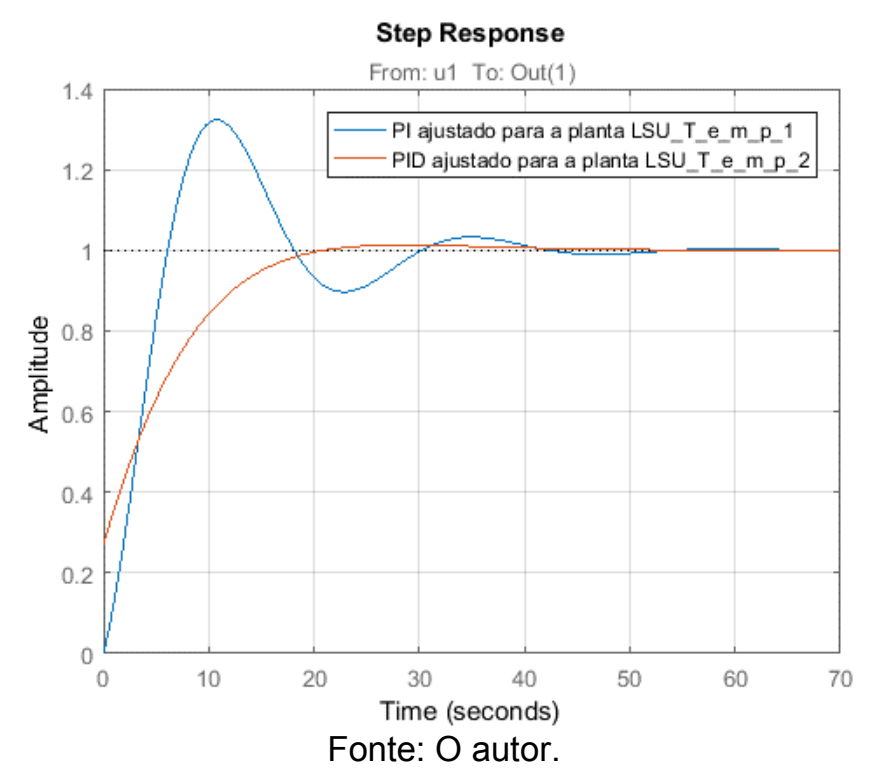

Aplicando a conversão discreta com amostragem de 20 ms e aproximação trapezoidal (tustin) digital às duas plantas de tempo contínuo para o controle da temperatura do sensor, obteve-se a plantas digitais exemplificadas nas Eqs (3.21) e (3.22) no domínio digital z.

$$
\begin{gathered}
G_{-} D_{L S U T e m p}(z)=\frac{0,01713 z+0,1713}{z-0,9953} \\
G_{-} D_{L S U \text { Temp } 2}(z)=\frac{1,974 \cdot 10^{-5} \cdot z^{2}+3,948 \cdot 10^{-5} \cdot z+1,974 \cdot 10^{-5}}{z^{2}-1,993 z+0,9931}
\end{gathered}
$$

A partir do emprego das plantas digitais, definiu-se dois compensadores com estrutura de ação paralela, um PI Eq. (3.23) e outro PID Eq. (3.24) no domínio digital Z.

$$
\begin{gathered}
C_{-} D_{\text {LSU Temp } 1}(z)=0,142+0,0994 \cdot \frac{T_{s^{*}}(z+1)}{2 \cdot(z-1)} \\
C_{-} D_{\text {LSU Temp } 2}(z)=0,27+0,0306 \cdot \frac{T_{s} \cdot(z+1)}{2 \cdot(z-1)}+0.518 \cdot \frac{2 \cdot(z-1)}{T_{s} \cdot(z+1)}
\end{gathered}
$$

Ao comparar-se as plantas e controladores em ambos os domínios (contínuos e discretos), constatou-se que a amostragem da conversão discreta não causou influência sobre os ganhos neste caso. A Figura 3.32 exibe a rotina utilizada para conversão e controle de temperatura do sensor de oxigênio de banda larga (LSU/UEGO). 
Figura 3.32 - Hierarquia LSU_CTRL_IN, utilizada para conversão e controle de temperatura do sensor de oxigênio de banda larga (LSU/UEGO). HIERARCHY: LSU_CTRL_IN pg: $1 / 2$

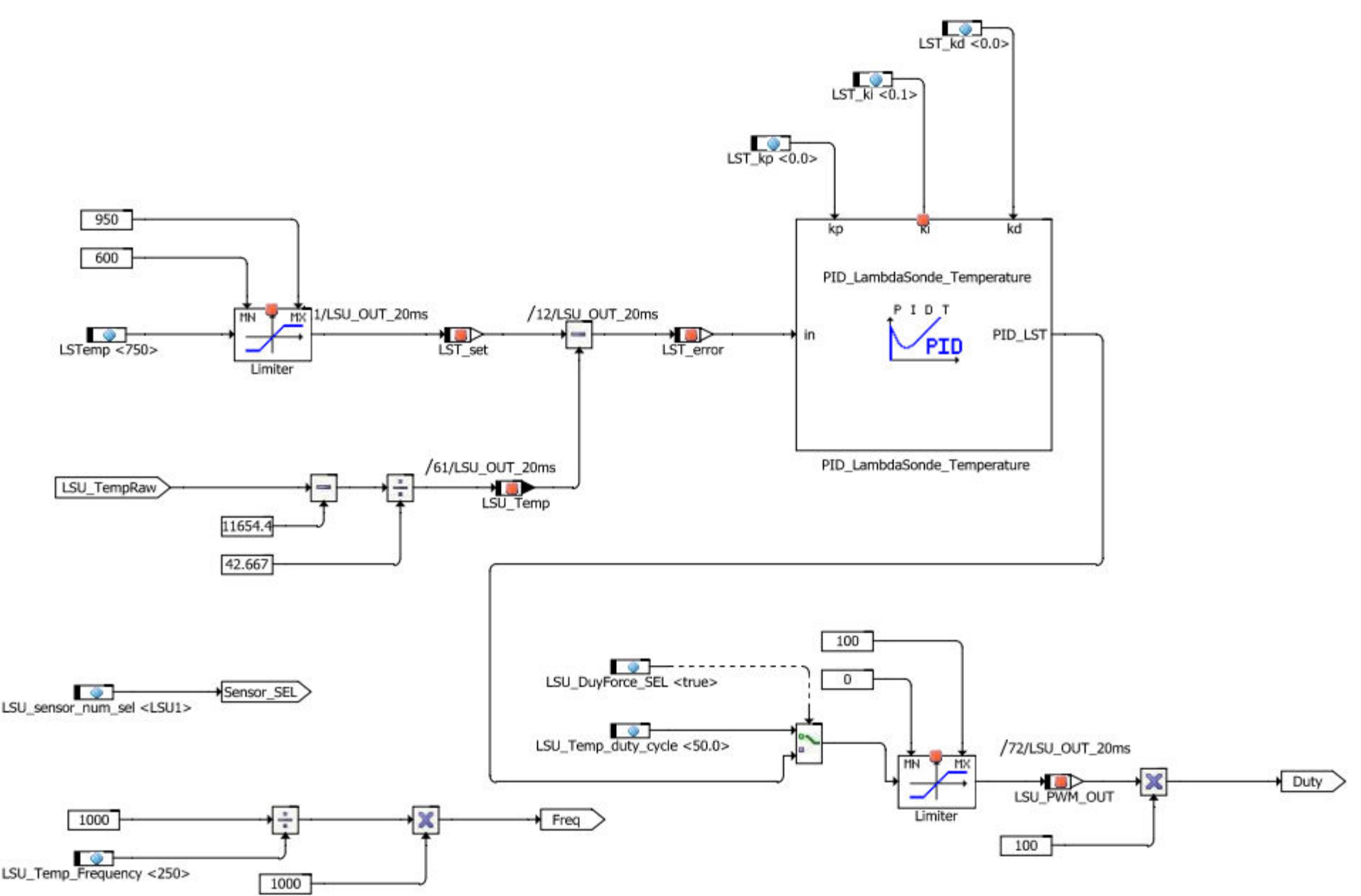

Fonte: $\mathrm{O}$ autor. 


\subsubsection{Características comuns às rotinas de controle e diagnose implementadas}

A distância entre o ponto de injeção até a posição do sensor de oxigênio e a dinâmica reciproca do motor causam um atraso de transporte variável. Este atraso pode ser dividido em duas partes: a primeira proveniente do transporte dos gases através dos ciclos do motor, sendo diretamente dependente da velocidade de giro do motor que resulta em um atraso de tempo da ordem de $\frac{180+180+180}{360 \mathrm{~N}}$ segundos ou $\frac{3}{2 \mathrm{~N}}$ como vimos na definição do termo $T_{\text {burn }}$ na Eq (3.9), por conta da mistura A/C ser aspirada para dentro do cilindro, comprimida, queimada e expandida no ciclo de trabalho durante o movimento descendente do pistão. A segunda parte vem do processo da exaustão, com o tempo que decorre entre a abertura da válvula de admissão e a abertura da válvula de escape e o transporte dos gases no sistema de exaustão em conjunto com o tempo de leitura do sensor de oxigênio (GUZZELLA e ONDER, 2010).

É possível concluir que devido ao processo de mensuração da relação lambda ser uma medida atrasada, pois, acontece momentos após a combustão ter ocorrido, seus pequenos retardos devem ser compensados de maneira suave e estável, o que influi diretamente no dimensionamento de ganhos para ação de seu controle.

As rotinas de controle do software são repetidas periodicamente, pois funcionam dentro de um RTOS ${ }^{32}$. A execução das rotinas de controle A/C (lambda) open-loop/feedforward foram definidas com amostragem síncrona a velocidade do motor, ou seja, são disparadas a cada revolução, pois, controlam também os ângulos de injeção e ignição, assim como seus respectivos tempos. Segundo (PEREIRA, 2015), o tempo de amostragem $T_{s}$ mínimo varia com o tempo de um ciclo completo do motor, de acordo com a Eq. (3.25).

$$
T_{s}=T_{\text {ciclo }}=\frac{120}{R P M}
$$

As rotinas de controle A/C (lambda) closed-loop/feedback possuem periodicidades fixas, e foram indicadas em $10 \mathrm{~ms}$, ou seja, um tempo de amostragem $T_{S}$ suficiente até rotação de corte do motor 6500 RPM (onde $T_{S} \cong$

${ }^{32}$ Real Time Operating System 
$18 \mathrm{~ms}$ ), com exceção das rotinas de controle A/C open-loop/feedforward. Portanto, o $T_{s}$ utilizado é o mesmo daquele que é empregado na execução da task em questão. Para as rotinas de controle de aquecimento dos sensores e diagnose foram escolhidas as amostragens mínimas de operação definidos em 20 ms.

As variáveis lambdab e lambdabOn Off representam respectivamente a medida do sensor de banda larga realizada pelo analisador lambda LA4 e a medida do sensor de banda estreita colhida diretamente de sua célula Nernst, que são lidas através da conversão A/D realizada pelo módulo ADC_READv34, como exibido na Figura 3.33.

Figura 3.33 - Leituras analógicas para os sensores de banda estreita (LSF/HEGO) e da saída do analisador LA4 para o sensor de banda larga (LSU/UEGO) presentes no módulo ADCv34.

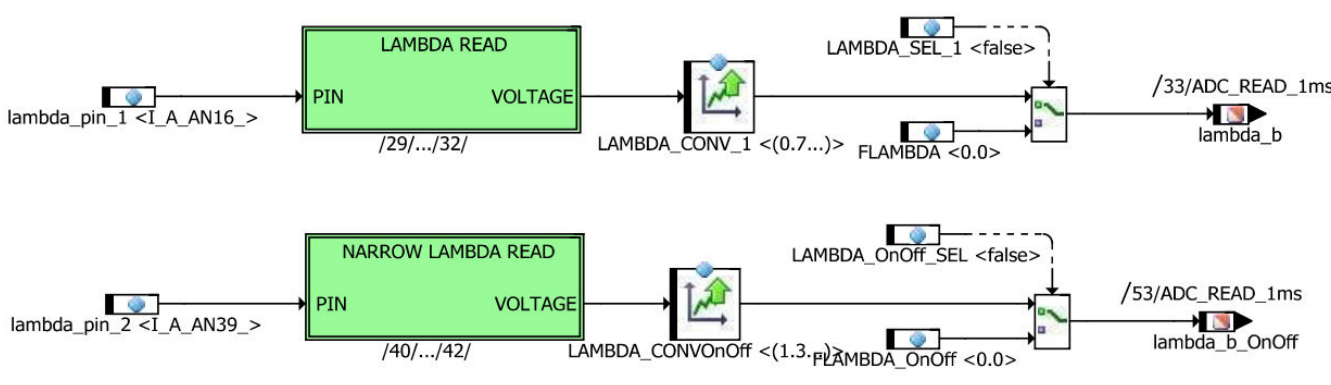

Fonte: $\mathrm{O}$ autor.

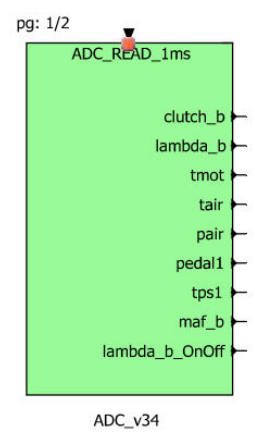

ADC $\vee 334$

As tensões analógicas lidas pelo módulo foram implementadas ainda com as tabelas de conversão LAMBDA_CONV1 e LambdaConvOnOff.

Com a existência de dois módulos de controle para os dois tipos de sensores de oxigênio (banda larga e estreita), implantou-se o parâmetro de calibração SondeTypeGain_InjSEL, onde é possível selecionar o uso do controle desejado no momento através da plataforma INCA, conforme ilustrado na Figura 3.34. 
Figura 3.34 - Hieraquia do módulo de injeção que exibe a possibilidade de seleção da correção lambda pelo tipo de sensor LSU(UEGO) ou LSF(HEGO/On-Off).

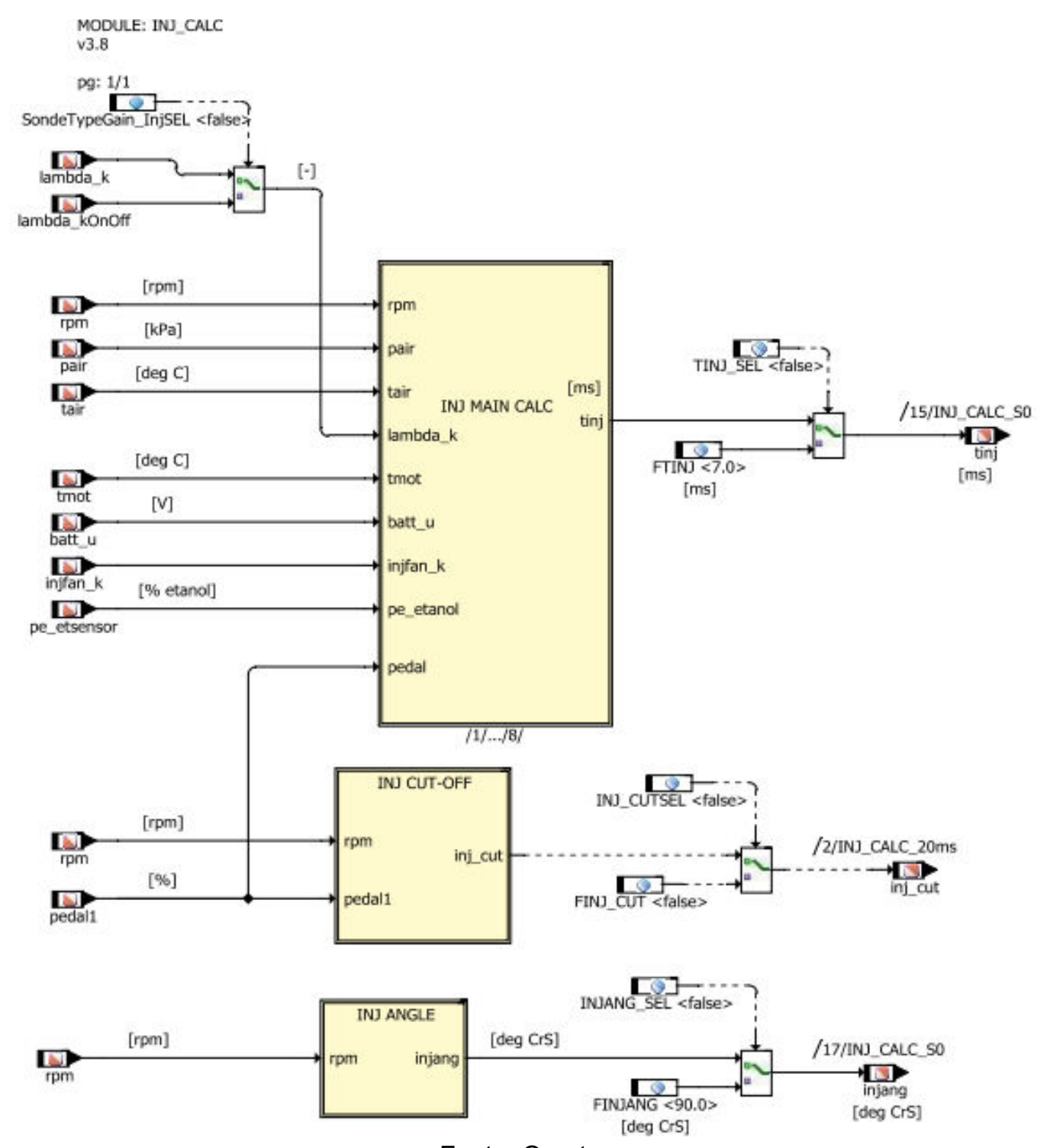

Fonte: $\mathrm{O}$ autor.

A diferença entre as rotações de referência e de saída constitui o erro do módulo ETC. Durante um regime transitório de rotação, a referência lambda torna-se dependente desse erro. Na detecção de um erro positivo pelo controle de rotação, é interpretada uma solicitação de aceleração. Através do sinal de pedal eletrônico, o ganho de enriquecimento da mistura endereçado pelos mapas de setpoint LAMBDA_CURVE (destacado na Tabela 3.4) e LAMBDA_CURVE_OnOff (destacado na Tabela 3.6). Como efeito primário, obtém-se o aumento da vazão de ar devido à rápida abertura aplicada na válvula borboleta, o que torna a mistura pobre durante este primeiro momento. Após isto, a malha de controle detecta a alteração da referência a ser seguida, e o período de injeção é maximizado pela 
ação de controle para obtenção do enriquecimento da mistura com o aumento do fluxo de combustível para os cilindros, resultando em reações de combustões mais carregadas do ponto de vista energético, com a finalidade de acréscimo da rotação do motor e, consequentemente, do seu torque de saída. Quando o erro de rotação se torna negativo, obtém-se o processo inverso, a referência desejada para a relação lambda é atingir uma mistura empobrecida, para auxiliar na desaceleração do veículo, contribuindo em conjunto com a estratégia de cut-off ${ }^{33}$ para aplicação do chamado "freio motor" com a finalidade de se evitar sobressinais na desaceleração do motor e garantir que ela ocorra de maneira suave e no menor tempo possível.

\subsection{ROTINAS DE DIAGNOSE}

\subsubsection{Diagnose da comunicação CJ125, aquecedor e do sensor de banda larga (LSU/UEGO)}

O LLSW provê funções API's de diagnostico para o aquecedor do sensor de banda larga LSU/UEGO denominada Get_Lambda_Heater_Diag() e para os principais pinos de medida do sensor (IP, UN e VG) e comunicação com o IC CJ125 denominada Cj125_GetErrorInfo.

Para a função Get_Lambda_Heater_Diag (Lambda_SensorNum sensorNumber), o parâmetro de entrada é o número de identificação do sensor, pois no caso da Flex_ECU podem ser utilizados dois sensores LSU/UEGO simultaneamente. O valor de retorno é armazenado na variável LSU_Heater_Diagn e possui uma codificação de bits onde cada flag de diagnóstico corresponde ao status destacados na Tabela 3.7.

${ }^{33}$ Termo utilizado para se referir ao método de corte ou diminuição do período de injeção, quando conceitualmente a mesma não se faz necessária. 
Tabela 3.7 - Codificação dos bits da variável de retorno da função de diagnóstico para o Heater (Aquecedor) para o sensor de banda larga LSU.

\begin{tabular}{|c|l|l|l|}
\hline Bit 3 & \multicolumn{1}{|c|}{ Bit 2 } & \multicolumn{1}{c|}{ Bit 1 } \\
\hline Sobre-temperatura & Carga aberta & $\begin{array}{l}\text { Ligação de curto ao } \\
\text { polo negativo }\end{array}$ & $\begin{array}{l}\text { Ligação de curto ao } \\
\text { polo positivo }\end{array}$ \\
\hline
\end{tabular}

Fonte: (ETAS, INC).

Se a função retornar o nível lógico 1 no bit 0 , isto significa que há um curto ao polo positivo da bateria no pino PWM do heater.

Para a Função Cj125_GetErrorlnfo (uint16 ChipNr_u16, uint16 SignalNr_u16), o primeiro parâmetro de entrada (ChipNr_u16) é o número do sensor utilizado, 0 para LSU1 e 1 para LSU2. O segundo parâmetro passado (SignalNr_u16) contém o identificador de seleção do sinal. A diagnose é realizada para cada pino (sinal de medida) e seus identificadores para seleção do sinal correspondente VG, UN e IP, que estão definidos na Tabela 3.8.

Tabela 3.8 - Identificadores de seleção para retorno da função de diagnóstico dos pinos de medição para o sensor de banda larga LSU.

\begin{tabular}{|c|c|c|}
\hline Identificador de seleção & Pino do sensor & Identificação do sinal \\
\hline 0 & VG & CJ125_DIAG_VM \\
\hline 1 & UM & CJ125_DIAG_UN \\
\hline 2 & IP & CJ125_DIAG_IAIP \\
\hline VG - Virtual Ground; UN - Tensão Nernst; IP - I Pump. Fonte: (ETAS, INC).
\end{tabular}

Exemplo de uso: LSU_Error $=$ Cj125_GetErrorlnfo $(1,0)$. O valor de retorno é a é codificado por bits onde cada flag é arranjada, como exemplificado na Tabela 3.9 .

Tabela 3.9 - Codificação dos bits da variável de retorno da função de diagnóstico para a comunicação com o CI CJ 125 utilizado para o controle e medição do sensor de banda larga LSU.

\begin{tabular}{|l|l|l|l|lr|l|}
\hline Bit 9 & Bit 8 & Bit 7 & bit 6 & bit 1 & bit 0 \\
\hline $\begin{array}{l}\text { Falha } \\
\text { inicialização }\end{array}$ & $\begin{array}{l}\text { Baixa } \\
\text { tensão de } \\
\text { bateria }\end{array}$ & $\begin{array}{l}\text { Erro no } \\
\text { SPI }\end{array}$ & Erro de COM & $\begin{array}{l}\text { Ligação } \\
\text { curto ao de } \\
\text { negativo } \\
\text { bateria }\end{array}$ & $\begin{array}{r}\text { Ligação de } \\
\text { de } \\
\text { curto ao } \\
\text { positivo } \\
\text { bateria }\end{array}$ & $\begin{array}{r}\text { polo } \\
\text { de }\end{array}$ \\
\hline
\end{tabular}

Fonte: (ETAS, INC).

Se o valor de retorno do bit 0 for 1 , isto significa que há um curto ao polo positivo da bateria no pino VG da LSU2.

A Figura 3.35 exibe a hieraquia utilizada para leitura de diagnose do circuito integrado CJ125 e do acionamento do aquecedor para a sonda LSU/UEGO. 
Figura 3.35 - Hieraquia utilizada para leitura de diagnose do circuito integrado CJ125 e do acionamento do aquecedor para a sonda LSU/UEGO. HIERARCHY: LSU Diagnostics $\mathrm{pg}: 1 / 1$

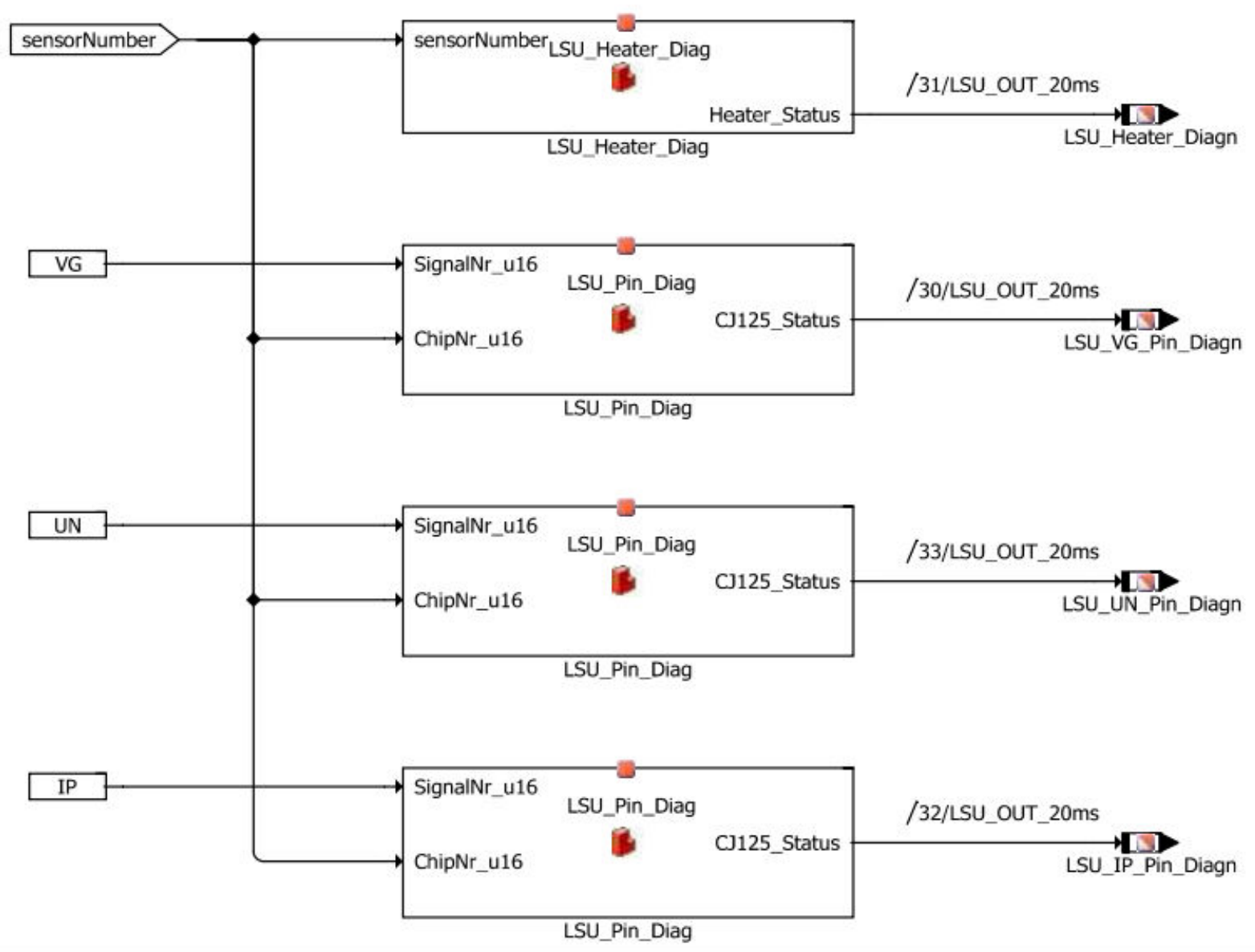

Fonte: $\mathrm{O}$ autor. 


\subsubsection{Diagnose do acionamento PWM do aquecedor do sensor de banda estreita LSF(HEGO/On-Off)}

Para a alternativa do sensor de oxigênio de banda estreita, o diagnóstico é realizado apenas em sua saída PWM, em razão de não haver um hardware dedicado disponível para esta aplicação.

No caso da função DevLib_PwmOut_GetError (Pwmout_Pin_t idx), o valor de retorno é armazenado na variável LSF_Heater_Diagn e possui uma codificação de bits onde cada flag de diagnóstico representa os status listados na Tabela 3.10.

Tabela 3.10 - Codificação dos bits da variável de retorno da função de diagnóstico para a saída PWM aplicada como Heater (Aquecedor) para o sensor de banda estreita LSF.

\begin{tabular}{|c|l|l|l|}
\hline Bit 3 & \multicolumn{1}{|c|}{ Bit 2 } & \multicolumn{1}{c|}{ Bit 1 } & \multicolumn{1}{c|}{ Bit 0 } \\
\hline Sobre-temperatura & Carga aberta & $\begin{array}{l}\text { Ligação de curto ao } \\
\text { polo negativo }\end{array}$ & $\begin{array}{l}\text { Ligação de curto ao } \\
\text { polo positivo }\end{array}$ \\
\hline
\end{tabular}
Fonte: (ETAS, INC).

Como na utilização do aquecimento deste sensor, não existe a medida de temperatura, a metodologia de aquecimento empregada foi de aplicar $90 \%$ de modulação PWM para o sensor frio e após a detecção da mudança de resistência de sua célula de Nernst (destacado na subseção 3.4.3), redução do PWM para 60\% apenas para manutenção do calor atingido. Esta estratégia ainda não foi aplicada de maneira automática, logo, é realizada através da ferramenta de calibração pelo operador do sistema.

A Figura 3.36 exibe a rotina de acionamento diagnose do sinal PWM para o aquecimento da sonda de banda estreita. 
Figura 3.36 - Módulo para acionamento diagnose do sinal PWM para o aquecimento da sonda de banda estreita.

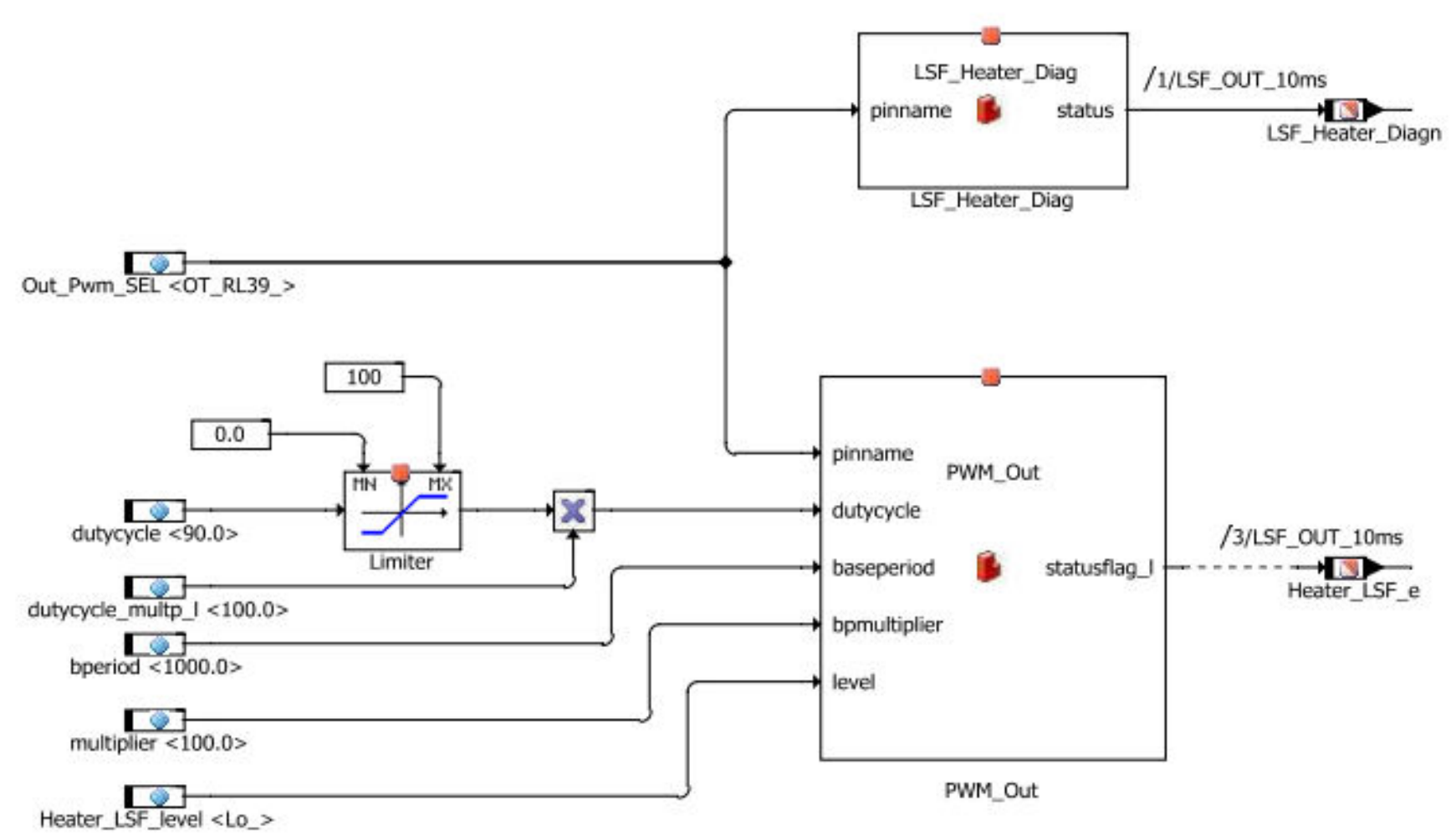

Fonte: O autor. 


\section{$4 \quad$ RESULTADOS}

\subsection{CONTROLE A/C EM MALHA ABERTA}

\subsubsection{Ajuste dos mapas básicos de injeção e ignição}

Conforme foi definido na subseção 2.2.4, mapas de calibração são frequentemente usados nos sistemas de controle para representação de parâmetros, controle e geração de setpoints. A ideia básica é usar quantidades medidas, como a velocidade do motor e a pressão do coletor de admissão (carga).

A calibração de ajuste dos mapas básicos de injeção foi realizada para uma relação de equivalência (lambda) alvo no ponto $(\lambda=0.92 \sim 0.98)$, deixando as pequenas parcelas situadas entre $0.02 \sim 0.08$ para serem compensadas automaticamente pelo controle A/C (lambda) realizado em malha fechada. A Tabela 4.1 exibe os dados da calibração realizada para o mapa básico de injeção para a gasolina (E27).

Tabela 4.1 - Calibração do mapa básico de injeção para a utilização de gasolina E27.

\begin{tabular}{|c|c|c|c|c|c|c|}
\hline & \multicolumn{7}{|c|}{ ROTAÇÃO [RPM] } \\
\hline MAP [KPa] & $\mathbf{1 5 0 0}$ & $\mathbf{2 0 0 0}$ & $\mathbf{2 5 0 0}$ & $\mathbf{3 0 0 0}$ & $\mathbf{3 5 0 0}$ & $\mathbf{4 0 0 0}$ \\
\hline $\mathbf{2 0}$ & 2,700 & 3,300 & 3,500 & 3,900 & - & - \\
\hline $\mathbf{3 0}$ & 3,750 & 3,750 & 3,900 & 4,000 & - & 4,700 \\
\hline $\mathbf{4 0}$ & 4,690 & 4,500 & 4,700 & 4,900 & 4,600 & 6,000 \\
\hline $\mathbf{5 0}$ & 5,500 & 5,600 & 5,800 & 5,900 & 5,900 & 7,000 \\
\hline $\mathbf{6 0}$ & 6,650 & 6,650 & 6,900 & 7,000 & 7,000 & 8,000 \\
\hline $\mathbf{7 0}$ & 7,650 & 7,800 & 8,100 & 8,200 & 8,200 & 9,100 \\
\hline $\mathbf{8 0}$ & 8,600 & 8,900 & 9,200 & 9,300 & 9,300 & 9,400 \\
\hline $\mathbf{8 2}$ & 9,000 & 9,000 & 10,000 & 10,000 & 9,500 & 9,600 \\
\hline $\mathbf{8 4}$ & 9,200 & 9,400 & 10,200 & 10,200 & 9,800 & 9,800 \\
\hline $\mathbf{8 6}$ & 9,300 & 9,700 & 10,300 & 10,300 & 10,000 & 10,000 \\
\hline $\mathbf{8 8}$ & 9,400 & 9,900 & 10,400 & 10,400 & 10,400 & 10,200 \\
\hline $\mathbf{9 0}$ & 9,500 & 10,300 & 10,600 & 10,500 & 10,400 & - \\
\hline
\end{tabular}

Fonte: $\mathrm{O}$ autor.

O mapa básico para injeção de combustível resultante para o etanol hidratado (E95), apresentado na Tabela 4.2, evidenciou um aumento considerável nestes parâmetros. Um resultado que era esperado em função do conhecimento da diferença das relações estequiométricas dos dois combustíveis, sendo que o E95 
necessita de uma maior quantidade de hidrocarbonetos (combustível) para reagir com uma mesma quantidade de ar (oxigênio).

Tabela 4.2 - Calibração do mapa básico de injeção para a utilização de etanol hidratado E95.

\begin{tabular}{|c|c|c|c|c|c|c|}
\hline & \multicolumn{7}{|c|}{ ROTAÇÃO [RPM] } \\
\hline MAP [KPa] & $\mathbf{1 5 0 0}$ & $\mathbf{2 0 0 0}$ & $\mathbf{2 5 0 0}$ & $\mathbf{3 0 0 0}$ & $\mathbf{3 5 0 0}$ & $\mathbf{4 0 0 0}$ \\
\hline $\mathbf{2 0}$ & 3,300 & 3,700 & 4,000 & 4,000 & - & - \\
\hline $\mathbf{3 0}$ & 3,700 & 4,200 & 4,800 & 5,000 & - & - \\
\hline $\mathbf{4 0}$ & 6,000 & 6,000 & 6,500 & 6,400 & 6,400 & 6,400 \\
\hline $\mathbf{5 0}$ & 7,400 & 7,400 & 7,800 & 7,900 & 7,900 & 7,900 \\
\hline $\mathbf{6 0}$ & 8,900 & 8,900 & 9,500 & 9,600 & 9,600 & 9,600 \\
\hline $\mathbf{7 0}$ & 10,500 & 10,600 & 10,900 & 11,000 & 11,100 & 11,400 \\
\hline $\mathbf{8 0}$ & 12,000 & 12,200 & 12,500 & 12,600 & 13,000 & 13,000 \\
\hline $\mathbf{8 2}$ & 12,300 & 12,500 & 12,700 & 12,900 & 13,300 & 13,400 \\
\hline $\mathbf{8 4}$ & 12,700 & 12,900 & 13,000 & 13,200 & 13,500 & 13,600 \\
\hline $\mathbf{8 6}$ & 12,700 & 13,100 & 13,400 & 13,700 & 14,000 & 14,200 \\
\hline $\mathbf{8 8}$ & 13,200 & 13,500 & 14,000 & 14,300 & 14,300 & 14,400 \\
\hline $\mathbf{9 0}$ & 13,700 & 14,200 & 14,500 & 14,600 & 14,600 & 14,700 \\
\hline
\end{tabular}

Fonte: $\mathrm{O}$ autor.

Para os mapas básicos de ignição do combustível E27 (gasolina), o critério escolhido foi adiantar o avanço de ignição até que se atingisse o ponto de máximo torque (MBT). A partir deste ponto então atrasava-se cerca de 5 a 8 graus deixando uma excursão de adiantamento do ponto de ignição a ser realizada em malha fechada com a realimentação realizada a partir de um sensor de oscilações sísmicas situado no bloco do motor, o chamado sensor piezoelétrico de detonação. A Tabela 4.3 exibe os dados da calibração realizada para o mapa básico de ignição para a gasolina (E27).

Tabela 4.3 - Calibração do mapa básico de ignição para a utilização de gasolina E27.

\begin{tabular}{|c|c|c|c|c|c|c|}
\hline & \multicolumn{7}{|c|}{ ROTAÇÃO [RPM] } \\
\hline MAP[KPa] & $\mathbf{1 5 0 0}$ & $\mathbf{2 0 0 0}$ & $\mathbf{2 5 0 0}$ & $\mathbf{3 0 0 0}$ & $\mathbf{3 5 0 0}$ & $\mathbf{4 0 0 0}$ \\
\hline $\mathbf{2 0}$ & 32,250 & 35,250 & - & - & - & - \\
\hline $\mathbf{3 0}$ & 23,000 & 35,250 & 34,500 & 35,250 & - & - \\
\hline $\mathbf{4 0}$ & 23,250 & 33,000 & 35,250 & 36,000 & 36,000 & 33,750 \\
\hline $\mathbf{5 0}$ & 19,500 & 27,750 & 33,750 & 34,500 & 33,750 & 29,250 \\
\hline $\mathbf{6 0}$ & 26,250 & 23,250 & 29,250 & 27,000 & 34,500 & 30,000 \\
\hline $\mathbf{7 0}$ & 21,000 & 24,750 & 26,250 & 27,000 & 28,500 & 27,000 \\
\hline $\mathbf{8 0}$ & & 19,500 & 20,250 & 24,000 & 27,750 & 22,500 \\
\hline $\mathbf{9 0}$ & & 15,750 & 19,500 & 21,750 & 23,250 & 21,000 \\
\hline
\end{tabular}


Fonte: O autor. 
Observou-se que para o mapa de ignição respectivo ao E95, não era necessária a aplicação do mesmo do E27, pois, ao alcançar-se o ponto de MBT na utilização do etanol, foi observado que o índice de detonação foi praticamente nulo, eliminado a necessidade de controle de detonação em malha fechada. O mapa básico de ignição resultante para o etanol hidratado (E95) apresentado na Tabela 4.4, evidenciou um aumento considerável nestes parâmetros.

Tabela 4.4 - Calibração do mapa básico de ignição para a utilização de etanol hidratado E95.

\begin{tabular}{|c|c|c|c|c|c|c|}
\hline & \multicolumn{7}{|c|}{ ROTAÇÃO [RPM] } \\
\hline MAP[KPa] & $\mathbf{1 5 0 0}$ & $\mathbf{2 0 0 0}$ & $\mathbf{2 5 0 0}$ & $\mathbf{3 0 0 0}$ & $\mathbf{3 5 0 0}$ & $\mathbf{4 0 0 0}$ \\
\hline $\mathbf{2 0}$ & 21,000 & 22,000 & - & - & - & - \\
\hline $\mathbf{3 0}$ & 19,500 & 23,000 & 23,000 & 24,000 & - & - \\
\hline $\mathbf{4 0}$ & 17,250 & 30,250 & 34,000 & 39,250 & 37,750 & 37,750 \\
\hline $\mathbf{5 0}$ & 18,750 & 31,250 & 35,500 & 33,250 & 36,250 & 38,500 \\
\hline $\mathbf{6 0}$ & 17,250 & 29,000 & 36,250 & 32,750 & 37,500 & 35,250 \\
\hline $\mathbf{7 0}$ & 17,250 & 27,750 & 32,750 & 32,750 & 34,500 & 33,000 \\
\hline $\mathbf{8 0}$ & 17,250 & 27,250 & 31,500 & 33,250 & 32,250 & 31,500 \\
\hline $\mathbf{9 0}$ & 15,250 & 26,750 & 30,750 & 33,000 & 31,500 & 31,000 \\
\hline
\end{tabular}

Fonte: $\mathrm{O}$ autor.

É importante ressaltar que esses ajustes foram realizados em razão da oportunidade da utilização de um banco dinamométrico dedicado ao motor, contudo, em suas instalações não haviam os equipamentos necessários para controle dos parâmetros de pressão e temperatura do ar ambiente a que o powertrain estava submetido.

O segundo ponto é que o tempo de carga da bobina e as correções do tempo de injeção e tempo de carga da bobina pela tensão do sistema elétrico estavam desligadas, pois, a sala dinamométrica contava com uma fonte de alimentação que possui 12 Volts. Uma situação diferente e mais realista é a do veículo, onde a tensão é controlada pelo circuito regulador do alternador podendo variar aproximadamente de 12 a 14,5 Volts e com isto, traria a necessidade de compensação da calibração dos mapas básicos de injeção e ignição, onde um dos métodos válidos para nesta aplicação seria o descrito na subseção 2.2.4. 


\subsection{CONTROLE A/C EM MALHA FECHADA PARA UM SENSOR DE OXIGÊNIO DE BANDA LARGA (LSU/UEGO)}

A seguir são demonstrados diferentes experimentos que foram realizados com o objetivo de avaliação dinâmica da malha de controle lambda em closed loop.

\subsubsection{Correção por composição do combustível}

Para avaliar a eficácia do método empregado para a correção da quantidade de combustível em função do percentual de etanol presente, aplicou-se uma condição adversa, que gerou o efeito apresentado na Figura 4.1 na rotação de saída do motor.

Figura 4.1 - Sinal de rotação do motor durante perturbação gerada na correção da composição.

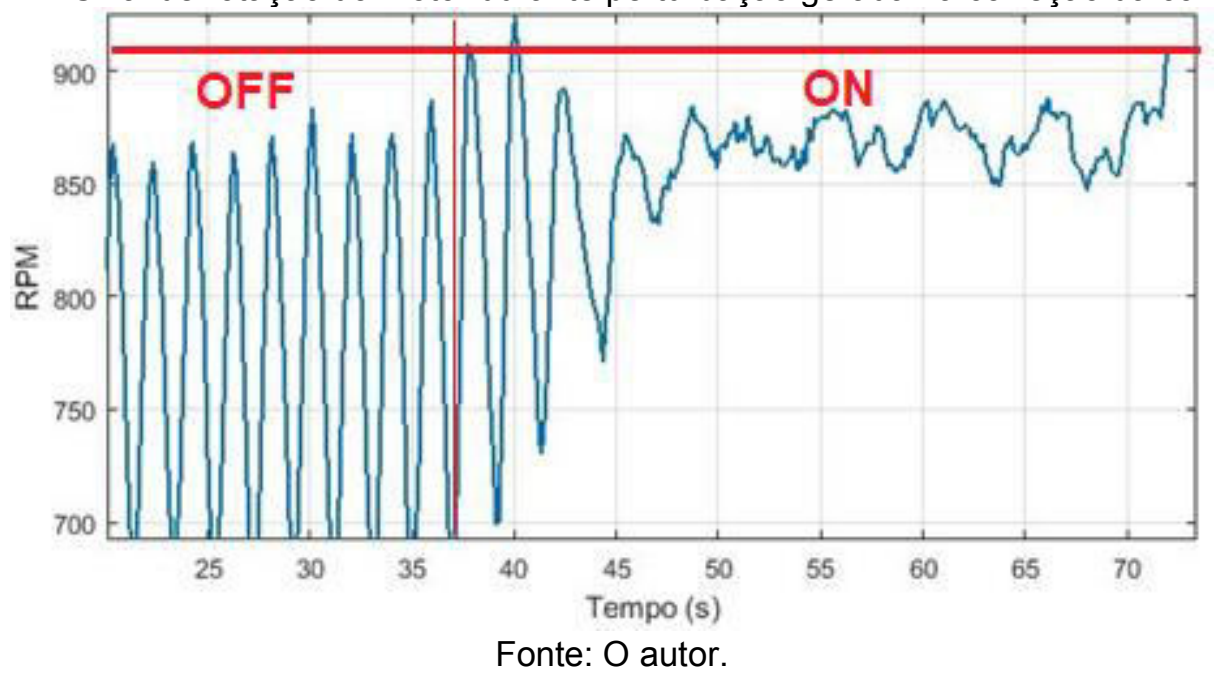

Durante os primeiros 36 segundos, o controle de composição foi propositalmente desativado, para que fossem utilizados os tempos de injeção relativos ao combustível E27 (gasolina). Como a composição real de combustível encontrava-se em 91 \% de etanol, o tempo de injeção não é suficiente para atingir a relação estequiométrica fazendo com que a malha de controle A/C (lambda) em malha fechada aumente e reduza o tempo de injeção de maneira abrupta. Observase um erro oscilatório de aproximadamente 150 RPM para a saída de rotação do motor. A correção open-loop/feedforward em função da composição do combustível foi habilitada após 36 segundos, o que restaura a estabilidade da rotação do motor ao decorrer de 9 segundos durante o regime de marcha lenta. 
Figura 4.2 - Sinais de referência alvo e medição do sensor UEGO oriundos do controle A/C.

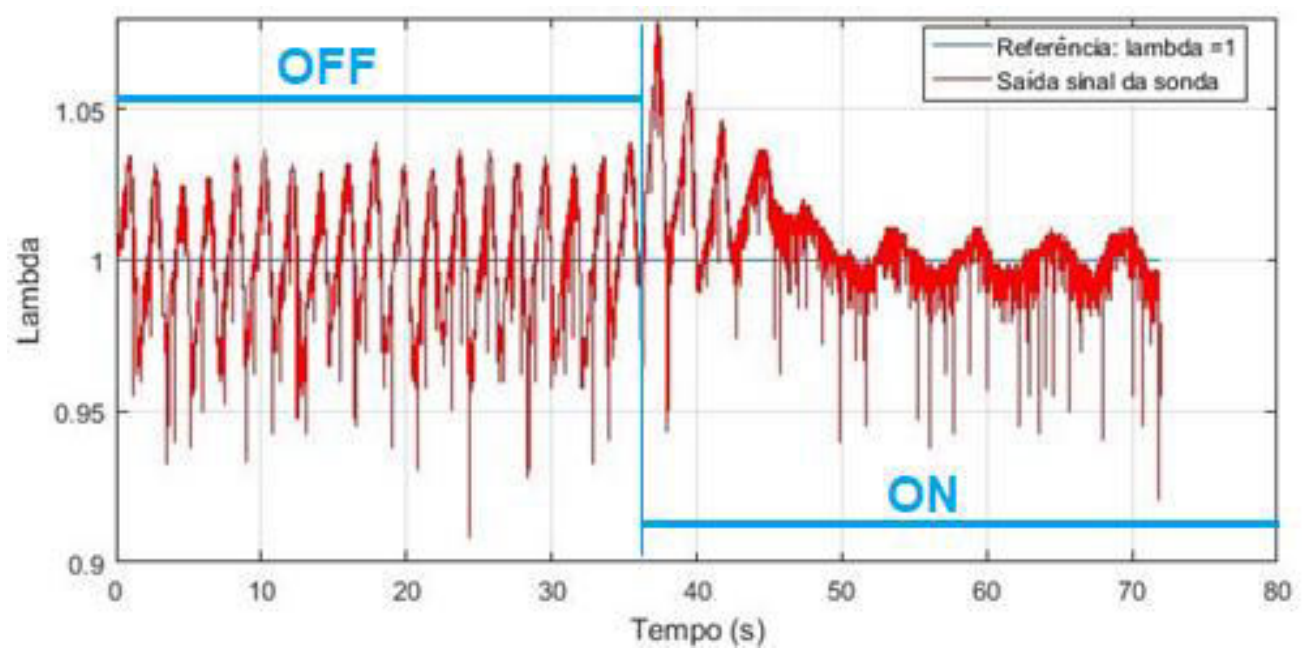

Fonte: O autor.

Conforme a medição apresentada na Figura 4.2, o controle em malha aberta em função da composição mostrou-se relevante para a manutenção da acurácia e estabilidade da rotação de marcha lenta. Entretanto, mesmo com a oscilação em regime estacionário na saída de rotação, a adequação da mistura $A / C$ ao ponto estequiométrico não fora seriamente prejudicada. O efeito da desconsideração do teor de etanol na mistura gera o erro de aproximadamente $5 \%$ para o fator lambda que é reduzido para $1 \%$, quando a porcentagem de etanol passa a ser incluída novamente na estratégia de correção feedforward.

Considerando os experimentos apresentados nas Figura 4.1 e Figura 4.2, pode-se notar a importância da segura determinação da estequiometria do combustível, função que é realizada pelo sistema em malha aberta. No momento em que a medida do sensor de composição de combustível ou concentração de etanol foi desconsiderada, implantou-se instabilidade no sistema, gerando oscilações tanto na velocidade angular do motor como em sua relação de equivalência lambda alvo.

\subsubsection{Enriquecimento da mistura A/C durante aceleração brusca (kick down) e aceleração gradual.}

Neste teste, a aceleração foi requisitada a partir do sinal eletrônico do pedal para que o controle do corpo de aceleração (válvula borboleta) atenda uma solicitação de abertura e controle a ponte $\mathrm{H}$, liberando a passagem do fluxo de ar para alimentar o motor, dois efeitos iniciais foram notados na Figura 4.3. 
Figura 4.3 - Variação no teor de etanol do combustível durante a realização do teste e sinal da solicitação de torque kick down realizada através do sinal eletrônico de pedal E-GAS para o módulo de controle eletrônico de aceleração (ETC).
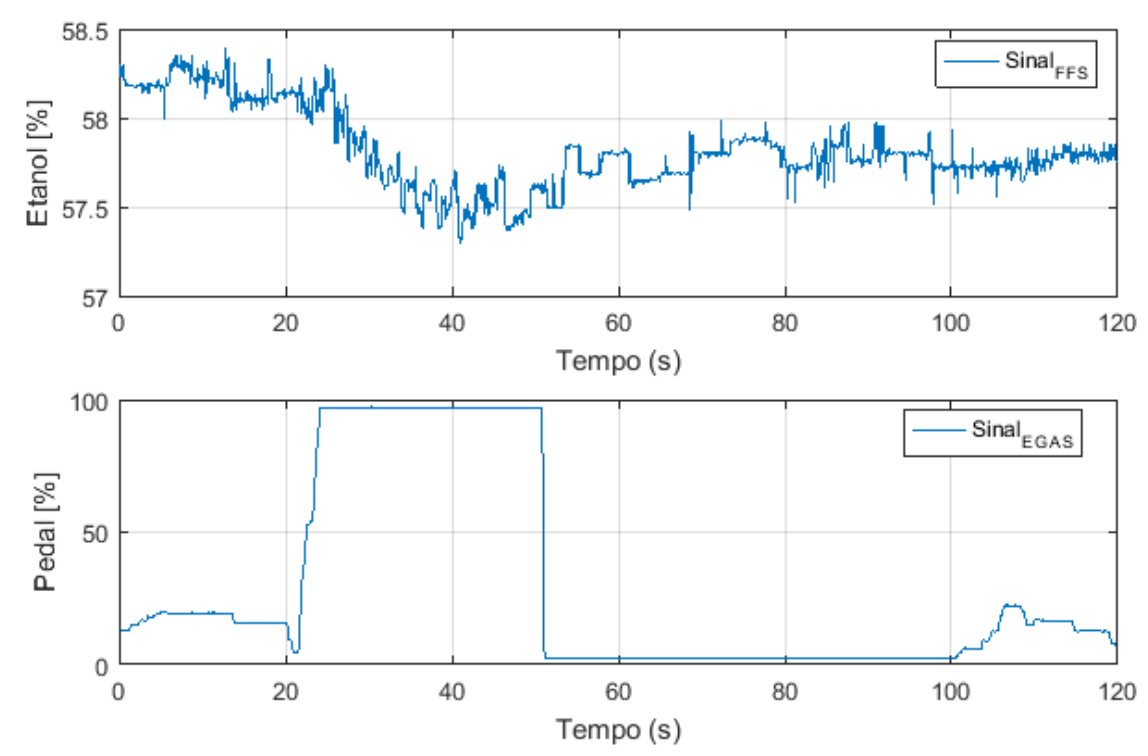

Fonte: $\mathrm{O}$ autor.

Distingue-se que a pequena variação medida no teor de etanol do combustível ocorreu-se no intervalo de 27 a 50 segundos, em função da mudança repetina no fluxo de combustível presente nas galerias de alimentação. $O$ sinal de pedal do motorista é utilizado para excitação do incremento de rotação no motor, evidenciando a operação do sistema E-GAS (Electronic $\underline{\text { Glow }}$ Adjustable $\underline{\text { Switch) }}$ durante a realização do teste.

Com esta imposição da demanda aceleração, a rotação foi acrescida de uma condição próxima a de marcha lenta (800 RPM) até atingir uma velocidade de giro igual a 5200 RPM, momento em que o pedal foi devolvido à condição de repouso, para que ocorresse a desaceleração e reestabelecimento da condição de marcha lenta, com base na interpretação de seu sinal.

A sequência dos acontecimentos relatados se aproxima muito de uma situação real de solicitação de torque e, por isso, deve possuir um funcionamento consideravelmente robusto, a fim de assegurar ao condutor o escape de uma condição arriscada em uma possível ultrapassagem. 
Figura 4.4 - Rotação do motor em regime de entrega de torque e referência em conjunto com o sinal de medição do sensor UEGO oriundos do controle A/C.
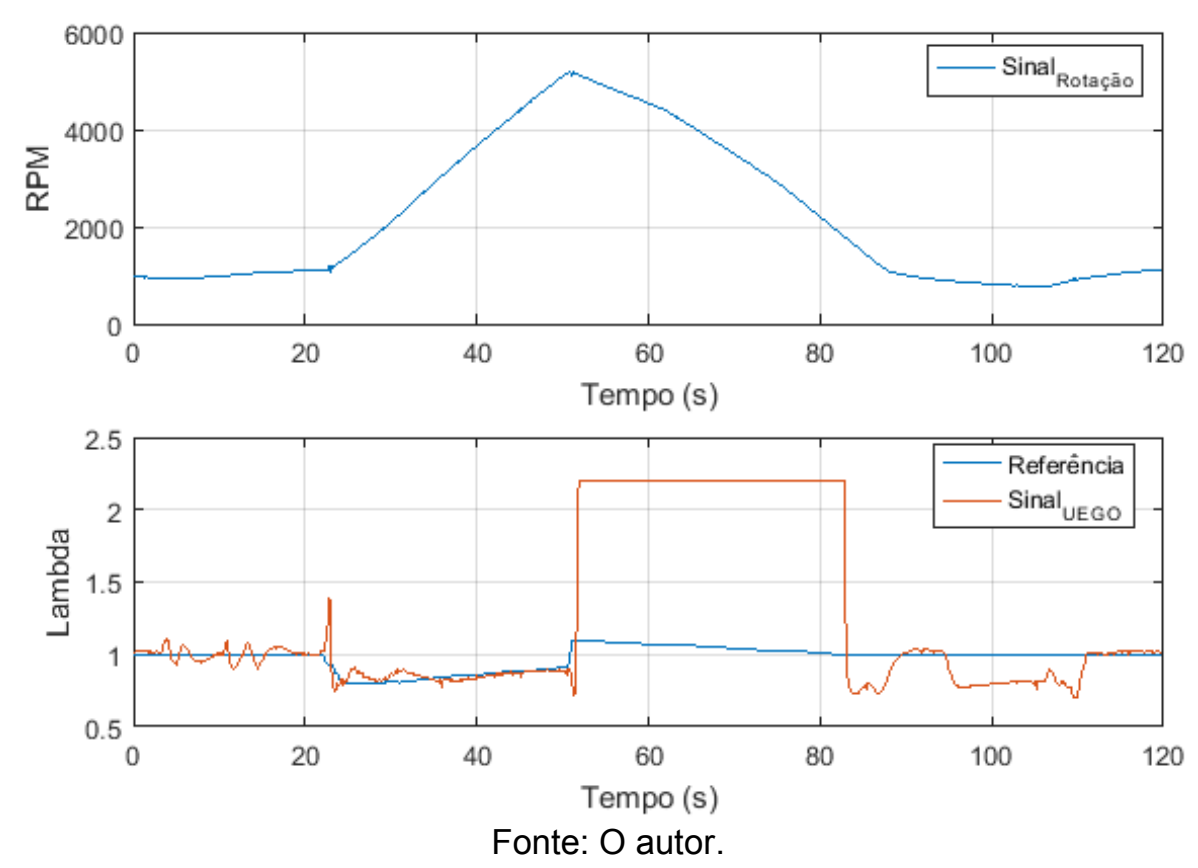

A Figura 4.4 exibe a rotação do motor em regime de entrega de torque e referência em conjunto com o sinal de medição do sensor UEGO oriundos do controle $A / C$. No instante inicial, a rotação do motor encontrava-se em regime de marcha lenta, com uma relação lambda que oscilava em torno de sua referência estequiométrica. $O$ valor da relação lambda começa a ser alterado no instante de 25 segundos, onde o sinal medido passa a ser o de uma mistura enriquecida aos 27 segundos, momento em que o sinal se torna rico até o ponto de 50 segundos, e empobrecido durante 30 segundos e posteriormente retorna ao ponto estequiométrico. A Figura 4.5 mostra os períodos base para correção, as parcelas corrigidas e os períodos efetivos para injeção do combustível. 
Figura 4.5 - Dinâmica dos paramêtros de correção para os períodos de injeção em função da composição do combustivel.

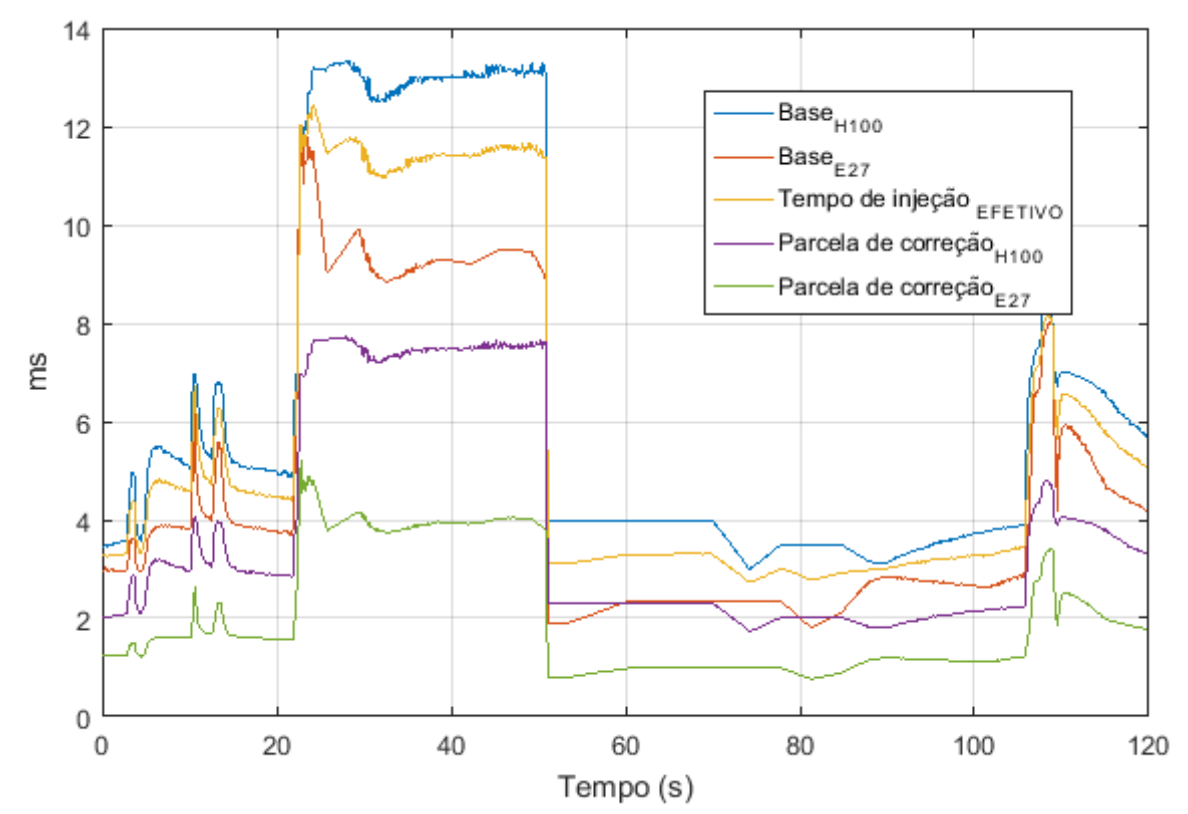

Fonte: $\mathrm{O}$ autor.

Essa correção está exemplificada pela Eq. (3.6) na seção 3.5.1, o ajuste dos parâmetros dependentes da composição do combustível, como tempo de injeção e avanço de ignição, corrigidos pelo método de interpolação em função do teor de etanol do combustível. Para que tais parâmetros estejam automaticamente adequados às variações de composição, a relevância deste controle é testada a na seção 4.1.1.

Nota-se que o tempo de injeção efetivo será sempre a soma das parcelas de correção entre os combustíveis de proporções extremas (E27 e H100). As parcelas de correção são índices percentuais variantes com a medida do sensor de composição do combustível (concentração de etanol). Desta maneira, tanto o período de injeção efetivo como as parcelas de correção baseadas na medida da concentração de etanol presente no combustível seguirá as características dos mapas básicos de injeção de maneira compensada.

O intuito do segundo experimento foi testar o controle de lambda, em um regime aceleração moderado. Neste experimento foi realizada uma aceleração em rampa, onde o veículo esteve tracionando a massa inercial em um dinamômetro passivo em uma faixa de rotação entre 1500 e 5000 RPM. Os sinais de rotação e lambda, medidos pela sonda estão exibidos na Figura 4.6. 
Figura 4.6 - (a)Sinal de rotação do motor em regime de aceleração em gradual e (b)sinais de referência alvo e medição do sensor LSU/UEGO oriundos do controle A/C.
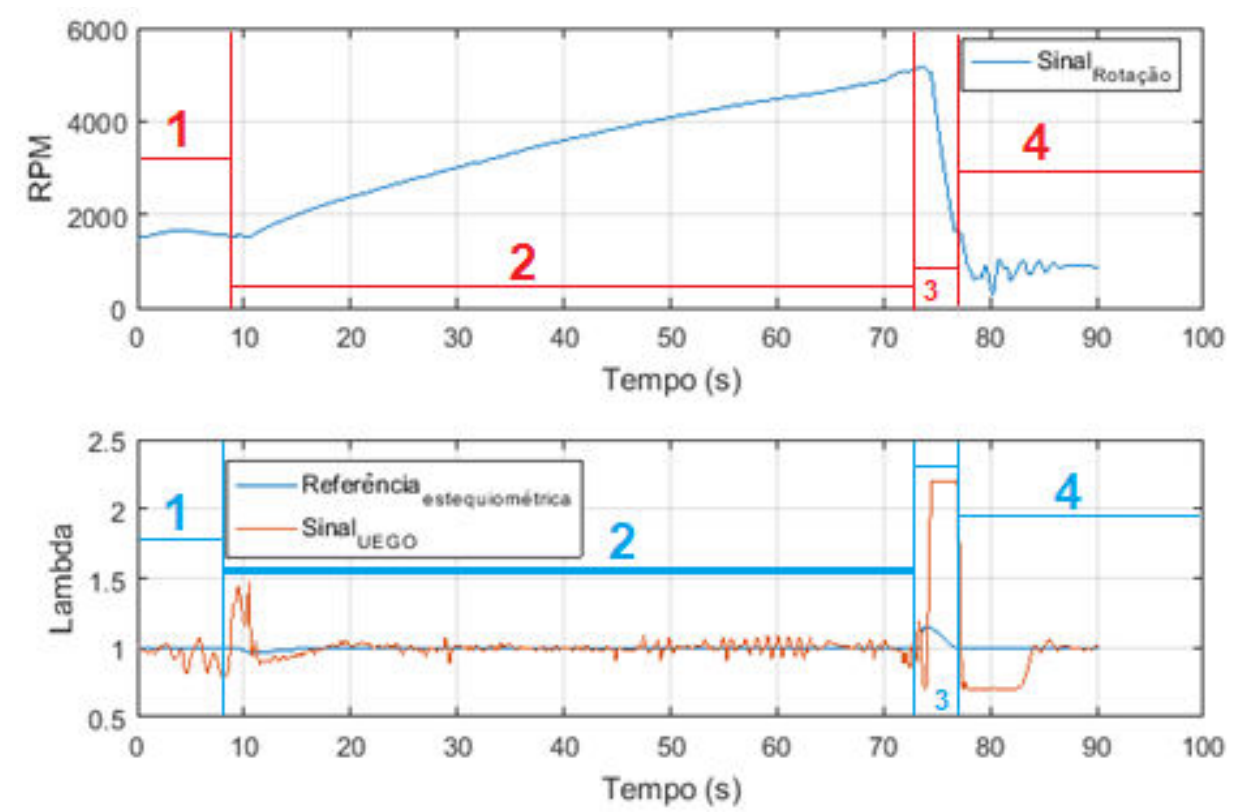

Fonte: O autor.

Controlando-se a abertura da válvula borboleta em uma rampa suave, obtevese o aumento gradual da massa de ar, onde foi possível acelerar o motor mantendoo em uma condição de mistura estequiométrica. Ao final do instante (1) da simulação, foi necessário o enriquecimento da mistura, para que o motor deixasse a condição de rotação estacionária em um regime crescente, a fim de compensar o aumento repentino de massa de ar causado pela abertura da válvula borboleta. Durante o período (2), momento em que a taxa de crescimento da massa de ar se torna constante, a malha de controle lambda mantém com desvios mínimos a condição da referência desejada. Na transição entre o instante (2) e (3), a válvula borboleta foi retornada à sua condição de repouso, com isto, a estratégia de cut-off retirou uma parcela fixa do tempo de injeção, fazendo com que a relação de equivalência atingisse valores acima de 2 na desaceleração do motor. Com o decaimento de rotação no início do instante (4), o tempo de injeção volta a ser controlado puramente pelo controle A/C (lambda) em malha fechada. A Figura 4.7 exibe a largura do período de injeção e a variação do coeficiente do fator de correção da malha durante o mesmo teste. 
Figura 4.7 - Período de injeção efetivo e fator de correção proveniente do controle A/C e variação da temperatura do ar de entrante para o motor.
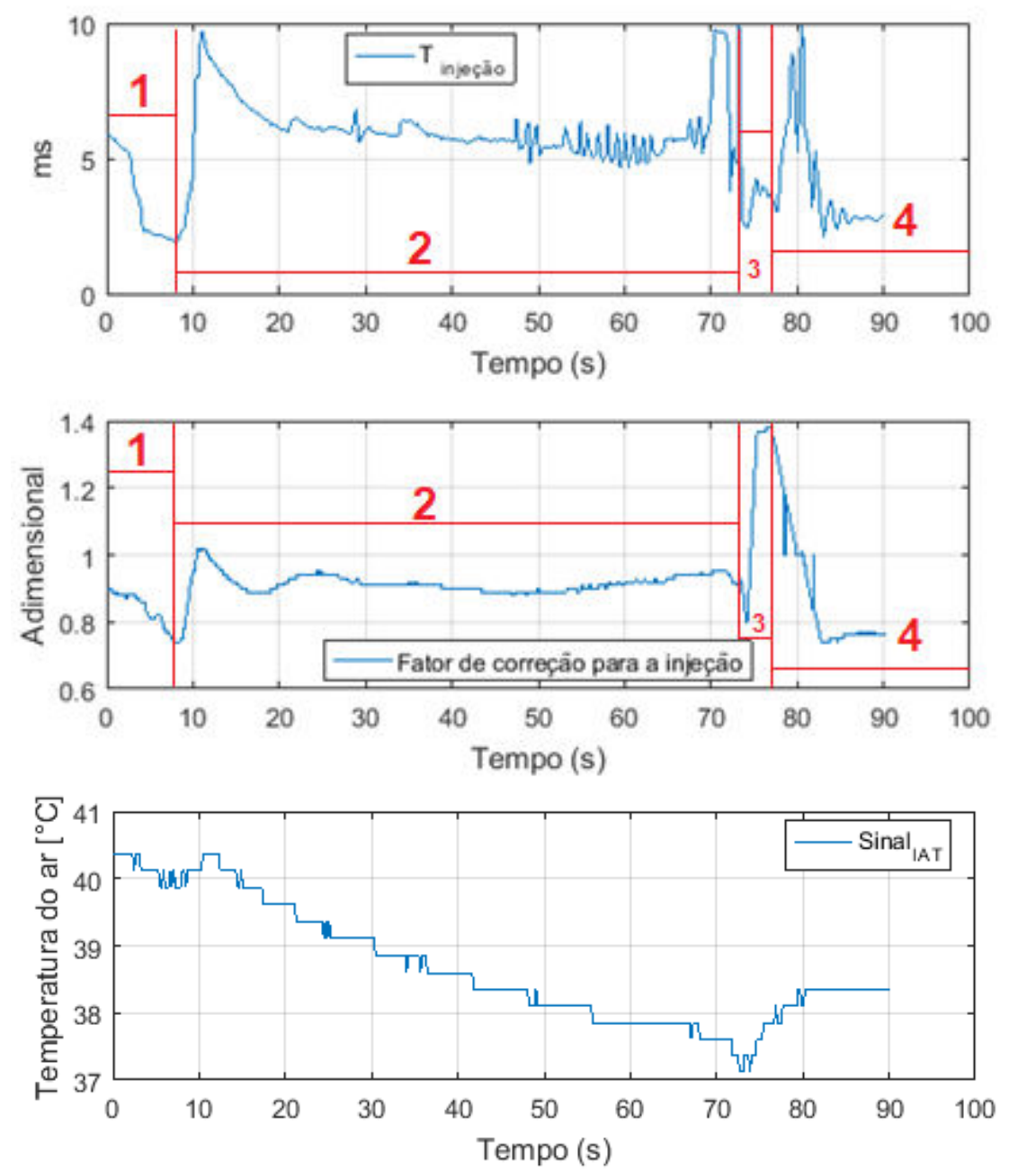

Fonte: $\mathrm{O}$ autor.

Este resultado mostra que, mesmo com o aumento de rotação, pode-se manter o ajuste da relação de equivalência lambda alvo, com uma ótima precisão de acompanhamento da referência. Observa-se que o tempo de injeção acompanha fielmente o formato imposto pela variação do fator de correção lambda, desconsiderando o momento em que ocorrem demais influências como a que é gerada pela estratégia de cut-off.

O decréscimo de 3 graus centigrados na temperatura do ar presente no coletor de admissão durante o teste na Figura 4.8, com um perfil de variação proporcional a velocidade do motor, denota que essa redução tenha ocrrido pelo efeito do aumento de velocidade e fluxo do ar para o motor, causado pela abertura da válvula borboleta. 
A Figura 4.8 mostra os avanços base para correção, as parcelas corrigidas e os períodos efetivos para o controle para avanço do ângulo de ignição aplicado durante o mesmo experimento. Nota-se que para uma mistura com teor igual a $58 \%$ de etanol, o avanço de ignição efetivo será a soma de $62 \%$ do avanço base do combustível E27/H0 (gasolina) com 58\% do avanço base do combustível H100/ E95 (etanol hidratado).

Figura 4.8 - Dinâmica dos paramêtros de correção para os ângulos de ignição em função da composição do combustivel.

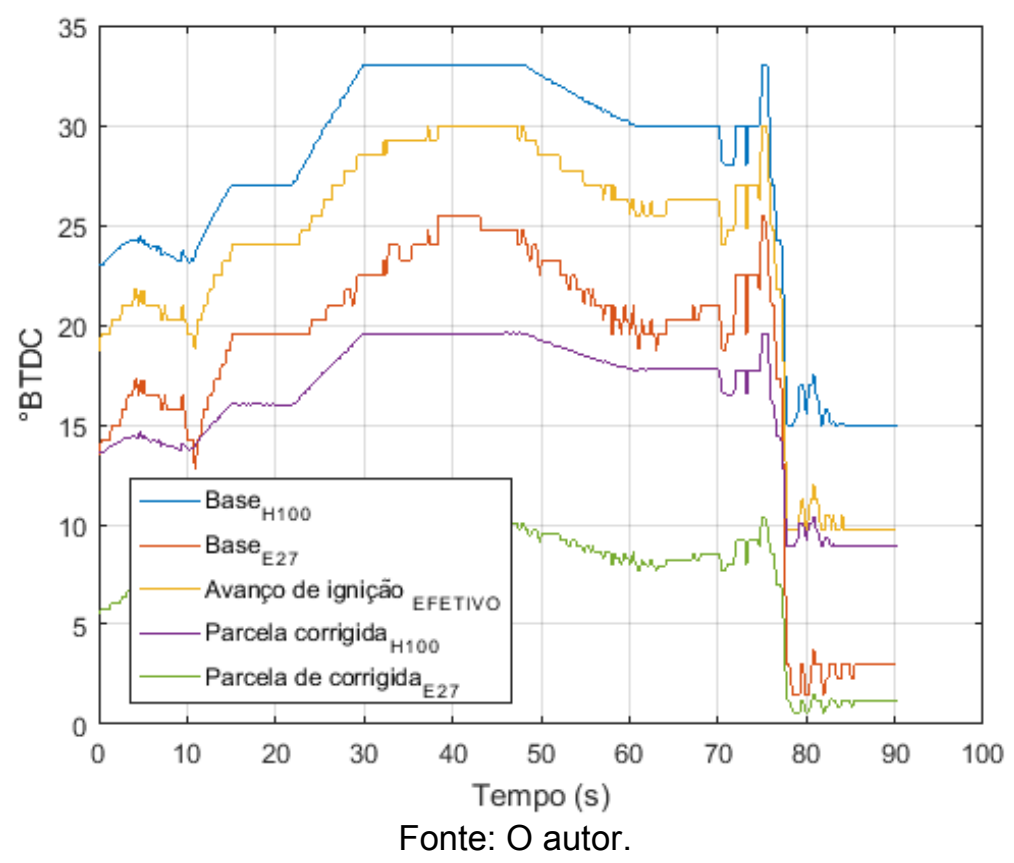

Essa correção está exemplificada pela Eq. (3.7) na seção 3.5.1, o ajuste dos parâmetros para ignição dependentes da composição do combustível, como tempo de injeção e avanço de ignição são corrigidos pelo método de interpolação em função do teor de etanol do combustível. Para que tais parâmetros estejam automaticamente adequados às variações de composição, a relevância deste controle foi testada e exibida na seção 4.2.1.

\subsubsection{Manutenção da relação estequiométrica durante regime de marcha lenta} e conversão da corrente de bombeamento para a relação de equivalência lambda

Este experimento foi realizado com a intenção de avaliar se a ação de controle seria capaz de manter a mistura estequiométrica durante a condição de marcha lenta. $O$ regime de marcha lenta é a condição em que o motor mantém a 
rotação mínima para o seu funcionamento, porém em stand-by ${ }^{34}$, aguardando possível requisição de potência. Os testes em condição de marcha lenta foram realizados sem requisição de trabalho do motor, ou seja, o acelerador estava em repouso, sendo que a rotação alvo era estipulada por meio de um parâmetro de calibração previsto na aplicação do software no ambiente ASCET para ser utilizado de forma posterior em testes através da ferramenta para calibrações e aquisições INCA.

O módulo ETC, que realiza a função de controlar a rotação, pode receber a referência como um parâmetro de calibração. Através desse parâmetro, é possível determinar a referência desejada de rotação durante os testes, sem que seja necessário o uso do pedal de acelerador na estratégia ETC/EGAS (acelerador eletrônico).

Figura 4.9 - Sinal de rotação do motor em regime de marcha lenta, sinais de referência alvo e medição do sensor UEGO oriundos do controle A/C.
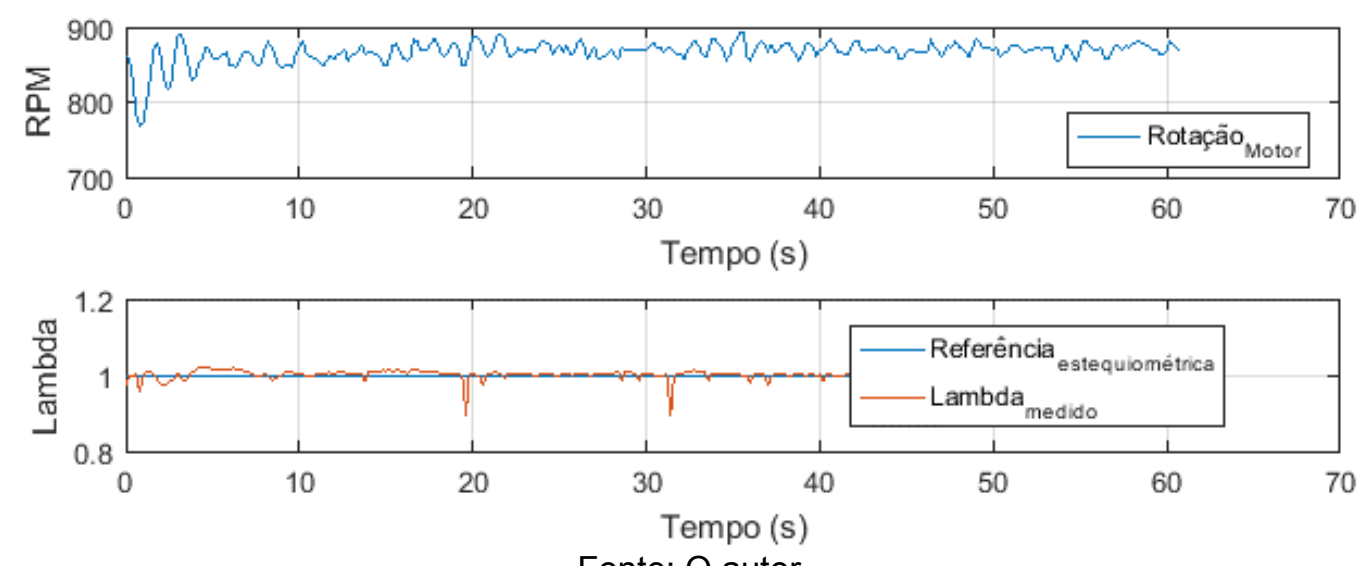

Fonte: $\mathrm{O}$ autor.

Com a rotação aproximadamente constante em torno de 800 RPM, conforme mostrado pela Figura 4.9, a rotina de controle lambda terá o objetivo de manter a mistura $A / C$ instantânea igual a relação $A / C$ estequiométrica, ou seja, lambda igual a um $(\lambda=1.0)$, a dinâmica deste controle está na Figura 4.10 , onde exibem-se o período de injeção corrigido, o coeficiente do fator de correção lambda, e o erro de controle da malha aplicados na planta real (motor) durante o regime de marcha lenta.

${ }^{34}$ Expressão da língua inglesa formada por stand, que significa parada, pausa e/ou descanso, em conjunto com by, que significa perto de, ao lado de, por meio de. Portanto "stand by" significa estar de prontidão a ou estar em espera de algo. 
Figura 4.10 - Período de injeção efetivo, fator de correção lambda e dinâmica dos ganhos existentes no controle $\mathrm{A} / \mathrm{C}$ em malha fechada.
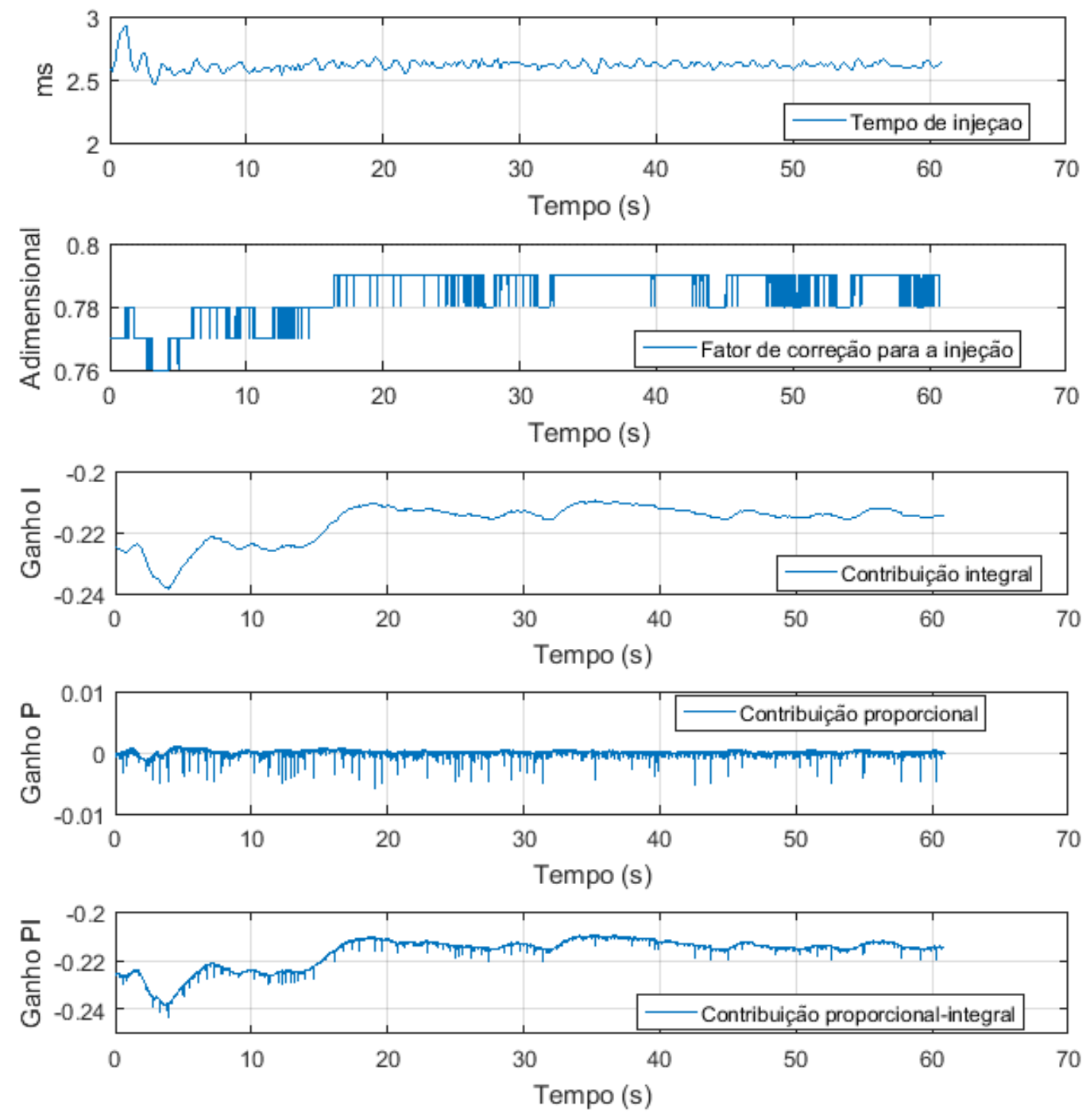

Fonte: $\mathrm{O}$ autor.

O experimento demonstrou que o controle obteve boa estabilidade, mantendo a relação estequiométrica com variações mínimas no tempo de injeção, sem causar grandes variações na rotação do motor. A dinâmica dos ganhos do controle PI em uma atuação paralela, os mesmos foram sintonizados a partir da aproximação utilizada para identificação (demonstrada na subseção 3.5.2), com objetivo principal da provisão de esforços de ação de controle adequados para o cumprimento do principal objetivo desta malha fechada.

O objetivo principal é fixar a relação ar/combustível desejada sem que sejam inseridas perturbações na operação do $\mathrm{MCl}$, causando instabilidade no sistema, o que poderia ocorrer, caso, os ganhos de controle não forem sintonizados. 
O segundo experimento teve o objetivo de quantificar o delta entre a medida realizada pelo analisador lambda LA4 da medida originada da corrente de bombeamento do CJ 125 através do LLSW.

Figura 4.11 - Resultado do teste de comparação entre a medida da (a) corrente de bombeamento do CJ 125 e sua conversão com a (b) medida do analisador lambda LA4.
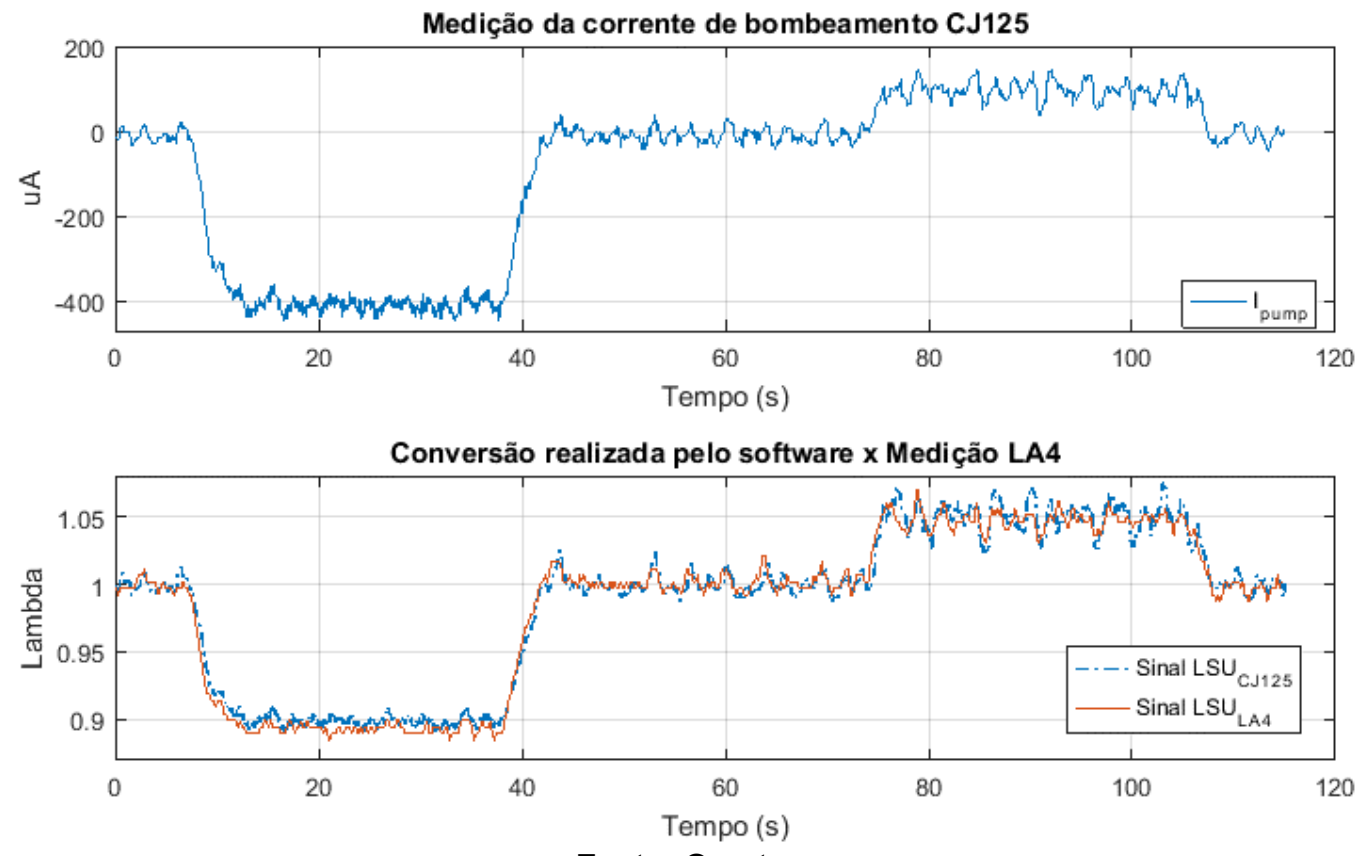

Fonte: $\mathrm{O}$ autor.

A Figura 4.11 mostra que a conversão da corrente de bombeamento se aproxima da medida do analisador lambda LA4 com um desempenho estável para relações de equivalência $(\lambda<1.0)$. Para relações de equivalência $(\lambda \geq 1.0)$, nota-se que ocorrem oscilações de medida em torno de $2 \%$ para alvo $(\lambda=1.0)$, e $4 \%$ para alvo $(\lambda<1.05)$, muito provavelmente isso se deve a correção por pressão absoluta para a corrente de bombeamento do sensor de oxigênio (destacada na Figura 4.12 da subseção 2.3.2) que não foi devidamente parametrizada no projeto.

É possível notar que existe um mínimo desvio entre as medidas quando estas começam a oscilar. Isso se deve ao fato do analisador lambda LA4 possuir maior precisão, pois conta com curva de correção em função da relação estequiométrica, das relações H/C (Hidrogênio/Carbono) e O/C (Oxigênio/Carbono) do combustível utilizado.

Existe ainda mais um fator que torna complexa a leitura da corrente de bombeamento do sensor de oxigênio, que é a variação da corrente de 
bombeamento em função da pressão absoluta dos gases de escape, como ilustrado na Figura 4.12.

Figura 4.12 - Variação da corrente de bombeamento medida por um sensor de oxigênio LSU/UEGO versão 4.9 em função da pressão absoluta no coletor de exaustão.

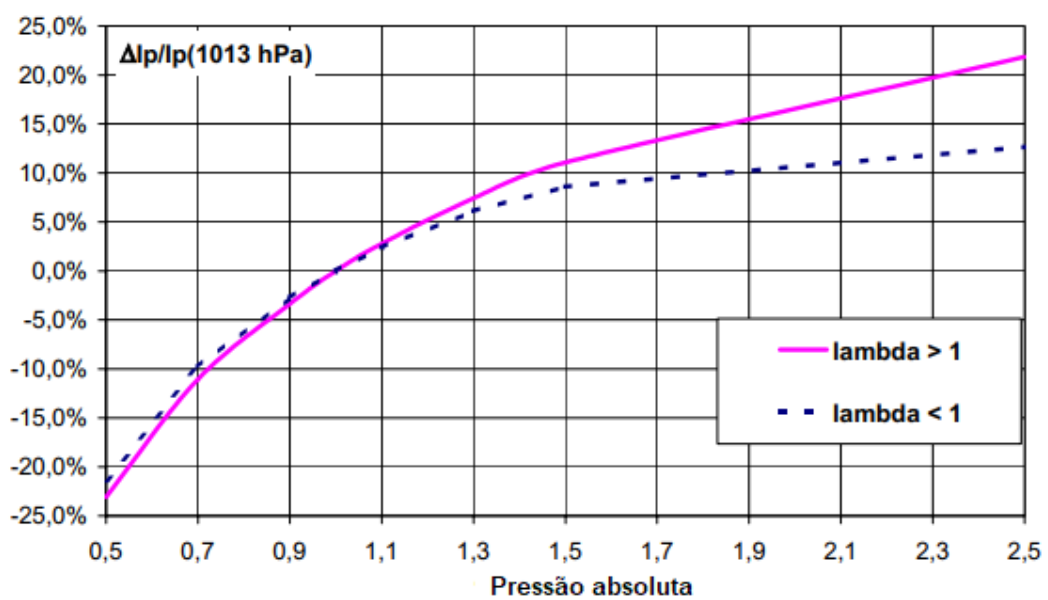

Fonte: Adaptado de (BOSCH, 2005).

Conclui-se, portanto, que a medida lambda de um sensor de banda larga amplificada é complexa comparada a medida de um sensor de banda estreita, e ainda no caso de utilização da Bosch LSU versão 4.9, necessita-se de trabalhos posteriores de calibração, o que seria minimamente necessário, caso, tivesse sido utilizada a sonda correta para a Flex-ECU, a Bosch LSU versão ADV, a qual possui curvas de desvio idênticas para as excursões $\lambda>1.0$ e $\lambda<1.0$.

\subsubsection{Regulação da temperatura de operação do sensor LSU/UEGO}

Em concordância com as descrições realizadas nas subseção 2.3.2, que descreve os princípios de funcionamento do sensor, e na subseção 3.5.4, que explicita a maneira como foi realizado o controle de temperatura do mesmo, O IC CJ 125 possibilita a medida direta da temperatura da célula de medição Nernst do sensor de banda larga amplificada LSU/UEGO. 
Figura 4.13 - Teste de variação de temperatura do sensor LSU/UEGO realizado de forma direta através da função de comunicação com o IC CJ 125.
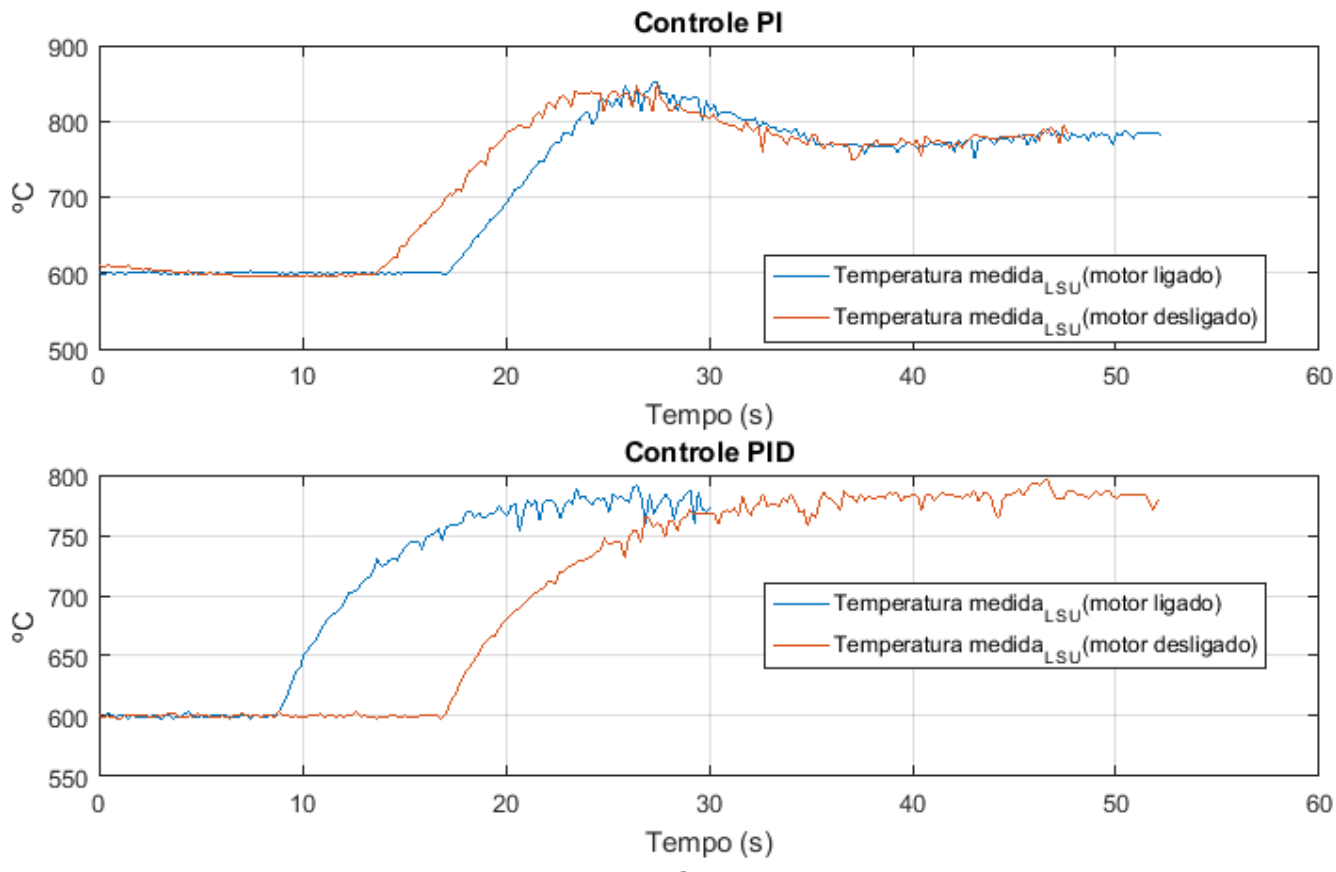

Fonte: $\mathrm{O}$ autor.

A Figura 4.13 exibe o teste de variação de temperatura do sensor LSU/UEGO realizado de forma direta através da função de comunicação com o IC CJ 125, onde estão exibidas as saídas das malhas de controle ajustadas em duas condições: com e sem o aquecimento gerado pelo funcionamento do motor.

Comparando-se a simulação apresentada na Figura 3.31, o controle PI com a aproximação de $1^{\text {a }}$ ordem agiu como esperado, possuindo uma resposta rápida em um formato de rampa, porém, com sobressinal de 10\%, o qual possui uma duração de aproximadamente 10 segundos. O controle PID, onde foi utilizada a aproximação de $2^{a}$ ordem, apresenta um comportamento similar ao virtual, com tempo de resposta maior, exibindo uma variação com aparência quadrática. Com o aquecimento do motor, ambas configurações receberam a referência de temperatura igual a $780^{\circ} \mathrm{C}$ e tiveram o tempo de acomodação reduzido em cerca de 5 segundos.

\subsection{CONTROLE A/C EM MALHA FECHADA PARA UM SENSOR DE OXIGÊNIO DE BANDA ESTREITA (LSF/HEGO/ON-OFF)}

\subsubsection{Conversão da Tensão Nernst e manutenção da relação estequiométrica durante regime de marcha lenta}

Este experimento tem a função de repetir o teste realizado na subseção anterior, entretanto, com a ressalva de que a referência do controle A/C (lambda) foi 
fixada $(\lambda=1.0)$, pois por se tratar de uma sonda de banda estreita (destacada na subseção 2.3.1), o controle preciso pode ser atingido apenas para mistura estequiométrica, ou seja, $(\lambda=1.0)$.

Figura 4.14 - Resultado do teste de comparação entre a medida da (a) tensão Nernst da sensor de oxigênio com banda estreita e (b) medida de conversão do analisador lambda LA4 com sonda de banda larga.
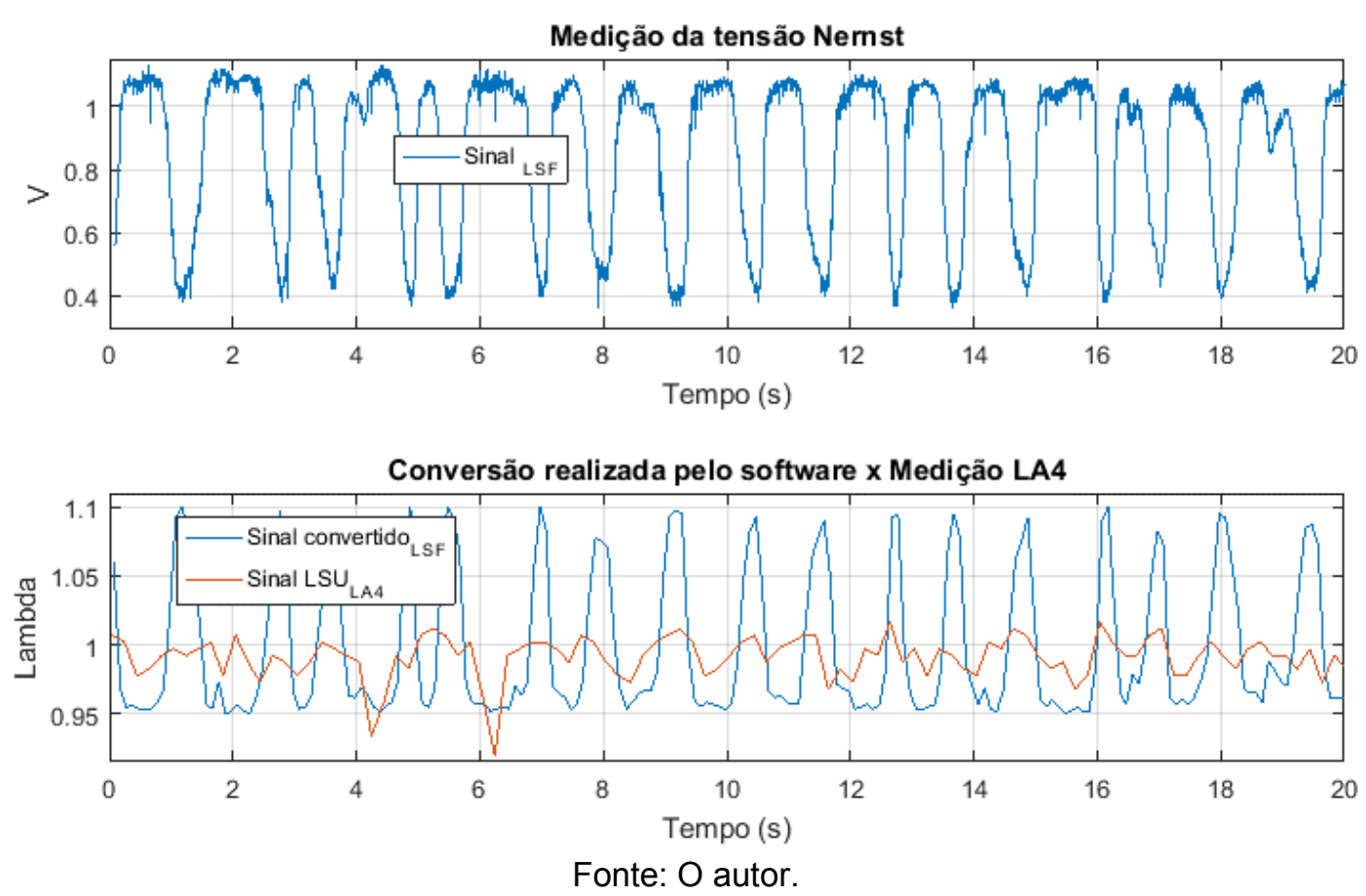

A partir da análise da Figura 4.14, é possível observar a razão da sonda de banda estreita ser comumente chamada também de sonda binária, possuindo apenas os estados de medida rico e pobre (Figura 4.14,a). Constata-se que, neste caso, a tensão Nernst deve estar sempre oscilando para se alcançar a relação estequiométrica. Ao se comparar o valor de conversão imposto no software com a medição real de um sensor de oxigênio de banda larga amplificada (Figura 4.14,b), nota-se que realmente o ponto estequiométrico $(\lambda=1.0)$ é atingido pela transição entre os estados rico e pobre. Com base nesta observação, pode-se entender que em uma região de medida próxima à estequiométrica, haveria a condição de se aplicar uma técnica de refino de medida. Essa técnica poderia ser baseada na razão cíclica o sinal chaveado, pois, não havendo saturação a um estado estacionária, o sensor apresenta uma medida consideravelmente precisa. 
Então, para o mesmo teste, foi observado o comportamento do fator de correção e tempo de injeção em função do sinal lambda convertido da tensão Nernst de um sensor de oxigênio de banda estreita, conforme mostrado na Figura 4.15.

Figura 4.15 - Resultado do teste de referência fixa do controle da mistura A/C (lambda) (a) Resposta do sensor oxigênio com banda larga amplificada, (b) fator de correção do tempo de injeção e (c) tempo de injeção aplicado.
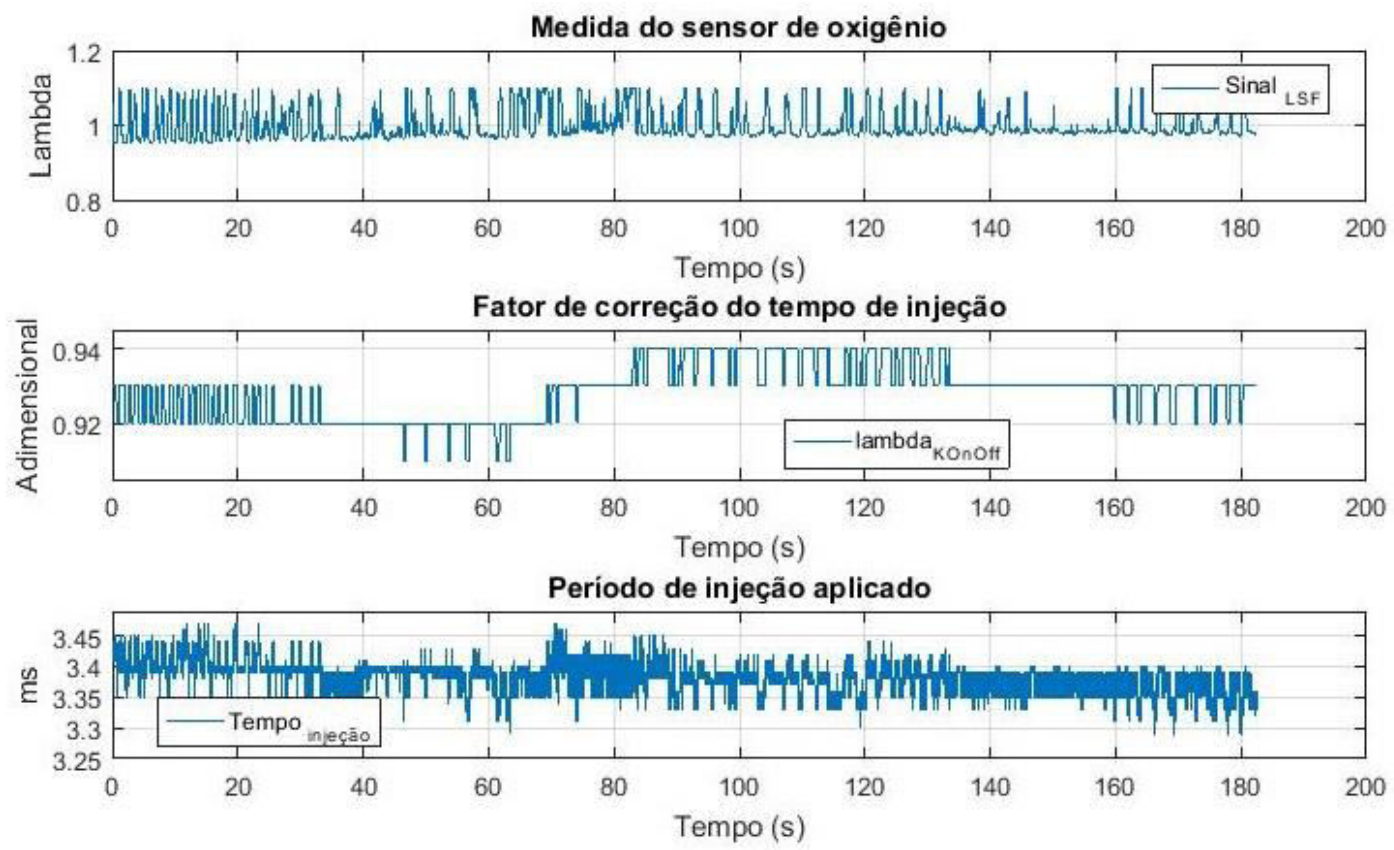

Fonte: O autor.

Os instantes de pico onde o sinal lambda convertido através da tensão Nernst oriunda do sensor de oxigênio LSF (banda estreita) possui amplitudes reduzidas (Figura 4.15,a), são interpretados como mistura rica, logo o fator de correção (Figura 4.15, b) diminui o tempo de injeção (Figura 4.15,c). Alternadamente, os momentos onde o sinal do sensor de oxigênio de banda estreita conserva amplitudes maiores (Figura 4.15,a) são interpretados como mistura pobre, assim, a saída de controle que é o fator de correção (Figura 4.15,b) enriquecerá a mistura com mais combustível. Nota-se que no fator de correção há uma variação máxima de 3\% no período de injeção (Figura 4.15,c).

Uma ação de controle suave como essa é importante, pois um dos requisitos para ação do controle lambda é não desestabilizar a velocidade de funcionamento do motor. 


\subsubsection{Regulação da temperatura de operação do sensor LSF/HEGO}

Conforme foi relatado nas subseções 3.4 .3 e 3.5.4, o aquecimento do sensor de oxigênio de banda estreita LSF/HEGO é controlado por uma simples variável de calibração em que não há retroalimentação de controle, e possui uma medida indireta pela variação resistiva do dielétrico presente na célula de medição Nernst da sonda, que se altera drasticamente com a variação de temperatura.

Figura 4.16 - Teste de variação de temperatura do sensor de banda estreita LSF/HEGO realizado de maneira indireta com a medida de tensão de sua célula Nernst.

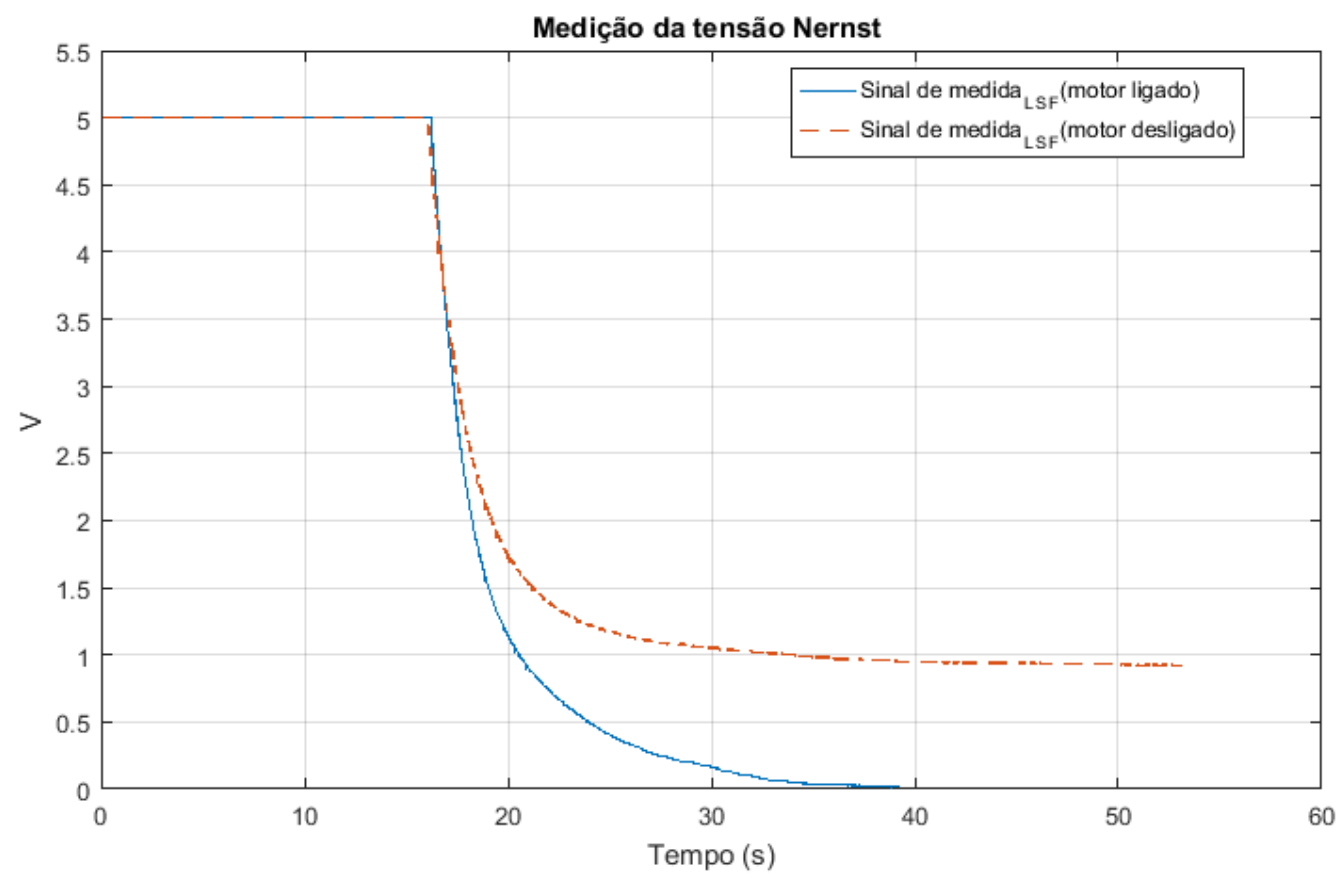

Fonte: $\mathrm{O}$ autor.

A Figura 4.16 exibe o teste de variação de temperatura do sensor de banda estreita LSF/HEGO realizado de maneira indireta com a medida de tensão de sua célula Nernst. $O$ intuito deste ensaio foi distinguir a influência causada pelo aquecimento do motor, observando-se o nível de tensão do sensor que varia proporcionalmente com a temperatura, por esta razão, foi aplicado o mesmo degrau de esforço em modulação PWM, com o ciclo de trabalho definido em $80 \%$.

É possível concluir que na utilização do sensor de banda estreita LSF/HEGO seria necessário um levantamento da temperatura em função da intensidade PWM aplicada, com correções em função da temperatura do motor, a consideração desta ideia traria o benefício da redução da estricção térmica do material desse sensor, possibilitando, consequentemente a extensão de sua vida útil. 


\subsection{OBSERVAÇÃO DOS FENÔMENOS DEPENDENTES DA}

\section{RELAÇÃO DE EQUIVALÊNCIA $\lambda(L A M B D A)$ PARA A CONDIÇÃO DE MBT}

As subseções a seguir discorrem sobre o mesmo experimento, e organizam as variáveis ordenadas para a alteração da relação de equivalência estabelecida.

\subsubsection{Busca dos avanços de ignição para o MBT}

$\mathrm{Na}$ literatura, nota-se frequentemente que os avanços de ignição são ajustados sempre com uma relação de equivalência $\lambda$ (lambda) fixa. Por isso, o presente experimento buscou investigar o efeito da variação da relação de equivalência $\lambda$ (lambda) nos avanços de ignição.

Neste ensaio, o critério para ajuste do avanço de ignição foi o ponto de máximo torque denominado MBT para a rotação de máximo desempenho de torque do motor em condição de máxima pressão de vácuo na admissão em aspiração natural, utilizando diferentes composições (classes) de combustível.

Figura 4.17 - Levantamento dos avanços de ignição encontrados para a condição de MBT em função da relação de equivalência $\lambda$ (lambda) para a rotação de 2500 RPM@90 KPa.

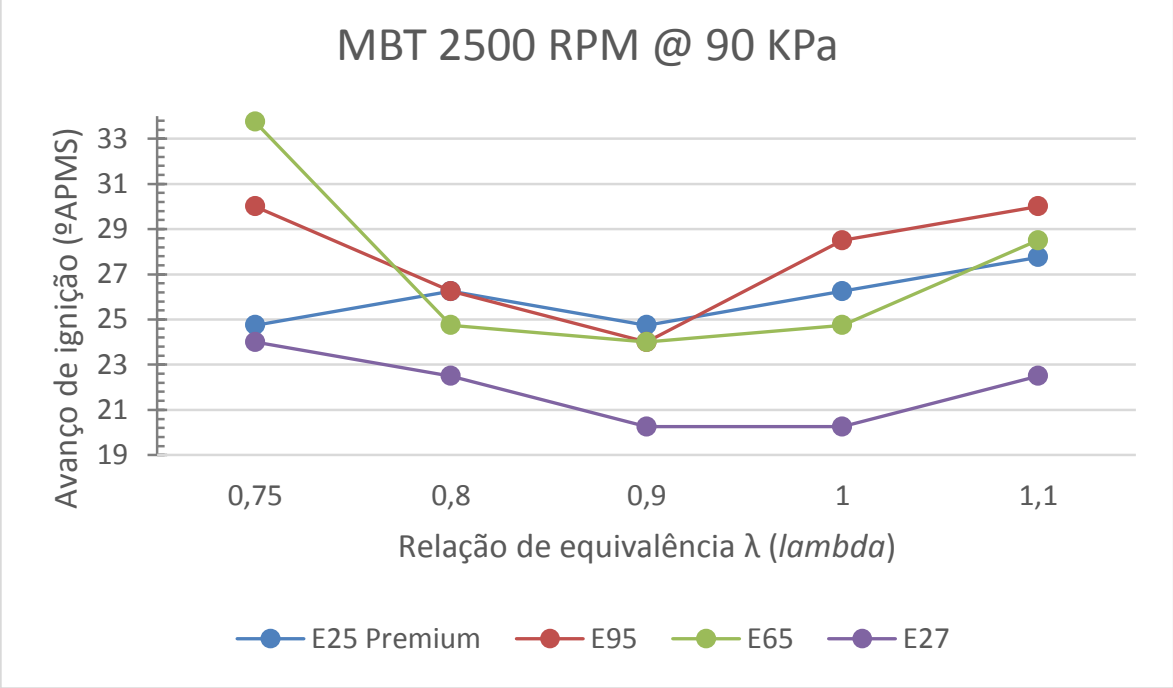

Fonte: $\mathrm{O}$ autor.

Os resultados apresentados na Figura 4.17 revelam que os maiores avanços de ignição para se alcançar a condição de MBT são aplicados na utilização do combustível etanol hidratado (E95) e da mistura centromédia E65 (50\% E95/50\% E27), que possuem maiores capacidades de octanagem em comparação a gasolina comum (E27) e a gasolina premium (E25). 
A observação desta variação do ângulo de melhor aproveitamento do torque denota a afirmativa de que os três subsistemas para gerenciamento de um motor PFI (Port Fuel Injection) naturalmente aspirado precisam operar de maneira harmoniosa e sincronizada, e podem assim endereçar os pontos relativos aos critérios e metas operacionais de desempenho. Esse fato comprova também a premissa de que a estrutura para realização do torque destacada na Figura 2.5, que foi relatada por (ERIKSSON e NIELSEN, 2014).

A variação ordenada com os alvos estabelecidos para a relação de equivalência $\lambda$ (lambda) aponta para a discussão encontrada em (EGOLFOPOULOS, et al., 2014), onde é relatada e demostrada a variação da velocidade laminar de chama resultante da relação A/C (lambda) e pressão aplicados a um combustível hidrocarboneto, demonstrado neste trabalho na Figura 2.13. Este resultado comprova também a premissa realizada por (ERIKSSON e NIELSEN, 2014) que afirma que o distanciamento do disparo da ignição da região ótima para iniciação da frente de chama da combustão a torna ineficiente, pois, afetam diretamente o equilíbrio cinético do motor e podem aumentar a tendência de eventos anormais de combustão tais como: a pré-ignição (caso o disparo da centelha seja atrasado demais) e detonação (caso o disparo seja adiantado demais).

Durante o mesmo experimento, observou-se também a variação de um índice utilizado para tratamento do sinal de detonação (Knock sensor). A medida é resultado da aplicação do cálculo integral definido limitado pelo ângulo de ocorrência da combustão, onde o sinal do acelerômetro (sensor de detonação) é retificado, filtrado e amplificado por um hardware específico para detecção remota de detonações exemplificado na seção 3.4.4. na está representada a medida que é resutado desse tratamento para o sinal de detonção (knock sensor). 
Figura 4.18 - Exemplificação de coleta do indice de detonação durante ensaio com o combustível E27.
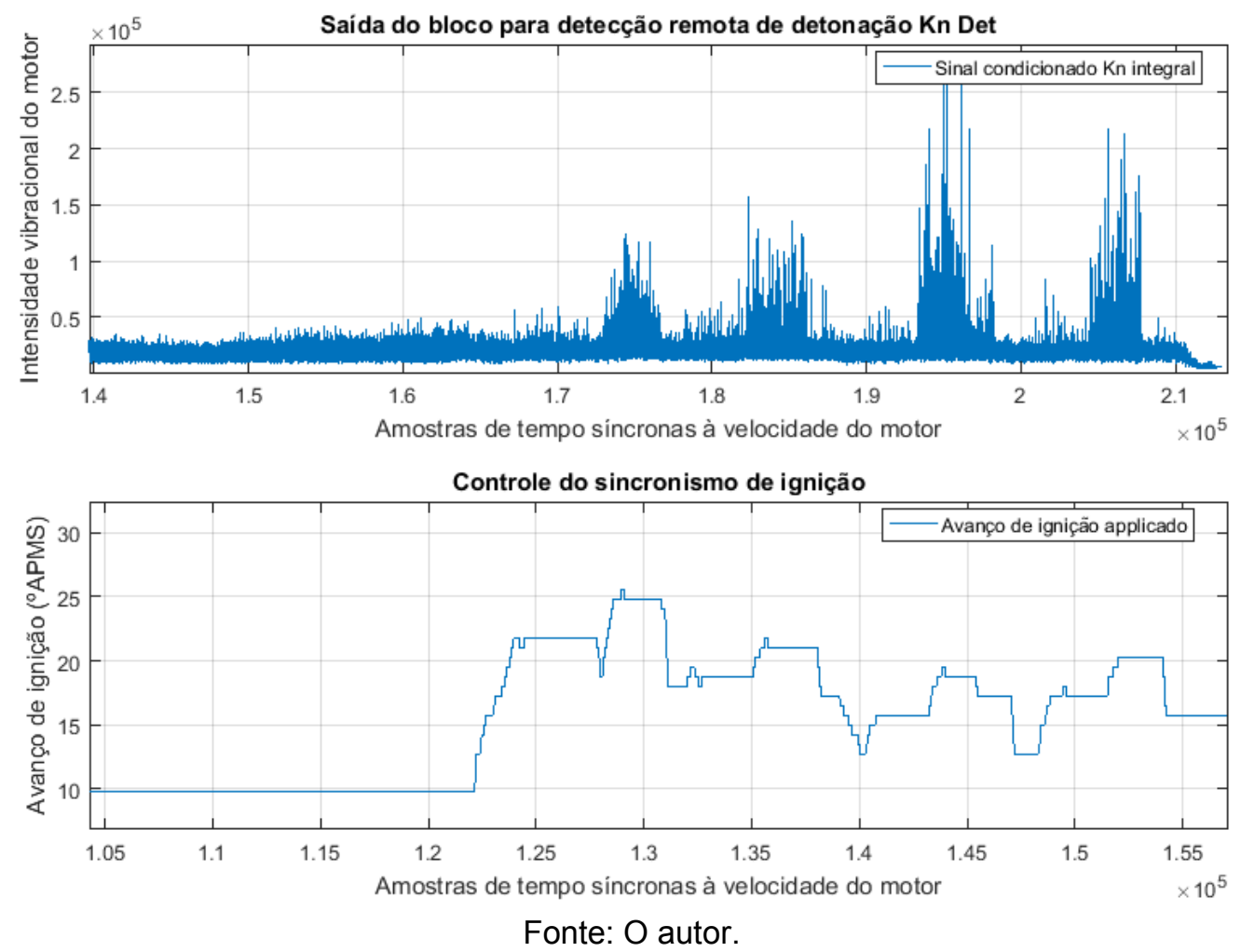

Além disso, o sinal do acelerômetro foi aplicado de maneira a excitar altofalantes, para confirmação da ocorrência de detonação através da audição do ruído característico amplificado.

Com a aplicação destes métodos de medida, levantou-se as médias desta variável de saída denominada Kn_integral. 
Figura 4.19 - Levantamento da variável de integração do sinal do acelerômetro preso ao bloco do motor (Knock sensor) para a condição de MBT em função da relação de equivalência $\lambda$ (lambda) para a rotação de 2500 RPM@90 KPa.

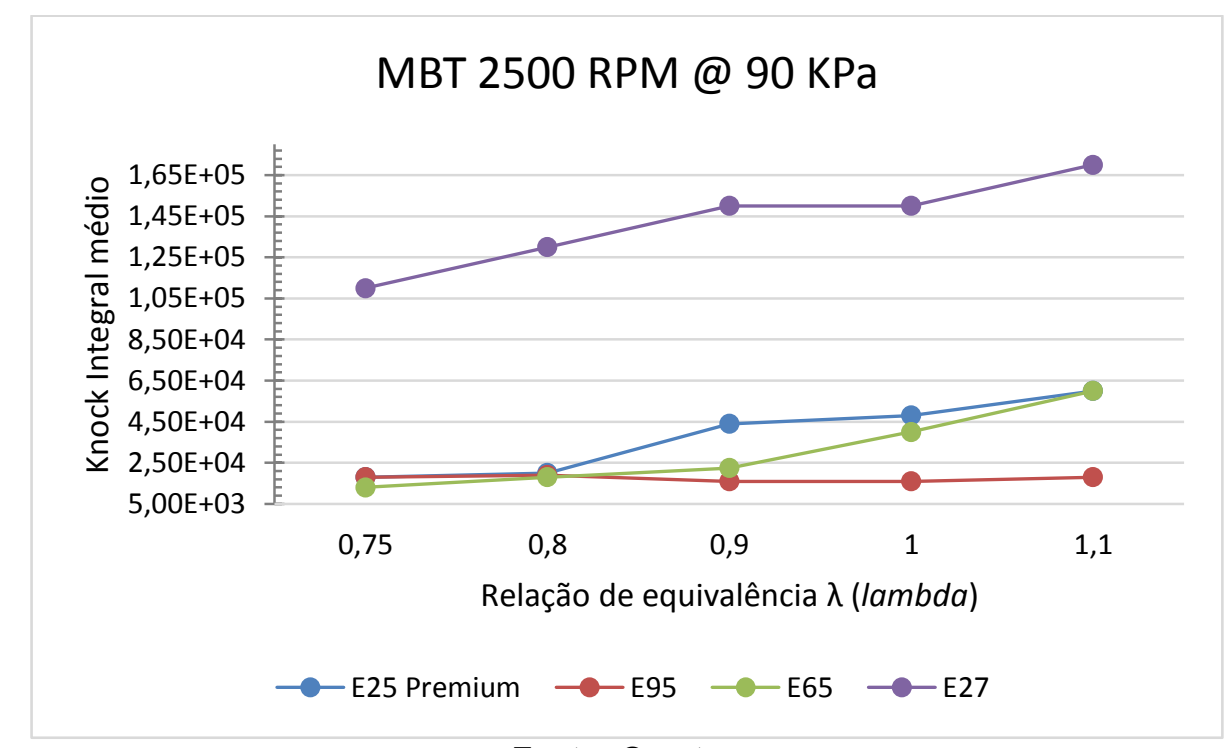

Fonte: $\mathrm{O}$ autor.

A Figura 4.19 mostra que os maiores índices integrais medidos para o sinal de detonação dentro da condição de MBT foram encontrados na utilização da gasolina comum $(E 27, \mid A D=88)$ e da gasolina premium $(E 25, I A D=92,2)$, que possuem menores índices antidetonantes em comparação ao etanol hidratado (E95, $I A D=100$ ) e da mistura centromédia (E65 - 50\% E95/50\% E27, IAD=97), conforme Tabela 2.2.

Novamente, há outra constatação que remete para os resultados de (EGOLFOPOULOS, et al., 2014) sobre a variação da velocidade laminar de chama resultante da relação A/C (lambda). Este resultado comprova a indexação da relação de equivalência lambda como forma de proteção da vida útil do motor, pois, pode sim reduzir os eventos de combustão descontrolada como a detonação. 


\subsubsection{Medição da variação de torque}

A referência utilizada para ajuste dos avanços para a condição de MBT foi a observação do torque gerado para as diferentes relações de equivalência $\lambda$ (lambda).

Figura 4.20 - Levantamento do torque encontrado para a condição de MBT em função da relação de equivalência $\lambda$ (lambda) para a rotação de 2500 RPM@90 KPa.

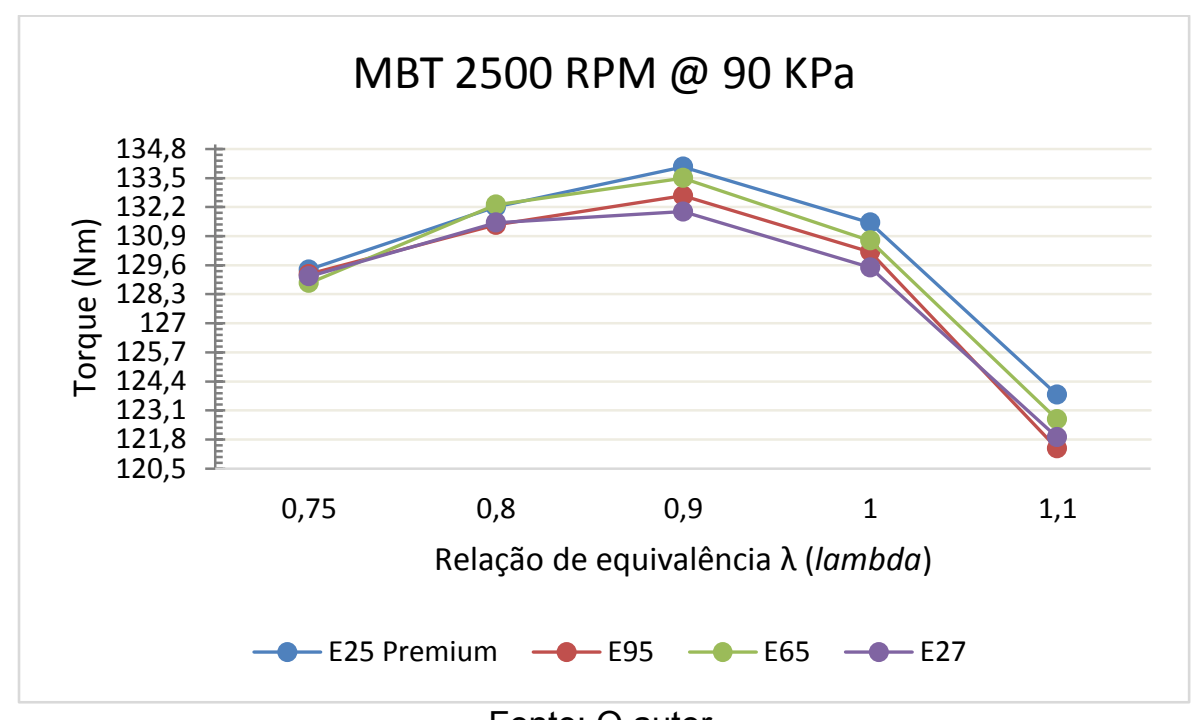

Fonte: $\mathrm{O}$ autor.

A Figura 4.20 exibe o torque gerado pelo motor durante os testes, que foi medido na utilização de um dos freios dinamométricos do Instituto de Pesquisa Tecnológicas (IPT) do Estado de São Paulo (destacado na subseção 3.3.4). Os resultados evidenciaram a análise energética dos combustíveis relatada na subseção 2.5.1, ainda que o etanol hidratado E95 possua maior resistência a auto inflamação (octanagem) e com isso traga a possibilidade de aplicar avanços de ignição significativamente maiores sem que se obtenha índices de detonação substanciais. O torque encontrado em sua utilização não ultrapassou o da gasolina premium E25, pois, em comparação a este combustível, o poder calorífico do etanol é inferior.

O fato da gasolina comum E27 não possuir aditivos que reduzam sua tendência ao Knocking, nota-se por este quesito, quanto a sua geração de torque foi comprometida, situando-se abaixo daquela gerada pelo E95. A melhor geração de torque deu-se com a gasolina premium E25, e foi acompanhada da segunda melhor produção de torque oriunda do combustível que apresenta mistura centromédia entre o E95 e o E27, possuindo assim, poder calorífico intermediário, o qual é denotado pela sigla E65. 


\subsubsection{Medição da variação do fluxo de combustível}

Foi demonstrado neste trabalho que a quantidade de combustível entregue é proporcional ao tempo de injeção, que é corrigido para se alcançar a relação de equivalência $\lambda$ (lambda) alvo.

Figura 4.21 - Levantamento do fluxo de combustível medido para a condição de MBT em função da relação de equivalência $\lambda$ (lambda) para a rotação de 2500 RPM@90 KPa.

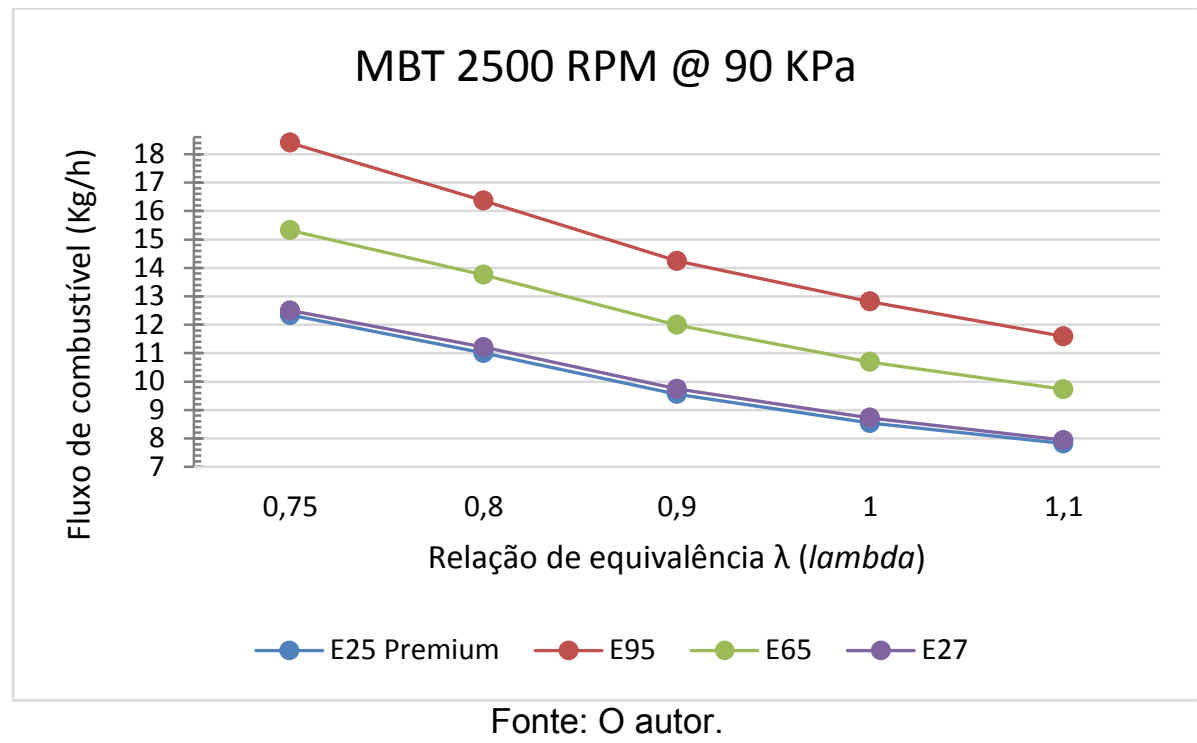

A Figura 4.21 exibe, para a condição de rotação e pressão indicadas, o fluxo de combustível consumido pelo motor durante a realização dos testes, o qual foi medido usando o medidor SITRANS MASSFLO 6000.

Nota-se evidentemente que, devido às relações $A / C$ estequiométricas dos combustíveis serem diferentes (E25=13,2; E27=13,1; E65=10 e E100=9, listados na Tabela 2.2), o fluxo mássico de combustível é proporcionalmente variante para se alcançar as relações de equivalência $\lambda$ (lambda) alvo definidas para o teste. Assim, nota-se que pontos operacionais semelhantes são alcançados com balanços estequiométricos variantes, que são relativos com as características do combustível. 


\subsubsection{Medição da variação do consumo específico de combustível}

Buscou-se, então, para os pontos medidos avaliar a eficiência dos combustíveis a partir do cálculo do consumo específico de combustível BSFC.

Figura 4.22 - Levantamento do consumo específico de combustível medido para a condição de MBT em função da relação de equivalência $\lambda$ (lambda) para a rotação de 2500 RPM@90 KPa.

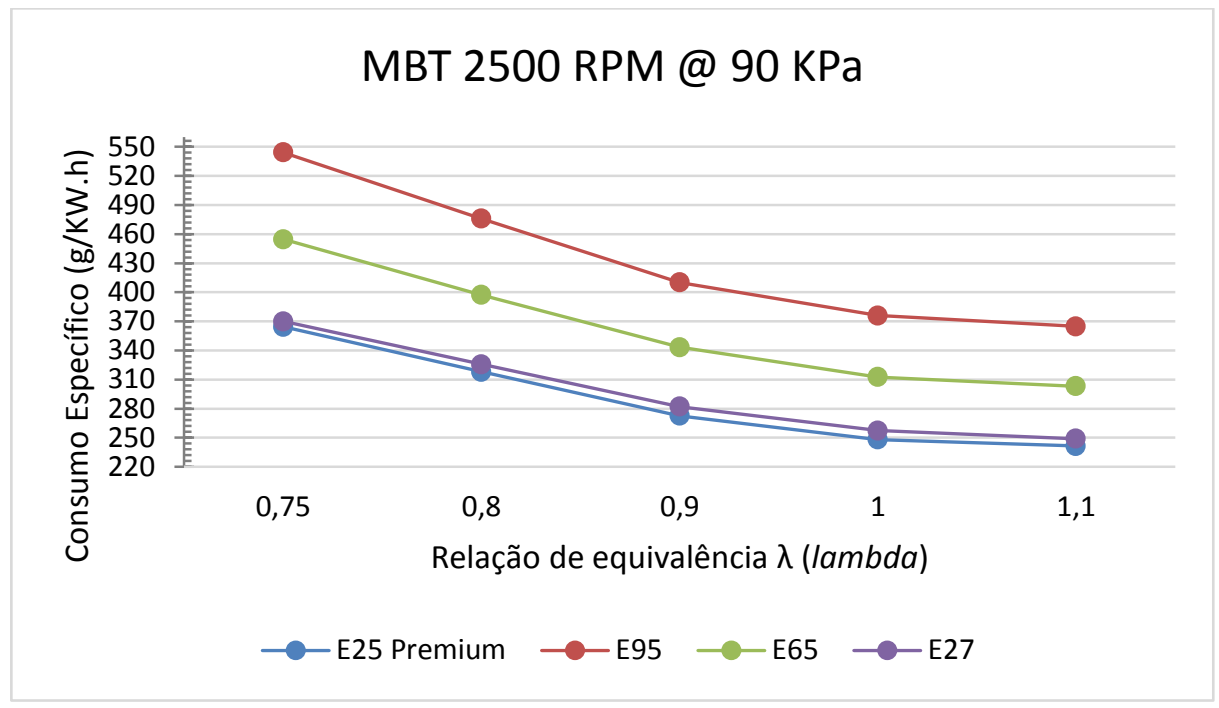

Fonte: $\mathrm{O}$ autor.

A Figura 4.22 mostra que os maiores índices de consumo especifico na condição de MBT são encontrados na administração do etanol hidratado (E95) com concentração 0 (zero) de gasolina e da mistura centromédia E65 (50\% E95/50\% E27). Devido ao poder energético do etanol, a concentração elevada de etanol presente nos dois combustíveis citados faz com que estes possuam energias de combustão reduzidas, quando comparados com os índices energéticos da gasolina comum (E27) e da gasolina premium (E25), conforme Tabela 2.3.

Nota-se que o consumo específico relativo a potência possuirá um perfil análogo ao da variação do fluxo de combustível medida no regime de rotação determinado, ou seja, o fluxo de combustível apresentou variação similar ao do consumo específico medidos no regime de 2500 RPM (Figura 4.21 e Figura 4.22).

\subsection{COMPARAÇÃO DOS RESULTADOS ENCONTRADOS NAS}

\section{METAS MBT E IKT}

Esta seção discute os resultados obtidos em relação ao ângulo de avanço limiar de detonação e do avanço para o máximo torque, em função da composição do combustível. Para os testes com o motor foram novamente utilizadas três composições distintas entre etanol, gasolina E65 e gasolina E27, incluindo-se 
também a gasolina premium. Definem-se as seguintes rotações de aquisição: 1500, 2500, 3500 e 4500 RPM. Todos os testes foram realizados com carga máxima e relação de equivalência lambda igual a 1 . Os testes foram realizados em um banco de testes dinamométrico marca Shenck D360-1E tipo hidráulico com controle Sptronic ECAT do Instituto de Pesquisas Tecnológicas (IPT) do Estado de São Paulo.

Dois métodos são empregados para detecção da detonação. O primeiro é a análise do indicador de detonação obtido através do sinal do sensor acelerômetro instalado no corpo do motor. Este sinal é lido pela Flex-ECU que então é submetido a um conversor $A / D$, amplificado, filtrado, submetido a um conversor D/A e então integrado. $O$ resultado da integração se relaciona com a ocorrência de detonação, e este parâmetro é medido através da plataforma de medição e calibração INCA, que também foi utilizada para as excursões realizadas no avanço de ignição. $O$ segundo método utiliza o sinal do acelerômetro para excitar alto-falantes, possibilitando a confirmação da ocorrência de detonação através da audição do ruído característico amplificado.

Avanço limiar de detonação: a partir da intenção de determinar-se o máximo avanço possível antes da ocorrência da detonação, o IKT (Incipient KKnock Timing). A metodologia empregada analisa o comportamento de 4 (quatro) composições distintas entre etanol, gasolina E65, gasolina E27 e gasolina E25 premium. Foram definidas as seguintes rotações de aquisição: 1500, 2500, 3500 e 4500 RPM. 
Figura 4.23 - Avanço de ignição em graus APMS no limiar de detonação para (azul) gasolina E27, (laranja) mistura entre gasolina e etanol E65, (preto) etanol hidratado e (amarelo) gasolina premium.

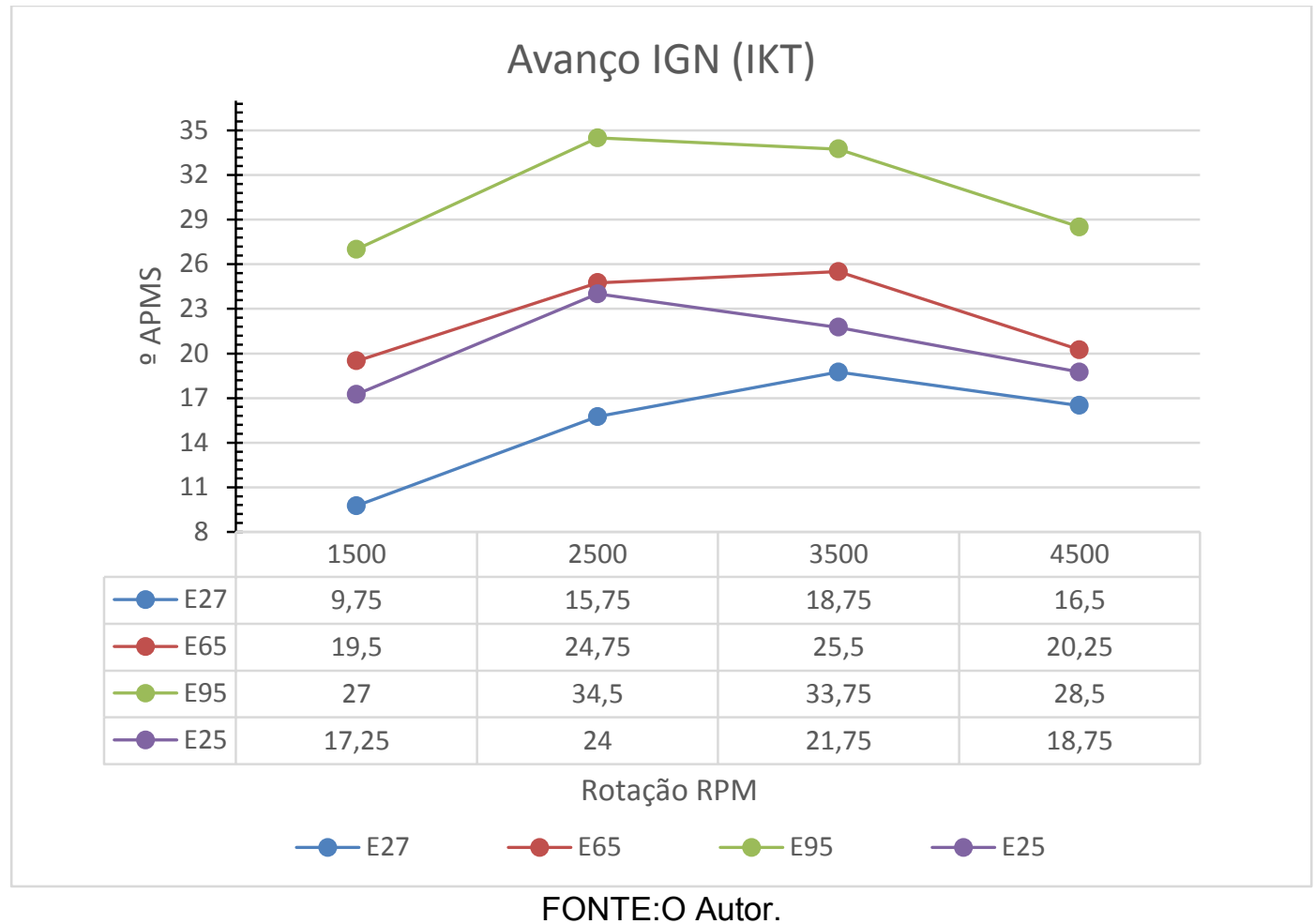

A Figura 4.23 ilustra o máximo avanço possível antes da ocorrência de detonação para as composições propostas. É possível observar que o avanço limiar de detonação aumenta proporcionalmente com a presença de etanol da composição. Este resultado pode ser explicado pelo fato de o etanol apresentar maior resistência à detonação que a gasolina E27. Outro fator que pode ser observado é que a gasolina premium apresenta melhores resultados em relação à gasolina E27, devido à gasolina premium (91 IAD) possuir IAD maior em relação a gasolina E27 (87 IAD).

Ângulo de avanço para máximo torque: Conforme foi definido na subseção 2.1.6, para cada relação $\lambda$ determinada, o avanço de ignição deverá ser adiantado para que o momento de máxima pressão seja oportuno ao melhor aproveitamento da energia cinética. Com o êxito desta meta, alcança-se o melhor aproveitamento do torque gerado pela combustão, ou seja, o ponto de MBT (Maximum Break Torque). Além disso, a economia de combustível e os níveis de emissões tem sua taxa reduzida quando próximos ao esse ponto. 
Figura 4.24 - Avanço de ignição em graus APMS que produz o maior torque de saída para os seguintes combustíveis: (azul) gasolina E27, (laranja) mistura entre gasolina e etanol E65, (preto) etanol hidratado e (amarelo) gasolina premium.

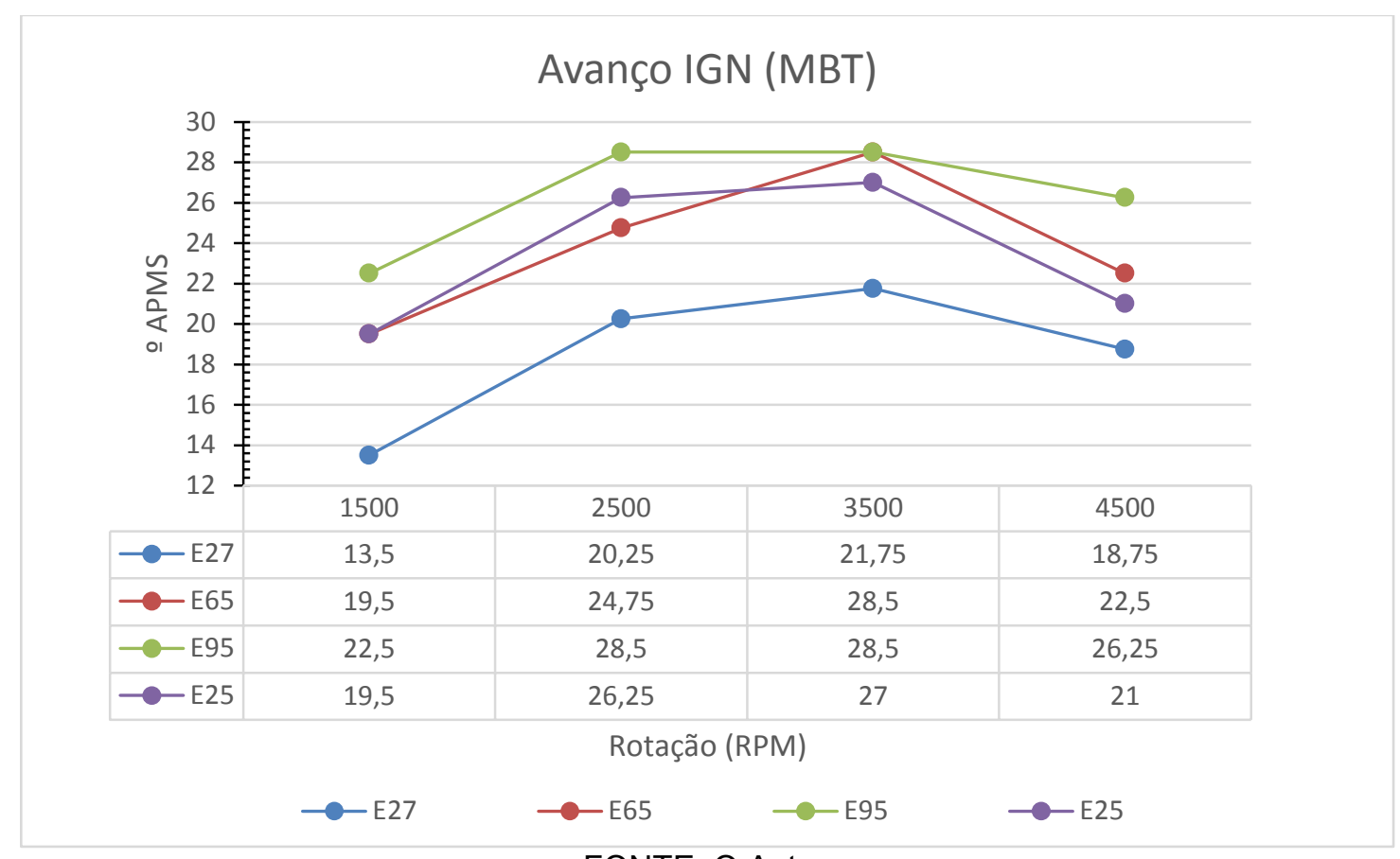

FONTE: O Autor.

A Figura 4.24 ilustra o avanço que obtém o MBT para as composições propostas. Como esperado, a composição com maior porcentagem de etanol permite-se obter maiores avanços em relação às outras composições em todas as faixas de rotação. Também é observado que a gasolina premium propicia avanços superiores para rotações abaixo de 3500 RPM em relação a composição de mistura centromédia E65. 
Figura 4.25 - Comparação entre o avanço limiar de detonação (IKT) e avanço para máximo torque (MBT) para gasolina E27.

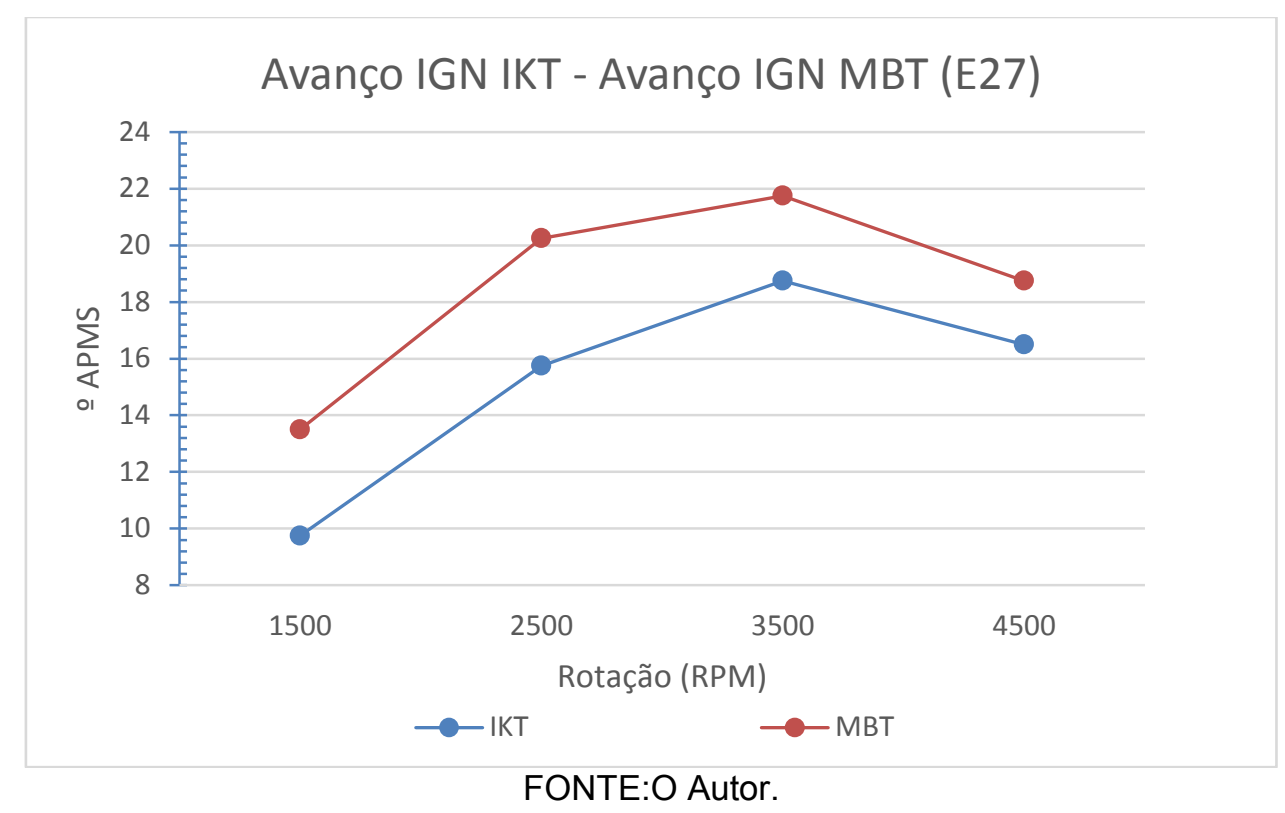

A Figura 4.25 ilustra a comparação entre o avanço limiar de detonação (IKT) e avanço de torque máximo (MBT) para mistura E27. Observa-se que o avanço MBT é superior em relação ao avanço limiar de detonação, deduzindo-se que, para esta composição, há benefício em se trabalhar com o avanço próximo à detonação, uma vez que o torque máximo ocorre logo após o início da ocorrência de detonação.

Figura 4.26 - Comparação entre o avanço limiar de detonação (IKT) e avanço para máximo torque (MBT) para mistura E65.

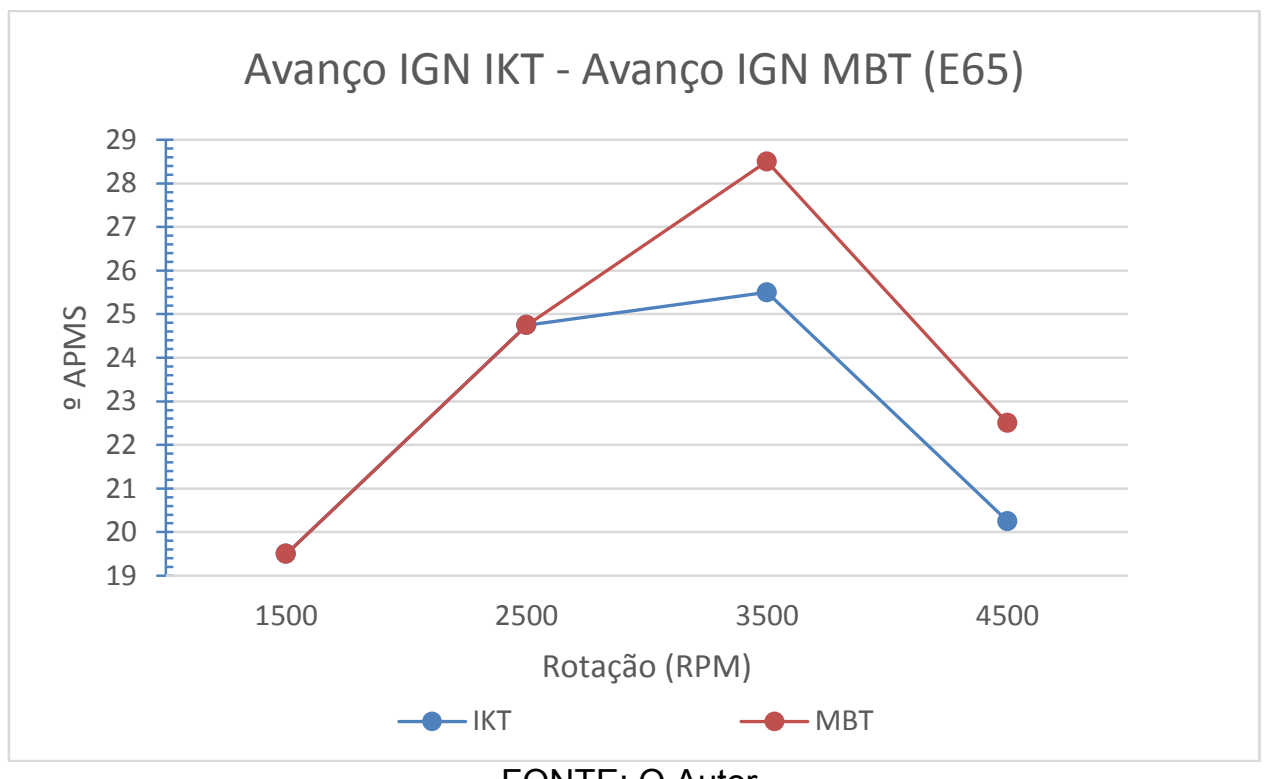

FONTE: O Autor. 
A Figura 4.26 ilustra a comparação entre o avanço limiar de detonação e avanço de torque máximo para mistura E65. Para esta condição, observa-se a redução da diferença entre o avanço limiar de detonação (IKT) e o avanço para MBT. Porém, a curva do avanço de torque máximo tem valor maior. Identifica-se novamente o benefício em se trabalhar próximo a detonação para esta composição.

Figura 4.27 - Comparação entre o avanço limiar de detonação (IKT) e avanço para máximo torque (MBT) para etanol hidratado E95.

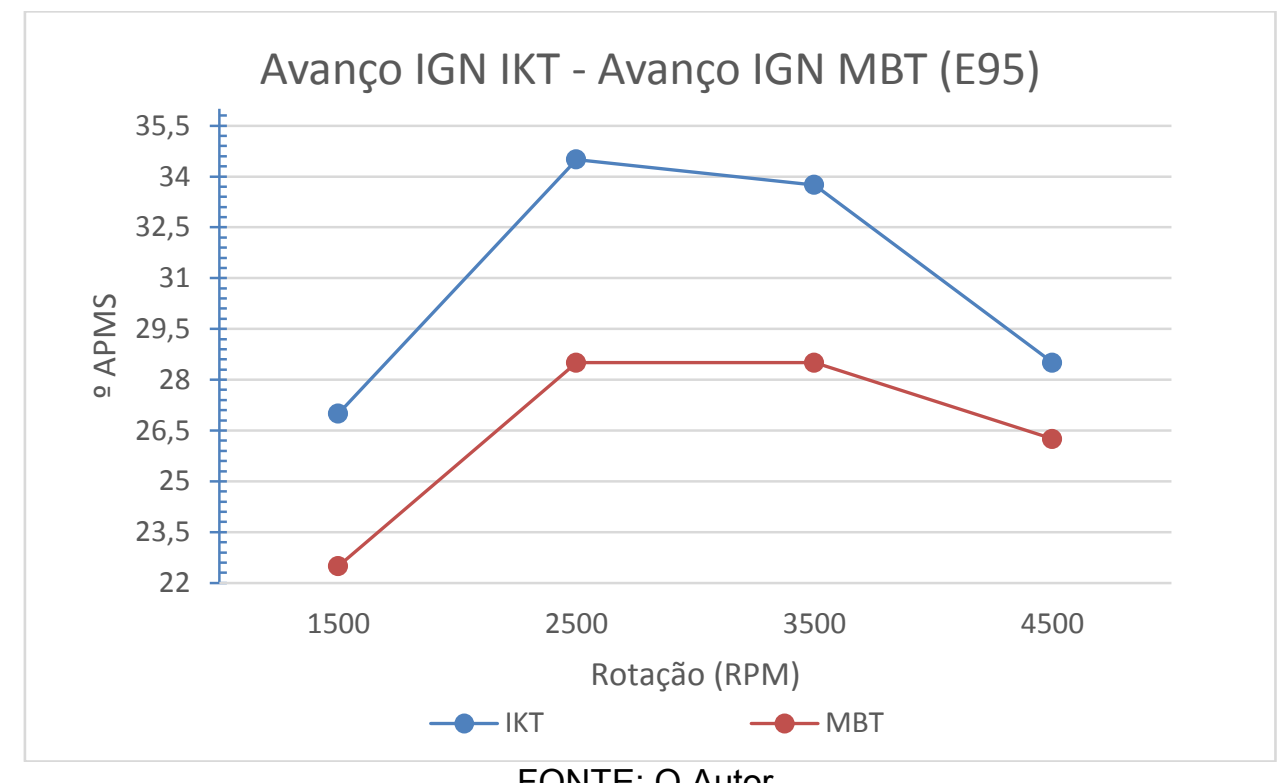

FONTE: O Autor.

A Figura 4.27 ilustra a comparação entre o avanço limiar de detonação e avanço de torque máximo para mistura E95. Para a composição de 95\% de etanol, apresenta-se resultado divergente dos anteriores, sendo que o avanço limiar de detonação ocorre após o avanço de torque máximo, demonstrando que não há benefício de se trabalhar com o avanço próximo da liminar, uma vez que o torque nesta condição não é o máximo.

Esse resultado pode ocorrer em função da taxa de compressão do motor de estudo ser de 12,1:1, inferior a aquela ideal para o etanol (acima de 13:1), segundo (NASCIMENTO, et al., 2010). Deste modo, o avanço, que proporciona a máxima transferência de força para taxas superiores a 13:1, não proporciona compressão suficiente da mistura no presente motor. Assim, a detonação ocorre demasiadamente atrasada, tendo a maior parte da energia sendo dissipada em forma de calor. 
Figura 4.28 - Comparação entre o avanço limiar de detonação (IKT) e avanço para máximo torque (MBT) para gasolina premium.

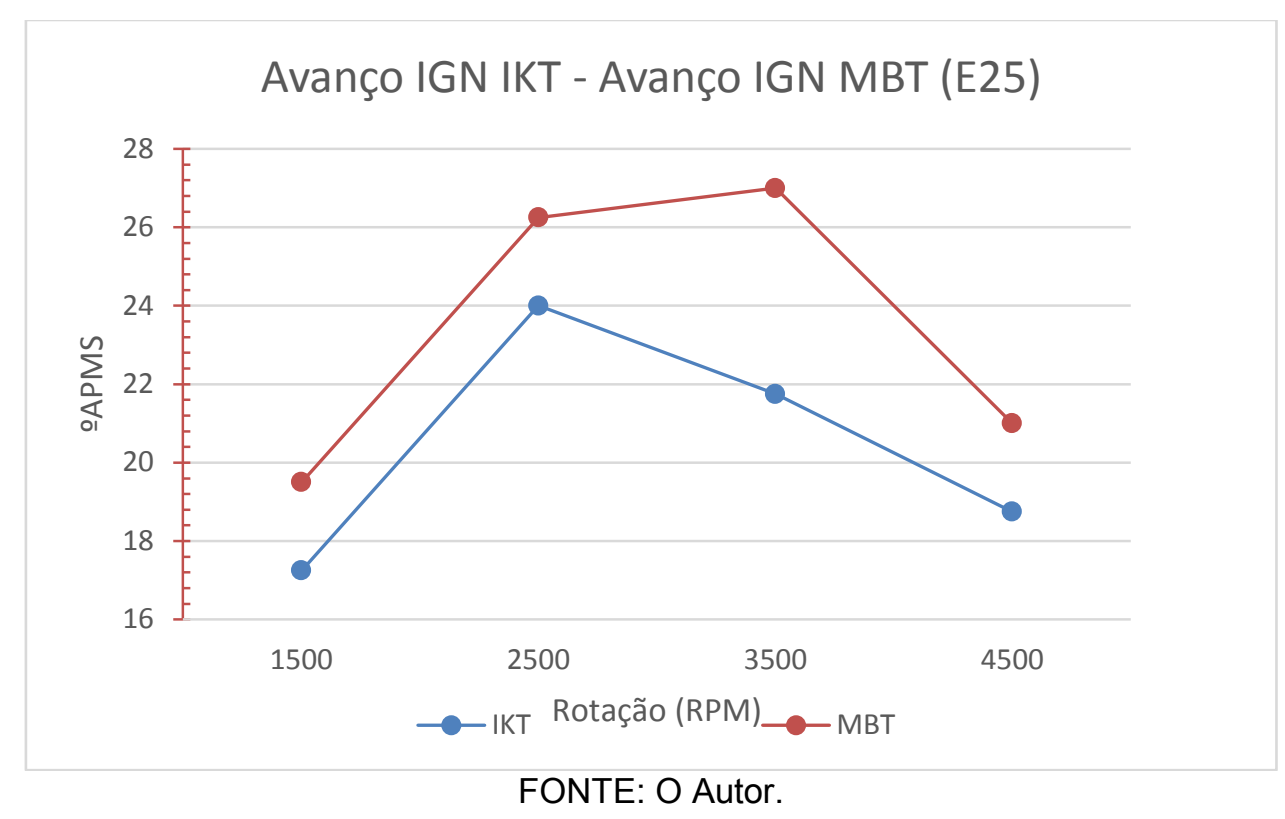

A Figura 4.28 ilustra a comparação entre o avanço limiar de detonação e avanço de torque máximo para gasolina premium. Em relação à gasolina premium, os resultados se aproximam dos obtidos pela composição E65, porém a composição de E65 apresenta melhor desempenho antidetonante para rotações superiores a 3500 RPM. A partir destes resultados, conclui-se que, em relação ao avanço para esse caso particular, tonar-se mais benéfico utilizar a mistura centromédia E65 em detrimento da gasolina premium.

\section{Torque limiar de detonação (meta IKT)}

Esta seção apresenta os torques de saída do motor para os avanços de limiar de detonação obtidos anteriormente. O resultado é apresentado na Figura 4.29. 
Figura 4.29 - Torque de saída do motor produzido pelo avanço de ignição no limiar de detonação para (azul) gasolina E27, (vermelho) mistura entre gasolina e etanol E65, (preto) etanol hidratado e (verde) gasolina premium.

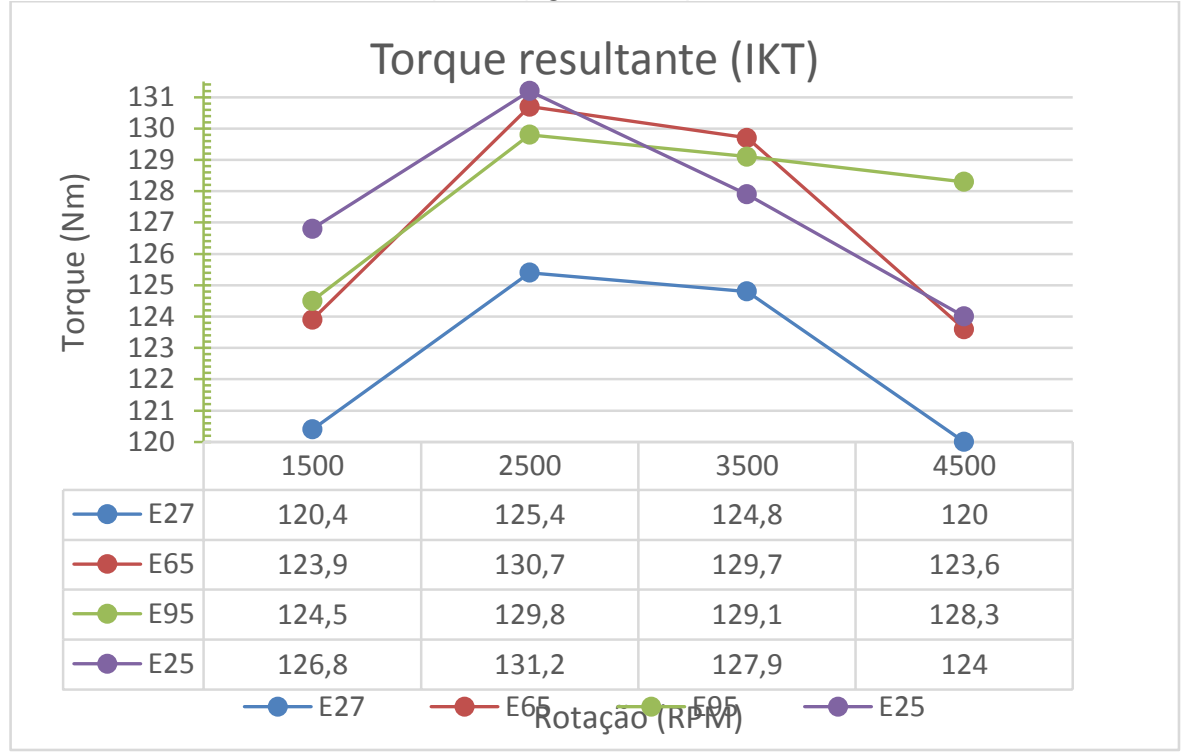

FONTE: Autor.

Pode-se observar que o maior torque apresentado para as rotações de 1500 e 2500 é da gasolina premium. Já a mistura E65 apresenta o maior torque para rotação de 3500 RPM e a composição de E95 apresenta o maior torque para 4500 RPM. O motivo de a composição de E65 apresentar maior torque do que a composição de E95 para 3500 RPM é porque, como analisado nos testes anteriores, quando o motor opera próximo ao limiar de detonação para composições com alta concentração de etanol, o torque máximo ocorre antes do ângulo limiar.

\section{Torque máximo (meta MBT)}

Esta seção apresenta os torques máximos de saída do motor para os avanços obtidos anteriormente. O resultado é apresentado na Figura 4.30. 
Figura 4.30 - Torque de saída do motor produzido pelo avanço de ignição que produz o máximo torque, para (azul) gasolina E27, (vermelho) mistura entre gasolina e etanol E65, (preto) etanol hidratado e (verde) gasolina premium.

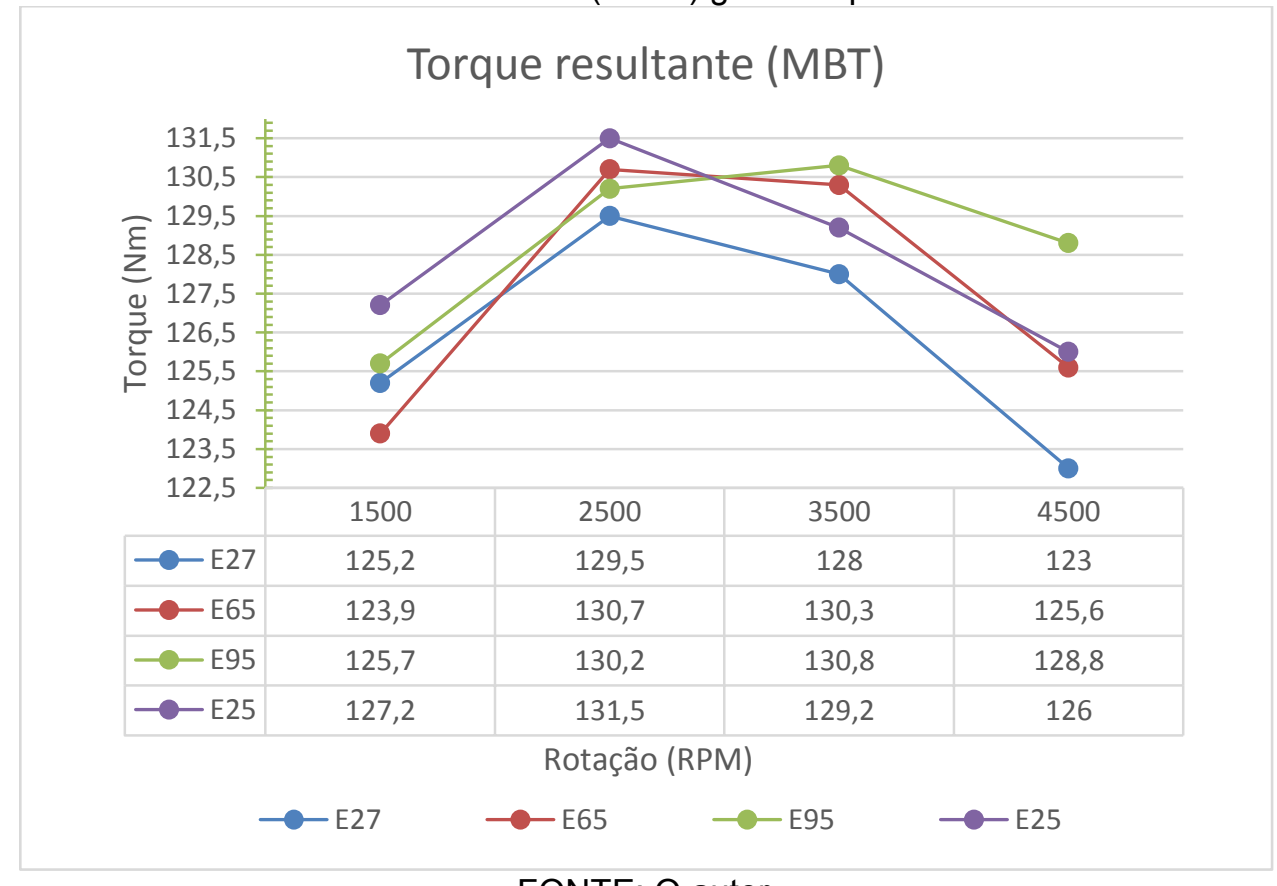

FONTE: O autor.

Pode-se observar que a gasolina premium apresenta o maior torque de saída para as rotações de 1500 e 2500RPM, enquanto a composição de E95 apresenta o maior torque para as rotações de 3500 e 4500 RPM. Como esperado, o comportamento anômalo apresentado na rotação de 3500 RPM não ocorre na condição de avanço de máximo torque.

\section{Comparação do torque atingido sob ambas as metas}

A Figura 4.31 tem como objetivo ilustrar o comportamento do torque de saída para composição E95 nas condições de avanço de limiar e avanço de torque máximo. 
Figura 4.31 - Comparação entre o torque produzido pelo avanço IKT (azul) e MBT (vermelho) para etanol hidratado E95.

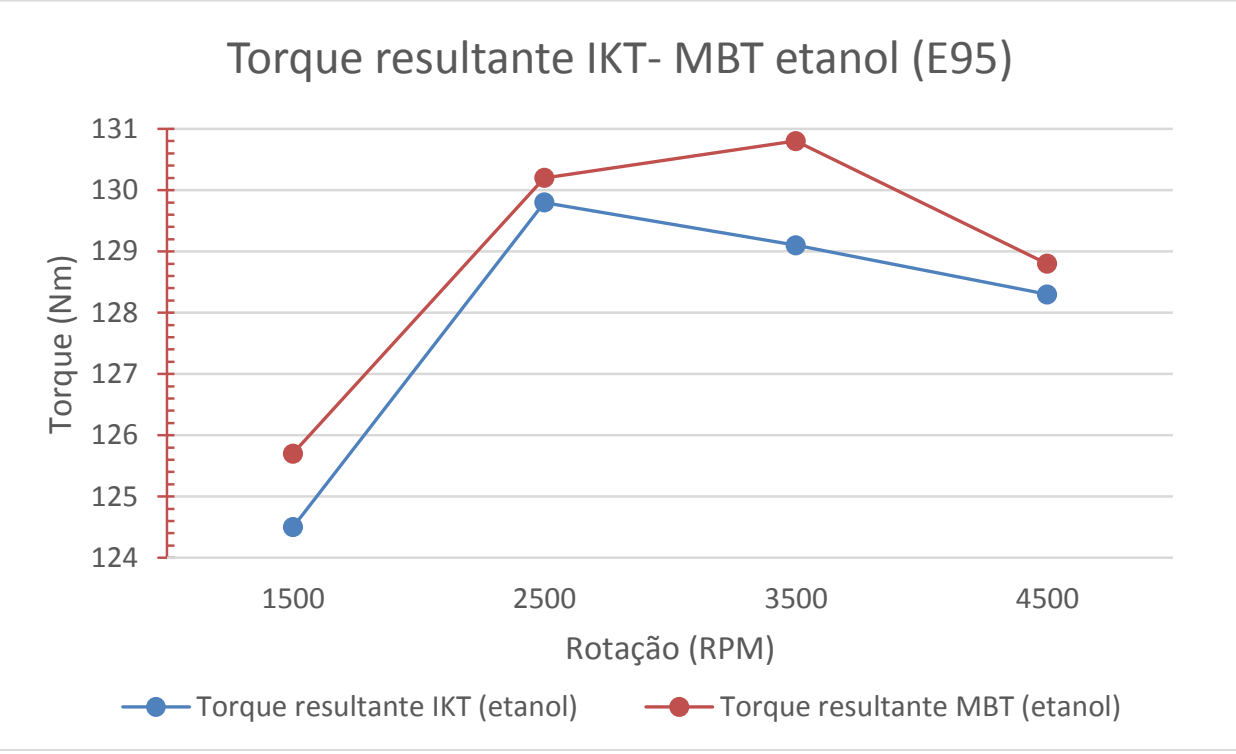

FONTE: $\mathrm{O}$ autor.

A comparação dos torques obtidos para os desígnios de IKT e MBT permite observar que, como esperado, o torque para meta da condição MBT foi sempre superior ao de IKT, com uma separação mais acentuada para a rotação de 3500 RPM. 


\section{$5 \quad$ CONCLUSÕES}

Este trabalho desenvolveu de maneira modular sistemas de controle da mistura $\mathrm{A} / \mathrm{C}$ em uma unidade dedicada ao desenvolvimento do gerenciamento de motores à combustão interna SI (Ciclo Otto). Adotou-se a estratégia de interpolação dos parâmetros de injeção e ignição com base na proporção volumétrica de etanol do combustível medido pelo sensor de composição. Posteriormente, aplicou-se uma malha de controle com realimentação em uma planta real utilizando a plataforma de desenvolvimento embarcado ETAS/Bosch MEDC17 FlexECU, através do AppSW Otto III, que foi desenvolvido com a ferramenta ASCET. Para o controle da planta, foi utilizado um modelo simples, porém eficiente, implementado um controlador PI na forma discreta, um dos mais utilizados para o tratamento A/C closed loop por sua robustez e aplicação simplificada.

Essa estratégia foi aplicada de maneiras distintas, para sensores de oxigênio de bandas larga e estreita, assim como os cuidados e maneiras de obtenções de medida particulares a cada um, e apresentou resultados satisfatórios.

Para alcance dos objetivos gerais, foram definidas as seguintes metas a serem alcançadas:

(i) Solução para identificação de combustíveis em tempo real, com o objetivo de eliminar estratégias reativas para a identificação de combustível.

(ii) Implementação do controle da mistura A/C (lambda) em malha fechada com 2 (duas) principais tecnologias de sensores de oxigênio:

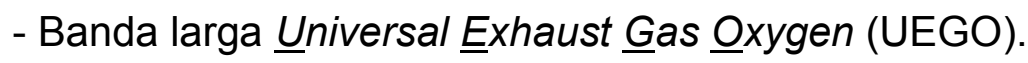

- Banda estreita Exhaust Gas Oxygen (EGO).

(iii) Contribuir modularmente para o domínio de tecnologias no gerenciamento eletrônico de um motor a combustão interna ciclo Otto bicombustível em um ambiente de desenvolvimento profissional.

Buscou-se também apresentar de maneira geral, os principais aspectos e vantagens do desenvolvimento de software embarcado com os benefícios computacionais trazidos pelos sistemas operacionais de tempo real.O desenvolivimento do software automotivo possui suas particularidades específicas de segurança, e portanto, precisa ser desenvolvido com a arquitetura e certificação adequadas aos modelos e normas de segurança, garantindo sua confiabilidade e capacidade de atualização durante os anos de vida útil do produto. 
Apresentou-se também uma aplicação de projeto que realizou o controle estequiométrico da mistura $\mathrm{A} / \mathrm{C}$ (lambda) foi aplicado em malha fechada para sondas lambda com princípios de medida distintos. A vantagem de se desenvolver através da metodologia estudada foi demonstrada através da reutilização de componentes entre diferentes funções, onde o aprendizado lógico-estrutural pôde ser reaproveitado, trazendo como benefício a economia de meses de desenvolvimento dos quais seriam necessários para criação do projeto desde sua gênese. Haja vista que para desenvolvimentos de novos produtos, o reuso de software torna-se uma prática necessária para garantir a robustez e entrega dos projetos.

O conceito MBD do ambiente ASCET proporciona o emprego e reutilização de diferentes representações de programa, a fim de facilitar seu uso a partir do nível de abstração da finalidade a ser atingida. Devido ao nível de abstração de funcionalidades proporcionado pelo empregos de RTOS's em uma arquitertura robusta e confiável para o desenvolvimento automotivo como a da AUTOSAR, o programa como um todo se mostrou eficiente e não foram demonstradas comportamentos anomalos na execução do software.

A ferramenta de aquisição INCA permitiu a calibração de todos os parâmetros necessários bem como a gravação dos dados de desempenho durante os experimentos, os quais foram apresentados nos resultados.

Foram investigadas as características dos combustíveis nacionais e $\mathrm{o}$ comportamento do torque de saída de um motor de combustão interna Flex-Fuel em relação à composição do combustível utilizado, diferentes setpoints para relação $\mathrm{A} / \mathrm{C}$ (lambda) com a ocorrência da detonação (Figura 4.19), geração de torque (Figura 4.20), variação do ângulo ótimo para a ignição (Figura 4.17), fluxo do combustível admitido pelo motor (Figura 4.21) e consumo específico (Figura 4.22). Os resultados obtidos indicaram que para um motor com as características do motor testado há benefícios em se trabalhar com o avanço próximo a limiar de detonação para as composições de E27, E65 e gasolina premium, pois, ao aumentar-se o indice de detonação em um determinado setpoint existe o ganho de torque.

Ao administrar-se o etanol hidratado E95, temos a inversão do fenômenocitado no paragrafo anterior, e ainda foi observado que o avanço para a meta de MBT mostrou-se inferior ao encontrado para a meta de IKT (Figura 4.27). Sendo assim, para o presente motor não houve benefícios em se trabalhar próximo 
ao limiar de detonação na utilização desse combustível. Tais fatos podem ser explorados em trabalhos futuros, aplicando a mesma metodologia a um motor de combustão interna com taxa de compressão variável a fim de se aproximar o avanço de MBT e IKT para esta composição ou para outras possíveis descobertas que justifiquem as ocorrências observadas.

Quanto ao sistema de pós-tratamento para emissões, não foram considerados ciclos de regeneração para o conversor catalítico devido à tecnologia do TWC não necessitar de tais procedimentos. Porém, estima-se que as emissões estiveram em níveis aceitáveis a legislação em razão da manutenção da referência estequiométrica, onde ocorre a maior eficiência das conversões catalíticas realizadas por um TWC (destacado na subseção 2.4.1).

São propostas como atividades futuras itens a seguir:

(i) Refinamento dos mapas básicos de injeção e ignição com o controle das variáveis de pressão e temperatura do ar atmosférico. Esta tarefa traria o benefício do afinamento do funcionamento do motor para várias condições, vale ressaltar que os mapas secundários de correção já foram previstos no software, faltando apenas a respectiva calibração em condições adequadas.

(ii) Levantamento da correção adequada para a medida da corrente de bombeamento de oxigênio da sonda lambda de banda larga em função da pressão absoluta dos gases de exaustão no motor. Sua execução trará benefícios a medida lambda e independência do uso de analisadores lambda.

(iii) Aprimoramento das estratégias para utilização de um sensor suplementar de banda estreita, quanto a realização de diagnoses para subsistemas do gerenciamento do motor, e identificação de um perfil de controle automático para sua temperatura seja em malha aberta ou a partir da consideração da mudança de resistência de sua célula de Nernst.

(iv) Levantamento de uma estratégia de correção pra a variação da pressão atmosférica: um aspecto que não foi levado em consideração na interpolação entres os períodos de injeção e avanços de ignição é a variação da pressão atmosférica que se altera com a diferença de altura relativa ao nível do mar. 
Em razão das diferentes constatações realizadas nesta pesquisa, nota-se algumas das várias e extensas razões da indústria automotiva investir tanto em trabalhos de calibração, pois, o etanol brasileiro possui características próprias e peculiares, além dos combustíveis comercializados em território nacional possuírem variabilidade de características físico-químicas. Nota-se fortemente as particularidades, ao se comparar os combustíveis brasileiros a seus pares semelhantes existentes pelo mundo. Destaca-se mais uma nuance em razão das diferentes condições de clima em nosso território, visto que, a grande maioria de novos produtos possuem origem estrangeira, e por isto, passam a ser fortemente submetidos a procedimentos de recalibração, quando introduzido no mercado nacional. 


\section{REFERÊNCIAS}

AEA, A. B. D. E. A.-. AEA 30 anos: a Associação Brasileira de Engenharia Automotiva e sua história. [S.I.]: Blucher, 2014.

AGUIRRE, L. A. Introdução à identificação de sistemas-Técnicas lineares e nãolineares aplicadas a sistemas reais. [S.I.]: Editora UFMG, 2004.

AHN, K. H. Estimation of Ethanol Content and Control of Air-to-Fuel ratio in Flex Fuel Vehicles. University of Michigan. [S.I.], p. 126. 2011. PhD Thesis.

ASHOK, B.; ASHOK, S. D.; KUMAR, C. R. A review on control system architecture of a Si engine management system. ANNUAL REVIEWS IN CONTROL, 41, 2016. 94118.

ASSOCIAÇÃO NACIONAL DOS FABRICANTES DE VEÍCULOS AUTOMOTORES ANFAVEA. Brazilian Automotive Industry Yearbook. [S.I.]: [s.n.], 2016.

BALEANI, M. et al. Correct-by-Construction Transformations across Design Environments for Model-Based Embedded Software Development. PROCEEDINGS OF THE DESIGN, AUTOMATION AND TEST IN EUROPE CONFERENCE AND EXHIBITION, 1530-159, 2005.

BALKI, M. K.; SAYIN, C. The effect of compression ratio on the performance, emissions and combustion of an SI (spark ignition) engine fueled with pure ethanol, methanol and unleaded gasoline. ENERGY, 71, 2014. 194-201.

BEGGREN, P.; PERKOVIC, A. Cylinder Individual Lambda Feedback Control in an SI Engine. REPORT LINKÖPING UNIVERSITY, 1996. 86.

BERGER, A. S. Embedded Systems Design. Kansas: CMP Books, 2002.

BLAIR, G. P. Design and simulation of four-stroke engines. Warrendale: Society of Automotive Engineers - SAE, 1999.

BORGES, R. W. Aplicabilidade de sistemas operacionais de tempo real (RTOS) para sistemas embarcadosde baixo custo e pequeno porte. Universidade de São Paulo Escola de de Engenharia de São Carlos. São Carlos. 2011. Dissertação de mestrado.

BOSCH. Planar Wide Band Lambda Sensor LSU 4.9. [S.I.], p. 1-13. 2005.

BOSCH PROFESSIONAL INFORMATION. Gasoline Management - Systems and Components. [S.I.]: Springer Vieweg, 2015.

BROY, M. et al. Engineering Automotive Software. PROCEEDINGS OF THE IEEE, 95, n. 2, 2007. 356-373.

CHEN, $\mathrm{H}$. et al. Automotive Control: the state of art and perspective. ACTA AUTOMATICA SINICA, 39, n. 4, 2013. 322-346. 
CONTINENTAL. Flex-Fuel Sensor Generation I/ Brazilian Calibration Specification. [S.I.]. 2014.

DE A DIAS, B. M. et al. Teaching microcontrollers using automotive electronic systems. International Journal of Electrical Engineering Education, 52, 2015. 23-35.

DE ANDRADE, R. et al. Analytical and Experimental Performance Evaluations of CAN-FD Bus. IEEE Access, 6, 2018. 1 - 10.

DIAS, B. M. D. A. et al. Model-Based Development of an Engine Control Module for a Spark Ignition Engine. IEEE Access 6, 2018. 53638 - 53649.

EGOLFOPOULOS, F. N. et al. Advances and challenges in laminar flame experiments and implications for combustion chemistry. PROGRESS IN ENERGY AND COMBUSTION SCIENCE, 43, 2014. 36-67.

ERIKSSON, L.; NIELSEN, L. Modeling and control of engines and drivelines. First Edition. ed. [S.I.]: John Wiley \& Sons Ltd, 2014. 564 p. ISBN ISBN: 978-1-11847999-5. Automotive series.

ETAS INC. INCA 7.1 - User Training Manual. [S.I.]: [s.n.].

ETAS, INC. Flex ECU-G1 Gasoline Low Level Software Interface Definition Description V1.2.2. Engineering Tool and Applications Services. [S.I.], p. 147. Manual de definição descritiva de interface.

FUCHS, M. et al. BMW ROOM: An Object-Oriented method for ASCET. SOCIETY OF AUTOMOTIVE ENGINEERS, Detroit, 1998. 1-11.

GANSSLEE, J. G. Art of programming embedded systems. 2nd. ed. Noida: Elsevier, 2008.

GIESE, H. et al. Model-Based Engineering of Embedded Real-TimeSystems International Dagstuhl Workshop. Dagstuhl Castle, Germany: Springer-Verlag Berlin Heidelberg, 2007.

GOLDEMBERG, J.; COELHO, S. T.; GUARDABASSI, P. The sustainability of ethanol production from sugarcane. ENERGY POLICY, 2008. 2086- 2097.

GUENTHER, D. W.; GERHARDT, J. MOTRONIC-torque guied engine mangement system to meet future challenges in emissions and fuel consumption reduction. SAE TECHNICAL PAPER, 2000-01-1420, 2000. 78-106.

GUZZELLA, L.; ONDER, C. H. Introduction to modeling and control of internal combustion engine systems. Zürich, Switzerland: Springer-Verlag Berlin Heidelberg, 2010. ISBN ISBN 978-3-642-10774-0/ e-ISBN 978-3-642-10775-7.

HAYASHIDA, P. A. P. Desenvolvimento de uma estratégia de controle de detonação para otimização do torque em um motor de combustão interna flex. Escola 
Politécnica da Universidade de São Paulo. Departamento de Engenharia de Sistemas Eletrônicos. [S.I.], p. 94. 2018. Dissertação de mestrado.

HEINTZ, N. et al. An approach to torque-based engine management systems. SAE TECHNICAL PAPER, 2001-01-0269, 2001. 1-10.

HENZINGER, T. A.; SIFAKIS, J. The embedded systems design challenge. International Symposium on Formal Methods, Berlin, 2006. 1-15.

HEYWOOD, J. B. Internal Combustion Egine Fundamentals. [S.I.]: McGraw Hill,Inc, 1988.

HONEKAMP, U. et al. Component - Node - Network: Three Levels of Optimized Code Generation with ASCET-SD. PROCEEDINGS OF IEEE- IINTERNATIONAL SYMPOSIUM ON COMPUTER AIDED CONTROL SYSTEM DESIGN, Kohala CoastIsland of Hawaii, 1999. 243 - 248.

HUANG, G.; HUANG, W.; ZHANG, Y. Actor-Oriented Methodology For Automotive Engine Control System Design. INTERNATIONAL CONFERENCE ON E-PRODUCT E-SERVICE AND E-ENTERTAINMENT, 2010. 1 - 4.

HYLE, J. H.; RABE, P. R. An on board sensor for percentage of alcohol. IEEE TRANSACTIONS ON VEHICULAR TECHNOLOGY, 27, n. 3, 1978. 142-144.

J. P. F. SANTOS, P. C. R. Otto III by FlexECU - Gerenciamento Eletrônico de um Motor VW 1.6L. Escola Politécnica da Universidade de São Paulo. [S.I.], p. 108. 2015. Trabalho de Conclusão de Curso.

KAR, K.; CHENG, W.; ISHII, K. Effects of ethanol content on gasohol PFI engine wide-open-throttle operation. SAE INTERNATIONAL JOURNAL OF FUELS AND LUBRIFICANTS, 2, 2009. 895-901.

KIENCKE, U.; NIELSEN, L. Automotive Control Systems - For Engine, Driveline and Vehicle. Berlin: Springer-Verlag, 2005. ISBN ISBN 3-540-66922-1.

KNIGHT, J. C. Dependability of embedded systems. Proceedings of the 24th International Conference on Software Engineering. ICSE, 2002. 685-686.

KRACKE, A. Untersuchung der Gemischbuildung durch Hochdruckeinspritzung bei PKW-Dieselmotoren. Dusseldorf: VDI Verlag, 1992.

LAGANA, A. A. M. et al. Identification of combustion and detonation in spark ignition engines using ion current signal. FUEL, 227, 2018. 469 - 477.

LEE, E. A. Embedded software. Advances in computers, 2002. 55-95.

LEE, J. H. Review on zirconia air-fuel ratios for automotive applications. JOURNAL OF MATERIALS SCIENCE, 38, n. 21, 2003. 4247-4257.

LI, Q.; YAO, C. Real-time concepts for embedded systems. [S.I.]: CRC Press, 2003. 
LIU, F.; NARAYANAN, A.; BAI, Q. Real-time systems. [S.I.]: [s.n.], 2000.

LJUNG, L. System Identification: Theory for the user. [S.I.]: Pearson Education, 1998. ISBN ISBN 9780132440530.

MCKAY, B. et al. An onboard ethanol concentration sensor for the brazilian market. SAE TECHNICAL PAPERSERIES, 2012. 1-11.

NASCIMENTO, P. T. D. S. et al. The Technological Strategy of Brazilian Automakers for Flex Fuel Vehicles: An Exploratory Study. TECHNOLOGY MANAGEMENT FOR GLOBAL ECONOMIC GROWTH (PICMET), 5, n. 20, 2010. 1-13.

NERY, M. Reduzindo a dispersão dos atrasos em sistemas de tempo real soft com restrições de média de tempo de resposta. Universidade de São Paulo. [S.I.]. 2009. Dissertação de mestrado. Instituto de ciências matemáticas e de computação.

NOEGAARD, T. Embedded systems architecture: a comprehensive guide for engineers and programmers. New Delhi: Elsevier, 2006.

NOGUEIRA HORTA, L. A. et al. The rationality of biofuels. ENERGY POLICY, 61, 2013. 595-598.

PASSARINI, L. C. Projeto e análise de válvulas eletromagnéticas injetoras de combustível: uma nova proposta. Universidade de São Paulo - Escola de de Engenharia de São Carlos. São Carlos. 1993. Tese de Doutorado.

PEREIRA, B. C. F. Evolução de uma Unidade de Gerenciamento Eletrônico de um motor VW 2.0 e Desenvolvimento de Controle de Cruzeiro: Projeto Otto IV. Escola Politécnica da Universidade de São Paulo. São Paulo, p. 274. 2017. Dissertação de mestrado.

PEREIRA, B. S. Controle da Mistura Ar/Combustível em um Motor a Combustão: Sistema em Malha Fechada. Escola Politécnica da Universidade de São Paulo. São Paulo, p. 92. 2015. Dissertação de mestrado.

PISCHINGER, S.; GÜNTHER, M.; BUDAK, O. Abnormal combustion phenomena with different fuels in a spark ignition engine with direct fuel injection. COMBUSTION AND FLAME, 175, 2016. 123-137.

POLICARPO, N. A. et al. Emission estimates for an on-road flex-fuel vehicles operated by ethanol-gasoline blends in an urban region, Brazil. URBAN CLIMATE, 24, 2018. 111-120.

RIBBENS, W. B. Understanding automotive electronics: an Engineering Perspective. 7th. ed. [S.I.]: Butterworth-Heinemann, 2012.

ROBERT BOSCH GMBH. Manual de Tecnologia Automotiva. Tradução de Euryale de Jesus Zerbini, et al. [S.I.]: Edgard Blucher, 2005. Tradução da $25^{a}$ edição alemã: Kraftfahrtechnisches Taschenbuch. 
ROBERT BOSCH GMBH. Product Information Lambda Probe Interface IC - CJ125. [S.I.]. 2006.

SANTOS, M. M. D. et al. Model-Based Design of Exterior Lighting Control Function for Automobile: MIL, SIL and RCP. International Journal of Innovative Computing, Information \& Control, 11, 2015. 1495 - 1507.

SARATHY, S. M. et al. Alcohol combustion chemistry. PROGRESS IN ENERGY AND COMBUSTION SCIENCE 44, 2014. 40-102.

SCHÄUFFELLE, J.; ZURAWKA, T. Automotive Software Engineering: Principles, Processes, Methods, and Tools. Tradução de Roger Carey. Warrendale: SAE International, 2005. 385 p. Translated from German language edition Automotive Software Engineering: Grundlagen, Prozesse, Methoden und Werkzeuge.

SERDAR, Y. H. et al. Effect of ethanol-gasoline blends on engine performance and exhaust emissions in different compression ratios. APPLIED THERMAL ENGINEERING, 26, 2006. 2272-2278.

SHU, G.; PAN, J.; WEI, H. Analysis of onset and severity of knock in SI engine based on in-cylinder pressure oscillations. APPLIED THERMAL ENGINEERING, 51, 2013. 1297-1306.

TEXAS INSTRUMENTS. LM9044 Lambda Sensor Interface Amplifier. [S.I.]. 2013.

VETROMILLE, M. et al. RTOS scheduler implementation in hardware and software for real time applications. Seventeenth IEEE International Workshop on Rapid System Prototyping (RSP'06), 2006. 163-168.

WAGNER, J. et al. Engine Knock Detection: Products, Tools, and Emerging Research. SAE TECHNICAL PAPER SERIES - INTERNATIONAL CONGRESS AND EXPOSITION, Detroit, Michigan, 1998. 1 - 11.

WOLF, W. Computers as components: principles of embedded computing system design. San Francisco: Morgan Kaufmann, 2005.

YU, A. S. O. et al. The evolution of Flex-Fuel technology in Brazil: The Bosch case. TECHNOLOGY MANAGEMENT FOR GLOBAL ECONOMIC GROWTH (PICMET), 2010. 1-11.

ZHEN, X. et al. The engine knock analysis - An overview. APPLIED ENERGY, 92, 2012. 628-636. 


\section{APÊNDICES}

APÊNDICE A - BREVE HISTÓRICO DO DESENVOLVIMENTO FLEX-FUEL

\section{Os primórdios do combustível etanol}

O combustível álcool (etanol) é produzido e utilizado em motores há quase um século. Na década de 30, a Escola Politécnica da Universidade de São Paulo desenvolveu um protótipo do Ford modelo T para a utilização do combustível álcool. $\mathrm{Na}$ época, o veículo de teses foi satirizado com a suposição de que também poderia ser movido a "cachaça". Em 1953, iniciou-se, nos laboratórios do ITA (Instituto de Tecnologia da Aeronáutica), em São José dos Campos, a adaptação de um motor a quatro tempos para funcionar com álcool combustível.

Figura 0.1 - Veículo Ford modelo T movido à "cachaça", adequação realizada na escola politécnica da Universidade de São Paulo.

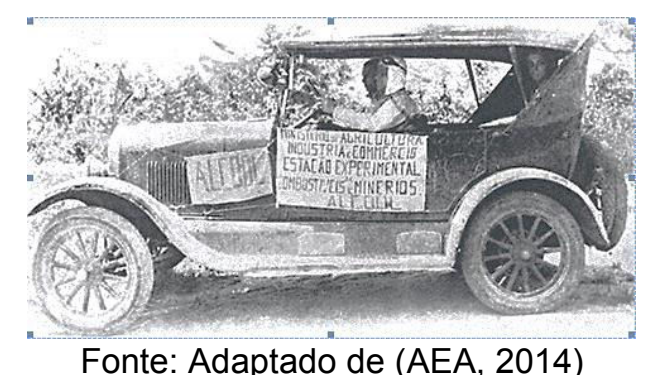

Em 1975, foi estabelecido o Proálcool ${ }^{35}$, idealizado como resposta do governo brasileiro à crise do petróleo de 1973, com a finalidade de substituir parcialmente a gasolina, devido aos altos preços do petróleo importado e para revitalizar a indústria da cana-de-açúcar. Esse programa estimulou a oferta do combustível álcool (etanol) no Brasil e, consequentemente, seu consumo como fonte energética. No ano de 1978 foi lançado o primeiro modelo de veículo do mercado movido exclusivamente à etanol no Brasil foi o Fiat 147. Nesse mesmo ano foi assinado um protocolo entre o Governo Federal e a ANFAVEA ${ }^{36}$ que estabelecia financiamentos e incentivos fiscais para que as montadoras se comprometessem a priorizar a opção do uso de etanol. (NASCIMENTO, et al., 2010)

\section{A crise no fornecimento do etanol}

Em 1986, no auge do Proálcool, cerca de $90 \%$ dos veículos comercializados no país eram equipados com motor a álcool hidratado. A produção de etanol

\footnotetext{
${ }^{35}$ Programa Nacional do Álcool

${ }^{36}$ Ássociação Nacional dos Fabricantes de $\underline{\text { VÉículos Automotivos }}$
} 
hidratado recebeu importantes subsídios do governo, o que o tornou competitivo em relação à gasolina, cujo preço era fortemente influenciado pelo mercado externo.

A demanda de etanol hidratado gerada pelo programa foi maior que a oferta. Esse desequilíbrio gerou uma crise de desabastecimento, o que fez com que os consumidores deixassem de adquirir carros a álcool. Assim, na década de 90, ocorreu o fim do ciclo dos carros movidos exclusivamente a álcool hidratado no Brasil. De 1986 a 1995, as vendas anuais de carro a álcool tiveram uma queda de $93 \%$.

\section{A ascensão da tecnologia Flex-Fuel}

De 1983 a 1088, a Bosch desenvolveu componentes capazes de operar tanto em motores a gasolina como a etanol, e depois exclusivamente em motores a etanol. Em 1992, o primeiro sistema $\mathrm{EFI}^{37}$ para carros alimentados a etanol foi desenvolvido e implantado em um protótipo do GM Ômega, aplicado em conjunto por três empresas (GM, Delphi e Bosch) em 1994. O modelo utilizava um sensor capacitivo para que fossem medidos os componentes do combustível antes do mesmo ser injetado no motor. Na época, o sensor trazia um custo elevado, cerca de US \$ 100. Este valor triplicaria no momento em que atingisse o consumidor. A Bosch havia tentado trazer esta tecnologia para o Brasil com o Ômega, porém não obteve êxito. O referido sensor não funcionou no Brasil devido à presença de água no etanol combustível e à sensibilidade do sensor às temperaturas tropicais. (YU, et al., 2010)

A ocorrência de possíveis crises no fornecimento de combustíveis levou o departamento de engenharia da filial brasileira da Robert Bosch a considerar a tecnologia Flex-Fuel, uma opção para reativar o mercado brasileiro de álcool hidratado. Naquela época, a escolha do combustível, etanol ou gasolina, poderia ser feita apenas no momento da compra do veículo. Em 2002, os veículos Flex-Fuel foram enquadrados na mesma categoria do carro a etanol para fins tributários (YU, et al., 2010), o que contribuiu para alavancar as vendas desses veículos.

A partir do lançamento dos veículos Flex-Fuel tornaram-se um grande sucesso. De 2003 a 2007, as vendas anuais de automóveis e veículos comerciais leves com essa tecnologia aumentaram de 48 mil para aproximadamente 2 milhões de unidades, conforme mostrado na Figura 0.2.

${ }^{37}$ Electronic Fuel Injection 
Figura $\mathbf{0 . 2}$ - Licenciamento de veículos automotores leves de passeio por fonte de energia utilizada.

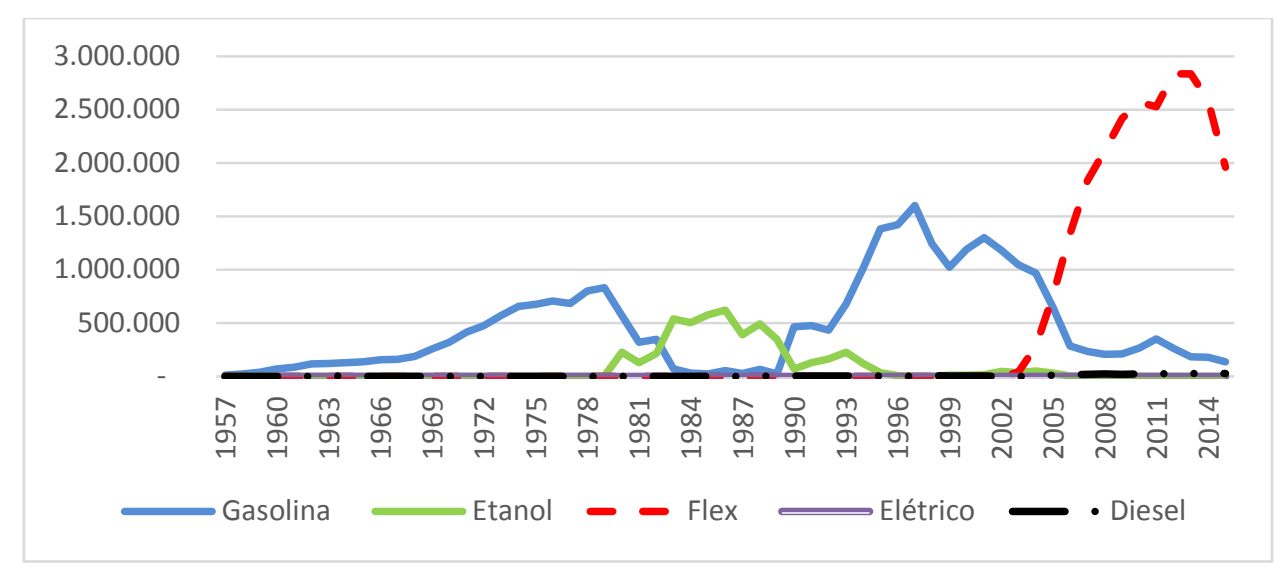

FONTE: Adaptado de (ASSOCIAÇÃO NACIONAL DOS FABRICANTES DE VEÍCULOS AUTOMOTORES - ANFAVEA, 2016).

É importante ressaltar que os motores Flex-Fuel produzidos nos Estados Unidos não eram compatíveis com os combustíveis nacionais, nem com o álcool hidratado ou com a mistura gasolina e álcool anidro. Foi o desenvolvimento da tecnologia Flex-Fuel baseada em um algoritmo de software com a leitura do sensor de oxigênio (sonda lambda) que levou a uma verdadeira revolução para o mercado nacional de automóveis. A opção foi priorizar o consumo do álcool hidratado produzido no Brasil, criando um sistema flexível simplificado para atender às necessidades nacionais. Destaca-se ainda que devido aos períodos de entressafra da cana-de-açúcar matéria-prima do etanol no Brasil, o motor Flex-Fuel e o seu gerenciamento foram desenvolvidos para o funcionamento misto, ou seja, podem funcionar com misturas variáveis de gasolina/etanol. Assim, os motores brasileiros com tecnologia Flex-Fuel nacional apresentaram melhor desempenho com o etanol hidratado do que com gasolina.

Todos os combustíveis derivados da gasolina contêm aditivos destinados a melhorar a qualidade do combustível em diferentes aspectos. O elemento antidetonante mais eficaz conhecido é o chumbo por ser estável e solúvel em combustíveis na forma de alquilos. $\mathrm{O}$ chumbo alquila ou tetraetila $\left(\mathrm{C}_{2} \mathrm{H}_{5}\right)_{4} \mathrm{~Pb}$, foi introduzido em 1923. A partir do momento em que a poluição do ar e o póstratamento dos gases de escape por catalisadores se tornaram um problema em meados da década de 1970, momento em eu empregou-se maiores esforços para o desenvolvimento de gasolinas livres de chumbo, utilizando aditivos menos nocivos ao meio ambiente. $O$ chumbo possui um alto efeito toxicológico nas áreas urbanas, 
além disso, se deposita no catalisador e diminui sua eficiência de conversão (ERIKSSON e NIELSEN, 2014)

\section{APÊNDICE B - RELEVÂNCIA DA CARACTERIZAÇÃO DA COMPOSIÇÃO DO COMBUSTÍVEL EM MOTORES FLEX-FUEL COM SOBREALIMENTAÇÃO E INJEÇÃO DIRETA}

$\mathrm{Na}$ utilização de combustíveis diferentes, torna-se mais complexo o controle de anomalias nos processos de combustão. Sendo assim, fenômenos anormais de combustão como a ignição superficial em ponto quente e autoignição em fase gasosa resultam em condições típicas de knock. A Figura 0.3 apresenta o experimento realizado por (PISCHINGER, GÜNTHER e BUDAK, 2016), em que os avanços de ignição foram fixados para que fosse observado apenas o efeito de mudança dos combustíveis utilizados. Na região esquerda, estão expostas as pressões internas dos cilindros para os combustíveis E0RON95 (0\% de volume de etanol e 95 octanas no método RON), E20SB ( $80 \%$ de E0RON95 e $20 \%$ de etanol em volume) e E100 ( $0 \%$ de E0RON95 e 100\% de etanol em volume) e à direita estão exibidas as respectivas imagens óticas dos momentos próximos à combustão extraídas por quimiluminescência. 
Figura 0.3 - Comparação da evolução da autoignição em fase gasosa para eventos de combustão com inicialização fixa para diferentes combustíveis.

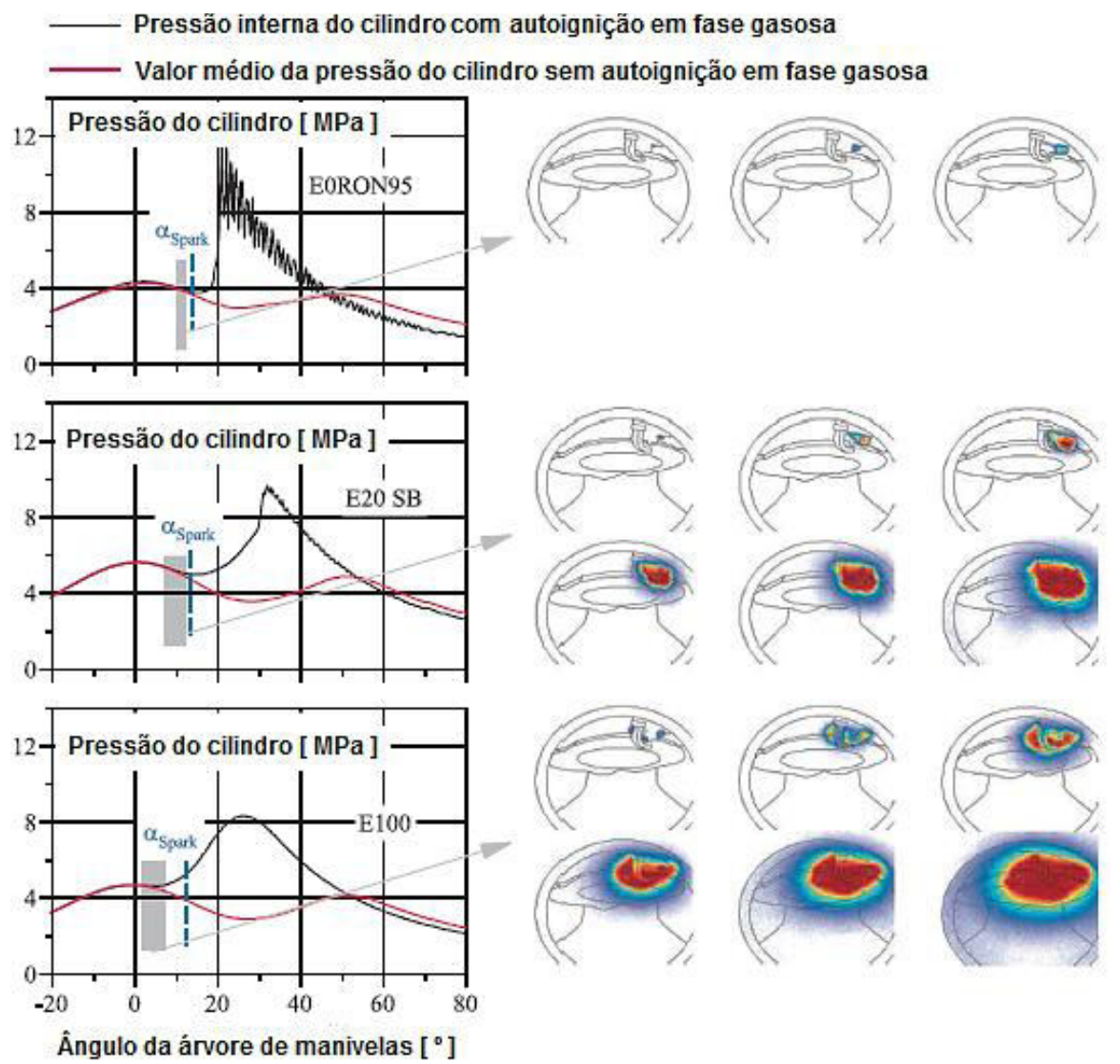

Fonte: Adaptado de (PISCHINGER, GÜNTHER e BUDAK, 2016).

O desenvolvimento atual dos motores SI mais sofisticados focou-se principalmente em: injeção do combustível de forma direta na câmara de combustão, o downsizing e a turbo-alimentação, o que trouxe consigo a elevação da temperatura e pressão internas dos cilindros, com a finalidade do aumento da eficiência de trabalho do motor. A alta octanagem dos biocombustíveis permitiu o aumento da taxa de compressão e, portanto, uma melhoria da eficiência térmica em todo os pontos de operação do motor. Contudo, as altas taxas de compressão, combinadas com melhorias de downsiszing ${ }^{38}$ e a utilização de combustíveis alternativos, revelaram novos desafios devido a fenômenos de combustão irregulares, cujo controle ainda não foi totalmente compreendido. Essas anomalias de combustão diferem significativamente dos processos de combustão convencionais e podem

${ }^{38}$ Conceito da indústria automotiva baseado na ideia de que veículos menores e mais leves consumam uma quantidade menor de combustível. Outra interpretação referente à motores, onde o downsizing consiste na utilização de um motor de menor volume em veículos para redução do consumo de combustível. A este tipo de downsizing realizado em motores, aplica-se também o princípio de sobre-alimentação, para que o motor menor obtenha um desempenho próximo ao de um motor que possui volume maior. 
levar a uma forte deterioração da operação do motor ou até mesmo à graves falhas materiais no motor. Além da sincronia de disparo da centelha como uma das principais preocupações e fatores limitantes, fenômenos de combustão anormais mais intensos ocorrem em motores SI com injeção direta de combustível e/ou sobrealimentados por pressões e temperaturas internas elevadas comparadas aos motores SI naturalmente aspirados.

Os fenômenos anormais de combustão ocorrem de forma distinta em razão dos diferentes combustíveis utilizados no mesmo motor. Portanto, a ideia de se medir a composição do combustível é importantíssima no gerenciamento de motores com sistemas mais sofisticados em termos de pressão de combustão. Antes da aplicação de medida da composição, a adequação de parâmetros nesses motores era mais imprecisa e vulnerável a falhas, ocasionando ruídos de estabilidade durante o funcionamento, tais como vibrações indesejadas e até mesmo eventuais colapsos de materiais do motor (quebras), devido a variação ruidosa na pressão interna do cilindro gerada por autoignição. 


\section{APÊNDICE C - DETERMINAÇÃO ONLINE DA COMPOSIÇÃO DO COMBUSTÍVEL}

\section{Princípios estimado a partir da medida da constante dielétrica e resistividade (síntese simplificada)}

O espaço existente entre as placas de um capacitor quando preenchido por um dado fluido, seja liquido ou gasoso, pode ser utilizado como um sensor de misturas, baseado na variação da constante dielétrica referente às componentes presentes em tais misturas (HYLE e RABE, 1978).

Um sensor baseado na constante dielétrica e resistividade possui princípio de funcionamento similar ao de um capacitor. A resistência e a capacitância são dependentes das características geométricas do meio, resistividade e permissividade elétricas, estas variam em função da temperatura, como expresso pelas Eqs. (0.1) e (0.2).

$$
\begin{aligned}
& C=\varepsilon(T) \cdot \frac{A}{l} \\
& R=\rho(T) \cdot \frac{l}{A}
\end{aligned}
$$

onde $A$ representa a área da seção do meio, $l$ o comprimento de seção do meio, $\varepsilon$ a permissividade ou constante dielétrica do meio em função da temperatura, e $\rho$ a resistividade elétrica do meio também variante com a temperatura.

A célula de medição é formada com a utilização do combustível como dielétrico, estando em um meio de espaço geométrico fixo e conhecido, como expresso na Eq. (0.5), a resistência e a capacitância resultarão apenas da variabilidade da resistividade e permissividade médias do combustível, exemplificados nas Eqs. (0.3) e (0.4).

$$
\begin{gathered}
R=K_{1} \cdot \rho_{\text {Med }}(T) \\
C=K_{2} \cdot \varepsilon_{\text {Med }}(T) \\
K_{1}=K_{2}{ }^{-1}
\end{gathered}
$$


onde $\rho_{\text {Med }}$ representa a resistividade média do meio, $\varepsilon_{M e d}$ a permissividade elétrica ou constante dielétrica, e $K_{1}$ e $K_{2}$ representam as características geométricas do meio.

O combustível, a priori, pode ser composto por três principais elementos: água, gasolina brasileira com $27 \%$ de etanol anidro, e etanol hidratado, possuindo as respectivas constantes dielétricas características e resistividades, expressas pelas Eqs. (0.6) e (0.7).

$$
\begin{gathered}
\rho_{M e d}=m \cdot \rho_{H_{2} O}(T)+n \cdot \rho_{E_{27}}(T)+k \cdot \rho_{E_{95}}(T) \\
\varepsilon_{M e d}=m \cdot \varepsilon_{H_{2} O}(T)+n \cdot \varepsilon_{E_{27}}(T) n+k \cdot \varepsilon_{E_{95}}(T)
\end{gathered}
$$

onde $m \rho_{x x x}$ representa e resistividade do respectivo componente, $\varepsilon_{x x x}$ a constante dielétrica novamente de cada componente.

As variações entre as misturas podem ser representadas por uma média ponderada dos coeficientes relativos ao volume dos diferentes produtos líquidos na composição do combustível conforme Eq. (0.8).

$$
m+n+k=1
$$

onde os coeficientes $m, n$ e $k$ representam a presença em volume dos três produtos principais que constituem o combustível.

A partir da observação de tais iterações, tornou-se possível que fossem multiplexadas e parametrizadas a constante dielétrica e a resistividade que são variantes com a composição e temperatura do combustível, um sensor real o qual emprega este princípio é abordado na seção 3.3.2, e o mesmo foi empregado na viabilização dos objetivos deste projeto. 


\section{APÊNDICE F - LEVANTAMENTO DO MBT}

\section{Buscas dos avanços de ignição para as condições de MBT}

Figura 0.4 - Levantamento dos avanços de ignição encontrados para a condição de MBT em função da relação de equivalência $\lambda$ (lambda) para as rotações de 1500, 2500, 3500 e 4500 RPM@90 KPa.

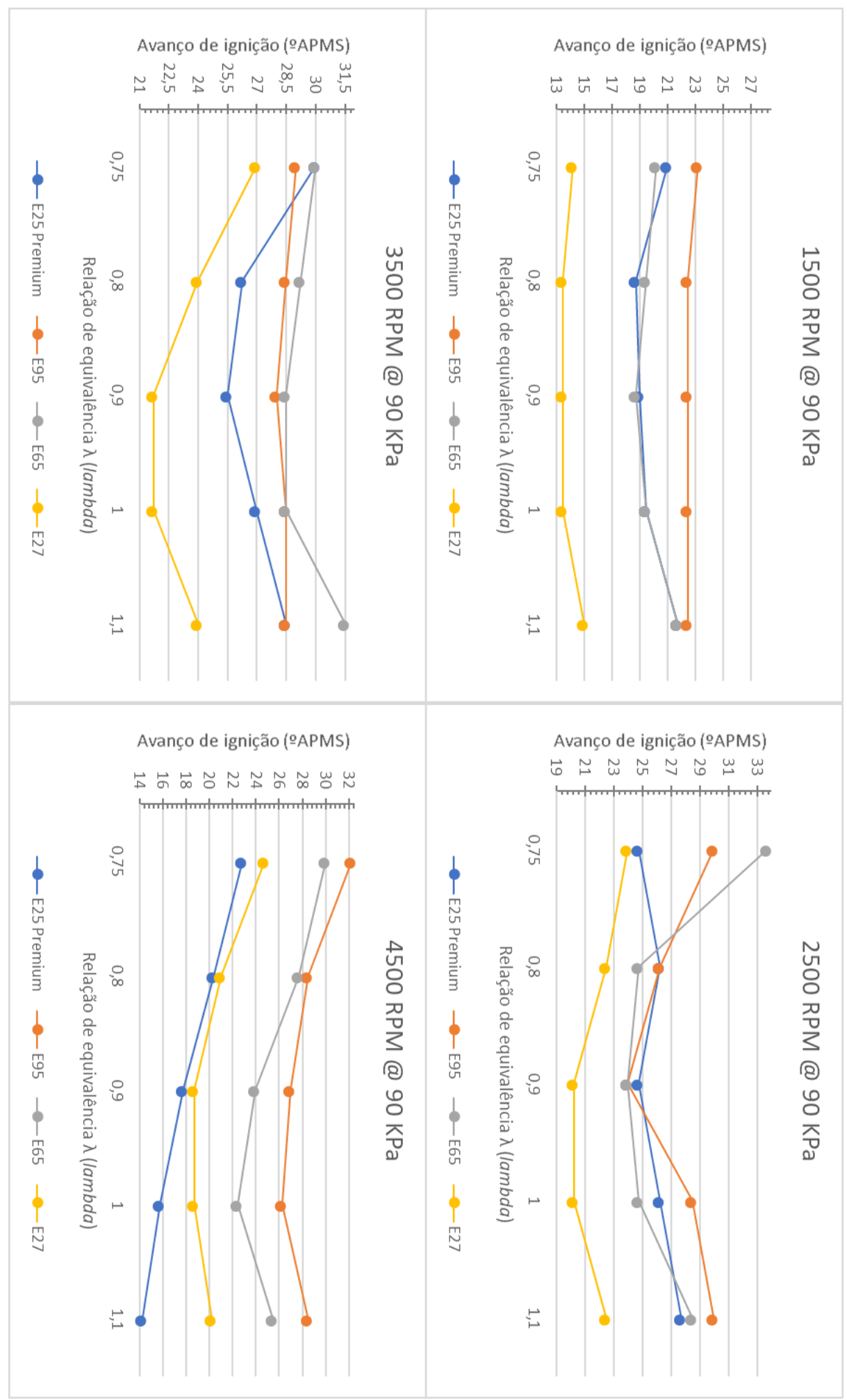

Fonte: $\mathrm{O}$ autor. 


\section{Medições dos índices de detonação para as condições de MBT}

Figura 0.5 - Levantamento dos índices de detonação encontrados para a condição de MBT em função da relação de equivalência $\lambda$ (lambda) para as rotações de 1500, 2500, 3500 e 4500 RPM@90 KPa.

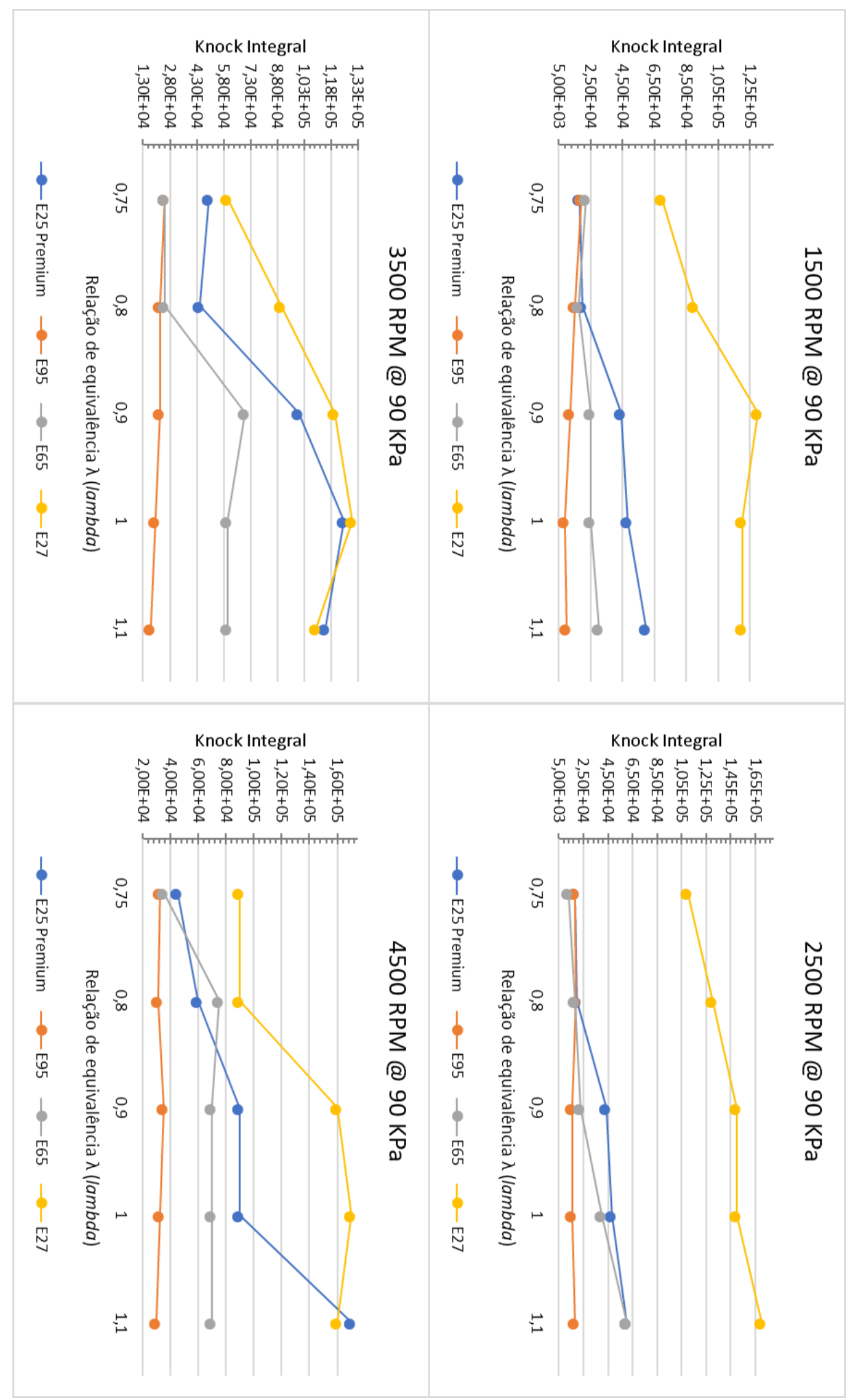

Fonte: $\mathrm{O}$ autor. 


\section{Medições de torque para as condições de MBT}

Figura 0.6 - Levantamento das medições de torque encontrados para a condição de MBT em função da relação de equivalência $\lambda$ (lambda) para as rotações de 1500, 2500, 3500 e 4500 RPM@90 KPa.

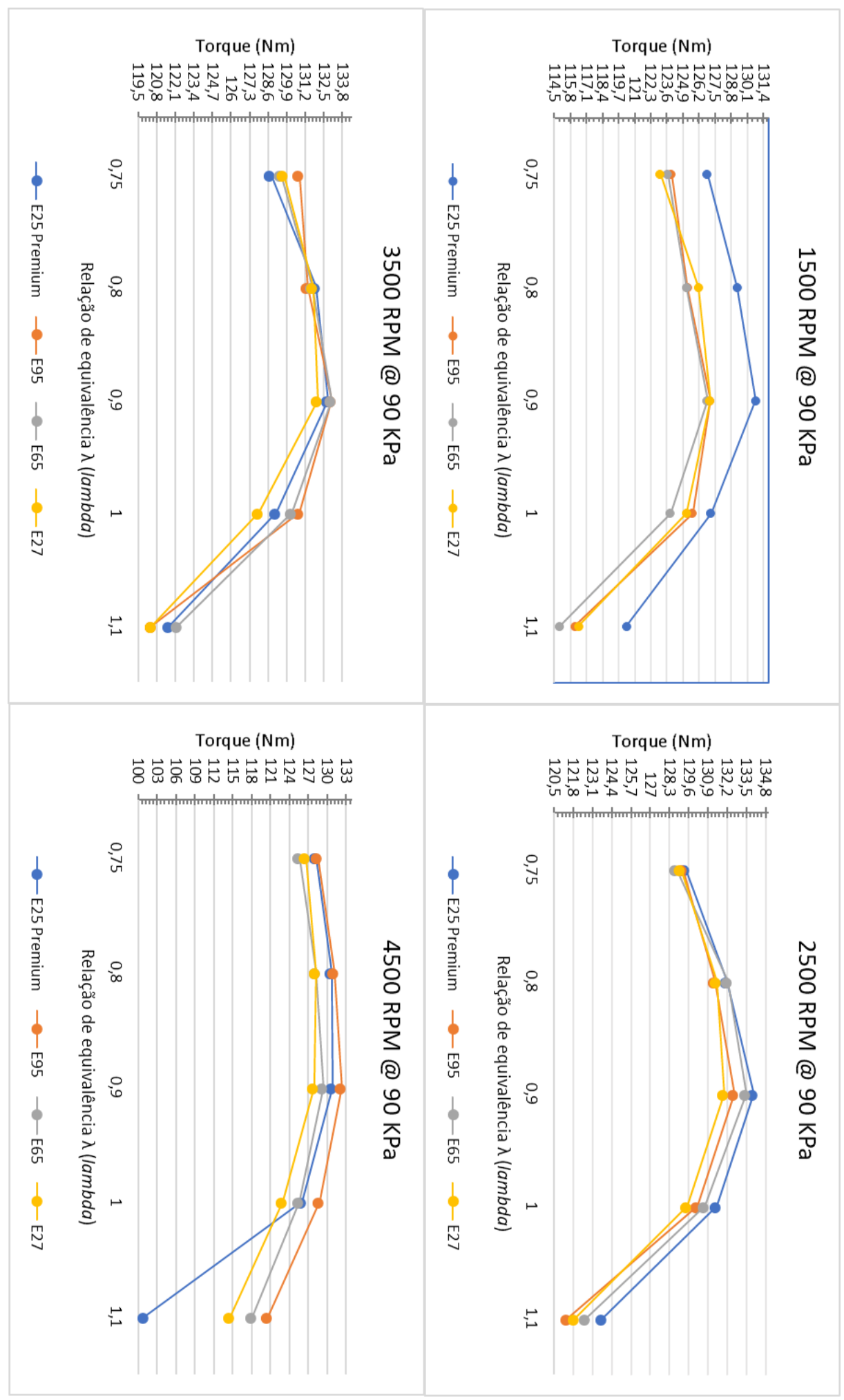

Fonte: $\mathrm{O}$ autor. 


\section{Medições de potência para as condições de MBT}

Figura 0.7 - Levantamento das medições de potência encontradas para a condição de MBT em função da relação de equivalência $\lambda$ (lambda) para as rotações de 1500, 2500, 3500 e 4500 RPM@90 KPa.

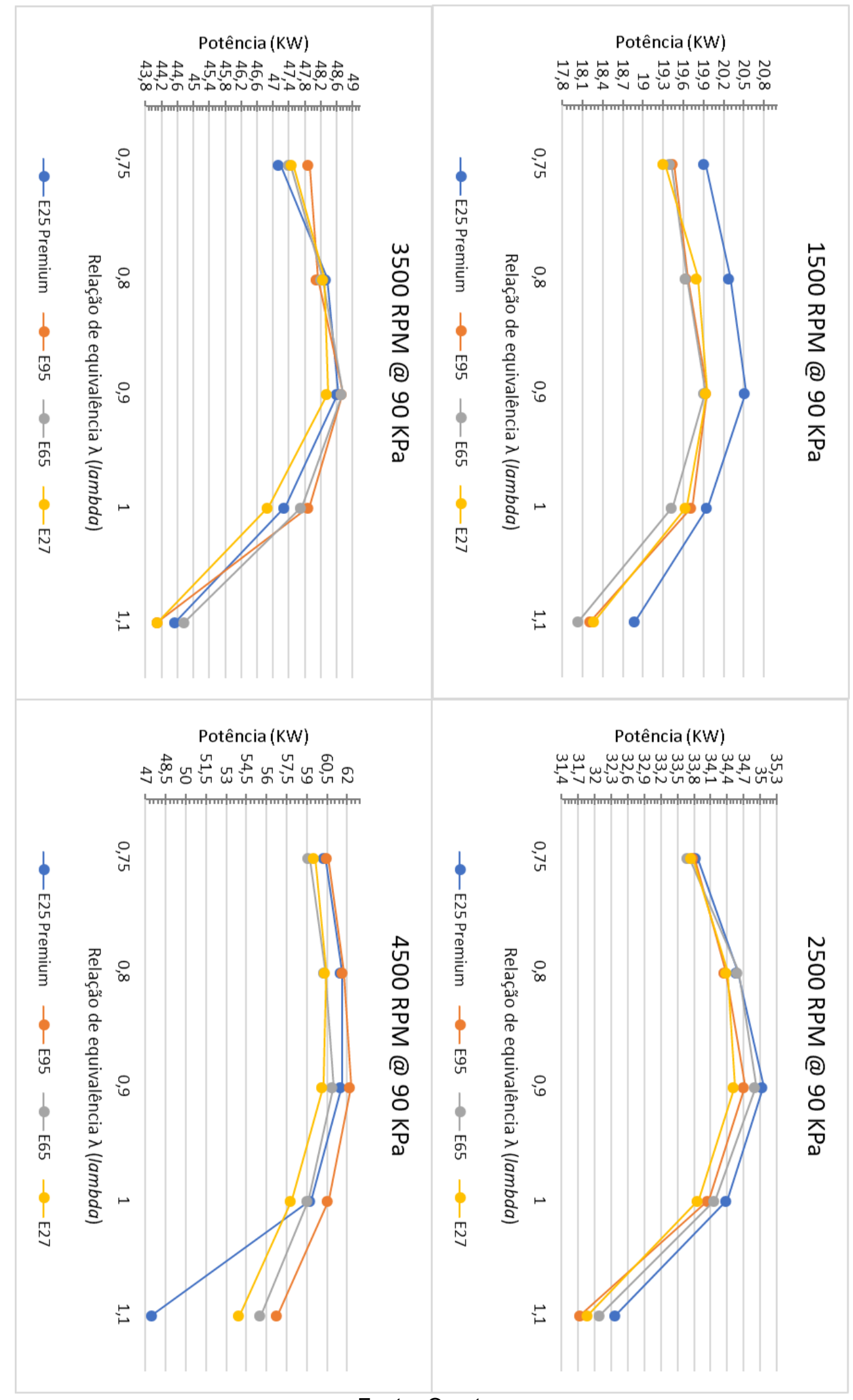

Fonte: O autor. 


\section{Medições de fluxo de combustível para as condições de MBT}

Figura 0.8 - Levantamento das medições de fluxo de combustível encontrados para a condição de MBT em função da relação de equivalência $\lambda$ (lambda) para as rotações de 1500, 2500, 3500 e 4500 RPM@90 KPa.

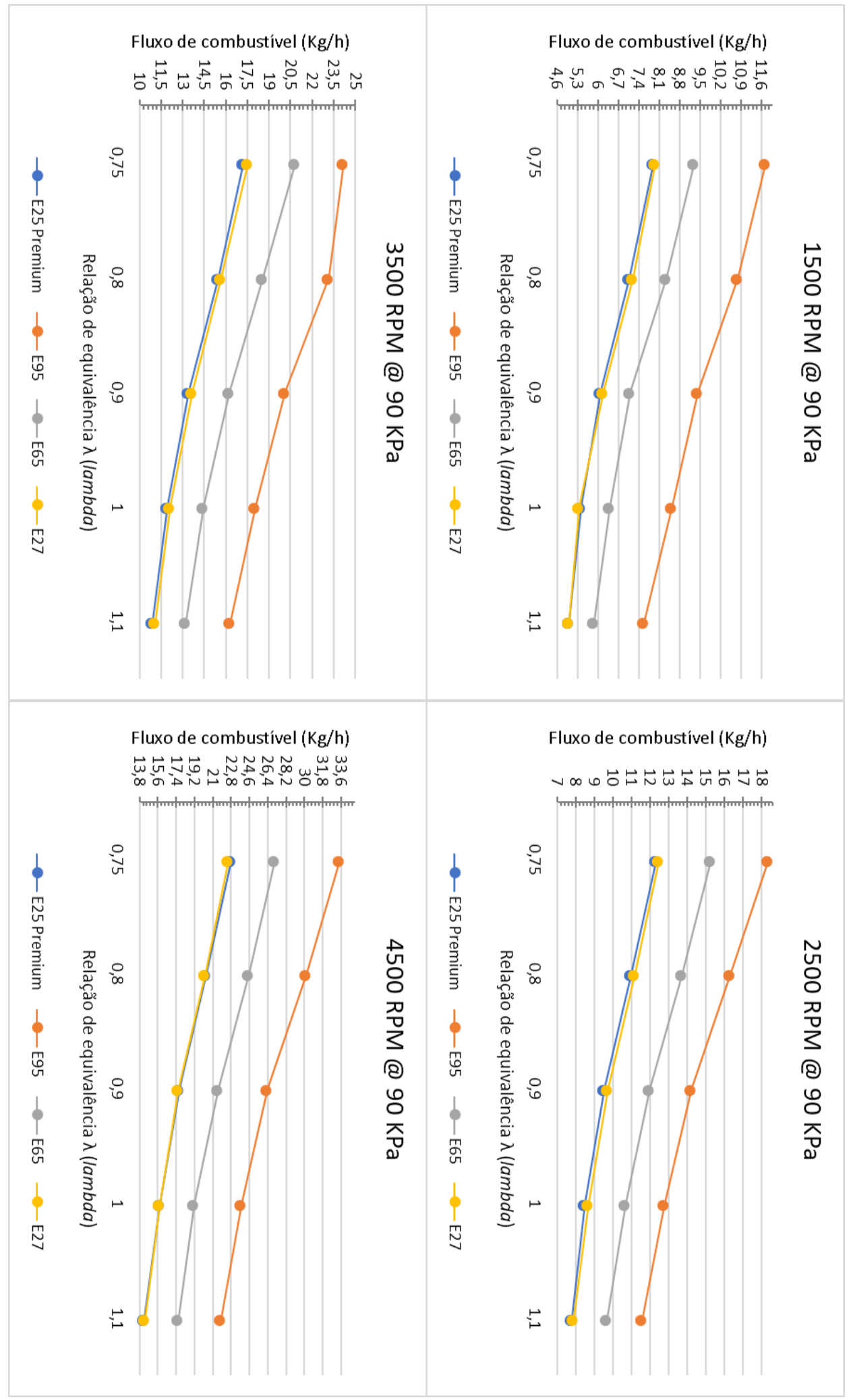

Fonte: $\mathrm{O}$ autor. 


\section{Medições de consumo específico para as condições de MBT}

Figura 0.9 - Levantamento das medições de consumo específico encontrados para a condição de MBT em função da relação de equivalência $\lambda$ (lambda) para as rotações de 1500, 2500, 3500 e 4500 RPM@90 KPa.

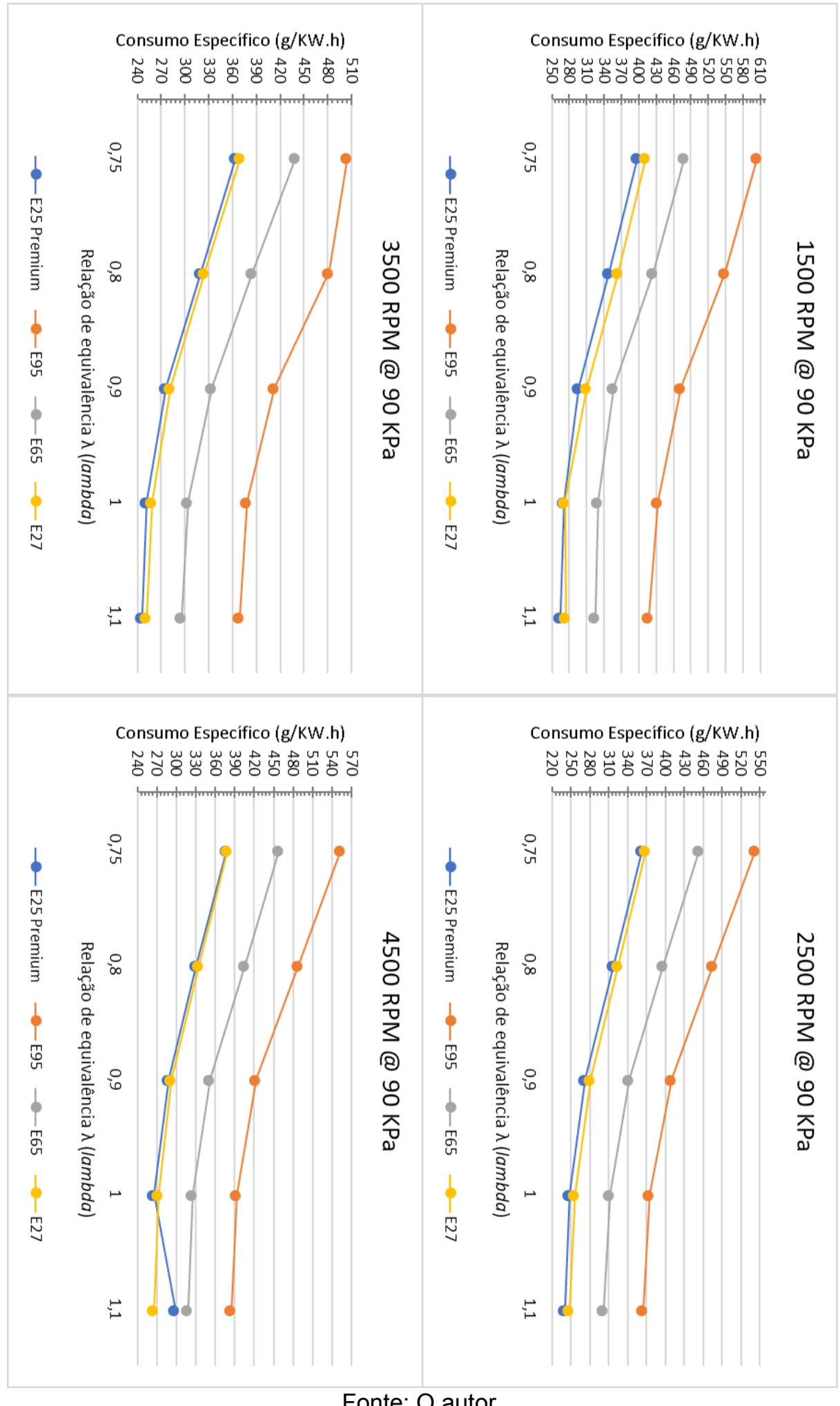

Fonte: O autor. 


\section{APÊNDICE G - LEVANTAMENTO DO IKT}

\section{Buscas dos avanços de ignição para a condições de IKT}

Figura $\mathbf{0 . 1 0}$ - Levantamento dos avanços de ignição encontrados para a condição de IKT em função da relação de equivalência $\lambda$ (lambda) para as rotações de 1500, 2500, 3500 e 4500 RPM@90 KPa.

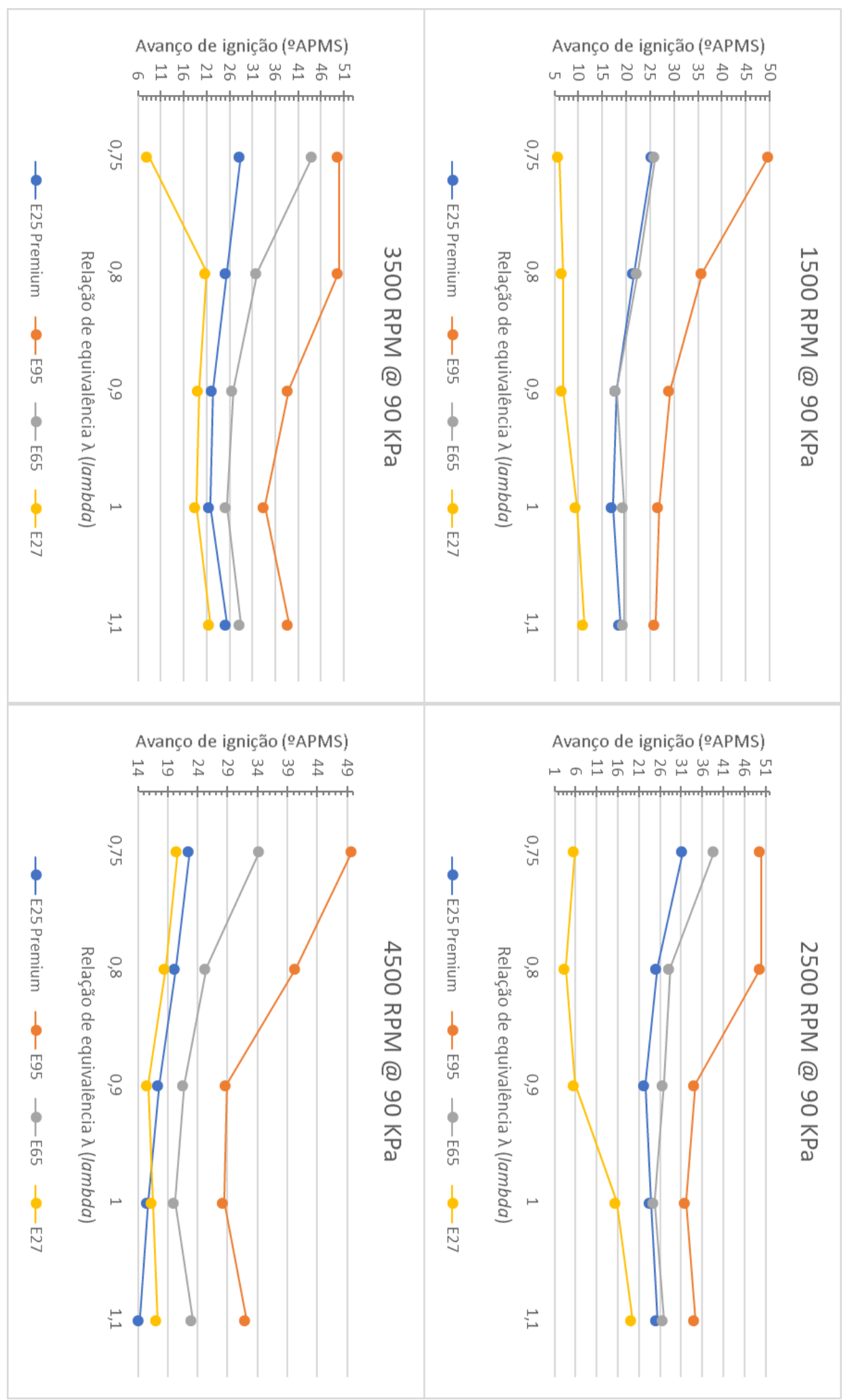

Fonte: $\mathrm{O}$ autor. 


\section{Medições do índice de detonação para as condições de IKT}

Figura 0.11 - Levantamento dos índices de detonação encontrados para a condição de IKT em função da relação de equivalência $\lambda$ (lambda) para as rotações de 1500, 2500, 3500 e 4500 RPM@90 KPa.

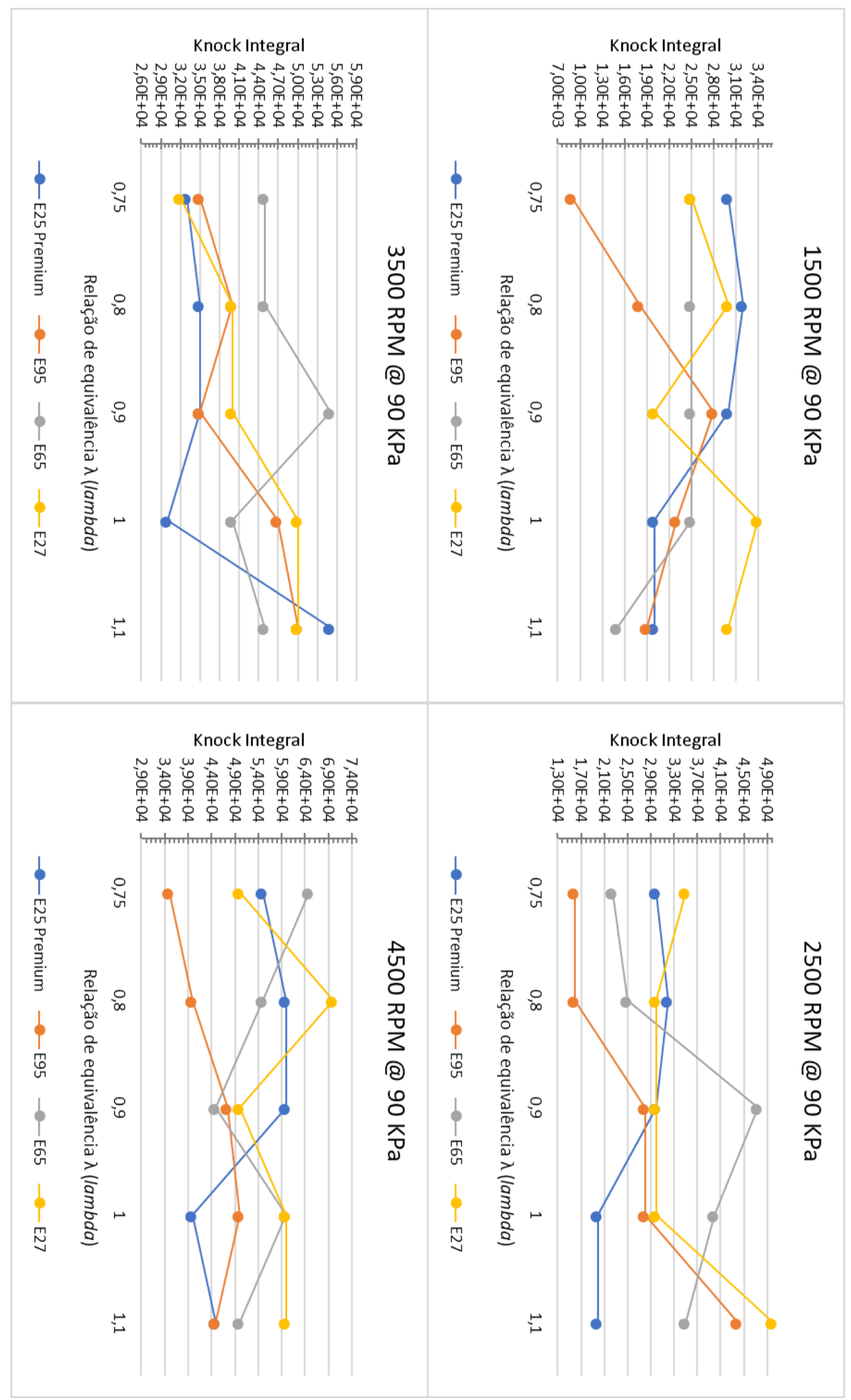

Fonte: $\mathrm{O}$ autor. 


\section{Medições de torque para as condições de IKT}

Figura 0.12 - Levantamento das medições de torque encontrados para a condição de IKT em função da relação de equivalência $\lambda$ (lambda) para as rotações de 1500, 2500, 3500 e 4500 RPM@90 KPa.

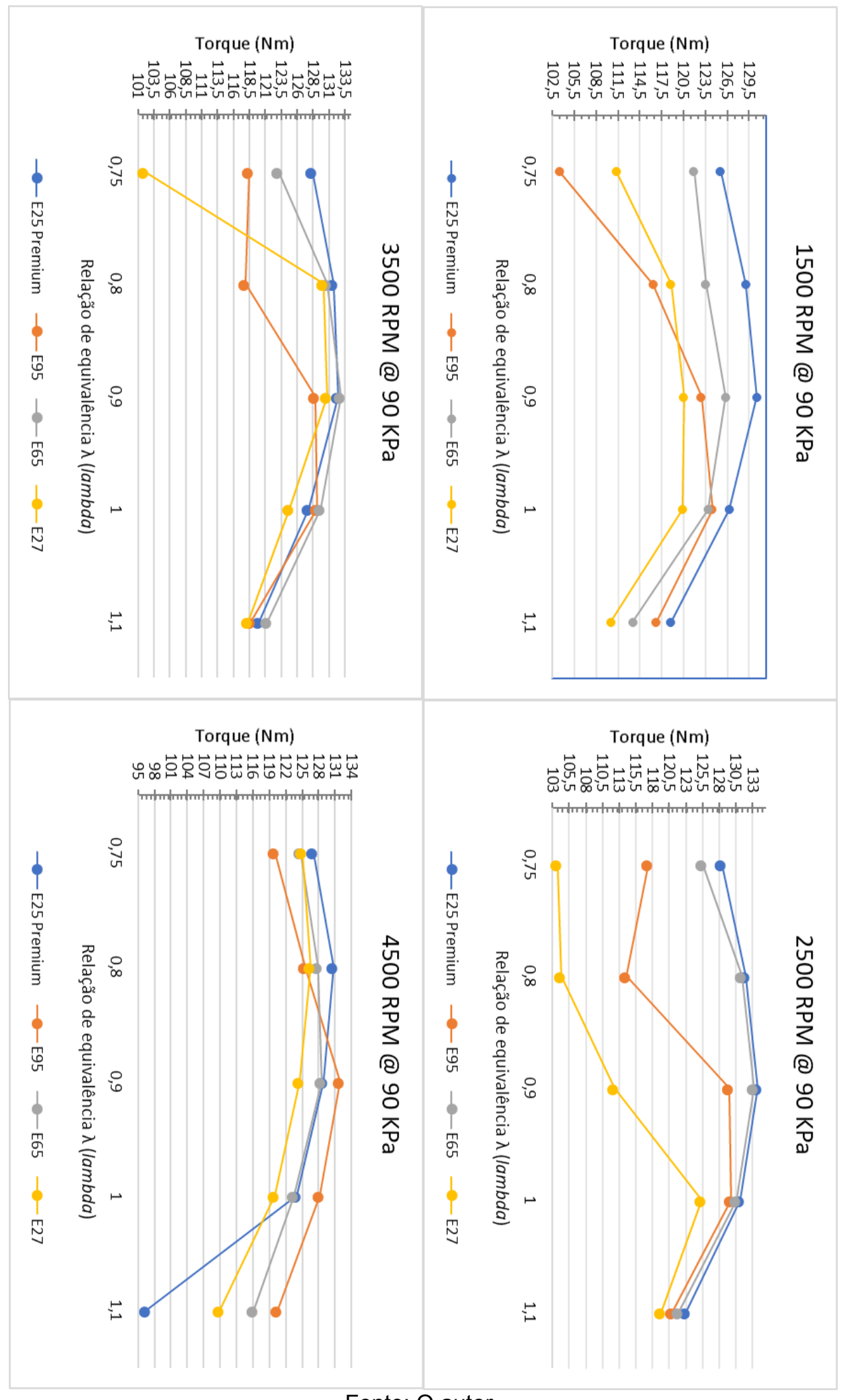

Fonte: $\mathrm{O}$ autor. 


\section{Medições de potência para as condições de IKT}

Figura 0.13 - Levantamento das medições de potência encontradas para a condição de IKT em função da relação de equivalência $\lambda$ (lambda) para as rotações de 1500, 2500, 3500 e 4500 RPM@90 KPa.

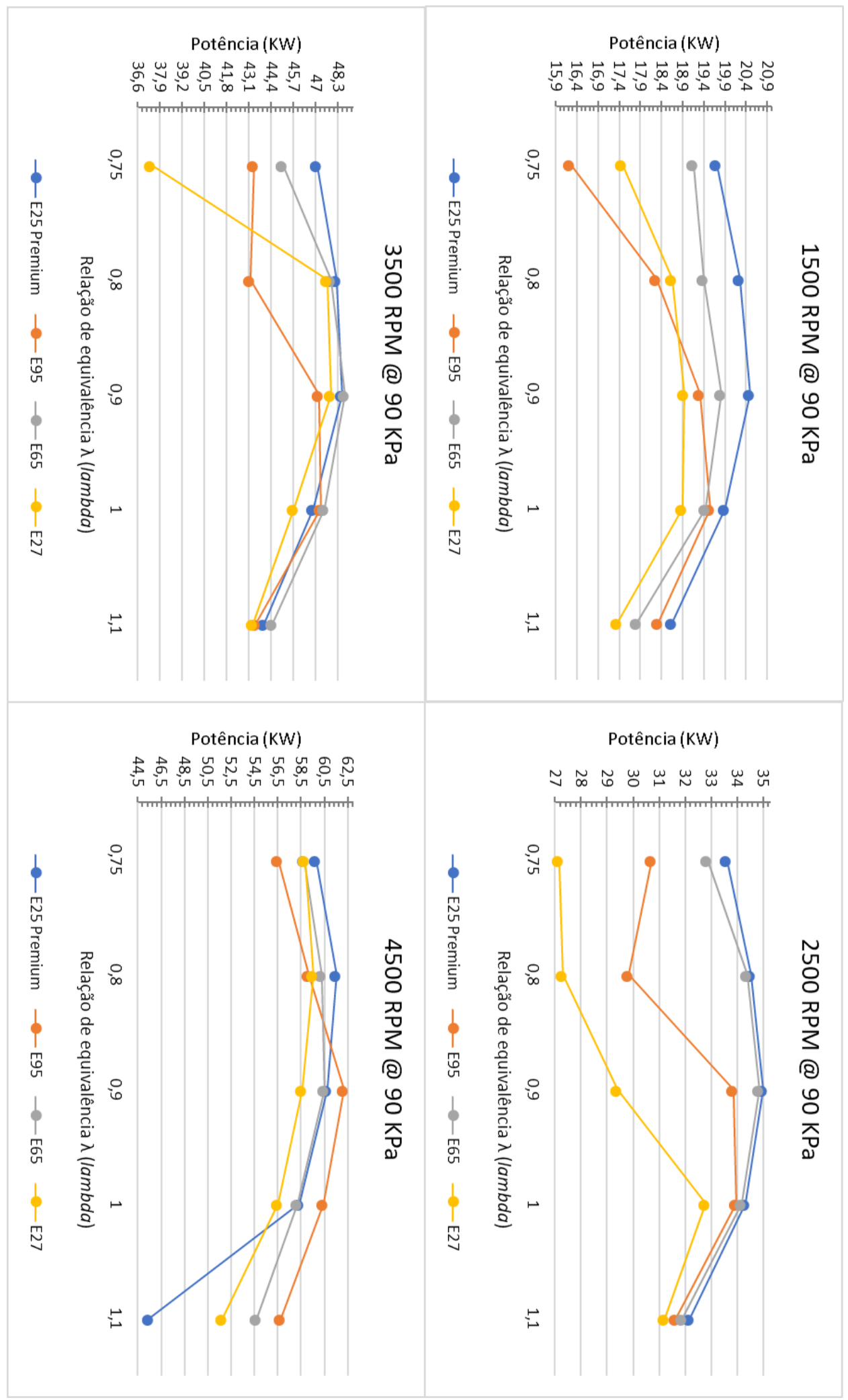

Fonte: $\mathrm{O}$ autor. 
Medições de fluxo de combustível para as condições de IKT

Figura 0.14 - Levantamento das medições de fluxo de combustível encontrados para a condição de IKT em função da relação de equivalência $\lambda$ (lambda) para as rotações de 1500, 2500, 3500 e 4500 RPM@90 KPa.

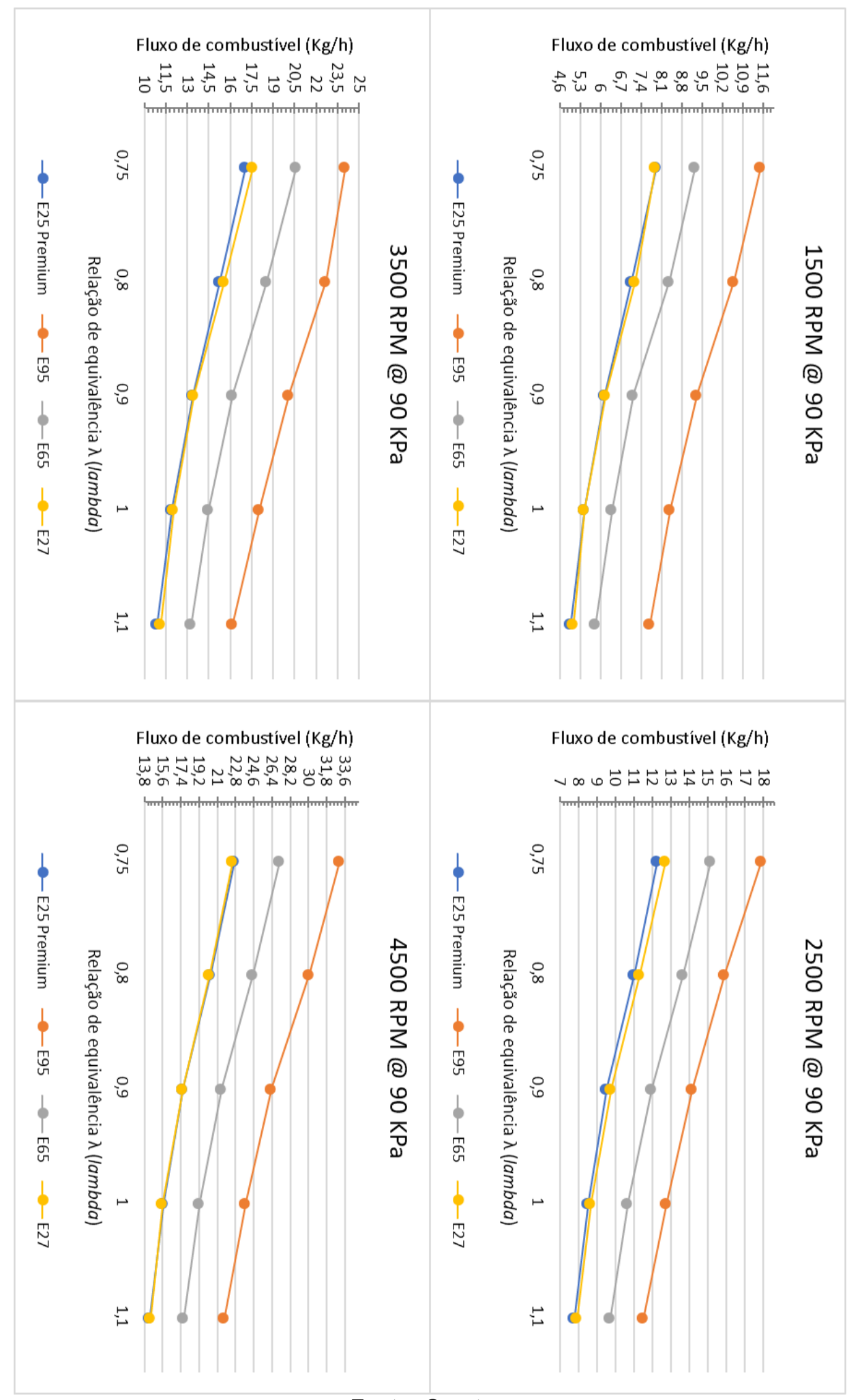

Fonte: O autor. 


\section{Medições de consumo específico para as condições de IKT}

Figura 0.15 - Levantamento das medições de consumo específico encontrados para a condição de IKT em função da relação de equivalência $\lambda$ (lambda) para as rotações de 1500, 2500, 3500 e 4500 RPM@90 KPa.

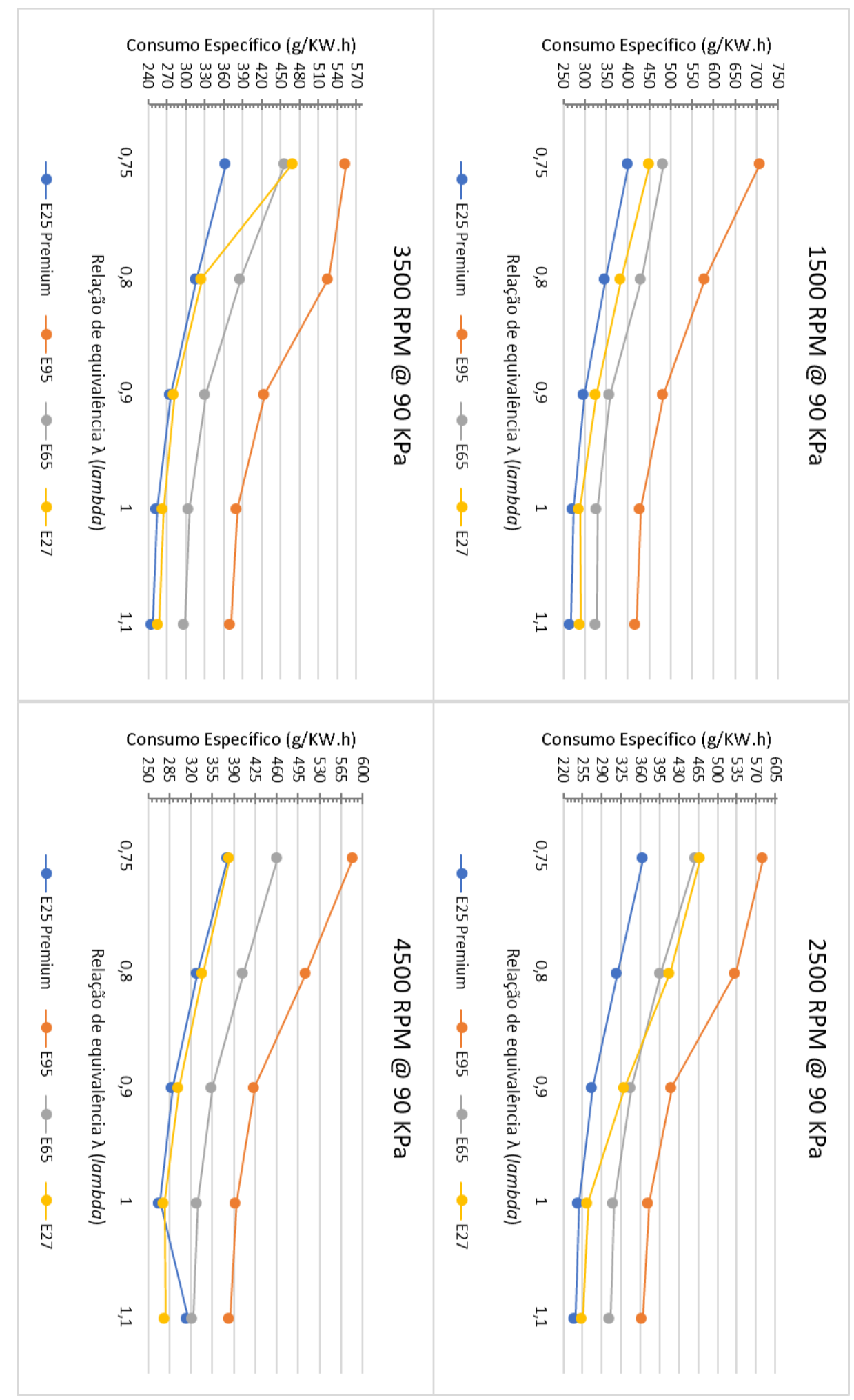

Fonte: $\mathrm{O}$ autor. 